\title{
Projeto de um Circuito Controlador de Rede com Tolerância a Falhas Baseado em Computação Reconfigurável
}

\author{
Klinger Gervásio da Silva
}

Orientador: Prof. Dr. Eduardo Marques

Dissertação apresentada ao Instituto de Ciências Matemáticas e de Computação - ICMC-USP, como parte dos requisitos para obtenção do título de Mestre em Ciências de Computação e Matemática Computacional.

\section{USP - São Carlos}

Julho/2001 
A Comissão Julgadora:

Prof. Dr. Eduardo Marques

Prof. Dr. Onofre Trindade|Junior

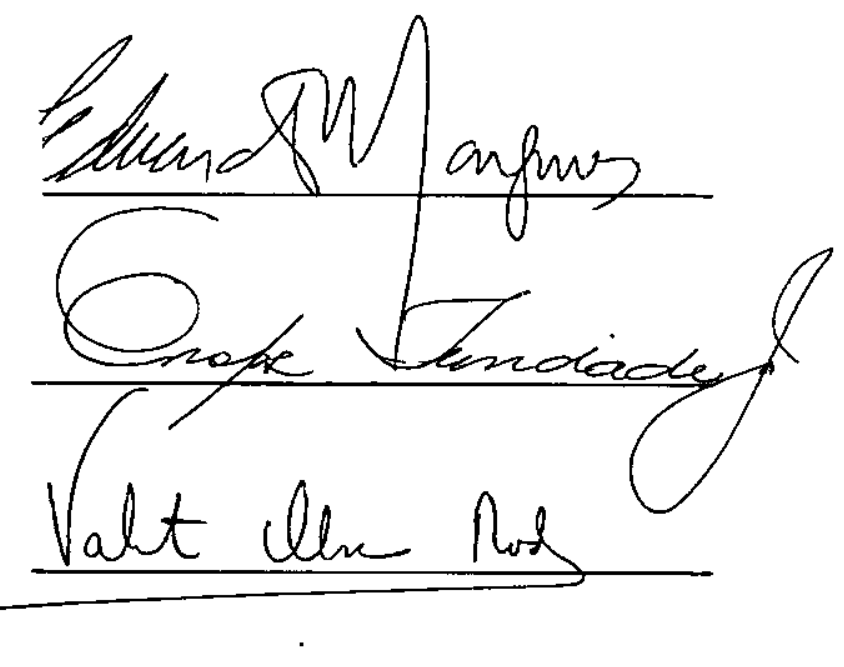


"Se vos falei de coisas terrestres, e não credes, como crereis, se vos falar das celestiais?"

(Jesus Cristo) $^{I}$

"O enorme déficit comercial e tecnológico brasileiro que foi ignorado de forma tão leviana em anos recentes não pode mais ser desprezado. $O$ Brasil pão pode prescindir de competências que permitam agregar valor de fato aos nossos produtos e serviços." (Arthur João Catto) $)^{2}$

${ }_{2}^{1}$ Bíblia Sagrada, Evangelho de São João cap. 3, vers. 12, 100 A.D.

2 Jornal da USP, 05 a 14/04/1999, pág. 08. 


\title{
MEMórias do SÉCULO XXI \\ Por Max Gehringer ${ }^{3}$
}

\begin{abstract}
As previsões sobre o futuro estão quase sempre erradas. Mas quem disse que é para as pessoas saberem o que vai acontecer com elas amanhã?
\end{abstract}

Hoje é 20 de agosto de 2124, quarta-feira, que no Brasil agora chama Wednesday, já que o português foi oficialmente banido quando nos tornamos o $67^{\circ}$ Estado dos United States of Wide America, em 2095. Teve quem não gostou, claro, principalmente depois que a Floresta Amazônica virou a Tropical Disney World, mas a maioria apoiou porque finalmente pôde tirar passaporte americano sem aporrinhação e passou a receber salário em dólar.

É verdade que muitos brasileiros ainda conservam um ranço xenófobo, o que é meu caso, por isso este relatório está sendo escrito em nossa antiga língua-mãe, que eu só domino porque nasci lá no distante 1980.

Fiz 144 anos, trabalho há 126, estou forte e saudável, mas já ouço insinuaçōes de que mihha carreira entrou no plano vegetativo. A vida corporativa do século XXII não é justa com o pessoal da sexta idade, como eu: basta a gente chegar aos 140, e começa a ser discriminado no trabalho...

Os velhos tempos me dão saudade (uma de nossas poucas palavras que entraram no Mega Dicionário Americano, como sinônimo para "senseless feeling"), apesar de quase mais nada ser como era. Por exemplo, eu nasci com unha, cabelo e dente, últimos resquícios de nossa ascendência selvagem. E na juventude pratiquei zelosamente um ato denominado "sexual" para a reprodução da espécie, coisa que, hoje, a ciência simplificou muito: basta ir a qualquer McDonald's, comprar um kit de óvulo e espermatozóide (o número 3 tem sido o preferido pelos consumidores, porque acompanha uma Coca-Cola grátis) e inseri-lo num tubo plugado a um sistema embrionário - cujo nome técnico é "tamagoshi". Aí, é só redigitar a configuração desejada do genoma e depois ir clicando os comandos para as cargas vitais de proteínas. Simples. Em seis semanas, aparece a ficha fitoergométrica da criança, os custos de alimentaçãol e educação e a mensagem "Are you sure you want to give birth?"

\footnotetext{
3 Em 1999, no auge de uma carre ra bem-sucedida que o levou à direçåo de grandes empresas (Pepsi, Elma Chips e Pullman), MAX GEHRINGER tomou uma decisão rarissima no mundo corporativo: abriu mão do poder e das mordomias de alto executivo para dedicar seu tempo a escrever e a fazer palestras pelo Brasil. Max escreve regularmente para VOCÉ s.a., Exame, Revista da Web!, Vip e Placar (todas publicadas pela Editora Abril).

Recentemente, Max lançou seu segundo livro, Comédia Corporativa (Editora Campus). O humor e a sensibilidade dos textos de Max vêm de sua vivência prática num mundo que ele conhece degrau por degrau: seu primeiro emprego, aos 12 anos, foi de auxiliar de faxina. O último: presidente da Pullman.
} 
Meu filho mais novo, o 365A27W648, vulgo "8", agora deu de ser curioso e me perguntar porque no meu tempo as coisas eram tão complicadas. Eu tentei explicar para ele que o tal ato ia além da simples reprodução, que a gente sentia prazer em copular, e ele fez aquela cara de nojo, típica de adolescente recém-saído da universidade. Mas, tudo bem, ele tem só 4 anos, um dia talvez entenda melhor.

Eu sei, estou divagando, desculpem. Não é das reviravoltas da natureza que este relatório trata, e sim das relaçóes no trabalho. Meu hiperboss vai fazer uma apresentação no mês que vem, em Urano - com o criativo título de "Como Enfrentar os Desafios do Século XXII" -, e pediu minha colaboração. Ele quer mostrar às novas gerações a evolução da interação entre empresas e funcionários ao longo dos últimos 150 anos, desde a chamada "Era Jurássica Trabalhista" (1980-2020) até o aparecimento do "Homo Pizza", no final do século XXI. E me escolheu porque eu vivi todas as etapas do processo, além de ser o único por aqui que ainda sabe usar algarismos romanos. Então, vamos lá:

\section{TRANSPORTE}

Os empregados acordavam de manhã e iam para seu local de trabalho dirigindo um veículo pesadão e lerdo, que funcionava queimando derivados do extinto petróleo, chamado "automóvel" - não sei bem por que esse nome, que significa "move-se por si mesmo", já que o tal veículo só se movia sob comando humano e, algumas vezes, nem assim. Mas a maior dificuldade era enfrentar o "trânsito", do latim transire, "ir para a frente", e esse era exatamente o problema, já que o trânsito quase nunca ia em frente, e daí originou-se uma frase de uso muito comum, "Atrasei por causa do trânsito", que literalmente significa "Fiquei para trás porque fui para a frente". Ou seja, aquele povo era duro de entender. $O$ mais incrivel é que, apesar de tanta confusão e contrariando a lógica, as pessoas ainda conseguiam chegar ao que chamavam "local de trabalho".

\section{LOCAL}

O sistema jurássico de trabalho era coletivo, e as empresas até usavam jargões como "teamwork" para incentivar essas aglomerações, sem atentar para o fato de que elas eram uma fonte de proliferação de micróbios. $O$ ponto de encontro era o escritório, um lugar onde os funcionários escreviam, daí a origem da palavra. Eram áreas enormes, onde pessoas se amontoavam em cubículos e passavam a maior parte do tempo produzindo "documentos", cuja principal finalidade era a de servir como evidência física de que as pessoas estavam ocupadas. Após produzidos, os documentos eram imediatamente "arquivados", de preferência em lugares onde nunca mais pudessem ser localizados. Isso na época tinha o mesmo nome de hoje, "burocracia". A diferença é que os atrasados do século XX faziam tudo com oito cópias, e nós, 150 anos depois, conseguimos reduzir para sete.

\section{INDIVIDUALIDADE}

O primeiro passo para erradicar o coletivismo inútil foi o "SoHo" (Small office, Home office), uma sigla surgida aí por 2000, que permitia aos funcionários trabalhar, confortável e produtivamente, em suas proprias casas. No Brasil, uma das conseqüências imediatas do SoHo foi o aparecimento de uma variante esperta, o "SoNo". O que obviamente implicou num aumento brutal da quantidade de documentos nduzidos, porque só assim os chefes acreditariam que seus funcionários estavam 
acordados em suas casas. Depois do SoHo veio o "SoCo", aí por 2050. O "Co", todo mundo sabe, significa Chip office. Foi quando as corporações conseguiram implantar um microchip em cada funcionário para controlá-lo 24 horas por dia desde o batimento cardíaco até o nível de atividade dos neurônios. Uma das características do SoCo que mais agradou às chefias - além do comando de "wake up call" - foi a possibilidade de emitir um choque elétrico remoto quando o funcionário atrasasse a remessa de um documento.

\section{JORNADA}

Trabalha-se oficialmente 2 horas por semana, mas já há rumores de que a jornada será reduzido para 100 minutos semanais. O que, tirando o tempo necessário para o sono e as inconveniências fisidlógicas - que não sofreram alteraçôes nos últimos 100000 anos -, dá umas 120 horas ociosas por semana. O professor Domenico De Masi, que vive em estado de hibernação metafísica na Itália, afirma que isso é um absurdo, e defende a tese de que no futuro trabalharemos 100 minutos por ano. Mas o problema, mesmo, é que nunca conseguimos nos acostumar com o ócio. Por isso, nossa maior fonte de renda atual é a hora extra - fazemos, em média, 14 delas por dia, inclusive aos sábados.

\section{EFEITOS COLATERAIS}

Hoje, as megacorporações vêm se questionando se essa troca do trabalho grupal pelo individual foi realmente um progresso. Primeiro, porque ninguém mais conhece ninguém, já que os "colegas" viraram imagens digitalizadas. Segundo, porque todo mundo ficou sedentário e engordou uma barbaridade. $E$ terceiro porque os antigos executivos eram estressados, e os novos sucumbem à depressão, o que acarreta muitos suicrdios (ou, em linguagem ciberneticamente correta, self alt+ctrl+del). O maior guru de administração do século XXII - Tom Peters, vivendo confortavelmente em estado gasoso, num tubo de ensaio - publicou recentemente um antigo que está causando uma comoçæ̃o corporativa. Ele defende a tese de que "nada substitui o contato humano". Incrível, dizem seus fiéis admiradores, que ninguém tivesse pensado nisso ainda.

\section{EMPREGO}

Conseguir um bom emprego hoje em dia não é difícil. $O$ duro é se manter nele, porque as exigências para resultados de curtíssimo prazo aumentam cada vez mais. O tempo médio de permanência num emprego é de 28 horas. Daí o conceito em moda ser o da habilidade para saltar de galho em galho, ou "businessbilidade", que se resume a três fatores: experiência cósmica, formação galáctica e ser bem relacionado com quem manda.

\section{SEXO}

As diferenças entre sexos não são mais limitantes para o preenchimento de um cargo. Não porque tenha acabado a discriminação, mas porque acabaram os sexos. A antiga classificação "masculino/feminino/outros" caiu em desuso a partir do momento em que os assim chamados "homens" $e$ "mulheres" equilibraram seus niveis de testosteronas $e$ estrógenos. A ambivalência chegou a tal ponto que hoje os dicionários só registram a palavra "testículo" como sinônimo de "pequeno teste aplicado a estagiários". 


\section{HIERARQUIA}

Nos tempos primitivos, as posiçōes hierárquicas eram decididas ou por competência ou por protecionismo. Mas levava vantagem quem acumulava mais diplomas. Tudo mudou a partir do momento em que foi implantado o sistema de "Transferência Integral de Informações", pelo qual qualquer ser humano, quando completa 2 anos de idade, é acoplado a um megacomputador Deep Blue e absorve, em 15 minutos, o conhecimento acumulado pela espécie nos últimos dez milênios. Tem aí uma novíssima teoria dizendo que isso nos transformou numa raça de esponjas, e que o grande diferencial atual é saber pensar por conta própria, em vez de enfiar o dedo no nariz e dar um "retrieve". Segundo a teoria, há uma minoria de pensantes que consegue se perpetuar nas chefias porque tem "Inteligência Psicoemocional", ou seja, uma combinação balanceada de "instinto", "conhecimento" e "autocontrole". Eu acho que já ouvi isso antes, só que não me lembro bem quando foi.

\section{RELACIONAMENTO}

Os funcionários têm abertura para se comunicar fora do trabalho, desde que respeitem o conceito-chave do século XXII: Lógica Absoluta, ou seja, os assuntos devem ficar restritos aos negócios. Sentimentos e emoçōes, manifestaçōes consideradas contraproducentes, estāo proibidas desde 2104. Mas sempre tem quem não sabe aproveitar a liberdade: hosso maior problema social são os subversivos que se reúnem escondidos para praticar o maior delito da atualidade: rir e contar piadas. Não é por acaso que o maior best-seller desta semana é o cibertexto de auto-ajuda "Vocé Pode Ser Feliz, Desde Que Ninguém Saiba".

\section{INFERNET}

A arcaica Internet, uma rede de comunicação que causou furor no fim do século $X X, e$ que hoje é citada como exemplo de paranóia coletiva, foi substituída pela Infernet, à qual todos somos plugados logo ao nascermos. A palavra veio do latim infernus, "subterrâneo", uma analogia a seu formato de raízes que alimentam o caule central. O caule, de onde saem e para onde convergem todas as informações, é a Suprema Inquisição, cuja regra é "Todos somos iguais perante Deus". Sendo que Deus, como todos sabem, é Bill Gates. Embora corra por aí o boato de que quem manda, mesmo, é o ACM.

\section{CONCLUSÃO}

Em meus 144 anos, vilo futuro ir acontecendo, e aprendi pelo menos uma coisa: as previsões estavam sempre erradas. Acho que descobri o porquê. Outro dia achei um livro antigo, que já caiu em desuso por ser a negação da lógica. De qualquer forma, lá foi escrito, há milhares de anos, que cada dia é diferente do outro, exatamente "para que o homem nunca possa descobrir nada sobre seu próprio futuro" (Eclesiastes 7.14). 
A Ethernet se tornou um padrão aberto de conectividade e através do protocolo HSE (High Speed Ethernet) pode se tornar o padrão mais popular dos fieldbuses. A Fieldbus Foundation mapeou neste protocolo toda a tecnologia do padrão H1 confirmando a tendência de que a Ethernet dominará também o chão de fábrica. Grande parte das aplicações da rede HSE da Fieldbus Foundation necessitam de uma disponibilidade maior do que um sistema não tolerante a falhas pode fornecer. Usualmente é incorporada uma redundância protetora através da adição de componentes que não seriam necessários num sistema livre de falhas. $O$ alicerce fundamental da redundância é a transparência operacional.

Computação reconfigurável é uma solução que combina processadores dedicados com memótia, lógica e programação (hardware/software), permitindo a integração de sistemas em um único FPGA (Field Programmable Gate Array). Estes conceitos possibilitarão a implementação do algoritmo de redundância previsto pela norma HSE de forma transparente para o processador, e conseqüentemente para a aplicação do usuário.

O propósito deste trabalho é fornecer um hardware que tenha duas portas Ethernet de $100 \mathrm{Mbps}$. Visa com isto fornecer um suporte para que sejam implementados os algoritmos de redundância especificados pelo protocolo HSE. A proposta é a definição de um hardware com dois controladores Ethernet de 100Mbps através do estudo de algumas tecnologias de fabricação de componentes e de alguns paradigmas de projeto de hardware. A forma de manipulação dos dados é um grande desafio para este trabalho, que irá identificar a melhor alternativa para o controle do fluxo de dados entre as portas Ethernet, uma vez que as velocidades envolvidas na transmissão são da ordem de $100 \mathrm{Mbps}$. A melhor alternativa deve levar em conta 0 custo, complexidade e desempenho da solução.

A incorporação de tecnologias como HSE e Web aos equipamentos para automação e controle industrial fará com que as soluções para o chão de fábrica acompanhem e desfrutem das tendências tecnólogicas da Internet e ainda será uma porta aberta para a tão desejada interoperabilidade. 
The Ethernet becomes an open connectivity standard and with the High Speed Ethernet (HSE) protocol can become the most used standard of fieldbuses. The Fieldbus Foundation mapped all the Layer 2 technologies from its $\mathrm{H} 1$ standard into Ethernet. Many target applications of Foundation Fieldbus HSE Network need to have higher availability of the automation system than a non-fault tolerant system can provide. The Fieldbus Foundation HSE approach to improving availability is by means of redundancy. That is, it provides additional hardware to be used in event of a failure. The fundamental underpinning of redundancy is operational transparency.

Reconfigurable Computing combines embedded processor with memory, logic and programming to integrate systems in a Field Programmable Gate Array (FPGA). This will allow implementing the redundancy algorithms of Foundation specification transparently.

This work will provide an hardware with two 100 Mbytes Ethernet port to support the implementing the redundancy algorithms of Foundation specification. The focus is to define the hardware based on studying of some integrated circuit manufacturing technologies and some hardware design techniques. The challenge is to find the best way to exchange information between the 100 Mbytes Ethernet controllers. The best solution must achieve low cost, low complexity and high performance.

The use of technologies as HSE and Web in industrial automation devices is allowing the plant floor solutions follow the Internet tendencies and can be the open door to the interoperability. 
1. INTRODUCCÃO

2. CONECTIVIDADE ETHERNET

2.1. EMBEDDED NETWORKING

2.2. CONEXÃo ETHERNet PaRA AUTOMAÇĀo

2.3. PROTOCOLO High SPEED ETHERNET FIELdBUS

2.4. CONSIDERAÇÕES FINAIS

3. COMPUTACÃO RECONFIGURÁVEL 13

3.1. COMPUTAÇĀo TradICIONAL

3.2. COMPUTAÇÃo RECONFIGURÁVEL

3.2.1. ARQUITETURAS

3.2.2. FluXo DE PROJETO DE Sistemas RECONFIGURÁveIS

3.2.3. APLICAÇÕES

3.3. Dispositivos Lógicos Programáveis

3.3.1. A TECNOLOGIA FPGA

3.4. LINGUAGEM DE DESCRIÇÃO DE HARDWARE

3.4.1. INTRODUÇÃO À LINGUAGEM VHDL

3.5. CONSIDERAÇÕES FINAIS

4. ETHERNET COM TOLERÂNCIA A FALHAS

4.1. TOLERÂNCIA A FALHAS

4.1.1. REDUNDÂNCIA PRQTETORA

4.2. REDUNDÂNCIA EM SISTEMAS DE AUTOMAÇĀO

4.3. REDUNDÂNCIA HIGH SPEED ETHERNET

4.3.1. REDUNDÂNCIA DA LAN HSE

4.3.2. EQUIPAMENTOS REDUNDANTES HSE $\quad 40$

4.4. IMPLEMENTAÇÃO

4.4.1. COMPONENTES CHAVES

4.4.2. MODELO

4.4.3. ALGORITMO

4.5. CONSIDERAÇÕES FINAIS

5. PARADIGMAS ESTUDADOS

5.1. SYSTEM-ON-CHIP

5.1.1. EDA

5.2. ComputaÇão Tradictonal

5.3. PROCESSADORES DEDICADOS

5.4. PLD COM PROCESSADORES EMBUTIDOS

5.4.1. SOFT CORE NIOS

5.4.2. HARD CORES ARM E MIPS

5.5. CONSIDERAÇÕES FXYNAIS 
6.1. NET+ARM

6.2. NET+OS

6.3. MAX 3000A

6.4. MAX+PLuS II

6.5. CONSIDERAÇõES Finais

7. DEFINICÃO DA AROUTTETURA

7.1. MEMória DUAL-PoRT

7.2. MESTRE/ESCRAVO

$\begin{array}{ll}\text { 7.3. MEMÓRIA COMPARTILHADA VIA ENI } & \mathbf{7 4}\end{array}$

7.4. HARDWARE RECONKIGURÁVEL $\quad 75$

$\begin{array}{ll}\text { 7.5. CONSIDERAÇÕES FIYYAIS } & 76\end{array}$

8. PROJETO DO HARDWARE 77

8.1. REQUISITOS DO PROJETO

8.1.1. PESQUISA DE COMPQNENTES

8.1.2. PROJETO DO MECANISMO DE INICIALIZAÇÃO

8.2. Programação do PLD $\quad 80$

8.2.1. MÁQUINAS DE ESTADO $\quad 81$

8.2.2. PROGRAMAÇÃo $\quad 86$

8.3. Circuito elétrico $\quad 91$

8.3.1. DEFINIÇÃO DAS CANIADAS DA PLACA 91

8.3.2. POSICIONAMENTO DOS COMPONENTES 92

$\begin{array}{ll}\text { 8.3.3. ROTEAMENTO } & 92\end{array}$

\begin{tabular}{l|r} 
8.4. PRODUÇão & 92
\end{tabular}

8.4.1. FABRICAÇÃO DA PLACA 93

8.4.2. AQUISIÇÃO DOS COMPONENTES

\begin{tabular}{l|l} 
8.4.3. MONTAGEM & 94
\end{tabular}

8.5. TESTES MODULARES $\quad 94$

8.5.1. GERAÇÃO DO CHIP-SELECT

8.5.2. GRAVAÇÃO DO PLD 96

8.5.3. COMUNICAÇÃo COM A CPU VIA ICE 97

8.5.4. COMUNICAÇÃO SERIAL. 99

8.5.5. COMUNICAÇÃo ETHERNET 102

$\begin{array}{ll}\text { 8.6. CONSIDERAÇÕES Finais } & 104\end{array}$

9. CONCLUSÃO

9.1. Contribuiçóes $\quad 106$

$\begin{array}{lr}\text { 9.2. Resultados } & 106\end{array}$

$\begin{array}{ll}\text { 9.3. FUTURO } & 109\end{array}$

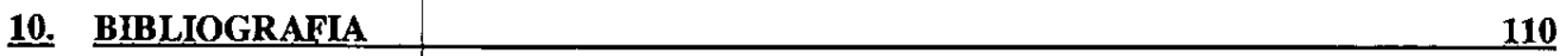

\begin{tabular}{l|r} 
APÊNDICE & 116 \\
\hline A
\end{tabular}

\begin{tabular}{ll}
\hline A - ESQuema Elétrico do Projeto & 116
\end{tabular} 


\section{ÍNDICE DE FIGURAS}

FIGURA 1 - DIAGRAMA EM BLOCOS DO SISTEMA A SER DESENVOLVIDO ….........................................

FIGURA 2 - RASCUNHO INICIAL DA TECNOLOGIA ETHERNET ............................................................

FIGURA 3 - HIERARQUIA DO HSE FIELDBUS FOUNDATION......................................................10

FIGURA 4 - TIPOS DE ACOPLAMENTO DE RPUS COM O SISTEMA HOST ..........................................16

FIGURA 5 - EXEMPLO DE RECONFIGURAÇÃO DINÂMICA EM PLDS.................................................17

FIGURA 6 - FLUXO DE PROJETO DE SISTEMAS RTR ……........................................................18

FIGURA 7 - ARQUITETURA BÁSICA DE UM FPGA ...................................................................22

FIGURA 8 - MODELO BÁSICO DE UMA ARQUITETURA DE ROTEAMENTO DE UM FPGA …................24

FIGURA 9 - SISTEMA EDA PARA PROJETOS COM FPGAS..........................................................26

FIGURA 10 - PROCESSO SIMPLIFICADO PARA PROJETO DE CIS LOGICAMENTE PROGRAMÁVEIS ......29

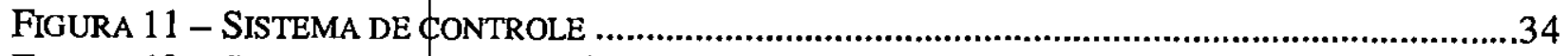

FIGURA 12 - SISTEMA COM REDUNDÂNCIA DE SERVIDOR …….....................................................35

FIGURA 13 - SISTEMA COMPLETAMENTE REDUNDANTE .........................................................36

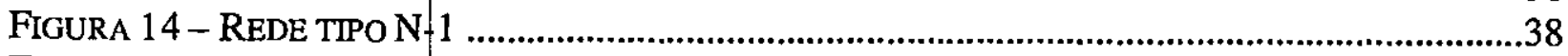

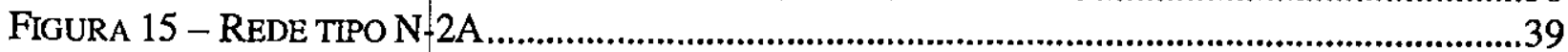

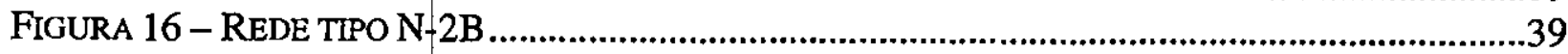

FIGURA 17 - TIPOS DE EQUIPAMENTOS REDUNDANTES HSE ....................................................41

FIGURA 18 - CLASSE REDUNDÂNCIA DE REDE ……............................................................44

FigURA 19 - PARES DE MENSAGENS DE DiagnóstiCo............................................................46

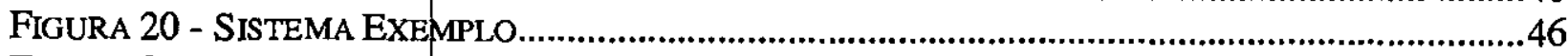

FIGURA 21 - EVOLUÇÃO DOS MÉTODOS DE PROJETO .............................................................49

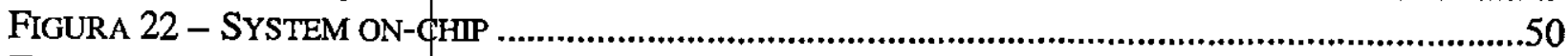

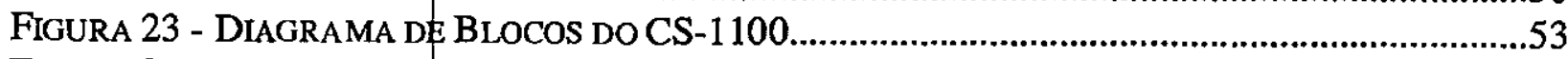

FIGURA 24 - NET+WORKS ARCHITECTURE OVERVIEW …........................................................5

FIGURA 25 - FLEXIBILIDADE E ESCALABILIDADE DOS PROCESSADORES EMBUTIDOS NIOS. ...........58

FIGURA 26 - DIAGRAMA EM BLOCOS DO HARD CORE EXCALIBUR ARM/MIPS ................................59

FIGURA 27 - MÓDULO PROCESSADOR NET+40 …….........................................................60

FIGURA 28 - NET+ARM HARDWARE ARCHITECTURE ……................................................61

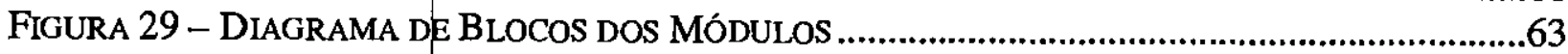

FIGURA 30 - NET+ARM GHIP HARDWARE BLOCK DIAGRAM...............................................6.

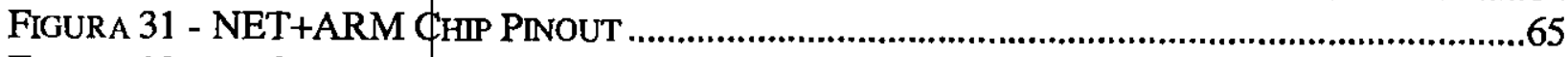

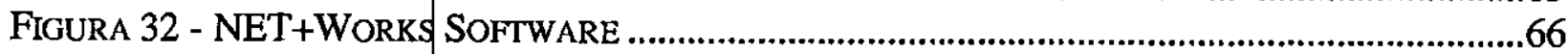

FIGURA 33 - NET+WORKS SOFTWARE EM CAMADAS........................................................67

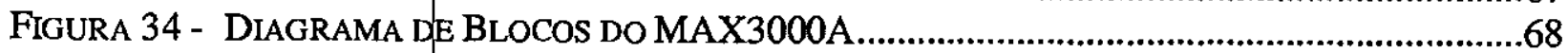

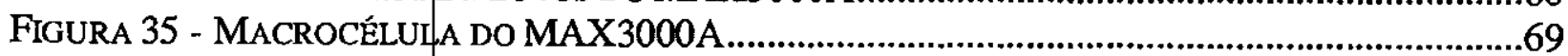

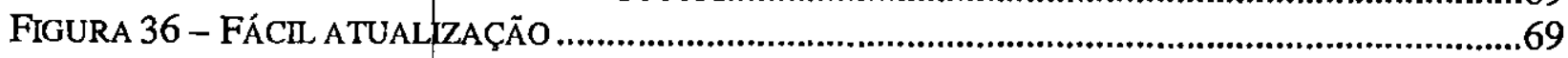

FIGURA 37 - PROJETO USANDO O MAX+PLUS II ..............................................................70

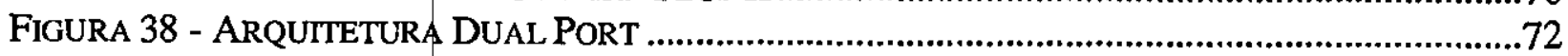

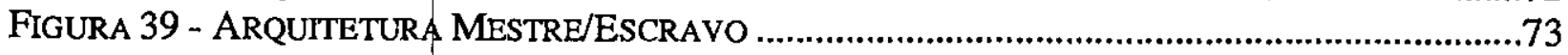

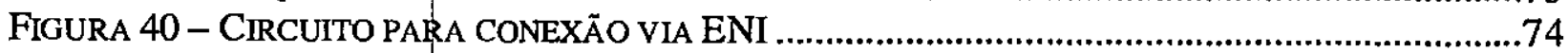

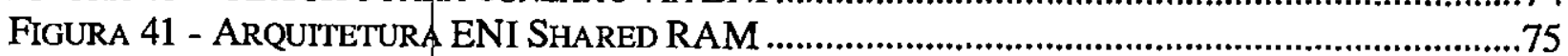

FIGURA 42 - DiAGRAMA DE BLOCOS DO HADWARE RECONFIGURÁVELL.........................................76

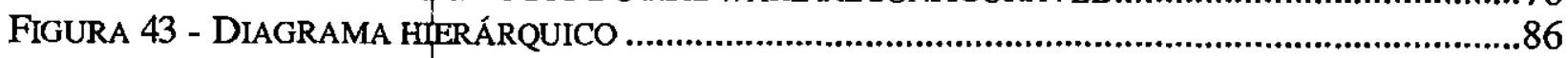

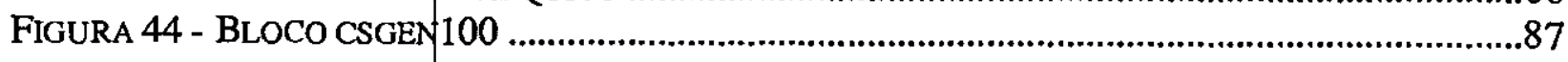




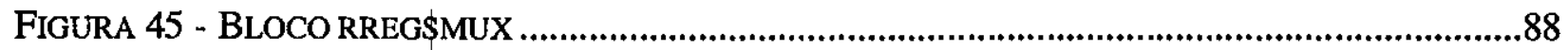

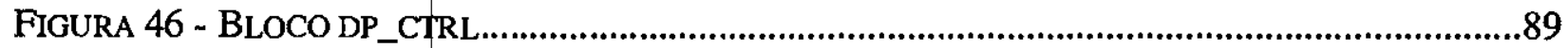

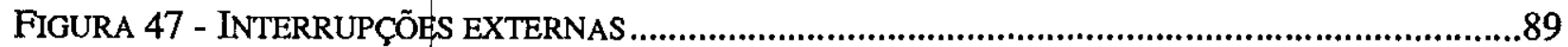

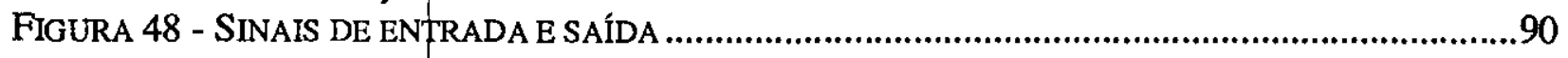

FIGURA 49 - TELA DO PROTEL.....................................................................................................

FIGURA 50 - DISTRIBUIÇÃ D DAS CAMADAS DA PLACA........................................................92

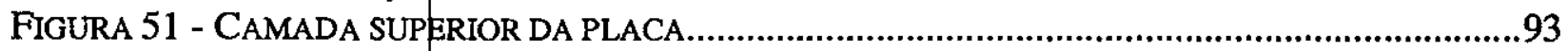

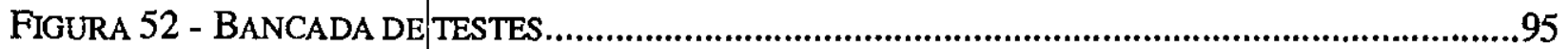

FIGURA 53 - TELA DE SIMULAÇÃO DOS CHIP-SELECTS .................................................................96

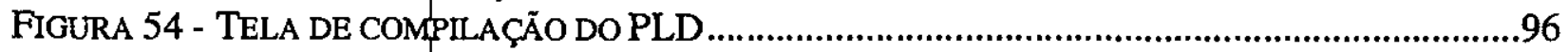

FIGURA 55 - TELA DA PROGRAMAÇÃO DO PLD...............................................................................97

FIGURA 56 - AMBIENTE DE DESENVOLVIMENTO DO MULTI 2000 …........................................97

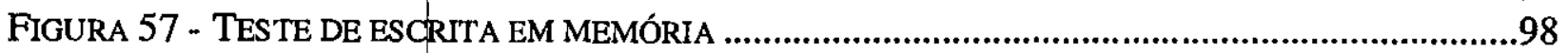

FIGURA 58 - ESCRITA DO PROGRAMA NA MEMÓRIA DA PLACA ..........................................................99

FIGURA 59 - VISUALIZAÇÃO DE UMA TRANSMISSÃO NO OSCILOSCÓPIO .........................................101

FIGURA 60 - CONFIGURAÇÃo DOS PARÂMETROS IP.....................................................................101

FIGURA 61 - TELA INICIAL DO NETWORK MONTOR .........................................................102

FIGURA 62 - VISUALIZAÇÃ DOS FRAMES .................................................................................103

FIGURA 63 - ESTRUTURA E COMPOSIÇÃO DE UM FRAME.............................................................103

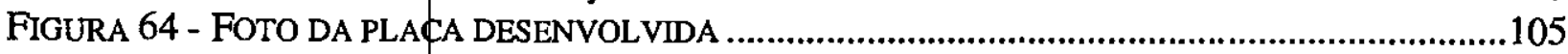

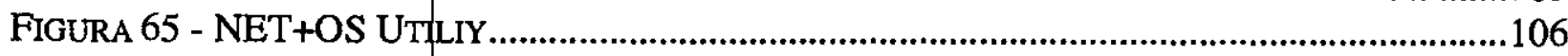

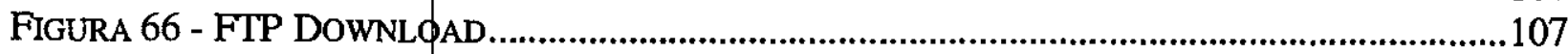

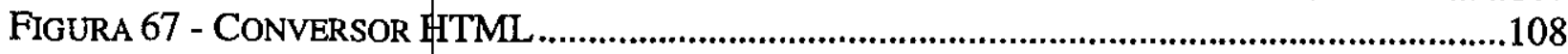

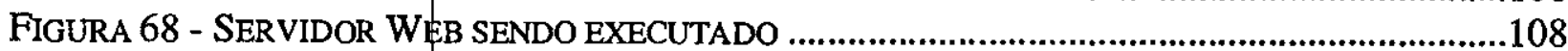

FIGURA 69 - DIAGRAMA DE BLOCOS DO HARDWARE ......................................................116

FIGURA 70 - MÓDULO PROCESSADOR NET+40 (CPU A) .............................................................117

FIGURA 71 - MÓDULO PROCESS ADOR NET+40 (CPU B) ............................................................118

FIGURA 72 - CONTROLE DE ACESSO A MEMÓRIAS E PERIFÉRICOS (PLD) ....................................119

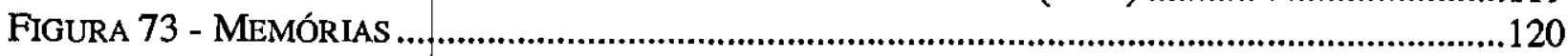

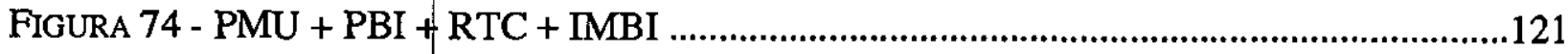

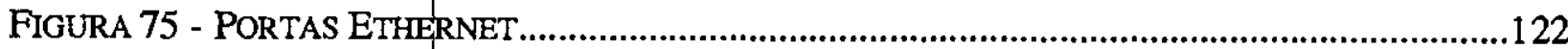

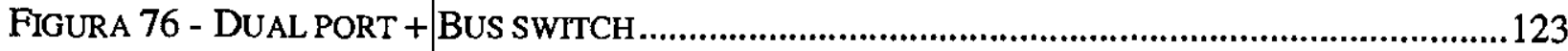




\section{ÍNDICE DE TABELAS}

TABELA 1 - VANTAGENS E DESVANTAGENS DAS TECNOLOGIAS DOS COMUTADORES .22

TABELA 2 - ATRIBUTOS DA ClASSE REDUNDÂNCIA DE REDE 43

TABELA 3 - MEMBROS DA Classe REDUNDÂNCIA DE REDE. .45

TABELA 4 - EXEMPLo dA TABELA dE ESTADOS DA REDE PARA O DEVICE 3 47

TABELA 5 - COMPARAÇÃ OE SOLUÇÕES PARA DESENVOLVIMENTO DE HARDWARE........................57

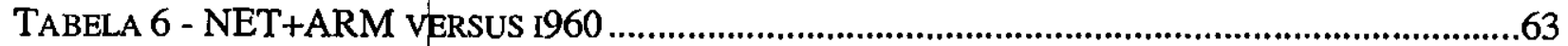

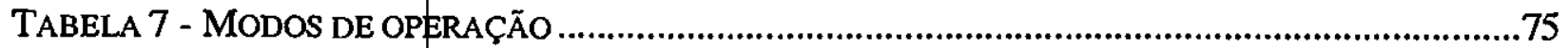

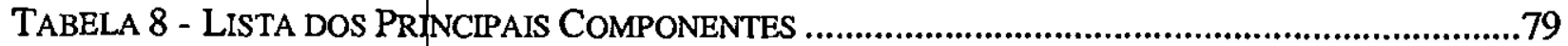

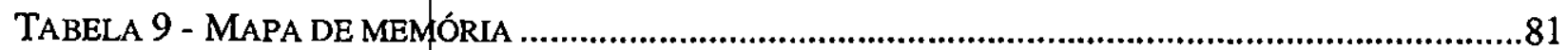

TABELA 10 - CÁLCULO DA S TAXAS PADRÕES POSSÍVEIS ......................................................100 


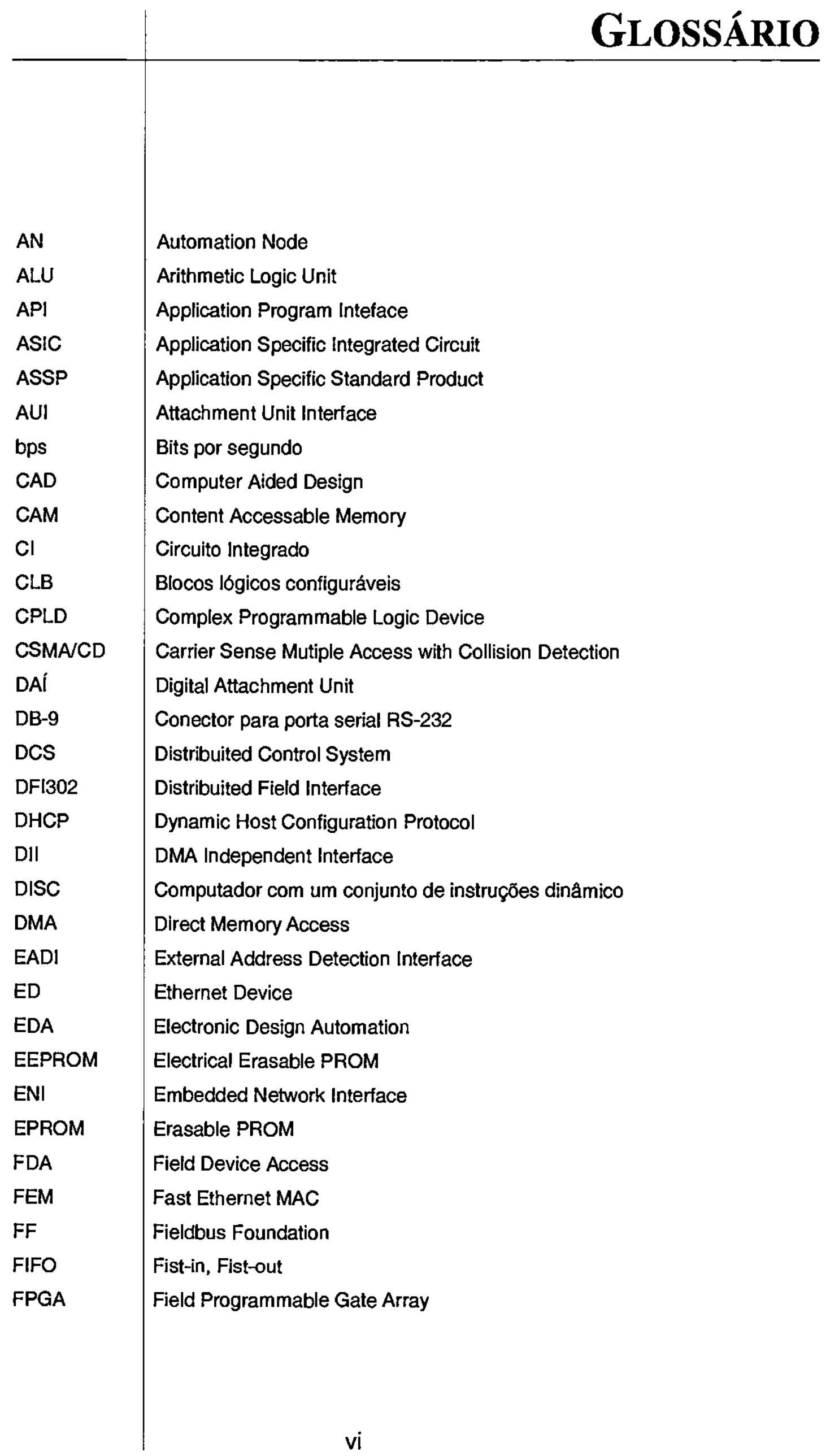




\begin{tabular}{|c|c|}
\hline FPU & Float Point Unit \\
\hline GAL & Gate Array Logic \\
\hline GD & Gateway Device \\
\hline GPSI & General Purpose Serial Interface \\
\hline GUI & Graphic User Interface \\
\hline $\mathrm{H} 1$ & H1 Fieldbus Foundation (@31.25 kbps) \\
\hline $\mathrm{H} 2$ & H2 Fieldbus Foundation (@ 1 or 2.5 Mbps) \\
\hline HD & Host Device \\
\hline HDL & Hardware Description Language \\
\hline HSE & High Speed Ethernet Fieldbus Foundation \\
\hline HW & Hardware \\
\hline $1 / 0$ & Entrada e Saída \\
\hline ICE & In Circuit Emulator \\
\hline IEEE & The Institute of Electrical and Electronic Engineers \\
\hline IP & Intelectual Property \\
\hline IP & Internet Protocol \\
\hline ISO & International Organization of Standardization \\
\hline ISP & Internet Service Provider \\
\hline IT & Information Tecnology \\
\hline JTAG & Joint Test Action Group \\
\hline$\angle A B$ & Logic Array Blocks \\
\hline LAN & Local Area Network \\
\hline LAS & Link Activity Scheduler \\
\hline LD & Linking Device \\
\hline LUT & Look-up Table \\
\hline MAC & Media Access Controller \\
\hline MACE & Media Access Controller for Ethernet \\
\hline MAU & Media Attachment Unit \\
\hline MDI & Medium Dependent Interface \\
\hline Mil & Media Independent Interface \\
\hline MPC & Memory and Peripheral Controller \\
\hline MVL.9 & Multivalued Logic or Nine Values \\
\hline NST & Network Status Table \\
\hline OLE & Object Link Embeded \\
\hline OPC & OLE for Process Control \\
\hline OSI/RM & Open System interconnect Reference Model \\
\hline PAL & Programmabie Array Logic \\
\hline $\mathrm{PC}$ & Personal Computer \\
\hline
\end{tabular}




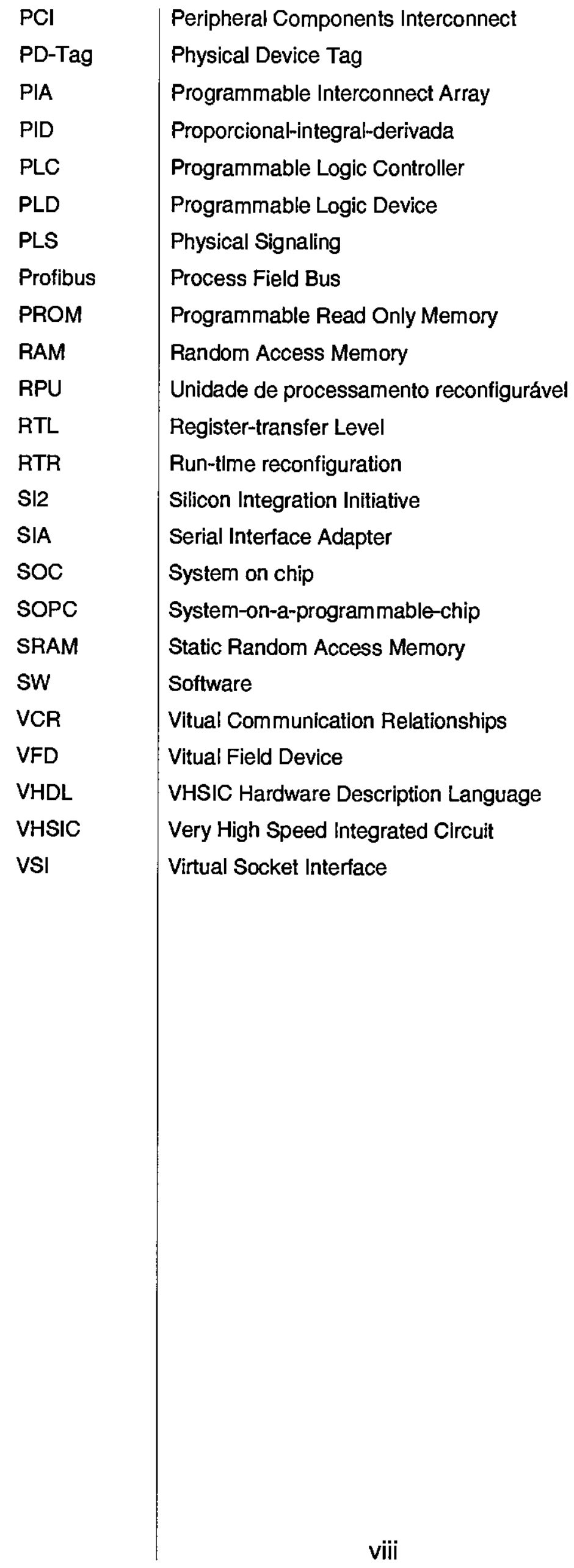




\section{INTRODUÇÃO}

A constante evolução da microeletrônica está disponibilizando dispositivos eletrônicos cada vez mais velozes, com maior capacidade, menor consumo e custos mais baixos, deixando para o projetista de hardware o desafio de equilibrar a velocidade de operação dos sistemas e o grau de generalidade destes sistemas [1].

A velocidade dos dispositivos de uso geral pode ser lenta se comparada à dos dispositivos com aplicações específicas que executam apenas um conjunto limitado de instruções. Exemplo destes sistemas de uso geral são os microprocessadores que por esta característica atendem um grande número de usuários de computador pessoal. Já os circuitos integrados conhecidos como ASIC (Applications-Specific Integrated Circuits), são desenvolvidos para uma determinada aplicação e por isto se tornam menores, mais velozes e consomem menos energia do que os processadores de uso geral. Por outro lado, o sistema implementado através de um ASIC não poderá ser modificado a um custo razoável após a conclusão do projeto.

Hoje estão disponíveis dispositivos de alta capacidade lógica como os FPGA (Field Programmable Gate Arrays) e CPLD (Complex Programmable Logic Devices) que oferecem um boa opção por se tratarem de circuitos de hardware que podem ser modificados facilmente. Estes dispositivos são a alternativa natural para a prototipação de projetos a serem implementados em 'gate arrays' ou ASIC por suas características de reprogramação e alta flexibilidade, que aliadas ao uso intensivo de ferramentas EDA (Electronic Design Automation) possibilitam a redução do tempo de realização de um projeto e redução dos custos envolvidos, propiciando uma redução do tempo necessário para se colocar um novo produto no mercado. Só para se ter uma idéia, o custo de projeto de um ASIC gira em torno de um milhão de dólares [67] e depois de pronto não pode mais ser modificado, enquanto os projetos para FPGA são mais baratos e podem ser reprogramados. O crescimento do mercado para estes dispositivos nos últimos anos confirma suas vantagens competitivas em relação a outras tecnologias [2], [3]. A utilização da característica de reprogramação destes dispositivos é genericamente denominada de Computação Reconfigurável.

Computação Reconfigurável ainda é uma área em desenvolvimento onde definir e validar conceitos e técnicas tornam-se grandes desafios para os pesquisadores atualmente [10]. $O$ enorme potencial para o desenvolvimento de aplicações fará com que esta tecnologia seja bastante explorada nos próximos anos [2], [6], [11], [12]. Este trabalho visa explorá-la de modo bastante prático.

Por outro lado, a tecnologia Ethernet cresce assustadoramente, na medida de que a oferta de produtos e serviços para a mesma são cada vez maiores. De olho nas facilidades proporcionadas pelo uso de uma tecnologia padronizada $e$ amplamente disponivel comercialmente, as indústrias tem procurado levar a Ethernet para dentro do chão de fábrica. 
$\mathrm{Na}$ tentativa de atender a uma demanda por maior robustez no monitoramento e controle através da Ethernet vários esforços têm sido feito no sentido de obter uma rede de comunicação confiável e de alta velocidade. Para atender a esta necessidade a Fieldbus Foundation especificou o protocolo High Speed Ethernet Fieldbus (HSE) [31] o qual prevê a existência de equipamentos com portas redundantes a serem conectados em redes redundantes [32].

Os fabricantes de processadores já têm disponibilizado comercialmente novos processadores dedicados para a comunicação em rede. Estes processadores possuem normalmente um controlador Ethernet embutido, com uma interface padronizada, de modo a facilitar o desenvolvimento de produtos que possam ser conectados facilmente a uma rede Ethernet.

O propósito deste trabalho é estudar uma forma de fornecer um hardware que tenha duas portas Ethernet de $100 \mathrm{Mbps}$. Visa com isto fornecer um suporte para que sejam implementados os algoritmos de redundância especificados pelo protocolo HSE. A proposta é a definição de um hardware com dois controladores Ethernet de $100 \mathrm{Mbps}$ através do estudo de algumas tecnologias de fabricação de componentes e de alguns paradigmas de projeto de hardware. A forma de manipulação dos dados é um grande desafio para este trabalho, que irá identificar a melhor alternativa para o controle do fluxo de dados entre as portas Ethernet, uma vez que as velocidades envolvidas na transmissão são da ordem de $100 \mathrm{Mbps}$. A melhor alternativa deve levar em conta o custo, complexidade e desempenho da solução.

O ideal é que aplicação trabalhasse como se existisse apenas uma porta, e que a escolha de qual porta se usar num determinado instante fosse feita por uma camada externa (seja em software ou em hardware). Na medida do possível nosso estudo avançará no sentido de criar uma interface o mais transparente para a unidade de processamento central (CPU) através do uso de uma unidade de processamento reconfigurável (RPU). A idéia é também visualizar uma camada de interface com os controladores o mais genérica possivel, que não descarte a hipótese de futuras implementações suportando, por exemplo, FDDI e/ou ATM. O diagrama de blocos geral para o circuito é mostrado na Figura 1.

Esta RPU é colocada no diagrama geral, pois independente do paradigma a ser utilizado ela dará muita flexibilidade ao hardware. Fisicamente será composta de um dispositivo lógico programável (PLD).

No próximo capítulo serão abordados conceitos relacionados à conectividade Ethernet. Também serão feitas considerações quanto ao uso de Ethernet em ambientes industriais. Na parte final do capítulo será apresentado um sumário da norma do protocolo High Speed Ethernet da Fieldbus Foundation (fundação responsável pela padronização do protocolo Fieldbus Foundation). Este protocolo está agora mapeando toda tecnologia do padrão $\mathrm{H} 1$ (também da Fieldbus Foundation) para Ethernet. 


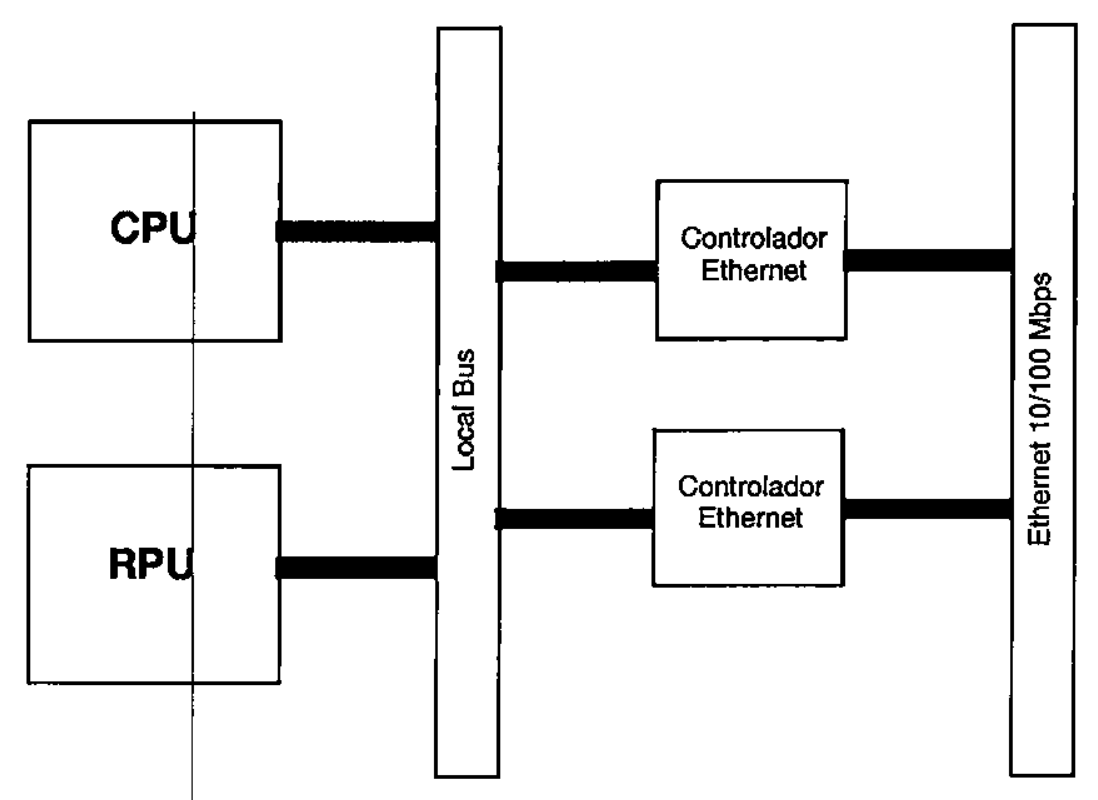

Figura 1 - Diagrama em blocos do sistema a ser desenvolvido

No capítulo 3 serão apresentados conceitos importantes de computação reconfigurável, além de algumas tecnologias envolvidas. Serão ainda identificadas as tendências tecnológicas nesta área. Estas tecnologias oferecem o suporte necessário para se alcançar os objetivos propostos por este trabalho, através de ferramentas, técnicas, linguagens e componentes.

No capítulo 4 serão abordados tópicos relacionados com a tolerância à falhas em sistemas, dando ênfase na redundância de componentes deste sistema. $O$ componente do sistema em questão será a rede Ethernet, e para isto será apresentado um resumo da especificação de redundância do protocolo High Speed Ethernet Fieldbus, uma vez que esta especificação norteará o escopo deste trabalho. A implementação da redundância não estará em foco, mas, serão abordados alguns aspectos da implementação para que a idéia do trabalho seja entendida naturalmente.

A seguir, no capítulo 5 , serão apresentados alguns estudos realizados em relação aos paradigmas de projeto de hardware aplicáveis a este projeto, suas vantagens e desvantagens, análise de custo, desempenho, flexibilidade e aplicabilidade. Através destas análises poderá se escolher o paradigma que será usado no desenvolvimento deste trabalho, dentro da disponibilidade de recursos.

Definido o paradigma, o capítulo 6 detalhará os principais componentes deste projeto. Os principais componentes envolvem o hardware, o sistema operacional, as ferramentas de desenvolvimento e programação. A partir daí, no capítulo 7, serão levantadas algumas possíveis arquiteturas para implementação do hardware. $O$ estudo das arquiteturas será no sentido de encontrar uma melhor forma de manipular os dados das duas portas Ethernet. A escolha da melhor arquitetura está relacionada à definição de alguns parâmetros como complexidade do software, complexidade do hardware, custo do hardware (componentes eletrônicos) e também com o desempenho. 
O capítul 8 estará mostrando todas as fases do projeto do hardware, assim como as dificuldades encontradas. Este capítulo terá uma abordagem bastante prática e tentará fornecer subsídios de estudo para novas implementações não só deste, mas também de outros projetos de hardware. Durante a fase de testes serão levantados vários resultados que estarão validando o projeto.

Finalmente, no capítulo 9 serão apresentados os resultados e as conclusões deste trabalho. Espera-se com este trabalho a consolidação de tecnologias emergentes além da criação de um protótipo que possibilite a implementação destes padrões em definição para análise técnica e posterior validação. Espera-se ainda despertar o interesse para tecnologias que têm surgido para acelerar o processo de desenvolvimento, mas que devido ao alto custo inicial não tem sido consideradas pelas indústrias nacionais como formas alternativas no desenvolvimento de novos produtos. 


\section{CONECTIVIDADE ETHERNET}

\subsection{Embedded Networking}

Nos próximos anos qualquer equipamento que manipula informação, controle ou medidas, tais como impressora, controladores industriais, equipamentos médicos, terminais de venda, e medidores estarão conectados à Internet/Ethernet.

A conexão de equipamentos na Internet e Ethernet já se tornou familiar. $O$ resultado de equipamentos inteligentes operando automaticamente numa rede aberta irá causar um grande impacto na vida das pessoas.

Esta conexão aberta é o que falta para se ter tudo junto e trabalhando no fechamento do ciclo de controle. Isto irá permitir uma melhora no custo, produtividade e no crescimento do negócio principal da empresa. Como o custo para se ter um equipamento na rede cai de acordo com o volume, isto irá desencadear uma taxa crescente de inovações e uma avalanche de novas aplicações e produtos, como tem acontecido hoje em dia com o mercado de computadores pessoais (PCs) e Internet para aplicações comerciais e pessoais. Só que esta realidade ainda está nos estágios iniciais para estes equipamentos dedicados (embedded).

Os OEMs estão se esforçando para melhorar. Os clientes irão trabalhar com aqueles que forem mais fácil para negociar. A Internet está trazendo toda uma nova geração de serviços on-line para vendas e suporte que permitirá aos OEMs formarem um sólido relacionamento com seus clientes e fortalecer as barreiras competitivas. Equipamentos conectados à Ethernet/Internet permitirá aos OEM uma significante redução no custo na área de venda e de suporte, além de melhorar a produtividade. Isto esta acontecendo rápido e os OEMs devem implementar isto ou ficarão para trás.

realizadas são:

As grandes oportunidades aqui levantadas que agora podem ser

- Melhores e rápidas decisões por acesso universal aos dados;

- Arquitetura flexível com interface comum;

- Escalabilidade que preserve os investimentos tecnológicos;

- Baixo custo de propriedade para novos desenvolvimentos altamente confiávies e rápidos;

- Competição entre fornecedores gera inovações e baixo custo.

Existem muitos benefícios na conexão a uma rede aberta. Primeiro porque ela permite acesso universal aos dados para uma melhor e mais rápida tomada 
de decisão. Finalmente poderá se conhecer e ter total controle desde os equipamentos de chão de fábrica até os computadores gerenciais. Isto cria uma sólida linha de controle. Uma rede aberta é um veículo para escalabilidade que permite preservar os investimentos do passado. Com padrões de rede proprietários, normalmente é necessário jogar tudo for a quando se deseja algo novo. Como a rede aberta já é um padrão em todo o mundo, isto leva a um baixo custo de propriedade: o cabeamento é padrão, os hubs são padrões, os protocolos são padronizados e muitas pessoas já estão treinadas neles, ișto é, são replicáveis.

A partir do momento que a rede aberta começa a ser instalada em grande volume, milhares de empresas desenvolvem pacotes de software para melhorar os negócios e isto, por sua vez, aumenta a competitividade e a taxa de inovação. A rede aberta é composta por todos os equipamentos que estão conectados em uma rede de alta velocidade através do mundo, 24 horas por dia em tempo real. Hoje a rede aberta é uma LAN - Ethernet e Internet.

Tudo isto está acontecendo como resultado da convergência de três tendências tecnológicas, as quais permitem que o padrão de serviços Internet/Ethernet seja oferecido em uma base já consolidada, presente em todos os lugares:

- O TCP/IP se definiu como o protocolo padrão de fato;

- A guerra das topologias que esta sendo liderada pela Ethernet $10 / 100$;

- A tecnologia ASIC fez grandes progressos na redução do custo do hardware para conectividade Internet/Ethernet, que agora está num patamar que tornou este hardware viável para uma maior variedade de equipamentos e maiores progressos têm sido feitos.

Os equipamentos dedicados (embedded) são aqueles que necessita de um baixo custo de conectividade para se tornarem viáveis. Os três maiores obstáculos para o progresso deste tipo de solução são:

- Custo: é necessário que o custo para que um equipamento esteja disponível na Internet/Ethernet seja de US\$10 a US\$15 por nó (em grande escala) que é o custo de um placa de rede padrão. Hoje em dia, usando componentes padrões, o preço está numa faixa de US\$50 a US\$100.

- Complexidade da implementação: ainda se é muito difícil para se implementar, uma vez que as empresas que projetam os equipamentos dedicados não estão focadas em redes e necessitam de produtos 'plug-and-play', ao invés de engenheiros de redes.

- Escalabilidade: estes produtos necessitam de uma larga variedade de MIPS ou potência, além de serem de baixo consumo para equipamentos muito pequenos.

O acesso remoto em tempo real a um equipamento/no, onde quer que ele esteja, será uma grande solução para as necessidades de tempo real dos negócios atuais. Este acesso possibilita a centralização da inteligência humana necessária para operar e suportar os equipamentos. Deve ser Internet e Ethernet porque esta é uma infraestrutura de baixo custo, alto desempenho, e tem provado que pode fazer 0 trabalho. A Internet é o foco dos negócios e tecnologias atualmente, e através um conjunto de hardware e software de padrão aberto, pode ser usada para transferência 
de informações e na đísponibilização de mecanismos de controle fáceis de se usar. Além disto, o crescente número de usuários aumenta ainda mais as possibilidades deste tipo de negócio.

A Internet e as conexões modernas de rede farão com que cinco das maiores funções sejam radicalmente melhoradas:

1. Facilidade de instalação do produto, tanto local quanto remotamente.

2. Automática monitoração do produto, através do envio de notificações ao usuário quando alguma coisa está errada.

3. Transferência de dados para programas em 'hosts' distribuídos para automação dos passos do processo.

4. Diagnóstico/reparo para ajudar a encontrar e resolver problemas com o equipamento ou no seu funcionamento.

5. Interface gráfica de usuário (GUI) usando um navegador Web para eliminar a necessidade de se escrever e projetar GUls para cada computador/terminal conectado ao equipamento.

Qualquer companhia baseada em tecnologia que não está pelo menos pensando como utilizar Internet está perdendo a próxima grande onda de oportunidades para produtos. Mas, até agora, desenvolver um equipamento com conectividade a uma rede Ethernet, muito mais a Internet, tem sido uma tarefa assustadora e cara, que relativamente poucas companhias de alta tecnologia tem se empreendido nesta área.

\subsection{Conexão Ethernet para Automação}

Ethernet e uma tecnologia importante, e que tem seu lugar no projeto do sistema de controle moderno [13]. Para os especialistas é a tecnologia de rede mais simples de ser implementada, por ser bem conhecida, além de estar se tornando cada vez mais barata devido a grande concorrência.

A Ethernet também oferece a possibilidade de um verdadeiro padrão aberto de conectividade. Fabricantes de PLCs ou de sistemas de controle distribuído (DCS) podem suportar apenas determinadas redes de equipamentos de campo, tais como Profibus ou Fieldbus Foundation. Mas todos os fabricantes suportam conectividade Ethernet, que pode então se tornar a língua franca do controle de processo; o RS-232 do próximo milênio.

Esta tecnologia (Figura 2) foi inicialmente desenvolvida pela Xerox nos anos 80 e foi adotada pelo Institute of Electrical and Electronic Engineer (IEEE) como o padrão 802.3. Desde então, ela se tornou o padrão dominante para redes locais (LANs) em todo mundo. 


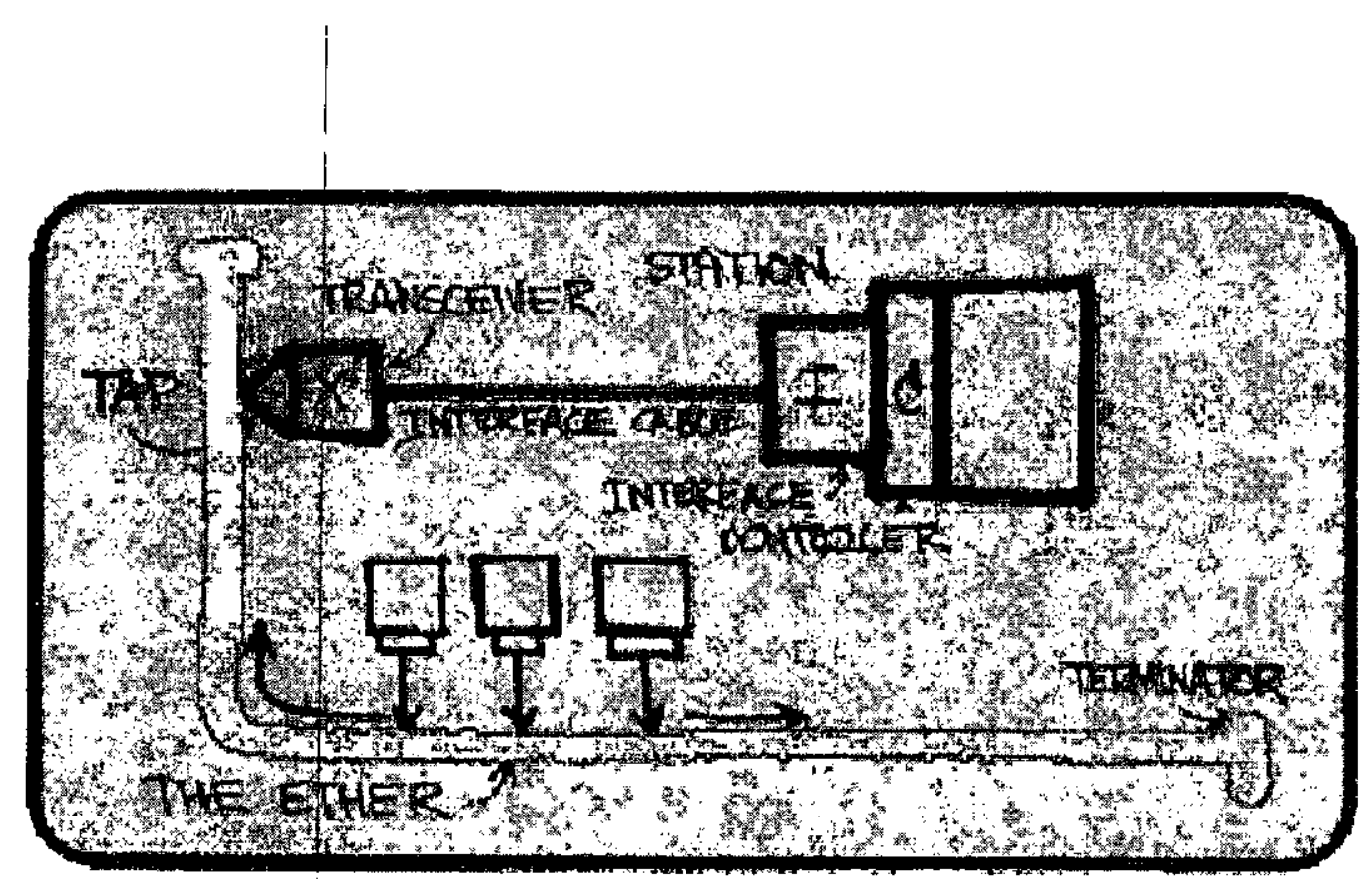

Flgura 2 - Rascunho iniclal da tecnologia Ethernet

Basicamente, Ethernet define a camada física e a camada de conexão dos dados segundo o modelo de referência OSI/RM (Open System Interconnect Reference Model) desenvolvido pela ISO (International Organization of Standardization). A camada física define os tipos de cabos, conectores e características elétricas. A camada de conexão dos dados define o formato para o quadro Ethernet, o método de verificação de erro e o método de endereçamento físico.

É importante entender que Ethernet é apenas um dos protocolos necessários para que uma LAN se torne operacional. Ethernet não pode ajudar uma mensagem encontrar seu caminho através de uma rede complexa, nem define como se realiza tarefas específicas na rede, tais como transferir um arquivo, mandar uma mensagem eletrônica ou ler um bloco de registradores em um PLC. Para estes objetivos são necessários protocolos adicionais sobre a Ethernet.

O grande argumento contra Ethernet é que não existe uma garantia de quando um nó tem acesso à rede. Se a rede estiver ocupada, então um nó com uma mensagem terá que esperar, indiferente de quão importante seja esta mensagem.

Ethernet é chamada de não-determinística e para entender porque isto pode ser um problema, imagine um controlador PID (proporcional-integral-derivada) coletando dados de um transmissor de campo sobre um seguimento Ethernet. Para ajustar o laço PID, um tempo de amostragem muito consistente é requerido e, na teoria, a Ethernet tradicional não pode garantir uma temporização consistente. $\mathrm{Na}$ prática, os atrasos na Ethernet são lineares e podem ser consistentemente mantidos abaixo de 2 milissegundos para uma rede levemente carregada e abaixo de 30 milissegundos para uma rede muito carregada. Estes atrasos são inconseqüentes para a maioria das aplicações de controle de processo.

Numa rede de controle Ethernet, a principal preocupação deve ser em manter o nível de tráfego baixo o bastante para que não haja colisões freqüentemente. 
Várias evidências mostram que este conceito pode funcionar bem no campo. $\mathrm{Na}$ década passada, alguns fabricantes de DCS (Distribuited Control System) usaram a Ethernet para a comunicação entre controladores. Eles apenas davam nomes comerciais a estes sistemas. Mais recentemente, fabricantes de PLC têm disponibilizado Ethernet I/O baseados na estratégia de manter o nível de tráfego baixo o suficiente para que a probabilidade de atrasos significantes devido às colisões seja da mesma ordem dos atrasos devido aos ruídos.

Um problema mais crítico é a necessidade de um padrão de conectores para o campo mais robustos. As mais comuns variaçōes da Ethernet (10Base-T e 100Base-T) usam o conector RJ-45 que não é adequado para o chão de fábrica, mas, ainda não existe uma alternativa satisfatória. Como solução paliativa alguns têm usado o conector DB-9. Outra medida para contornar este problema pode ser a utilização de algum nivel de redundância. Desta forma, a redundância de rede (ou caminho) é visualizada como uma șolução satisfatória.

Uma das maiores forças da Ethernet pode também ser sua maior fraqueza: é muito fácil instalar e conectar-se a ela sem levar em consideração uma estratégia de projeto peculiar. Qualquer rede de controle deve ser segmentada e protegida do tráfego comercial para assegurar a confiança e o determinismo desejado, o que é muito mais complexo do que se imagina. O simples fato de separar a rede de controle e a rede comercial através de uma 'bridge', ou mesmo através de um servidor raramente é suficiente. Então, estratégias de projeto bem analisadas são necessárias para assegurar confiança às redes Ethernet de controle.

Em 1998, a Fieldbus Foundation concordou em usar a 'fast Ethernet' (hoje sendo chamada de HSE) como o protocolo de nível básico para sua rede $\mathrm{H} 2$ (rede de alta velocidade). A fundação está agora mapeando toda tecnologia da segunda camada de seu padrão H1 para Ethernet, incluindo as características chaves como 'scheduling', serviços de produtor/consumidor, e o modelo de objetos. Isto permitirá desenvolver um 'stack' de protocolo que possa rodar em qualquer microprocessador.

Este é um projeto ambicioso e é muito mais complexo do que a proposta dos outros desenvolvedores de equipamentos de campo para rede. A maioria dos outros sistemas simplesmente planeja encapsular seus protocolos dentro de um quadro Ethernet. Esta técnica é conhecida como 'tunneling'.

\subsection{Protocolo High Speed Ethernet Fieldbus}

O High Speed Ethernet é uma parte formal da arquitetura do Fieldbus Foundation [24], e será doravante identificado como HSE Fieldbus Foundation, ou simplesmente HSE. 
O HSE representa a tecnologia central do Fieldbus Foundation que integra a tecnologia $\mathrm{H} 1$ em nível de controle da planta e em nível de informação da empresa em redes internas. O ambiente HSE Fieldbus inclui quatro componentes, a própria estrutura HSE e três classes de sistemas finais (ou 'automation nodes', AN). Os três tipos de AN do HSE Fieldbus incluem 'linking devices' (LD), 'gateway devices' (GD) e 'Ethernet Field Devices' (ED).

O HSE Fieldbus é baseado em padrões de comunicação aceitos internacionalmente (e suas derivaçōes), sendo que os mais essenciais são:

- Protocolo da camada física - IEEE Std 802.3u e suas extensões

- Protocolo da camada de conexão dos dados - IEEE Std 802.2

- Protocolo da camada de rede - Internet Protocol Version 4 (IPv4, RFC 791)

- Protocolos da camada de transporte - Transmission Control Protocol (TCP, RFC 793) e User Datagram Protocol (UDP, RFC 768)

O HSE Fieldbus pretende ser implementado como uma subrede IP dentro de uma intranet particular do chão de fábrica. Como exemplo, a Figura 3 mostra quatro subredes H1 Fieldbus (Domain A, B, C, D) acopladas ao HSE através de dois LDs (LD1 e LD-2). Dentro de uma planta industrial típica, pode existir vários destes LD acopladores de domínio $\mathrm{H} 1$.

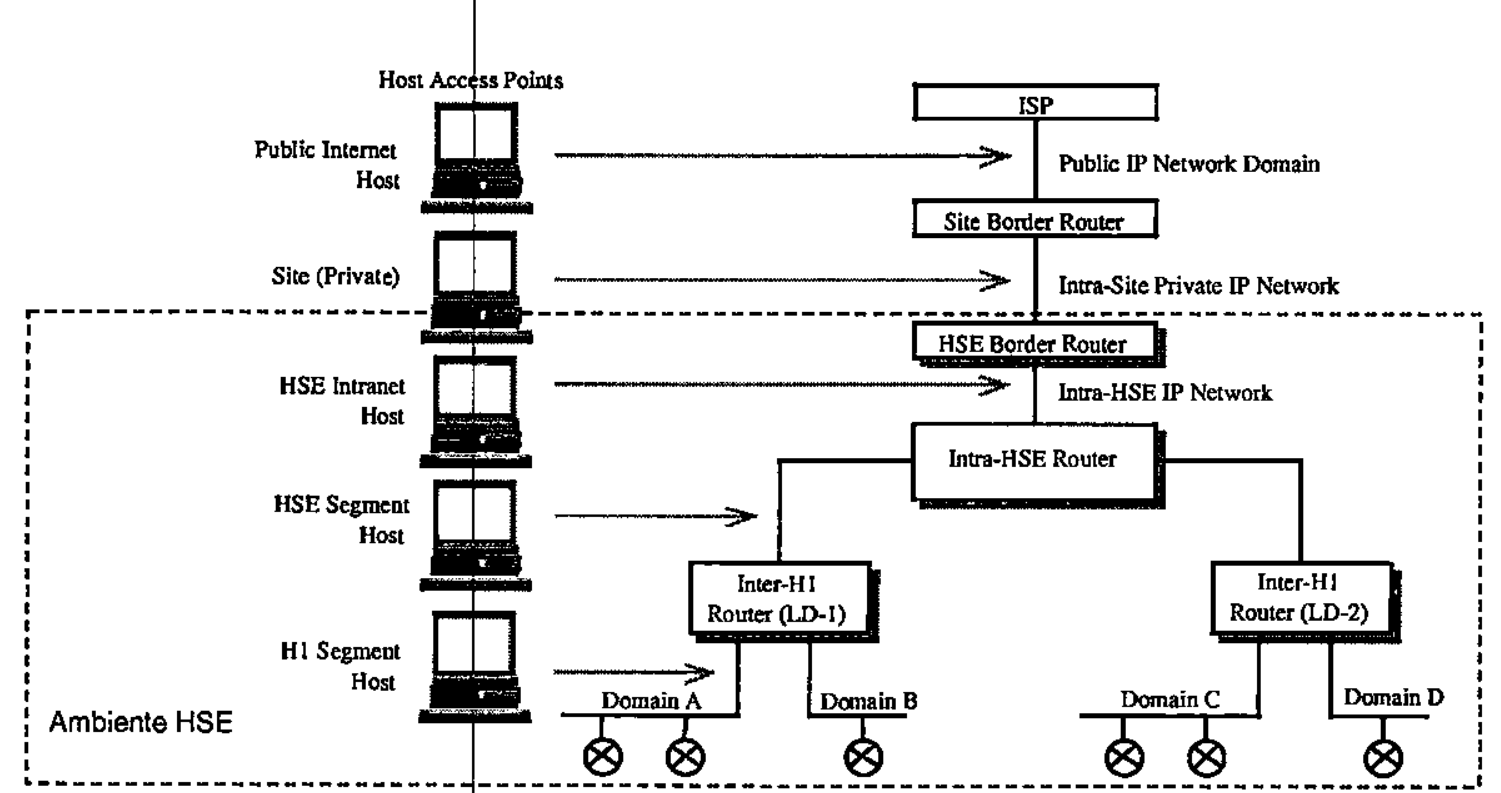

Figura 3 - Hierarqula do HSE Fieldbus Foundation

Os segmentos $\mathrm{H} 1$ são agregados às sub-redes HSE opcionalmente por roteadores IP intra-HSE. Estes roteadores HSE definem domínios 'broadcast' e provê para as sub-redes HSE isolação de endereço e partição do domínio de controle quando desejado. Sub-redes HSE por sua vez agregam-se às 'intranets' HSE as quais são isoladas da intranet geral da planta (sub-rede IP particular da empresa) por um 'border router' HSE. Tudo isto junto, define o ambiente HSE Fieldbus, que envolve os três niveis mais baixos de uma infraestrutura de automação industrial. 
A Figura 3 mostra o ponto de acesso "host' disponível dentro do ambiente HSE. Sistemas finais 'host' podem ser anexados em nível de sub-rede $\mathrm{H} 1$, em nível de segmento HSE, ao nivel de intranet HSE, em nível de 'site' intranet, e a nível empresarial ou Internet.

O HSE Fieldbus oferece interconexão e interoperação de três classes de equipamentos 'end-system' Fieldbus Foundation, ou 'automation nodes' (AN). Cada classe suporta um conjunto específico de serviços para comunicação e gerenciamento dentro de um ambiente HSE:

- Linking Device (LD) - um nó HSE para conexão de um ou mais segmentos H1 ao HSE.

- Gateway Device (GD) - um nó HSE para conexão de um ou mais redes diferentes (não HSE) à HSE.

- Ethernet Field Device (ED) - um nó HSE oferecendo aplicações (controle e medição) conectadas diretamente.

Um 'host device' (HD) HSE suporta aplicações clientes que usam protocolos padrões IT para acessar AN HSE. Desta forma, um HD participa na intranet HSE como um 'end-system' Ethernet com acesso aos ANs.

O ambiente HSE deve suportar os serviços de comunicação Fieldbus Foundation. $\mathrm{O}$ segmento $\mathrm{H} 1$ transfere informações entre equipamentos usando canais de comunicação pré-configurados chamados 'Virtual Communication Relationships' (VCRs). Para os VCRs estão definidos três mecanismos para a realização destas relações de comunicaçăo

- Cliente/Servidor - um Servidor responde a uma requisição do Cliente.

- Distribuição de Relatório (ou Source-Sink) - uma fonte envia uma mensagem para um ou mais receptores (sink).

- Produtor/Consumidor - um produtor envia uma mensagem para um ou mais receptores (subscriber).

E estes mesmos três mecanismos são implementados usando mensagens 'Field Device Access' (FDA) sobre uma rede Ethernet. Dentro do ambiente HSE, os nós suportam serviços de gerenciamento Fieldbus Foundation.

\subsection{Considerações Finais}

Apesar de todas as vantagens do uso de uma rede aberta para o controle industrial, vale aqui res\$altar que tal solução cria o problema de segurança. 
- Como impedir aces\$o indevido ao controle de uma planta?

- Como ocultar informações vitais para a companhia?

São perguntas como estas que devem estar em mente ao se projetar um sistema de controle baseado numa rede aberta. Este discussão não será levantada neste trabalho e só está sendo colocada aqui como alerta.

A grande motivação para este trabalho é exatamente o uso cada vez mais freqüente da Ethernet na automação industrial, sendo que este ambiente além flexibilidade exige confiabilidade. Com este trabalho estará se estudando uma forma de fornecer todos os serviços que rodam numa rede Ethernet de forma mais confiável, através da aplicação de conceitos de tolerância à falhas e computação reconfigurável. 
Neste trabalho serão empregados alguns conceitos de computação reconfigurável. Basicamente, computação reconfigurável combina a velocidade do hardware com a flexibilidade do software [63]. Antes, torna-se necessário entender as diferenças básicas entre a computação tradicional e a computação reconfigurável. Também será importante conhecer as principais tecnologias envolvidas, técnicas e ferramentas à disposição. Todos estes tópicos serão abordados neste capítulo para fornecer um suporte teórico para o entendimento da solução de hardware escolhida.

\subsection{Computação Tradicional}

Ao implementar um sistema computacional, tradicionalmente decide-se entre implementações em hardware customizado (fixo) ou software. Em alguns sistemas, toma-se esta decisão para cada sub-tarefa, alocando algumas em hardware e outras em software em processadores de finalidade geral [38]. Os projetos em hardware oferecem alto desempenho pois:

- São customizados para o problema em particular - não há um overhead extra para interpretação de instruções ou circuitos extras para solucionar um problema mais genérico.

- São relativamente rápidos devido à execução espacial com um alto grau de paralelismo.

Já as implementações em software exploram um processador de finalidade geral que interpreta um determinado fluxo de dados como instruções que indicam quais operações deve realizar. Como resultado o software é:

- Flexível - uma tarefa pode ser mudada simplesmente trocando-se o fluxo de instruções numa memória regravável.

- Relativamente lento devido principalmente à execução temporal.

- Relativamente ineficiente, uma vez que os operadores podem ser inadequados à tarefa a ser realizada.

Cada nova geração desses microprocessadores possibilita um aumento de desempenho na execução das aplicações. Entretanto, na maioria dos casos, a aplicação precisa ser recompilada para melhor usufruir as novas características desses processadores. 
Em implementações espaciais, cada operador existe em um diferente ponto no espaço (área do chip), permitindo que a computação explore o paralelismo e alcance uma alta taxa de transferência de dados e baixa latência. Em implementações temporais, um pequeno número de recursos computacionais é reutilizado ao longo do tempo, permitindo que a computação seja implementada de forma compacta.

\subsection{Computação Reconfigurável}

Um recente avanço nos esforços de obter maior poder de processamento é o uso de dispositivos lógicos programáveis (PLDs). Estes dispositivos contêm hardware configurável que pode ser reprogramado para a aplicação sendo executada, tornando possivel obter um desempenho comparável aos ASICs sem o custo e risco inerentes a esta tecnologia. Os mais comuns dispositivos de hardware reconfigurável são os FPGAs. Os FPGAs contêm arranjos de blocos lógicos configuráveis (CLBs) interligados por recursos de roteamento [39],[40].

O principal benefício dos dispositivos lógicos programáveis é que eles introduzem uma classe de dispositivos configuráveis pós-fabricação que suportam a realização de computação espacial. Os dispositivos reconfiguráveis têm o benefício óbvio do paralelismo espacial, permitindo a realizaçăo de mais operações por ciclo. Além disso, destaca-se sua ótima flexibilidade em função da alta capacidade lógica; a facilidade de programação pelo usuário final, que reduz o tempo de fabricação para minutos; o ciclo curto de projeto possibilita que o produto seja rapidamente colocado no mercado; o baixo custo do dispositivo e dos custos fixos do projeto.

categorias [41]:

O uso de hardware reconfigurável pode ser classificado em três

- Lógica (em substituição a outros dispositivos para uso em glue logic);

- Coprocessadores (chips específicos para determinadas tarefas); e

- Computadores (plataformas de computação completamente reconfiguráveis CCMs).

\subsubsection{Arquiteturas}

Normalmente um sistema de Computação Reconfigurável é implementado com múltiplos PLDs (geralmente FPGAs baseados em SRAM), os quais atuam como Unidades de Processamento Reconfiguráveis (RPUs), acoplados a um computador hospedeiro (host) [42]. A junção de hardware dedicado com um 
computador host para acelerar algumas tarefas computacionalmente intensivas não é um conceito novo. Um exemplo comum na indústria de PCs é o uso de placas aceleradoras gráficas. Porém, tais circuitos aceleradores para aplicações específicas requerem grande esforço de projeto e tipicamente usam mais área de silício que o próprio microprocessador.

O uso de hardware reconfigurável torna possível juntar o computador host com recursos de hardware mais flexiveis, melhores adaptados à aplicação sendo executada, e com a possibilidade de adaptar-se às versões novas de uma aplicação.

O tipo de interconexão entre a RPU e o sistema hospedeiro e o nível de granulosidade da RPU constituem dois importantes aspectos a serem considerados na implementação de sistemas reconfiguráveis. Muitos pontos relativos a esses tópicos já foram explorados e muítos ainda remanescem para pesquisa adicional. Porém, ainda não é possivel identificar uma solução dominante para todos os tipos de aplicações.

\subsubsection{Acoplamento de RPUs com o Host}

O tipo de acoplamento das RPUs com o sistema de computação existente tem um impacto grande nos custos de comunicação. $O$ acoplamento pode ser classificado em um dos quatro grupos listados abaixo e ilustrados na Figura 4, que são apresentados em orden de custos de comunicação decrescentes [42]:

- RPUs acopladas ao barramento de $1 / O$ do host. Este grupo inclui muitas placas de circuito comerciais. Alguns deles são conectados ao barramento PCl de um PC.

- RPUs acopladas ao barramento local do host.

- RPUs acopladas como coprocessadores.

- RPUs atuando como um datapath estendido do processador.

\subsubsection{Reconfiguração Dinâmica}

PLDs reconfiguráveis dinamicamente permitem que uma parte selecionada da lógica programável e dos recursos de roteamento sejam atualizados enquanto o restante do\$ recursos continuam a funcionar [43],[44].

Como os tempos de configuração não são despreziveis, a habilidade de intercalar execução e reconfiguração sem prejuízo do desempenho é uma questão que ainda merece atenção e esforços de pesquisa. Com a introdução de PLDs com tempos de reconfiguração mais rápidos e suporte a reconfiguração parcial , é possivel usar PLDs em um ambiente de reconfiguração dinamica. (RTR, Run-Time Reconfiguration). 


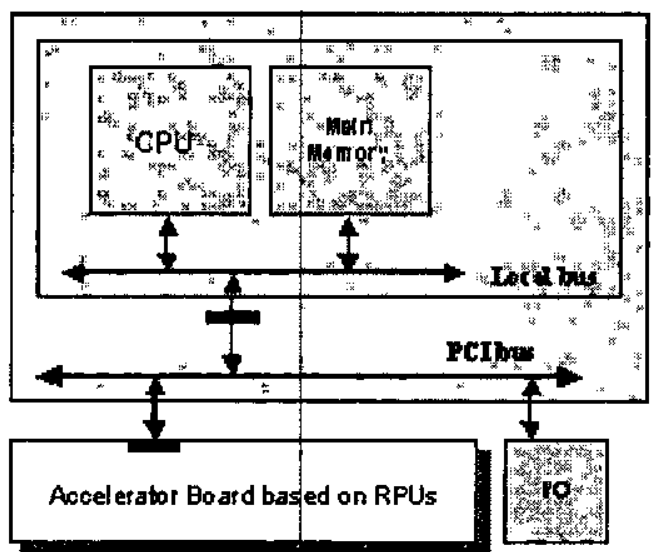

a) RPU acoplada ao barramento de $1 / 0$.

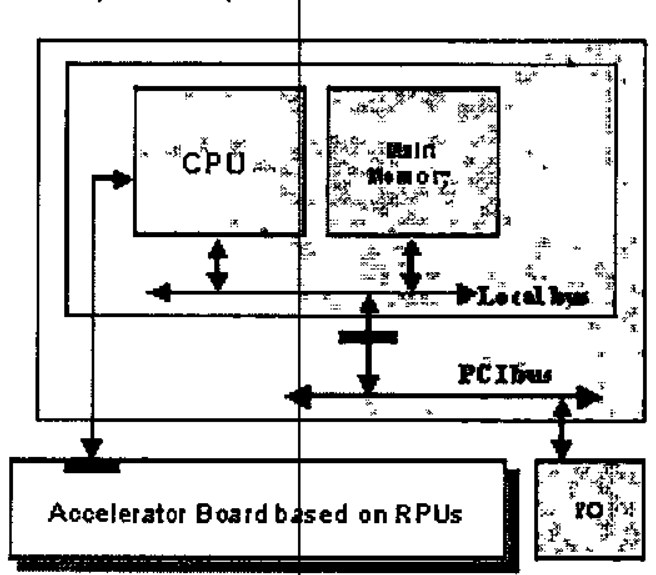

c) RPU acoplada a CPU.

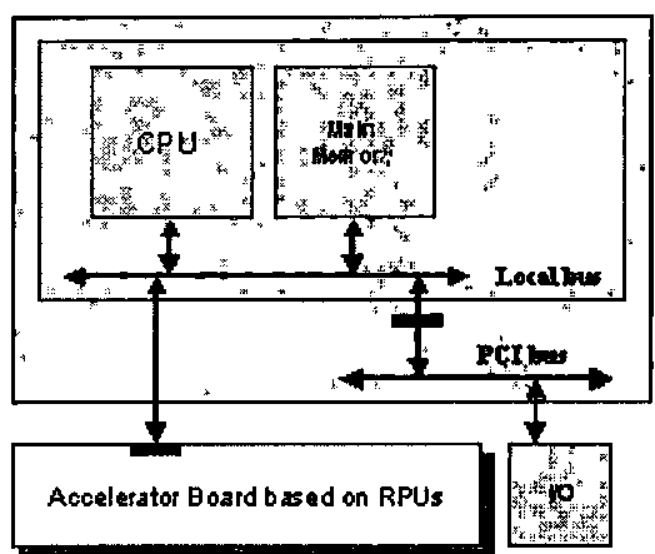

b) RPU acoplada ao bairamento local.

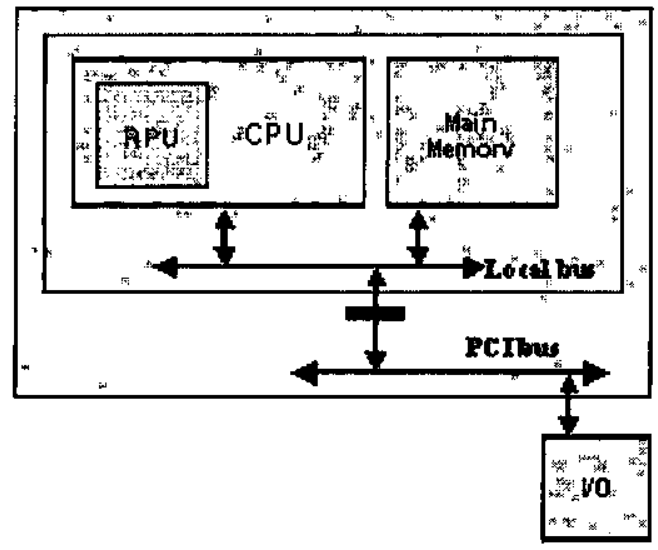

d) RPU integrada no chip de processamento.

Figura 4 - Tipos de acoplamento de RPUs com o Sistema Host

Um sistema de reconfiguração dinâmica inclui pelo menos uma área de reconfiguração onde blocos lógicos podem ser carregados em tempo de execução. A Figura 5 ilustra a reconfiguração dinâmica de um sistema composto de cinco circuitos ou tarefas. A tarefa A é uma função de entrada que alimenta as tarefas $B, C$ ou $D$, que alimentam a tarefa $E$ que é a função de saída do sistema. As tarefas de entrada e saída são permanentemente residentes no PLD enquanto as três tarefas dinâmicas alternam-se sob o controle de um sinal de Swap.

A capacidade de reconfiguração dinâmica permite o compartilhamento ao longo de tempo de tarefas diferentes, o que pode reduzir significativamente a área de silício exigida. Esta tecnologia torna possível o conceito de hardware ilimitado ou "Hardware Virtual" [42],[45],[46]. Este conceito é similar ao de memória virtual e está sendo adotado para permitir que múltiplos conjuntos de configuração sejam armazenados para serem usados pelas RPUs quando necessário. $O$ hardware virtual é implementado por compartilhamento de tempo (time-sharing) de uma dada RPU, necessitando de um escalonador que é responsável pelas configurações, a execução e as comunicações entre as partições temporais. 

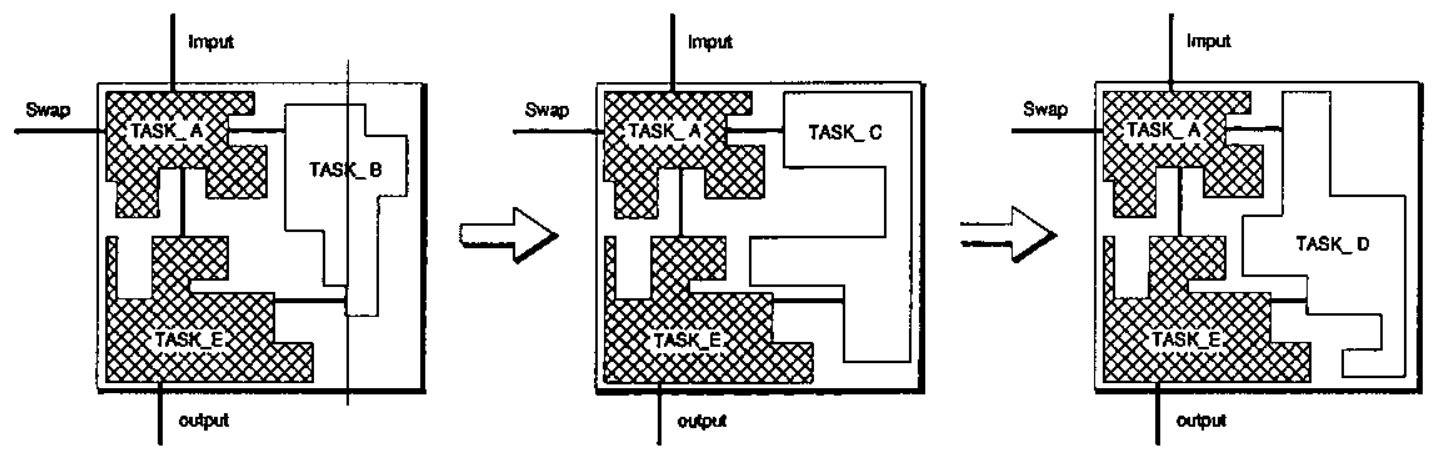

Flgura 5 - Exemplo de reconflguração dinâmica em PLDs.

problemas [47]:

O projeto de um sistema que explore essa possibilidade possui vários

- particionamento da descrição em alto nível de um sistema em blocos (tarefas) que possam ser trocadas (carregadas e descarregadas) na área reconfigurável.

- a busca de um escalonamento otimizado para esses blocos.

- a determinação de um conjunto de serviços que auxiliam a executar apropriadamente a funcionalidade requerida.

A questão crucial nesta abordagem é a implementação de um controlador capaz de manipular a reconfiguração de todas essas tarefas. Este controlador deve oferecer (assim como Sistemas Operacionais) serviços como o carregamento e remoção de tarefas, escalonamento de tarefas e gerenciamento dos recursos.

A reconfiguração dinâmica tem sido proposta no projeto de alguns sistemas experimentais. Um sistema operacional que auxilia a reconfiguração dinâmica de unidades funcionais é proposto por Brebner [48]. A Universidade de Brigham Young tem usado computação reconfigurável para construir um computador com um conjunto de instruções dinâmico (DISC) [49], que efetivamente acopla um microprocessador com um PLD e demonstra o potencial da reconfiguração automática usando configurações armazenadas. À medida que um programa é executado, o PLD requisita a reconfiguração se o circuito designado não está residente. A arquitetura DISC permite que o projetista crie e armazene um grande número de configurações e as ative assim como um programador costuma chamar uma sub-rotina de software em um microprocessador. 


\subsubsection{Fluxo de Projeto de Sistemas Reconfiguráveis}

O processo de desenvolvimento de aplicações RTR pode ser uma tarefa longa e árdua. As ferramentas de software para o desenvolvimento de aplicações para CCMs ainda estão numa fase prematura. Elas oferecem uma limitada capacidade de simular a interação host/hardware e são incapazes de explorar as possibilidades de reconfiguração destas plataformas [50]. Um fluxo de projeto típico é apresentado na Figura 6.

Um dos objetivos principais da comunidade de pesquisa em RTR é desenvolver um compilador para máquinas $\mathrm{CCM}$ que aceite um modelo comportamental de alto nivel e otimize a aplicação, provendo o particionamento e escalonamento que maximize a velocidade da aplicaçăo [51],[52]. O compilador deve criar de forma transparente a implementação final completa com o código em software para o host e os arquivos de configuração dos PLDs. Alguns trabalhos têm sido realizados para converter algoritmos escritos em linguagens de alto nível, como $\mathrm{C} \mathrm{e}$ Java, em hardware, mas esta ainda é uma tarefa muito difícil [42],[53],[54]. Este seria o ambiente ideal de projeto e constitui um ponto crucial para a expansão do uso de sistemas RTR entre os desenvolvedores de software. Na Universidade da Califórnia em Berkeley estão sendo desenvolvidos sistemas que combinam microprocessadores e PLDs [55]. A partir do código do programa, um compilador especial de software gera automaticamente uma combinação de instruções de máquina e configurações de PLDs para alcançar o melhor desempenho. Nesta linha de pesquisa o LCR-ICMC está desenvolvendo o projeto ARCHITECT [56].

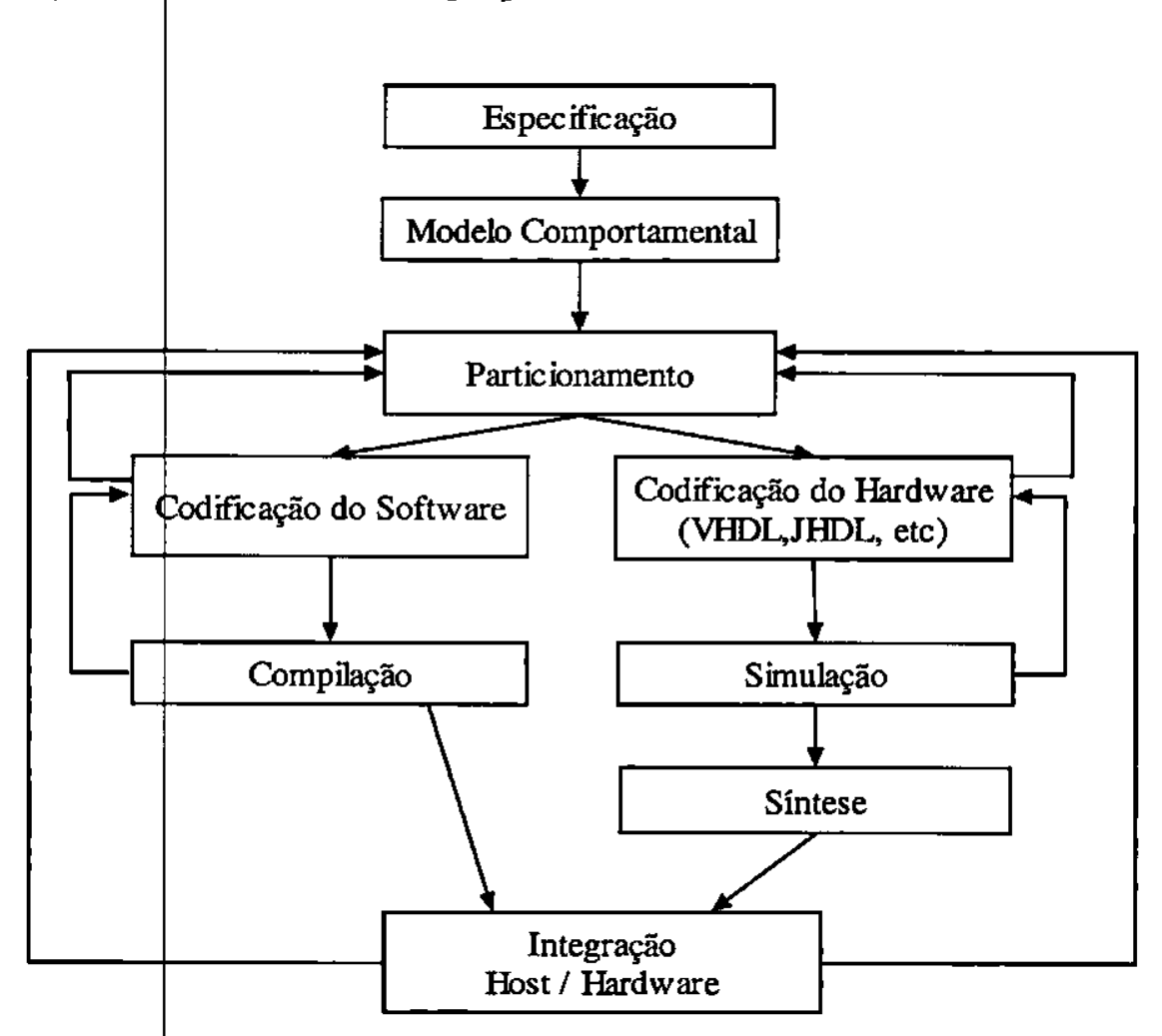

Figura 6 - Fluxo de Projeto de Slstemas RTR 


\subsubsection{Aplicações}

Vários grupos de pesquisa têm construído sistemas de computação reconfigurável visando obter alto desempenho a baixos custos especializando a máquina para a tarefa computacional desejada [57],[58],[59]. Alguns exemplos são:

- A arquitetura PRISM que acopla um elemento programável com um microprocessador. Para cada aplicação, novas "instruções" são sintetizadas no elemento reconfigurável que são projetadas para acelerar a aplicação.

- Supercomputing Research Center construiu uma série de arranjos sistólicos programáveis conhecidos como SPLASH. Cada arranjo do SPLASH é acoplado a uma workstation e é composto de um conjunto de FPGAs da Xilinx . A arquitetura SPLASH tem sido muito utilizada para aplicações de comparação de sequências de genoma.

- PAM (Programmable Active Memories) é um arranjo de FPGAs da Xilinx acopladas a uma workstation. Com esta arquitetura foram obtidas significantes melhorias de desempenho em muitas aplicações, realizando especializações apropriadas no acelerador PAM.

Numerosos outros sistemas têm sido e continuarão sendo construídos devido à favorável relação custo/desempenho [60]. Máquinas reconfiguráveis tais quais as citadas têm sido efetivamente empregadas em uma ampla gama de aplicações, incluindo:

- Operações binárias - lógica reconfigurável pode realizar operações binárias muito eficientemente e com substancial paralelismo. Quando as aplicações requerem a avaliação de grandes e regulares operaçōes binárias, máquinas reconfiguráveis podem oferecer vantagens significativas sobre a lógica fixa disponíveis nos microprocessadores típicos.

- Aritmética - quando as operações aritméticas requeridas pela aplicação não correspondem exatamente às fornecidas pela ALU/FPU dos processadores convencionais ou quando as operações admitem um alto grau de paralelismo bitlevel, há um amplo espaço para especialização da lógica reconfigurável para obter alto desempenho.

- Encriptação/Decriptação e Compressão - estas aplicações requerem a realização de seqüências simples de operações lógicas e aritméticas em um grande conjunto de dados. Entretanto tais operações não são nativas dos processadores. Máquinas especializadas podem fornecer os operadores apropriados e fazer uso do paralelismo e regularidade da aplicação para alcançar um alto desempenho.

- Comparação de seqüências e strings - pelo reconhecimento da estrutura natural da aplicaçăo e especializando uma máquina reconfigurável para tirar vantagem da estrutura, pesquisadores têm obtido alto desempenho a baixos custos. 
- Ordenação - as tarefas de ordenação apresentam naturalmente um paralelismo de granulosidade fina. Explorando este paralelismo, grandes tarefas de ordenação podem ser realizadas eficientemente com redes de ordenação construídas com lógica reconfigurável.

- Simulação de Sistemas Físicos - a simulação de fenômenos físicos geralmente requer a avaliação repetidamente de variáveis de estado usando computações regulares de precisão limitada. Máquinas especializadas para avaliar sistemas particulares de equações podem alcançar significante vantagem sobre processadores de finalidade geral.

- Processamento de Imagens - a granulosidade fina e o paralelismo bit-level presente em muitas aplicações de processamento de imagens tornam extremamente cômoda a aceleração usando arranjos de granulosidade fina [61].

Um aspecto comum nessas aplicações é que a utilização de um sistema de computação reconfigurável prover um desempenho bem superior ao dos processadores de finalidade geral. O custo da lógica reconfigurável é tipicamente menor que o de aumentar a capacidade do microprocessador. É comum observar níveis de desempenho de "supercomputadores" em sistemas que custaram muito menos para serem montados. Para várias aplicações a máquina reconfigurável especializada apresenta o melhor desempenho já relatado por qualquer outra máquina. As aplicações apresentadas foram construídas numa variedade de arquiteturas e configurações de diversos tamanhos. Não pode-se concluir que uma única arquitetura reconfigurável irá necessariamente exibir ganhos de desempenho. Apesar de tudo, a amostra demonstra um claro potencial para aceleração do desempenho através da especialização da lógica reconfigurável em uma grande variedade de aplicações. Estes trabalhos demonstram que esta área tende a se desenvolver muito, a médio e longo prazo.

\subsection{Dispositivos Lógicos Programáveis}

Dispositivos lógicos programáveis (PLDs) são circuitos integrados configuráveis, usados para implementar funções lógicas definidas pelo usuário. Já por volta de 1980 , os PLDs foram usados para integrar vários dispositivos de lógica discreta, sendo o projeto representado em termos de equaçzes Booleanas. Hoje, PLDs de alta densidade são usados para integração em nível de sistema, e tem se tornado uma alternativa cada vez mais freqüente aos circuitos integrados para aplicação específica (ASIC) ou aos produtos padronizados para aplicação específica (ASSP) [68].

O termo "lógico programável" é aplicado a todos circuitos digitais lógicos que podem ser configurados pelo usuário final, incluindo os simples dispositivos 
PAL/GAL, os field-programmable gate arrays (FPGAs) e os complexos PLDs (CPLDs). Estes dispositivos são oferecidos em diferentes arquiteturas, com uma grande variedade na quantidade de elementos de memória para configuração, além de se diferenciarem também no número de pinos para entrada e/ou saída. Os PLDs permitem um alto grau de flexibilidade, que combinado com velocidade e riscos reduzidos tornam a lógica programável a solução para as aplicações eletrônicas de hoje em dia.

CPLDs e FPGAs possuem diferentes estruturas de interconexão. A estrutura de interconexão segmentada dos FPGAs usam múltiplas linhas de vários comprimentos, conectadas por transistores de passagem ou 'anti-fuses', para conectar as células lógicas. Por outro lado, a estrutura de interconexão contínua dos CPLDs usa linhas de metal contínuas para fornecer a conectividade lógica entre as células.

\subsubsection{A Tecnologia FPGA}

Um FPGA (Field Programmable Gate Array) [14] consiste de uma única pastilha com um grande arranjo de células configuráveis (ou blocos lógicos) e recursos de interconexão. Cada célula contém uma capacidade computacional para implementar funções lógicas e/ou realizar roteamento para permitir a comunicação entre as células. Os recursos de interconexão podem ser programados eletricamente pelo usuário assim como outros PLDs (Programmable Logic Devices). As diversas opções apresentam diferentes arquiteturas, diferentes estruturas de roteamento e blocos lógicos de granularidade variada, onde a aplicação determinará a escolha mais apropriada [4], [5], [6].

A arquitetura básica de um FPGA consiste de um arranjo bidimensional de blocos lógicos, sendo que a comunicação entre os blocos é feita através de recursos de interconexão. A borda externa do arranjo consiste de blocos especiais capazes de realizar operações de entrada e saída (I/O). Esta arquitetura pode ser vista na Figura 7.

A arquitetura de um FPGA é definida a partir de três aspectos: o tipo de tecnologia de programação utilizada, a arquitetura dos blocos lógicos e a estrutura de sua arquitetura de roteamento. Estes aspectos influenciam diretamente o desempenho e a densidade das diferentes arquiteturas de FPGAs, entretanto não se pode afirmar que há uma melhor arquitetura e sim a mais adequada para uma determinada aplicação.

A capacidade computacional e a configuração de roteamento para cada bloco lógico podem ser programadas via comutadores programáveis eletricamente. As propriedades destes comutadores tais como tamanho, resistência, capacitância, afetam principalmente 0 desempenho e definem características como volatilidade e capacidade de reprogramação que devem ser avaliadas na fase inicial do projeto para a escolha do dispositivo. Basicamente existem três tipos de tecnologias usadas na implementação destes comutadores programáveis: 


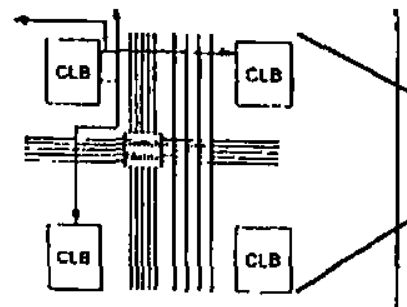

Interconexâo

Programável

해후해해후해후해해해후

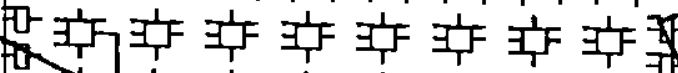

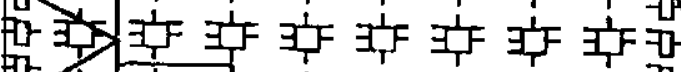

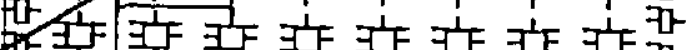

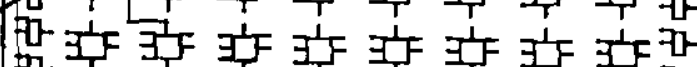

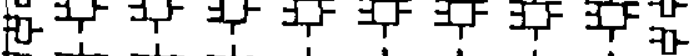

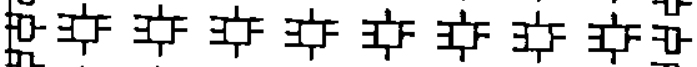

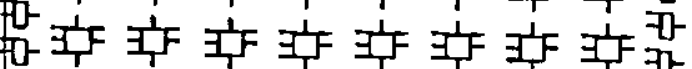

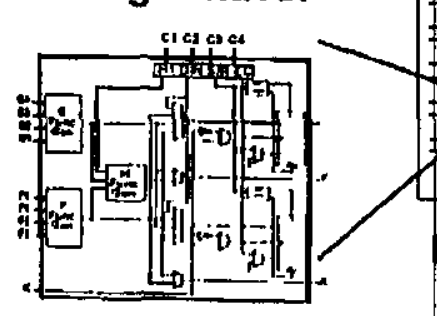
据年 1

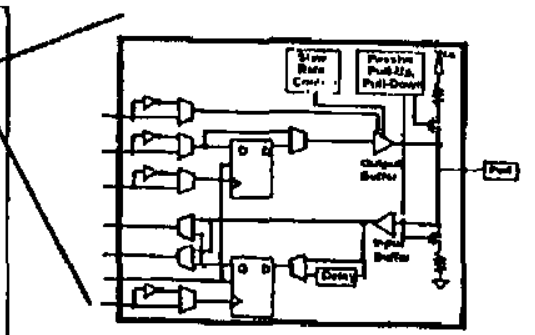

Blocos de $1 / O$

Figura 7 - Arquitetura básica de um FPGA

- SRAM (Static Random Access Memory), onde o comutador é um transistor de passagem controlado pelo estado de um bit da SRAM.

- Antifuse é originalmente um circuito aberto que quando programado forma um caminho de baixa resistência.

- Gate Flutuante, onde o comutador é um transistor com 'gate flutuante' igual aos usados nas memórias EPROM (Erasable PROM) e EEPROM (Electrical Erasable PROM).

As vantagens e desvantagens de cada tecnologia pode ser comparada através da Tabela 1.

\begin{tabular}{|c|c|c|}
\hline TECNOLÖGIA & VANTAGENS & DESVANTAGGENS \\
\hline SRAM & $\begin{array}{l}\text { Rapidamente reprogramável e } \\
\text { requer apenas tecnologia padrão } \\
\text { de circuitos integrados para sua } \\
\text { fabricacãa }\end{array}$ & $\begin{array}{l}\text { Necessita de uma memória } \\
\text { externa não volátil para } \\
\text { configuração quando o circuito é } \\
\text { ligado, e ocupa muito espaço }\end{array}$ \\
\hline Antifuse & 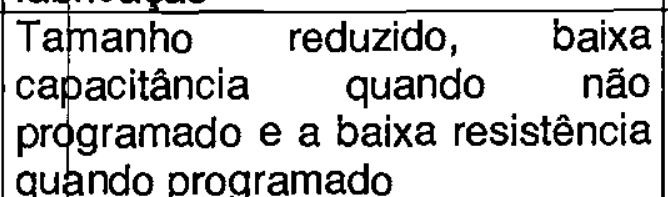 & Não permite a reprogramação \\
\hline Gate Flutuante & $\begin{array}{l}\text { Capacidade de reprogramação e } \\
\text { retenção dos dados, mesmo com } \\
\text { a pastilha já instalada na placa }\end{array}$ & $\begin{array}{l}\text { Complicações no processo de } \\
\text { fabricação e alem disso, a } \\
\text { resistência dos comutadores } \\
\text { ligados não atinge valores baixos }\end{array}$ \\
\hline
\end{tabular}

Tabeia - Vantagens e desvantagens das tecnologlas dos comutadores 
A fim de dlassificar os FPGAs quanto ao bloco lógico, foram criadas duas categorias: a granularidade fina e a granularidade grossa, sendo a primeira a designante para blocos simples e pequenos e a segunda para os blocos mais complexos e maiores.

O melhor exemplo para um bloco de granularidade fina seria um bloco contendo alguns transistores interconectáveis ou portas lógicas básicas (por exemplo, NAND). A principal vantagem no uso de blocos de granularidade fina é que estes são quase sempre totalmente utilizados. A desvantagem reside no fato de serem em um número muito grande devido à baixa capacidade lógica, requerendo, portanto, uma grande quantidade de trilhas de conexão e comutadores programáveis. Um roteamento deste tipo de FPGA se torna lento e ocupa grande área na pastilha.

Já os blocos de granularidade grossa geralmente são baseados em multiplexadores ou 'look-up tables' (LUTs). Os blocos lógicos baseados em multiplexadores têm a vantagem de fornecer um alto grau de funcionalidade com um número relativamente pequeno de transistores. No entanto, eles possuem muitas entradas necessitando de muitos comutadores, o que sobrecarrega o roteamento. Logo, a tecnologia 'antifuse' é mais adequada para fabricação deste tipo de FPGA, devido ao tamanho reduzido dos comutadores. A vantagem das LUTs é que apresentam um alto grau de funcionalidade e a desvantagem é que são inaceitavelmente grandes para mais que cinco entradas. Apesar do número de funçōes que podem ser implementas aumentar muito rapidamente com o aumento do número de entradas, essas funções adicionais geralmente não são utilizadas em projetos lógicos e são difíceis de serem manipuladas por uma ferramenta de síntese lógica.

A maioria dos blocos lógicos apresenta alguma forma de lógica seqüencial. Geralmente utilizam flip-flop tipo $D$ que podem ser conectados (via programação) às saídas dos blocos combinacionais. Em alguns dispositivos, a lógica seqüencial não está explicitamente presente, e deve ser formada utilizando-se o roteamento programável e os blocos puramente combinacionais.

A arquitetura de roteamento de um FPGA é a maneira pela qual os comutadores programáveis e segmentos de trilha são posicionados para permitir a interconexão das células lógicas. As arquiteturas de roteamento podem ser descritas a partir do modelo geral apresentado na Figura 8.

O modelo contém duas estruturas básicas. A primeira é o bloco de conexão que aparece em todas as arquiteturas. $O$ bloco de conexão permite a conectividade das entradas e saídas de um bloco lógico com os segmentos de trilha nos canais. A segunda estrutura é o bloco de comutação que permite a conexão entre os segmentos de trilhas horizontais e verticais. Em algumas arquiteturas, o bloco de comutação e o bloco de conexão são distintos, em outras estão combinados numa mesma estrutura. Nem todas as arquiteturas seguem esse modelo: há arquiteturas que apresentam uma estrutura hierárquica e outras que possuem somente canais horizontais. 
Uma importante questão a ser considerada é se a arquitetura de roteamento permite que se alcance um roteamento completo e, ao mesmo tempo, uma alta densidade lógica. Sabe-se que usando um grande número de comutares programáveis torna-se fácil alcançar um roteamento completo, mas esses comutadores consomem área, que é desejável minimizar. Algumas pesquisas estabeleceram uma relação entre a flexibilidade da arquitetura de roteamento, a capacidade de roteamento e uso eficiente da área [5].

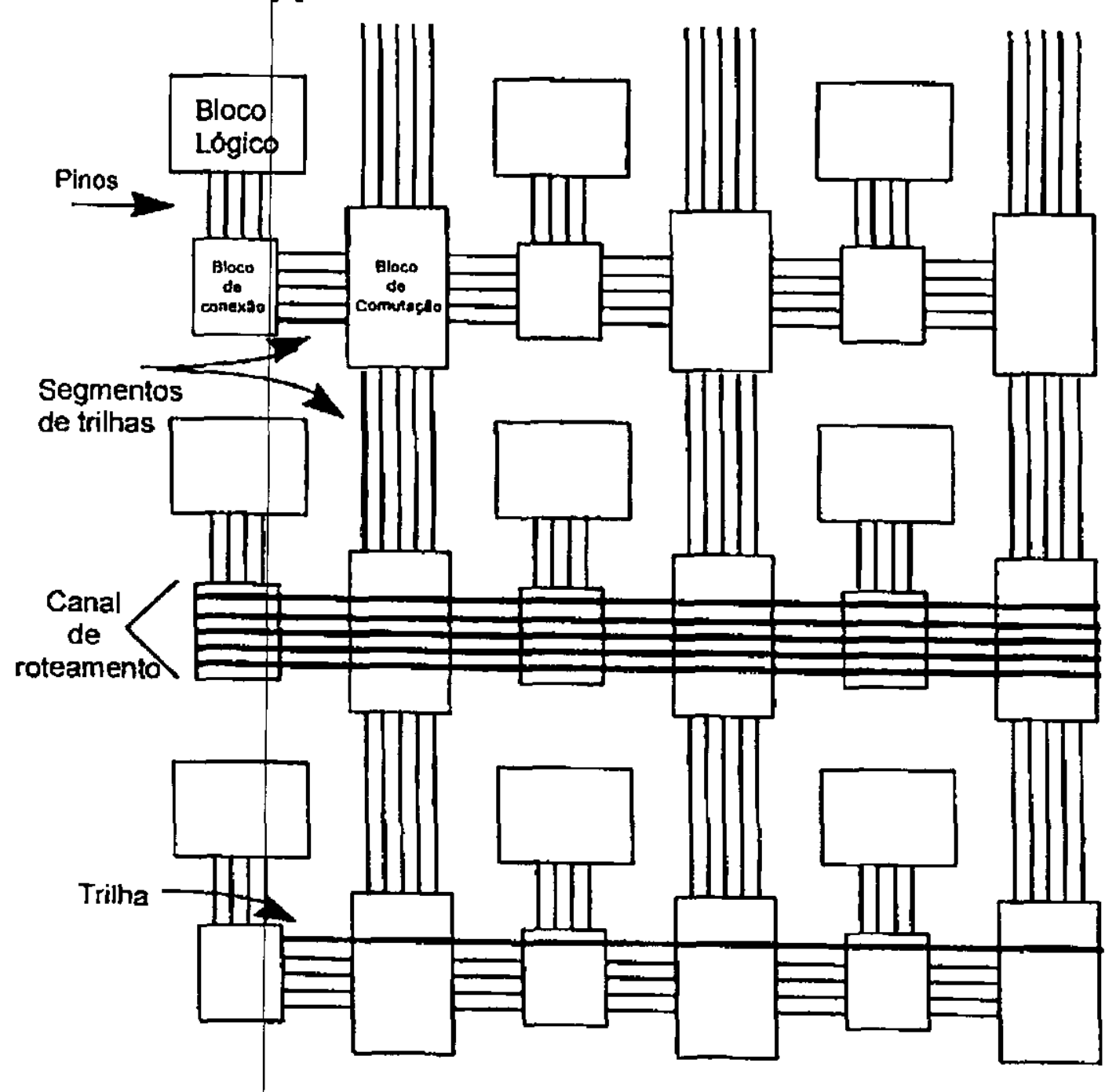

Figura \& - Modelo báslco de uma arquitetura de roteamento de um FPGA

\subsubsection{Desenvolvimento e Implementação de Projetos Usando FPGAs}

O processo de projeto com FPGAs inicia-se com a descrição do projeto com um editor de esquemático ou uma HDL. A tendência atual é intensificar a utilização de linguagens de descrição de alto nível, principalmente a VHDL (VHSIC Hardware Description Language) [7], [8], [9]. Em seguida são aplicadas ferramentas de síntese lógica para otimização do projeto. As próximas etapas se encarregam do 
mapeamento, posicionamento, roteamento do projeto e implementação através de uma unidade de programação. Podemos resumir o processo nos seguintes passos [4]:

- Especificação e entrada do projeto

- Síntese lógica e mapeamento na tecnologia

- Posicionamento e roteamento

- Verificação e Testes

- Configuração/programação do FPGA

O projetista é responsável pela entrada inicial do projeto e pelas verificações durante o processo. As fases mais críticas como otimização lógica, mapeamento, posicionamento e roteamento são realizados por softwares específicos, possibilitando que o projetista se concentre nas especificações do projeto e trabalhe em alto nivel. Um sistema típico EDA (Electronic Device Automation) para FPGAs consiste de vários programas interconectados como ilustra a Figura 9.

A entrada do projeto pode ser feita criando-se um diagrama esquemático com uma ferramenta gráfica, ou usando um sistema textual para descrever um projeto em uma linguagem de descrição de hardware, ou com uma mistura desses dois métodos de entrada de projeto.

Como a lógica inicial não está geralmente numa forma otimizada, algoritmos são empregados para otimizar os circuitos, manipulando-os para minimizar área, atraso, ou a combinação de área e atraso. Esse passo geralmente realiza 0 equivalente a uma mihimização algébrica de equações booleanas e é apropriado quando se implementa um circuito em qualquer tecnologia [15].

Para transformar as equações booleanas em circuito de células lógicas de FPGA, a rede otimizada alimenta um programa de mapeamento na tecnologia. Esse passo mapeia as equações em células lógicas, que também é uma oportunidade para otimizar, ou minimizar o número total de células requeridas (otimização de área) ou 0 número de células lógicas em caminhos críticos (otimização de atraso). O circuito de células lógicas é então passado para um programa de posicionamento, que seleciona uma localização espedífica no FPGA para cada célula lógica. Algoritmos típicos de posicionamento geralmente tentam minimizar o comprimento total das interconexões necessárias [15].

O passo final do sistema de EDA é realizado pelo software de roteamento, que aloca os recursos de roteamento do FPGA para interconectar as células lógicas posicionadas. As ferramentas de roteamento devem assegurar que $100 \%$ das conexões requeridas são realizadas, e alcançadas. Finalmente, a saída do sistema EDA alimenta a unidade de programação que é utilizada pra configurar o FPGA. 


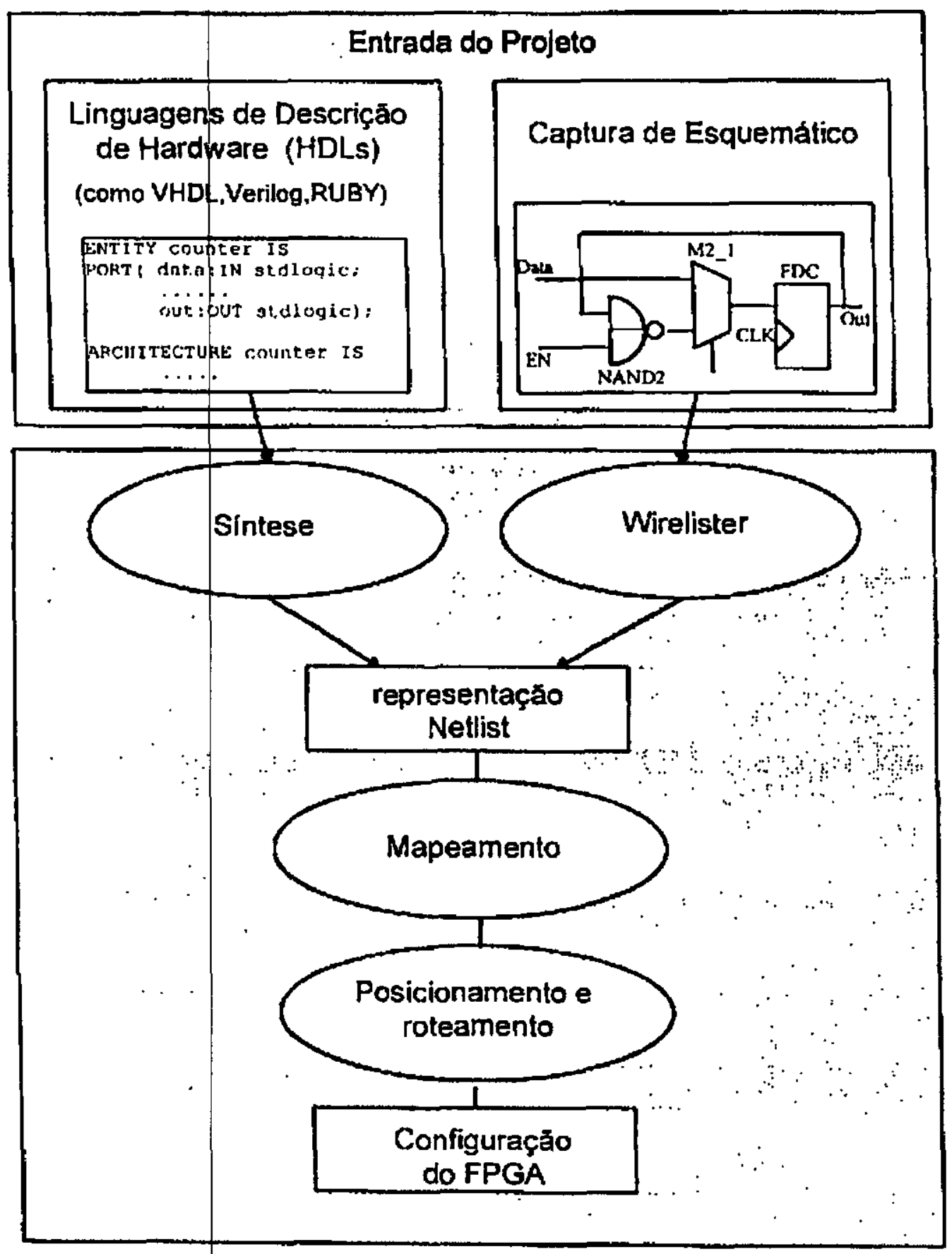

Figura 9 - Sistema EDA para projetos com FPGAs

\subsection{Linguagem de Descrição de Hardware}

Uma linguagem de descrição de hardware (Hardware Description Language - HDL) é uma linguagem textual para representar o hardware. Existem várias disponiveis no mercado atualmente: VHDL, Verilog, AHDL, etc. 
Neste trabalho será usada a AHDL (Altera Hardware Description Language), pois esta é a linguagem disponível no software que será usado (MAX+Plus II). Esta é uma linguagem modular e de alto nível que é completamente integrada ao MAX+Plus II. AHDL suporta equações Booleanas, máquinas de estado, lógicas condicional e funções parametrizadas.

Como a VHDL é a mais importante de todas, pois foi padronizada pelo IEEE, será comentada mais detalhadamente, mostrando seus principais conceitos, os quais também são válidos para a maioria das outras linguagens, uma vez que as outras linguagens são similares a VHDL.

\subsubsection{Introdução à Linguagem VHDL}

VHDL (VHSIC Hardware Description Language) [16] está se tornando cada vez mais popular como um modo de capturar circuitos eletrônicos digitais complexos tanto para simulação como para síntese. Circuitos digitais capturados usando VHDL podem ser facilmente simulados, são mais aptos a serem sintetizados em várias tecnologias, e podem ser arquivados para futuras modificações e reutilizações.

VHDL é uma linguagem de programação que foi desenvolvida e otimizada para descrever o comportamento de circuitos e sistemas digitais. Desta forma, ela combina as seguintes características:

- Modelagem de simulação - VHDL possui muitas características apropriadas para descreverem (para um determinado nível de detalhe) o comportamento de componentes eletrônicos, desde simples portas lógicas até completos microprocessadores. Características da VHDL permitem que aspectos elétricos do comportamento do circuito (tais como 'rise and fall times' dos sinais, atrasos através das portas, e operação funcional) sejam descritos com precisão. O modelo de simulação resultante pode ser usado como um bloco pré-definido em um circuito maior (usando esquemático, diagrama de blocos ou descrições VHDL em nível de sistema) para o propósito de simulação.

- Entrada do projeto - Da mesma forma que as linguagens de programação de alto nível permitem que complexos conceitos de projeto sejam expressos como programas para computador, VHDL permite que o comportamento de circuitos eletrônicos complexos seja capturado de um projeto para uma síntese automática do circuito ou para um sistema de simulação. Como Pascal, C e C++, VHDL inclui características úteis para técnicas de projeto estruturado, e oferece um rico conjunto de representação de dados e controle. Diferente destas linguagens de programação, VHDL possul características que permitem que eventos concorrentes sejam descritos. Isto é importante porque o hardware descrito usando VHDL é inerentemente concorrente em sua operação. 
- Teste - Um dos mais importantes (e sub-utilizado) aspectos da VHDL é sua capacidade de capturar a especificação de desempenho para um circuito, em uma forma comumente referenciada como 'test bench', ou plano de testes. Plano de testes são descriçâes VHDL dos estímulos ao circuito e suas correspondentes saídas desejadas, que verificam o comportamento do circuito através do tempo.

- Netlist - VHDL é uma poderosa linguagem para desenvolvimento de projetos em alto nível, mas também é útil como uma forma de comunicação de baixo nível entre diferentes ferramentas em um ambiente computacional. A característica de linguagem estrutural da VHDL permite que ela seja usada efetivamente como uma linguagem 'netlist'.

- Padrão - Foi adotada como padrão pela comunidade de projetos eletrônicos, o que significa que novas gerações de ferramentas continuarão suportando os métodos de entrada de projeto suportados atualmente, além de inerentemente atribuir características de portabilidade e re-utilização aos projetos desenvolvidos.

VHDL foi desenvolvida nos anos 80 como um 'spin-off de um projeto de pesquisa de um circuito integrado de alta velocidade, patrocinado pelo Departamento de Defesa dos Estados Unidos. Durante o programa VHSIC, pesquisadores se confrontaram com a tarefa de descrever circuitos de larga escala (para aquela época) e gerenciar problemas no projeto de grandes circuitos que envolviam várias equipes de engenheiros. Dispondo de ferramentas para projetos 'gate-level apenas, logo se tornou claro que melhores e mais estruturados métodos e ferramentas de projeto deveriam ser desenvolvidos.

Para resolver este desafio, uma equipe de engenheiros de três companhias - IBM, Texas Instruments e Intermetrics - foi contratada pelo Departamento de Defesa para completar a especificação e implementação do novo método de descrição de projeto baseado em linguagem. A primeira versão publicada da VHDL (versão 7.2) tornou-se disponível em 1985.

Em 1986 o IEEE recebeu a proposta para padronizar a linguagem, o que foi feito em 1987 depois que substanciais melhoras e modificações foram feitas por uma equipe de representantes comerciais, acadêmicos e do governo. $O$ padrão resultante, IEEE 1076-1987, é a base para praticamente todo produto de simulação e síntese vendido hoje em dia. Uma versão melhorada da linguagem, IEEE1076-1993, foi lançada em 1994, e os fabricantes de ferramentas estão adicionando estas novas características da linguagem a seus produtos.

Embora o padrão IEEE 1076 defina completamente a linguagem VHDL, existem alguns aspectos da linguagem que são difíceis de serem escritos completamente numa descrição de projeto portável (que possa ser simulada identicamente usando ferramentas de diferentes fabricantes). O problema origina do fato de que VHDL suporta muitos tipos de dados abstratos, mas não endereça o problema da caracterização de sinais de intensidades diferentes ou condições comumente usadas em simulações tais como 'unknows' e alta impedância. Logo depois que o IEEE 1076-1987 foi adotado, os fabricantes de simuladores começaram a melhorar o VHDL com hovos tipos de sinais (através do uso de tipos enumerados, não padronizados, mas legais) para permitir que seus clientes simulassem circuitos eletrônicos complexos corretamente. Isto causa problemas porque as descrições de 
projetos feitas usando um simulador são freqüentemente incompatíveis com outros ambientes de simulação. Rapidamente VHDL tornou-se uma linguagem não padrão.

Para resolver este problema de tipo de dados não padronizados, outro padrão foi adotado pelo IEEE. Este padrão, número 1164, define um pacote padrão contendo definições para um tipo padronizado de dados de nove valores que é referenciado como 'standard logic package', ou algumas vezes MVL9 (multivalued logic, nine values). Os padrões IEEE 1076-1987 e IEEE 1164 juntos formam o padrão completo VHDL largamente usado nos dias de hoje.

VHDL é uma linguagem de programação de propósito geral otimizada para o projeto de circuitos eletrônicos. Desta forma, existem muitos pontos do processo nos quais VHDL pode ajudar: especificação, captação, simulação, documentação e como uma alternativa aos editores esquemáticos e às linguagens proprietárias.

O diagrama apresentado na Figura 10, mostra um processo simplificado incluindo síntese e simulação, para um ou mais Cls logicamente programáveis ou ASICs. A chave para entender o processo e entender como melhor usar VHDL é lembrar a importância do desenvolvimento do plano de teste. Este desenvolvimento deve ser iniciado tão logo os requisitos gerais do sistema sejam conhecidos.

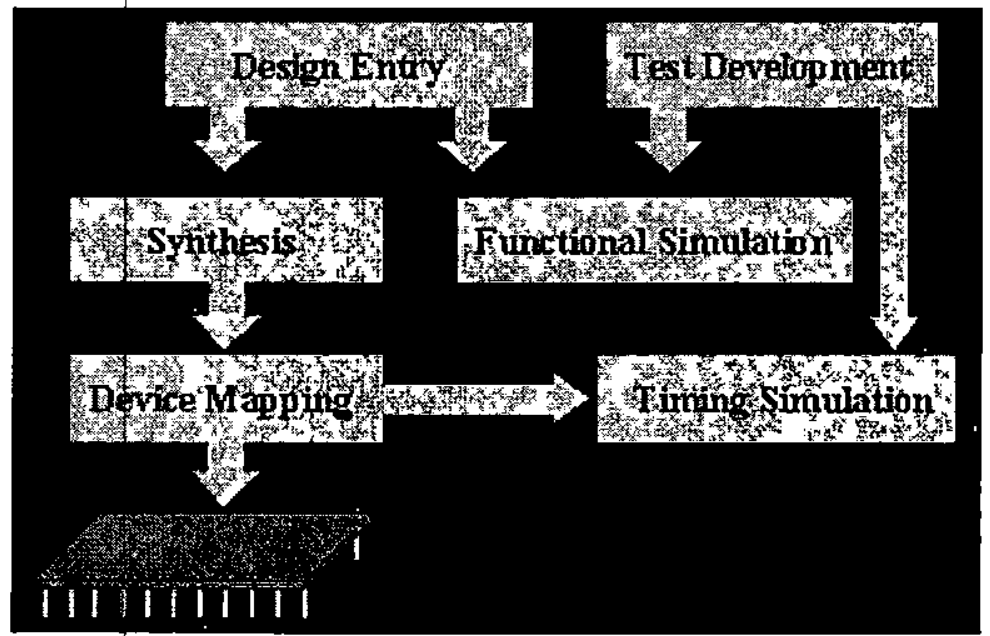

Flgura 10 - Processo simplificado para projeto de Cls loglcamente programávels

A linguagem VHDL será usada para as entradas do projeto (design entry): depois de ser capturada por um sistema, ou usando um editor de texto ou através de uma ferramenta que gere VHDL a partir de uma representação gráfica de alto nível. $\mathrm{O}$ código fonte VHDL pode ser a entrada para simulação (functional simulation), permitindo que sua funcionalidade seja verificada, ou ser passado diretamente para uma ferramenta de síntese (syntesis) para implementação em um tipo de componente específico (device mapping).

Quanto ao desenvolvimento dos testes (test development), o plano de testes em VHDL pode ser criado para garantir que o circuito atenda as especificações funcionais e as restrições de tempo (timming simulation). Este plano de testes pode ser descrito usando um editor de texto, ou pode ser gerado por outras formas de informação de estímulo de teste, tal como um gráfico em forma de ondas. 
Uma melhor utilização da VHDL ocorre quando se usa uma estrutura 'topdown' para o projeto. Um real aumento da produtividade ocorrerá depois de superado o aclive maior da curva de aprendizagem e quando já tiver acumulado uma biblioteca de componentes VHDL re-utilizáveis. A re-utilização de projetos torna-se natural devido à facilidade de se construir e de se usar as bibliotecas dos módulos VHDL mais usados e então, a escrita de código portável será um reflexo natural.

VHDL torna mais rápido o processo de desenvolvimento em ferramentas EDA e nas tecnologias de gravação de $\mathrm{Cl}$. O uso de uma linguagem padrão pode aumentar a chance de estar sempre usando as ferramentas mais avançadas sem a necessidade de re-entrar as descriçōes do circuito. A capacidade de redirecionar circuitos para novos tipos de componentes também será melhorada pelo uso de um método padrão para as entradas do projeto.

\subsection{Considerações Finais}

Neste trabalho a computação reconfigurável será aplicada na configuração dos modos de operação do hardware desenvolvido, conforme mostrado na Seção 7.4. Pode-se classificar o hardware reconfigurável deste trabalho na categoria lógica, ou seja, a RPU será usada em substituição outros dispositivos lógicos. A arquitetura escolhida para a interconexão com a CPU será a RPU acoplada com o barramento local, conforme pôde ser observado na Figura 1.

Apesar da crescente tendência em usar a reconfiguração dinâmica, aqui ela náo será abordada para evitar maiores complexidades no desenvolvimento do trabalho. O mesmo se aplica a VHDL, que seria ideal num hardware com reconfiguração dinâmica ou num hardware com funçōes mais especializadas. Assim, para a programação da RPU será usada a descrição em forma de esquema (esquemático) juntamente com a linguagem de descrição AHDL, própria do fabricante da RPU a ser usada.

Será usado como RPU um PLD com as seguintes características:

- Programação na própria placa, usando a porta JTAG.

- Além da capacidade de retenção da programação mesmo desligando o equipamento.

Estas características darão maior flexibilidade e desempenho respectivamente, portanto, passarăo a ser requisitos do projeto. 
Uma vez que este trabalho se propõe a fornecer um hardware que suporte determinado nivel de tolerância a falhas, torna-se necessário fornecer alguns conceitos relacionados a este assunto.

\subsection{Tolerância a Falhas}

Um sistema computacional deve ser confiável, ou seja, deve continuar funcionando corretamente, mesmo na presença de falhas [70]. Sistemas que possuem esta característica são denominados sistemas tolerantes a falhas. Se o sistema é tolerante a falhas, isto implica que o sistema pode detectar o erro quando ele ocorrer, ter informação suficiente sobre a falha para corrigir seu impacto no sistema e colocá-lo em operação normal dentro de um período de tempo aceitável. Um exemplo de uma rede tolerante a falhas já foi projetado no ICMC-USP [21]. Sistemas tolerantes a falhas apresentam as seguintes características essenciais:

- Confiabilidade - é o grau de sucesso que um sistema atinge dentro de um certo período de tempo;

- Manutenção 'on-line' - capacidade de correção da falha sem interrupção do serviço;

- Degradação suave - consiste no fato do sistema continuar fornecendo algum serviço útil, mesmo durante a ocorrência de falhas;

- Operação a prova de falhas - continuidade da operação mesmo diante de falhas;

- Disponibilidade - é a probabilidade do sistema estar operacional dentro de um intervalo de tempo.

Em sistemas que requerem alta confiabilidade normalmente usam-se técnicas que asseguram que as falhas sejam evitadas ou eliminadas antes que elas sejam percebidas pelo sistema [22]. Um certo nível de abstração se faz necessário, uma vez que não foi provado que um alto nível de confiabilidade seja suficiente. A razão para isto é que sistemas complexos sempre irão conter falhas residuais. Conseqüentemente, técnicas que possibilitem ao sistema tolerar a ocorrência e as conseqüências das falhas são requeridas.

Todas as medidas de tolerância à falhas dependem da utilização eficiente dos elementos do sistema e podem ser obtidas por redundância protetora. As técnicas 
que utilizam esta redundância podem ser classificadas de diferentes maneiras; uma possivel classificação identifica as estratégias por:

- Detecção de erro;

- Avaliação do dano;

- Recuperação a partir do erro;

- Tratamento da falha.

Num determinado sistema, a estratégia particular usada pode variar em partes diferentes do sistema, e em tempos diferente durante sua operação. Por isso, nem sempre é possível fazer uma identificação positiva dos elementos responsáveis pela constituição de cada estratégia usada em uma dada técnica de tolerância à falhas. Enquanto o ponto de entrada é sempre a detecção de um estado de erro, a ordem na qual as outras estratégias são conduzidas podem variar, e ainda podem existir muitas interações entre elas. Deste modo, qualquer identificação irá depender de uma visão particular da estrutura do sistema.

\subsubsection{Redundância Protetora}

Usualmente é incorporada no sistema através da adição de componentes e algoritmos, que são redundantes no sentido de que eles não podem ser necessários num sistema que possa garantidamente ser livre de falhas. Redundância no tempo pode ser utilizada num sistema, por exemplo, fazendo uso repetido de um determinado componente.

Redundância estática (ou mascarante) é a redundância introduzida para mascarar ou esconder os efeitos do componente falho, de modo que a falha não tenha impacto sobre o ambiente no qual o componente está envolvido, tem sido diferenciada da redundância dinâmica na qual um componente é usado para indicar que a saída daquele componente está errada. $\mathrm{Na}$ realidade esta distinção não está muito relacionada com o tipo de estratégia utilizada, mas, com a maneira na qual a redundância é incorporada na estrutura do sistema.

\subsubsection{Detecção de erro}

O ponto de início para todas as técnicas de tolerância a falha é a deteç̧ão de um estado errôneo que pode conduzir o sistema a uma falha. Idealmente, o controle desempenhado pelo mecanismo de detecçáo de erro deve satisfazer a três critérios:

1. Ser baseado somente na especificação do serviço que o sistema supostamente provê;

2. Assegurar uma absoluta precisão do procedimento do sistema com relação à especificação;

3. Ser independente do próprio sistema. 
Se estes controles forem desenvolvidos, implementados e complementados por um meio apropriado de recuperação a partir dos erros detectados, então nenhuma falha simples de um componente ou de um algoritmo irá causar a falha do sistema. Na prática, estes controles rigorosos não podem ser conseguidos.

\subsubsection{Avaliação do dano}

Quando um erro é detectado, outras partes do sistema podem ser suspeitas e não apenas aquela em que o erro foi descoberto. Devido ao provável atraso entre a ocorrência da falha e a detecção de suas conseqüências, informações inválidas podem ter sido propagadas pelo sistema. Desta forma, antes de uma recuperação a partir do erro, pode ser útil tentar avaliar a extensão do dano que tem sido causado ao estado do sistema.

Avaliação do dano é sempre baseada numa idéia prioritária para uma maior ou menor extensão. A avaliação pode ser baseada somente na idéia prioritária ou pode ser acrescida pelo próprio sistema, adotando técnicas exploratórias para tentar determinar a extensão do dano. Cada aproximação pode envolver confiança na estrutura do sistema para determinar qual atividade do sistema deveria ter seguido a ocorrência da falha.

\subsubsection{Recuperação a Partir do Erro}

Recuperação da conseqüência de uma falta envolve a transformação de um estado errôneo e inconsistente num estado válido através do qual o sistema pode continuar a prover o serviço específico. Duas estratégia de recuperação do erro podem ser identificadas:

1. 'Backward Error Recovery' - Recuperação de erro fornecida a um sistema e envolvendo a restauração de um estado prévio do sistema (ou parte do sistema);

2. 'Forward Error Recovery' - O próprio sistema fazendo um maior uso do seu estado de erro atual para obter um outro estado.

O objetivo das duas estratégias é conseguir um estado no qual é esperado que seja livre de erros. Uma estratégia 'reset' é usada alguma vezes para fornecer uma recuperação de erro na qual o estado corrente é descartado e substituído por um estado predefinido.

\subsubsection{Tratamento da Falha}

O aspecto de tolerância à falhas que é chamado de tratamento de falhas assume todas as atividades anormais do sistema para assegurar que ele continue fornecendo seu serviço especifico, mesmo sabendo da presença da falha. Deste modo, técnicas para localização, reparo ou para ignorar uma falha estão dentro desta classificação. 


\subsection{Redundância em Sistemas de Automação}

As características sofisticadas da geração atual dos sistemas de monitoração e controle de planta têm garantido a aceitação destes sistemas em fábricas através do mundo [23].

O sistema de controle mostrado na Figura 11 possui um único ponto de falha. Este sistema falha totalmente se uma parte do hardware (o computador conectado às unidades de monitoração e controle) falha. Se algum dos processos (ou todos) em uma planta são críticos, ou se o custo de uma parada na produção devido uma falha do sistema é alto, deve ser incorporada redundância ao sistema. Em um sistema inerentemente redundante, interrup̧̧ôes devidas à falhas de equipamentos são eliminadas.

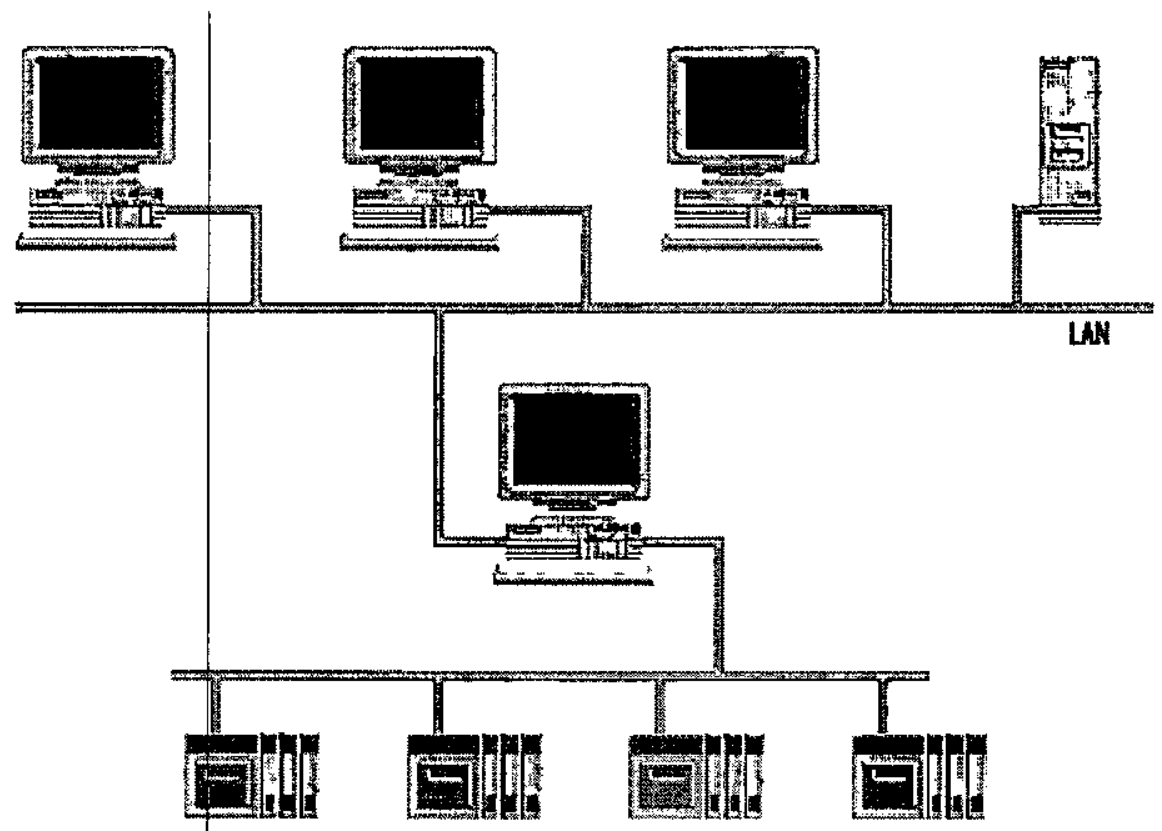

Figura 11 - Sistema de controle

Através da distribuição das tarefas do processo em dois ou mais computadores (usando uma LAN) pode-se aumentar a velocidade e eficiência do sistema. Numa aplicação simples, como a mostrada na Figura 11, o computador conectado às unidades de monitoração e controle torna-se o servidor, dedicado para a comunicação com os equipamentos de controle, enquanto os outros computadores são clientes de exibição de informações. Então um cliente solicita ao servidor um dado a ser exibido e processa este dado localmente.

Para oferecer redundância, um segundo (standby) servidor pode ser adicionado, também dedicado para a comunicação com os equipamentos de controle da planta. Se o servidor primário falha, a requisição do cliente é chaveada para 0 servidor secundário. 
O servidoł secundário não deve duplicar as funções do servidor primário, senão ambos terão que comunicar com os PLCs (controladores lógicos programáveis), dobrando a carga na rede PLC, e reduzindo o desempenho. $O$ ideal é que apenas o servidor primário comunique com a rede PLC e que este também comunique com o servidor secundário, para atualizá-lo continuamente com o estado da planta. Se a comunicação com o servidor primário é interrompida, o secundário assume que o servidor primário falhoy e passa a operar no lugar deste. Quando o servidor primário é reparado e retorna ao serviço, ele lê o estado da planta através do servidor secundário e continua seu papel como servidor primário.

como:

Também pode se dividir as tarefas do servidor em algumas sub-tarefas

- $\quad / O$ (entrada/saída)

- Alarmes;

- Curvas de tendência;

- Relatórios

Cada uma destas tarefas pode gerenciar seu banco de dados independentemente, de forma que a redundância de cada uma delas possa ser manipulada diferentemente. Pode-se ainda adicionar ao sistema um servidor de arquivos dedicado que centralize os bancos de dados e as telas de apresentação. Isto garantiria a continuidade mesmo em caso de falha do servidor primário, conforme mostra a Figura 12.

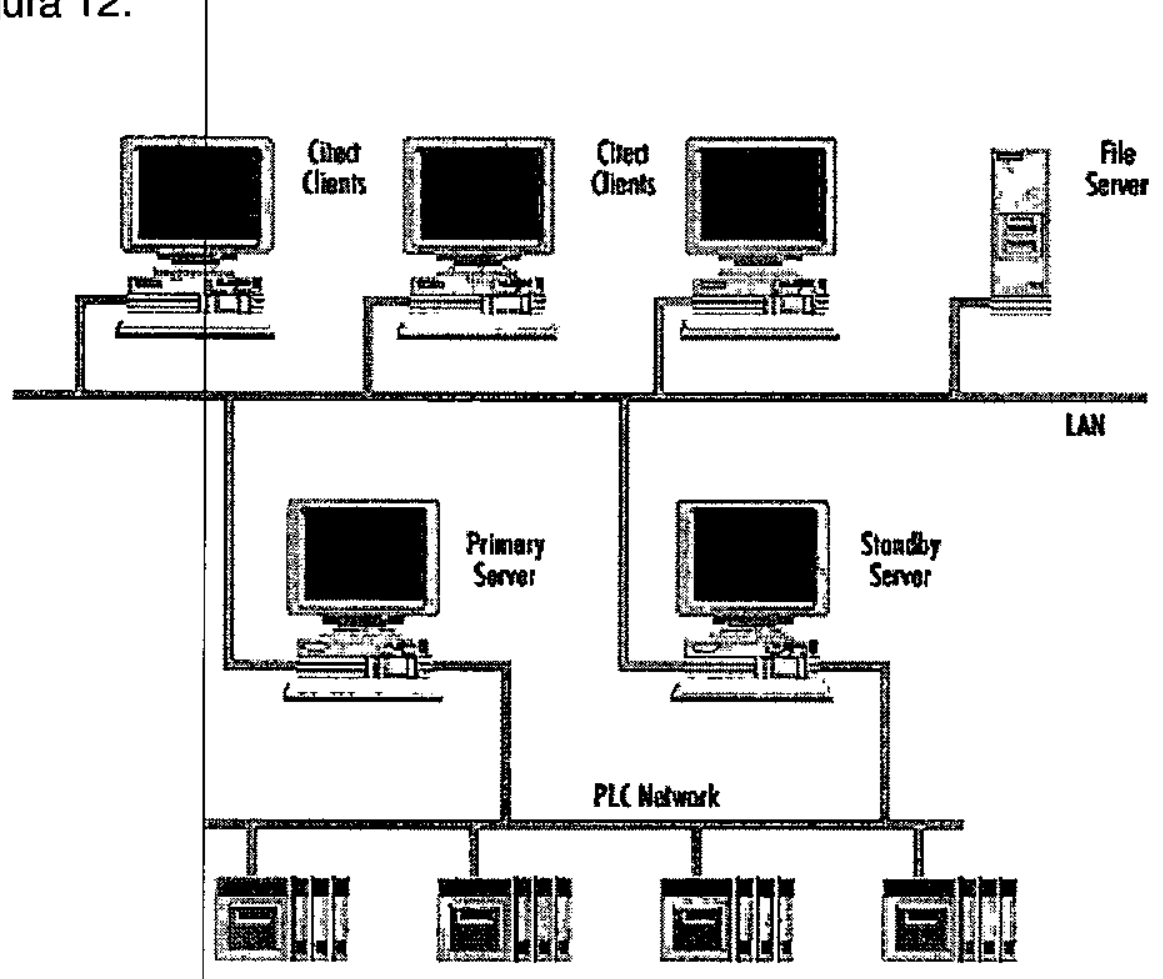

Figura 12 - Slstema com redundâncla de servidor 
Esta configuração garante o funcionamento do sistema no caso de falha de um dos servidores, contudo, uma falha na LAN pode derrubar o sistema. Uma segunda LAN e um segundo servidor de arquivos pode assegurar a estabilidade do sistema no caso de ocorrer uma falha na rede.

Para uma máxima estabilidade pode se conectar unidades paralelas (PLCs) para o mesmo equipamento de campo, mostrado na Figura 13. Qualquer componente de hardware neste sistema pode falhar sem interromper a monitoração e controle da planta. Este nível de redundância é diretamente desejado pela parte centralizada do processamento.

\subsection{Redundância High Speed Ethernet}

Muitas das aplicações da Rede HSE Fieldbus Foundation necessitam ter uma disponibilidade do sistema de automação maior do que um sistema não tolerante a falhas pode fornecer [25]. Enquanto espera-se que uma rede HSE seja aplicável para o controle e monitoramento da maior parte de uma planta industrial, não se pretende usá-la em aplicações críticas, no aspecto de segurança. 
O alicerce fundamental da redundância é a transparência operacional, que significa que a redundância não é visível para as aplicações que estão se comunicando. Apesar disto, para as aplicações de diagnóstico, tanto os equipamentos que estão operacionalmente transparentes, como os que estão em operação devem ser visíveis para que elas possam confirmar que os componentes redundantes estejam operando corretamente.

A especificação da Fieldbus Foundation prevê dois tipos de redundância que serão tratados nos tópicos seguintes:

- Redundância de rede (ou caminho);

- Redundância de equipamento.

\subsubsection{Redundância da LAN HSE}

- Maximizar o uso das tecnologias comerciais disponíveis.

- Fornecer caminhos alternativos para a comunicação entre os equipamentos na LAN.

- Fornecer transparencia operacional aos Virtual Field Devices (VFDs) e às aplicações HD.

- Permitir que os equipamentos sejam construídos apenas com configurações necessárias para que eles operem em todos os tipos de LAN HSE.

- Permitir a co-existência com equipamentos não HSE. consideraçōes:

Adicionalmente, a redundância da LAN HSE faz as seguintes

- Nenhuma falha localizada no caminho de comunicação ou num VFD pode causar a perda total da comunicação.

- Num sistema em funcionamento, o status do caminho de comunicação entre os equipamentos é acessado contínua e sistematicamente.

- Cada equipamento na rede detecta falhas e toma ações corretivas baseadas na falha detectada: não existe um "gerente de redundância" central.

- Cada equipamento regularmente distribui sua visão do status da LAN para os outros equipamentos. Deste modo, cada equipamento pode manter uma base de conhecimento para uma deteç̧ão inteligente da falha e uma tomada decisão.

tipos:

A especificação divide a topologia das redes High Speed Ethernet três 


\subsubsection{Tipo N-1 - Non Fault Tolerant}

Uma rede não tolerante a falhas, tipo $\mathrm{N}-1$ (Figura 14), possui conectados apenas equipamentos com portas simples e não possui uma LAN tolerante a falhas.

\subsubsection{TIpo N-2A - Dual LAN}

As redes tipo $\mathrm{N}-2 \mathrm{~A}$ (Figura 15) consiste de duas LANs independentes. Os equipamentos podem ser conectados às duas LANs, usando portas HSE diferentes para cada uma, ou podem ser conectados a apenas uma das LANs, sendo que neste caso eles só poderão se comunicar com os equipamentos que estiverem na mesma LAN. As duas LANs não precisam ser idênticas e não existe conectividade entre elas.

\subsubsection{Tipo N-2B - Single Fault Tolerant LAN}

As redes tipo $\mathrm{N}-2 \mathrm{~B}$ (Figura 16) consistem de uma LAN que possui capacidades embutidas de tolerância a falhas. O grau e os mecanismos de tolerância a falhas não serão especificados. Os mecanismos de redundância da LAN HSE são implementadas nas camadas superiores destas LANs. Como o Tipo N-2B é uma rede única, um equipamento pode ser conectado usando uma porta e ter acesso a todos os outros equipamentos. A topologia da LAN não é restrita. 


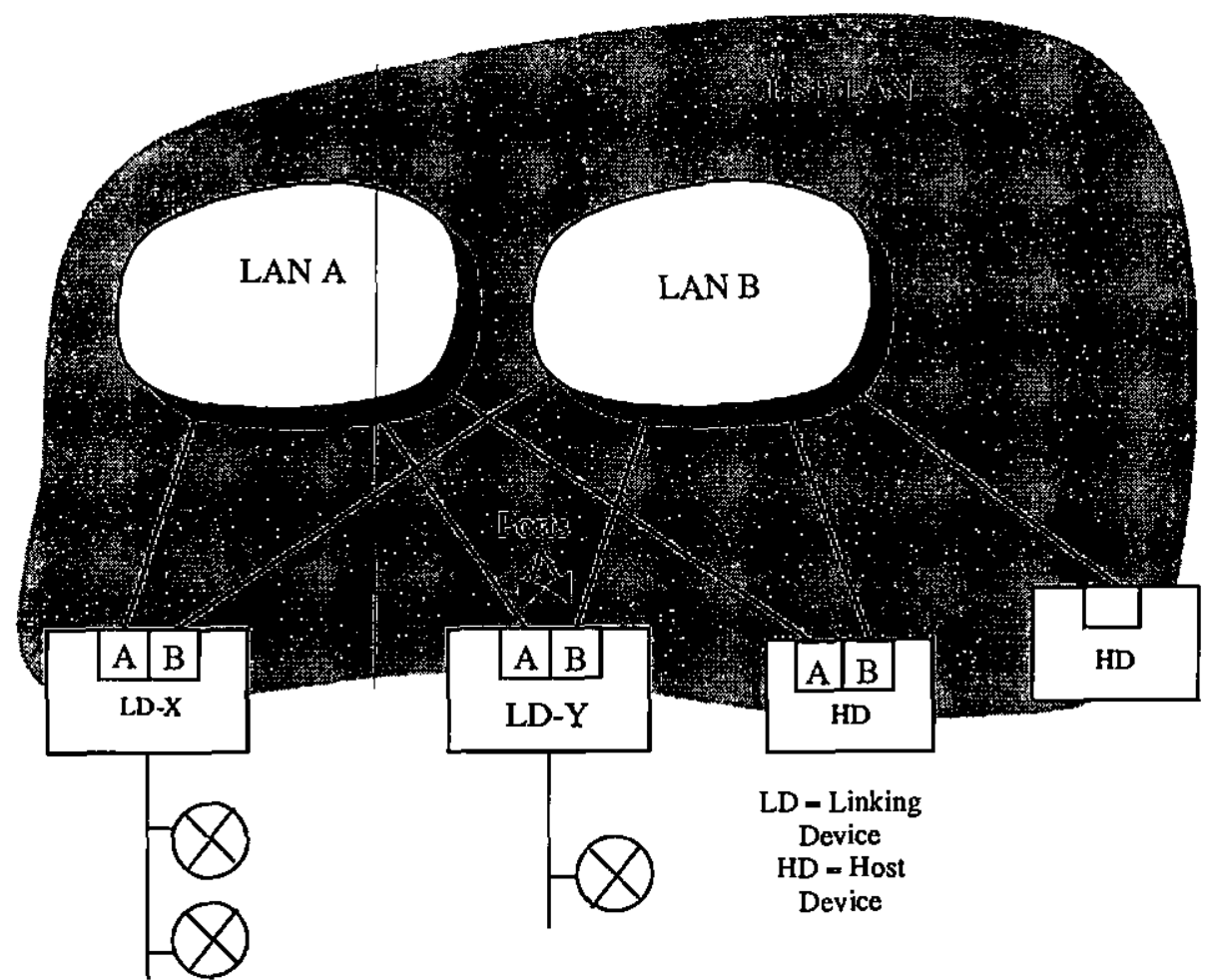

Figura 15 - Rede tipo N-2A

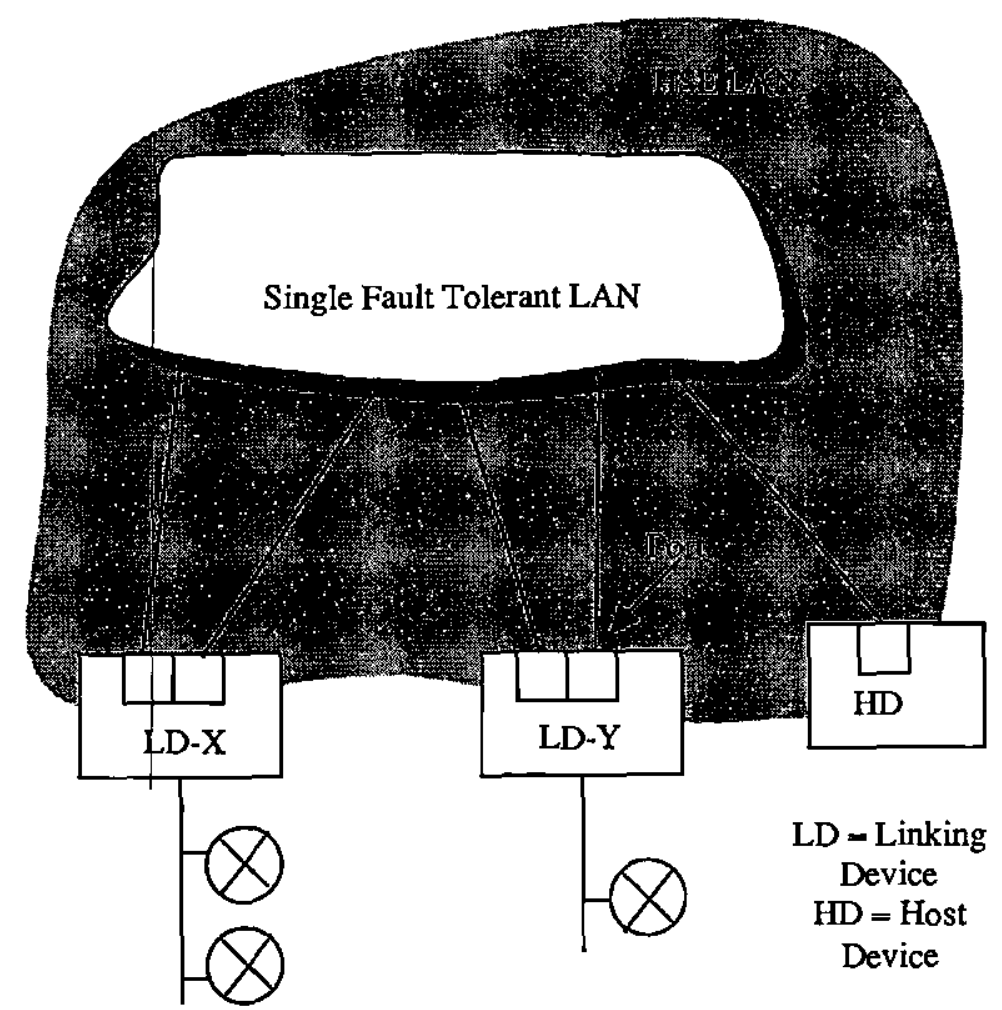

Figura 16 - Rede tlpo N-2B 
Todos os equipamentos que estão aptos a participarem da redundância de LAN, enviam e recebem mensagens de diagnóstico (diagnostic messages) que contém um resumo do status da rede visualizada pelo equipamento. Estas mensagens são transmitidas periodicamente pelo equipamento por cada uma de suas portas e permitirá que os equipamentos atualizem suas 'Network Status Table'.

Cada equipamento manterá em sua 'Network Status Table' sua visibilidade da rede. Esta tabela será usada para ajudar na escolha de qual porta usar para a transmissão para um determinado endereço de destino, como também para escolha de qual porta (ou portas) usar para recepção de transmissões 'multicast'.

\subsubsection{Equipamentos Redundantes HSE}

Existe uma ampla faixa de capacidades de redundância a ser definida para os equipamentos. De um lado, pode-se ter um equipamento não projetado para ser redundante representando este papel. Por outro lado, pode-se ter equipamentos especificamente projetados para operações redundantes que minimizem o tempo levado para detectar e recuperar a partir de uma falha. Os mecanismos de detecção de falhas, sincronização e recuperação dependerão do grau de acoplamento destes equipamentos.

Um equipamento redundante HSE é um conjunto de equipamentos HSE que possuem operacionalmente as mesmas capacidades. Quando todos estão em funcionamento, um é o primário e os outros são os secundários. O primário participa da operação do sistema, enquanto que o secundário é responsável por assumir o papel do primário em caso de falha, ou quando for diretamente direcionado a fazer isto. Todos eles são acessíveis pela rede para propósitos de diagnóstico. Os equipamentos num conjunto redundante possuem seus próprios endereços $I P$, um para cada porta, e não existe troca de endereços IP entre os equipamentos na ocorrência da falha.

A redundância do equipamento é independente da redundância da LAN. A deteç̧ão da falha no primário faz com que o segundo assuma seu lugar. Quando o primário original retorna a um estado operacional, ele retorna ao sistema como secundário. Três tipos de equipamentos são previstos pela norma:

\subsubsection{Tipo D-1 - Uncoupled}

Os equipamentos tipo D-1 não possuem suporte específico para redundância embutido, mas podem assumir o trabalho no caso de falha do outro equipamento. A detecção da falha e o chaveamento são controlados por uma aplicação de configuração. O secundário não é configurado, nem possui um PD-Tag até que primário falhe. Contudo, é atribuído a ele um endereço IP por um servidor DHCP para permitir visibilidade para diagnóstico. 


\subsubsection{Tipo D-2 - Lobsely coupled}

Os equipamentos tipo D-2 não possuem mecanismos de sincronização, detecção de falhas ou recuperação entre primário e secundário fornecida pelo fabricante. O secundárib possui PD-Tag e informações de configuração para permitir uma resposta às falhas mais rápida. A detecção da falha e o chaveamento também são controlados por uma aplicação de configuração.

\subsubsection{Tipo D-3 - Tightly coupled}

Os equipamentos tipo D-3 são construídos com mecanismos de redundância embutido. Este tipo permite que o fabricante desenvolva conjunto de equipamentos redundantes que apareçam para o sistema como um único equipamento. Este tipo de equipamento possui mecanismos de sincronização, de detecção de falhas e de recuperação fornecidos pelo fabricante, o que permite uma resposta às falhas ainda mais rápida. Esta sincronização é feita através de um canal dedicado de comunicação entre o primário e o secundário de modo que informações de monitoração sejam trocadas.

A Figura 17 ilustra os diferentes tipos de equipamentos que podem estar disponiveis para sistemas redundantes. Os conjuntos redundantes estão ilustrados como pares. A linha superior mostra todos os equipamentos que possuem porta única para LAN, enquanto que a linha inferior mostra os equipamentos com duas portas para LAN.
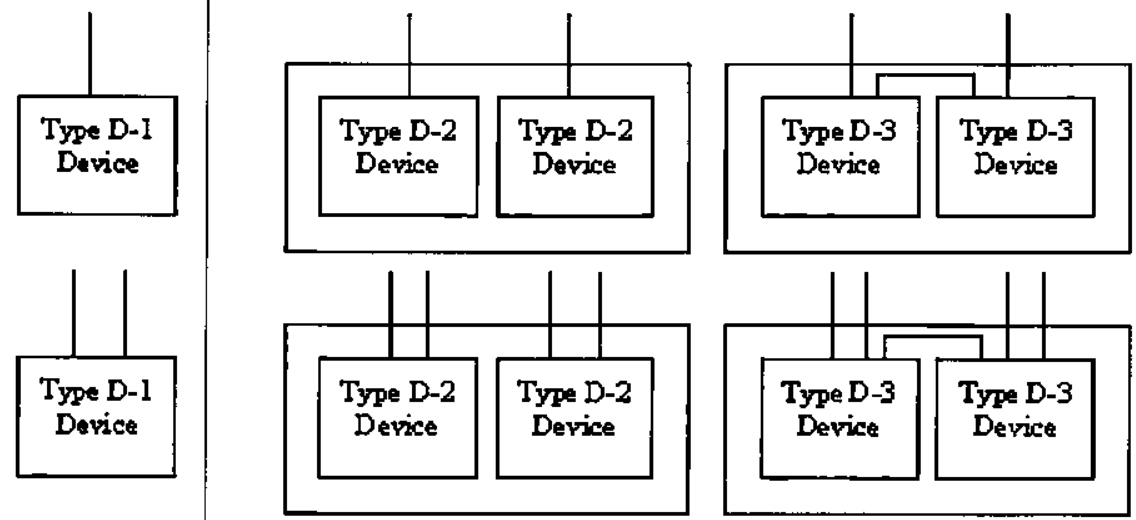

Flgura 17 - Tipos de equlpamentos redundantes HSE 


\subsection{Implementação}

Dos tipos de redundância previstos pela norma da Fieldbus Foundation [32] (de rede e de equipamento) estará sendo abordado somente a redundância de rede, por ser mais geral, uma vez que a redundância de equipamento pode ser feita através de mecanismos que dependerão de cada fabricante.

\subsubsection{Componentes Chaves}

Uma mensagem de diagnóstico é uma mensagem que contém um resumo da saúde e do estado da rede do ponto de vista do equipamento. Todo equipamento numa rede redundante transmite periodicamente mensagens de diagnóstico em cada uma de suas interfaces. Cada equipamento pode reconhecer, através das mensagens recebidas, a ausência de mensagens de diagnóstico de outros equipamentos. Estas mensagens permitirão que o equipamento atualize sua tabela de estado da rede (NST - Network Status Table).

Cada equipamento mantém na tabela de estado da rede (NST) a sua visualização da rede. Esta tabela é usada para identificar qual interface usar quando for transmitir para um determinado endereço e também qual interface usar para a recepção de transmissōes 'multicast'. A NST é construída através das mensagens de diagnóstico recebidas a seu conteúdo é refletido nas mensagens de diagnósticos enviadas.

Cada mehsagem 'unicast' é enviada por apenas uma interface do equipamento que participa da rede redundante. Mensagens enviadas para endereços 'multicast' podem ser enviadas pelas duas interfaces, mas as mensagens de diagnóstico e as mensagens de anunciação devem ser enviadas pelas duas interfaces. As mensagens de anunciação são mensagens que informam na rede que o equipamento está funcionando. O equipamento avalia sua NST e seleciona uma interface para um endereço de destinatário específico, e esta é então designada por Interface de Transmissão Selecionada.

Em algumas topologias de rede, uma mesma mensagem 'multicast' operacional pode ser recebida em cada uma das interfaces de um mesmo equipamento. Se um equipamento tem duas interfaces, então ele pode ser configurado para usar a NST para selecionar uma interface de recepção (Interface de Recepção Selecionada) para mensagens 'multcast' operacionais, reduzindo com isto suas interrupções e sua carga no processamento de mensagens. 
Cada interface de um equipamento numa rede redundante deve ser associada a um único endereço IP. Aplicações remotas podem determinar qual endereço IP usar para comunicar com o equipamento através de serviços especiais. Um destes serviços irá retornar sempre o mesmo endereço IP (Endereço IP em Uso da Interface) para todas as consultas, independente de qual interface recebeu a consulta.

\subsubsection{Modelo}

A partir dos estudos da norma iniciou-se o modelamento da especificação, usando para isto o software Rational Rose. O modelo será desenvolvido usando a linguagem UML (Unified Modeling Language).

A Figura 18 mostra a classe da entidade Redundância de Rede (LAN Redundancy) conforme definida pela norma da Fieldbus Foundation [32]. Esta classe definirá a interface com o mecanismo de redundåncia e ajudará no desenvolvimento do hardware, na medida que dará uma boa noção dos recursos necessários.

A Tabela 2 mostra os atributos da classe que fazem parte da interface interna da mesma (private).

\begin{tabular}{|c|c|}
\hline Attributes & Descriptlon \\
\hline port & LAN assigned port. \\
\hline MaxDevindex & Maximum devlce index allowable. \\
\hline MaxNumDiff & Defines the Max Message Number Difference. \\
\hline agingTime & Defines the Aging Time. \\
\hline MsgVersionNumbe & Defines the message version number. \\
\hline \begin{tabular}{l|l} 
Flags & \\
\end{tabular} & Defines the LAN Redundancy Flags attribute. \\
\hline interval & Defines the Diagnostic Message Interval attribute. \\
\hline state & Controis the LRE state (Closed or Open). \\
\hline Time & Contains the system time when the Diagnostic Message is received. \\
\hline msgNumber & $\begin{array}{l}\text { Defines the message number that will be present in the trailer of it } \\
\text { Diagnostic Message sent by the HSE device. }\end{array}$ \\
\hline hsLockList & $\begin{array}{l}\text { This semaphore protects the access to the list that contains the } \\
\text { Network Status Table. }\end{array}$ \\
\hline & - Atrlbutos da Classe Redundâncla de Rede \\
\hline
\end{tabular}




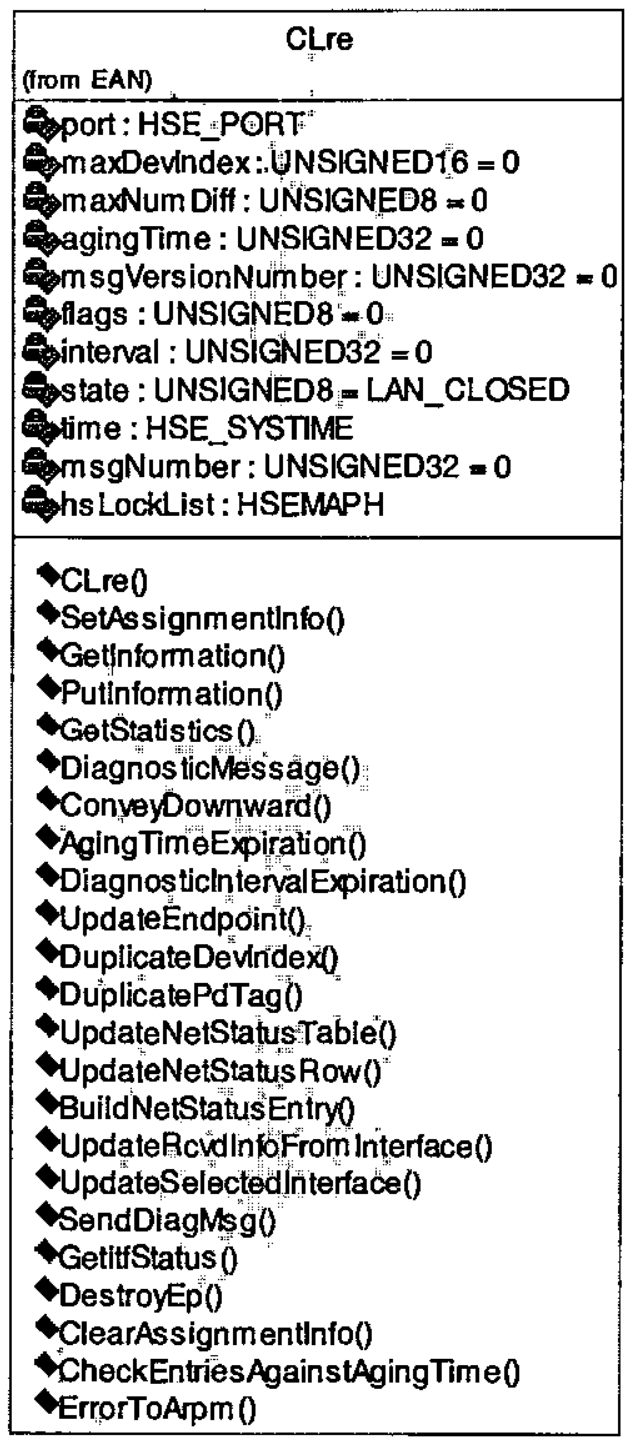

Figura 18 - Classe Redundâncla de Rede

A descrição de cada um dos métodos desta classe está sendo mostrada na Tabela 3. Estes métodos (ou operaçōes) compōem a interface externa (public) do mecanismo de redundância. A maioria destas operaçōes serão abordadas no desenvolvimento dos algorítmos (Seção 4.4.3). 


\begin{tabular}{|c|c|c|}
\hline Operation name & & Description \\
\hline CLre & & LRE constructor. \\
\hline SetAssignmentlnfo & & $\begin{array}{l}\text { This routine is called by the SMK to set new values for LAN Redundancy Port, } \\
\text { Device Index and Max Device Index. Returns True if LAN Redundancy Port is } \\
\text { acceptable. } \\
\text { Note: all the above parameters must be in Network Byte Order. }\end{array}$ \\
\hline Getlnformation & & Treats the LAN Redundancy Get Information service. \\
\hline Puttnformation & & Treats the LAN Redundancy Set Information service. \\
\hline GetStatistics & & Treats the LAN Redundancy Get Statistics service. \\
\hline DiagnosticMessage & & Treats the LAN Redundancy Diagnostic Message service. \\
\hline ConveyDownward & & $\begin{array}{l}\text { Compð̃e a interface pública de acesso a um cliente. Sentido é assumido da } \\
\text { rede HSE para H1. }\end{array}$ \\
\hline AgingTimeExpiration & & Friend routine that is called when the Aging Time expires. \\
\hline DiagnosticlntervalExpiration & & Friend routine that is called when the Diagnostic Message Interval expires. \\
\hline UpdateEndpoint & & $\begin{array}{l}\text { This operation updates the LAN endpoint if the 'ipv6' contains a new value. } \\
\text { Returns False if the 'ipv6' is not } \\
\text { new or the new endpoint is not ok. }\end{array}$ \\
\hline DuplicateDevindex & & Checks duplicate device index and retums True if this condition is found. \\
\hline DuplicatePdTag & & Checks duplicate pd tag and retums True if this condition is found. \\
\hline UpdateNetStatusTable & & This operation updates de Network Status Tabie. \\
\hline UpdateNetStatusRow & & This operation updates an entry in the Network Status Table. \\
\hline BuildNetStatusEntry & & $\begin{array}{l}\text { This operation builds an entry for the Network Status Table based on } \\
\text { parameters of the received Diagnostic Message. }\end{array}$ \\
\hline UpdateRcvdlnfoFromlnterfac & & $\begin{array}{l}\text { This operation updates an exlsting entry with the information received on } \\
\text { interface } A \text { or } B \text {. }\end{array}$ \\
\hline UpdateSelectedlnterface & & $\begin{array}{l}\text { This operation updates the selected path in the Network Status Table for the } \\
\text { entry. }\end{array}$ \\
\hline SendDiagMsg & & Builds and publishes a Diagnostic Message on the HSE network. \\
\hline GetlttStatus & & $\begin{array}{l}\text { This operation scans the network status table and fills in the interfaces' status } \\
\text { in the diagnostic message. }\end{array}$ \\
\hline DestroyEp & & $\begin{array}{l}\text { This operation destroys the LRE endpoints related to the LRE due a SM Clear } \\
\text { Address service. } \\
\text { Note: the parameter 'type' can be ITF_A, ITF B or ALL_ITF. }\end{array}$ \\
\hline ClearAssignmentInfo & & $\begin{array}{l}\text { This routine is called by the SMK to clear assignments for LAN Redundancy } \\
\text { Entity. At this moment, the LRE will destroy all its endpoints and wait for a new } \\
\text { set assignment info request to reestablish itself. Retums True if all endpoint } \\
\text { were destroyed ok. }\end{array}$ \\
\hline CheckEntriesAgainstAgingTin & ime & $\begin{array}{l}\text { This operation updates the Network Status Table based on the expiration of } \\
\text { Aging Timer. }\end{array}$ \\
\hline ErrorToArpm & & $\begin{array}{l}\text { Primitive exchanged between the ARPM (referred to as session) and SMPM. } \\
\text { It is used to convey selected Communication errors reported by the socket } \\
\text { model to a designated ARPM. }\end{array}$ \\
\hline
\end{tabular}

Tabela 3 - Membros da Classe Redundâncla de Rede

\subsubsection{Algoritmo}

Aqui serão apresentados alguns conceitos do algoritmo de detecção de falhas de caminho (rede). Para isto será usada uma aproximação de pares de mensagens de diagnósticos. Cada equipamento que participa de uma rede redundante envia um par de mensagens de diagnóstico (uma em cada uma de suas interfaces) a cada período de tempo $\left(T_{P}\right)$. Cada equipamento, quando recebe uma mensagem de diagnóstico em uma interface, espera pela outra mensagem do par na outra interface. Em uma 'single $L A N$ ', os equipamentos recebem ambas as mensagens nas duas interfaces. Se um equipamento não recebe a segunda mensagem de diagnóstico na outra interface antes de receber mais mensagens de diagnóstico na mesma interface, ele registra uma falha na linha da tabela de estados da rede (NST) correspondente ao equipamento que está enviando as mensagens. Veja a Figura 19. 


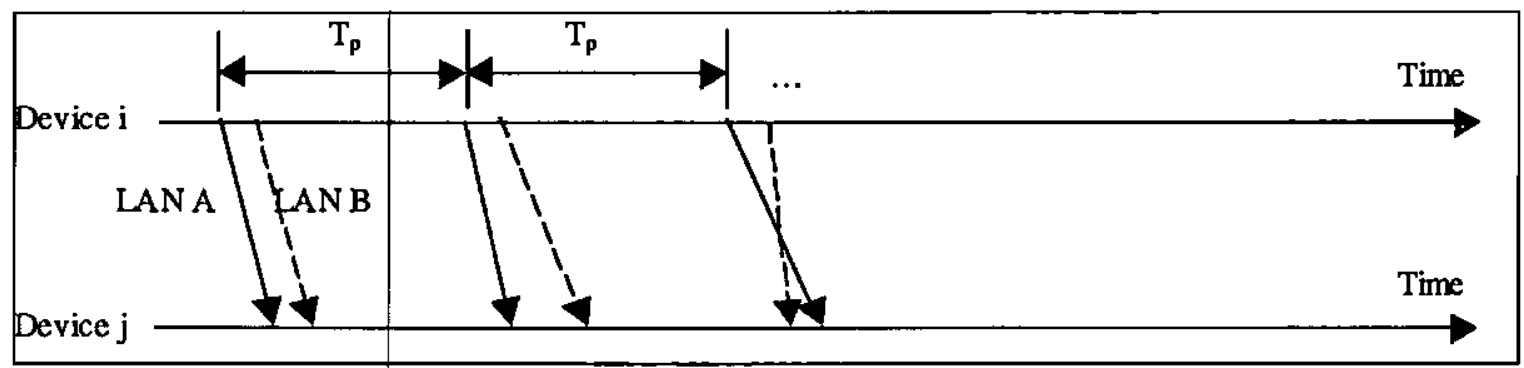

Figura 19 - Pares de Mensagens de Dlagnóstico

$\mathrm{Na}$ prática, o equipamento que está recebendo as mensagens compara o número de série da última mensagem recebida na outra interface com o número de série da mensagem que ele acabou de receber. Se a diferença for maior do que a maior diferença permitida (este valor é configurado), uma falha é registrada.

Por exemplo, considere o fluxo das mensagens de diagnóstico observado através do equipamento Device 3 na Figura 20. Este equipamento mantém uma tabela de estados da rede com informações dos equipamentos Device 1, Device 2 e Device 4. Numa mensagem de diagnóstico cada equipamento envia sua visualização dos equipamentos a ele conectado em adição a outras informações de estado (endereço da interface de origem, 'device index', etc. ).

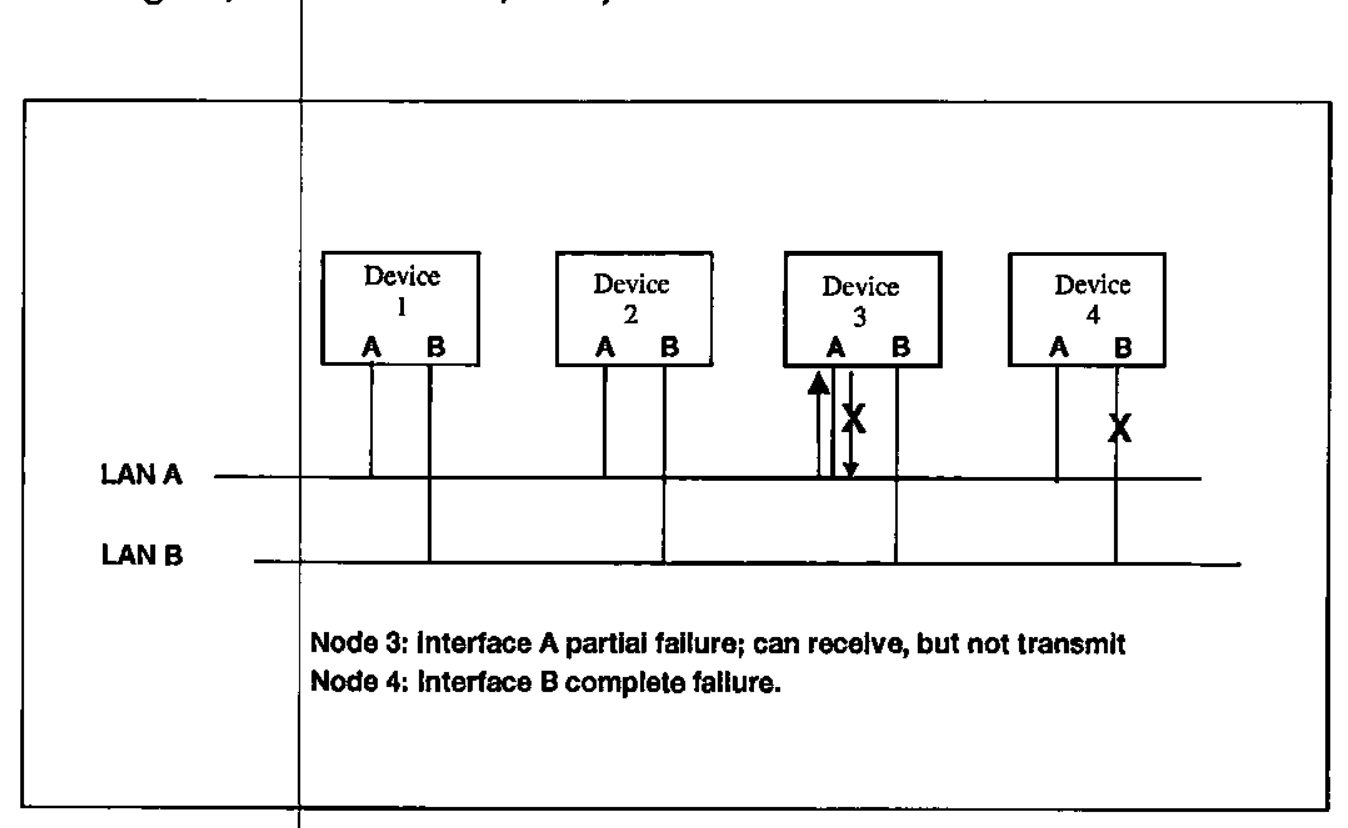

Figura 20 - Slstema Exemplo

Usando as três primeiras colunas da tabela de estados de rede ilustrada na Tabela 4, 0 equipamento Device 3 envia uma mensagem de diagnóstico pela interface A como [OK, OK, OK, OK] e para interface B como [OK, OK, OK, X]. Similarmente, o equipamento Device 1 envia sua visualização dos equipamentos Device 2, Device 3 e Device 4 como [OK, X, OK, OK] para a interface A e como [OK, $O K, O K, X]$ para a interface $B$. $O$ estado visualizado pela interface $A$ e $B$ do equipamento Device 3 é mostrado na Tabela 4. Note que a linha para o próprio Device 
3 é preenchida baseada no teste do próprio equipamento, e como neste caso não existe um teste, todas as informações de estado aparecem como OK.

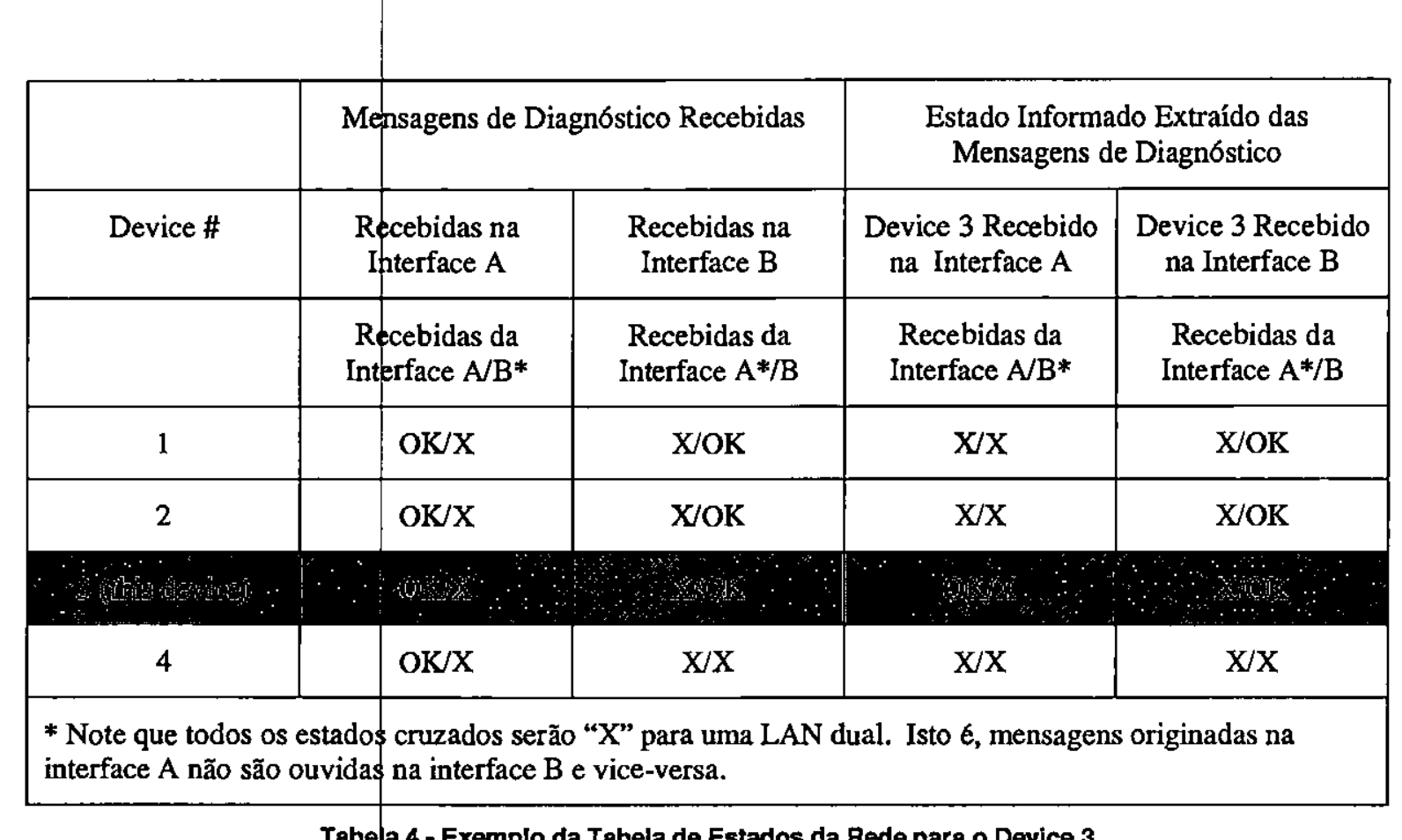

\subsection{Considerações Finais}

O coração do algoritmo de redundância é a interpretação da Tabela de Estados da Rede (NST), mas outro ponto muito importante é a manutenção da mesma. Esta implementação deve estar presente no software e está fora do escopo deste trabalho. Os conceitos e termos foram aqui apresentados apenas para que a definição do hardware leve em conta os recursos que serão necessários e forneça todo suporte necessário a esta implementação.

A redundância de equipamentos ainda não está sendo abordada pela norma, portanto, não fo comentada. Contudo ela poderá até ser implementada através do uso da própria porta Ethernet, da porta serial ou do canal H1 (fieldbus).

A redundância de rede será feita então através de Redundância Protetora, sendo que a partir da deteç̧ão de uma falha será reportado um alarme para que haja substituição ou manutenção do equipamento problemático. O que, no escopo deste trabalho, significa fornecer um hardware que suporte redundância de rede, ou seja, tenha duas portas Ethernet rodando a $100 \mathrm{Mbps}$. 
A caminho do objetivo proposto iniciaram as pesquisas do paradigma de hardware a ser utilizado no desenvolvimento deste trabalho.

\subsection{System-on-chip}

Desde o jnício, os sistemas digitais têm progredido em direção a altos niveis de integração. A alta integração oferece vários benefícios para o projetista de sistemas, incluindo custos de desenvolvimento mais baixos, ciclos de projeto mais curtos, maior desempenho e geralmente menor consumo de potência. No nível de dispositivos, esta integração tem sido alcançada pelo acúmulo de funções, antes realizadas por múltiplos componentes individuais, por dispositivos de alta densidade e com mais capacidade. Tais sistemas têm sido denominados SOC (System-On-a-Chip), como o ZFx86 da ZF Linux Devices que integra um PC completo em um único chip [71].

Este desenvolvimento tem sido acelerado pelo avanço das ferramentas e técnicas de projeto de circuitos integrados, conhecidas por Electronic Device Automation (EDA).

\subsubsection{EDA}

Este é o último paradigma no projeto de circuitos integrados e é resultado do avanço no processo de fabricação. Isto está permitindo que os projetistas coloquem todos os circuitos necessários para sistemas eletrônicos completos numa única pastilha. Esta capacidade, por sua vez, é resultado do esforço desempenhado pela indústria de automaçãa do projeto de circuitos eletrônicos (EDA) para estabelecer novas metodologias para o projeto de circuitos integrados [17]. Mas nenhuma mudança de paradigma é fácil. Algumas destas mudanças foram colocadas em prática antes de 1998, com várias tomadas de atitudes:

1. A formaçăo do grupo de trabalho Virtual Socket Interface (VSI) Alliance;

2. Novas ferramentas para o projeto integrado de hardware e software;

3. Verificação formal; 
4. Otimização de projeto no nível de transferência por registro (register-transfer level, RTL);

5. Completa integração do projeto físico com a síntese lógica.

As tendên cias das novas ferramentas, padrões e métodos continuam avançar no sentido de que o projeto seja feito com um alto nível de abstração, ou seja, saindo do nível de transistores e portas lógicas no passado, para o nível de transferência por registro hoje em dia, e para o nível de sistema no futuro. A Figura 21 mostra a migração entre estas metodologias de projeto.

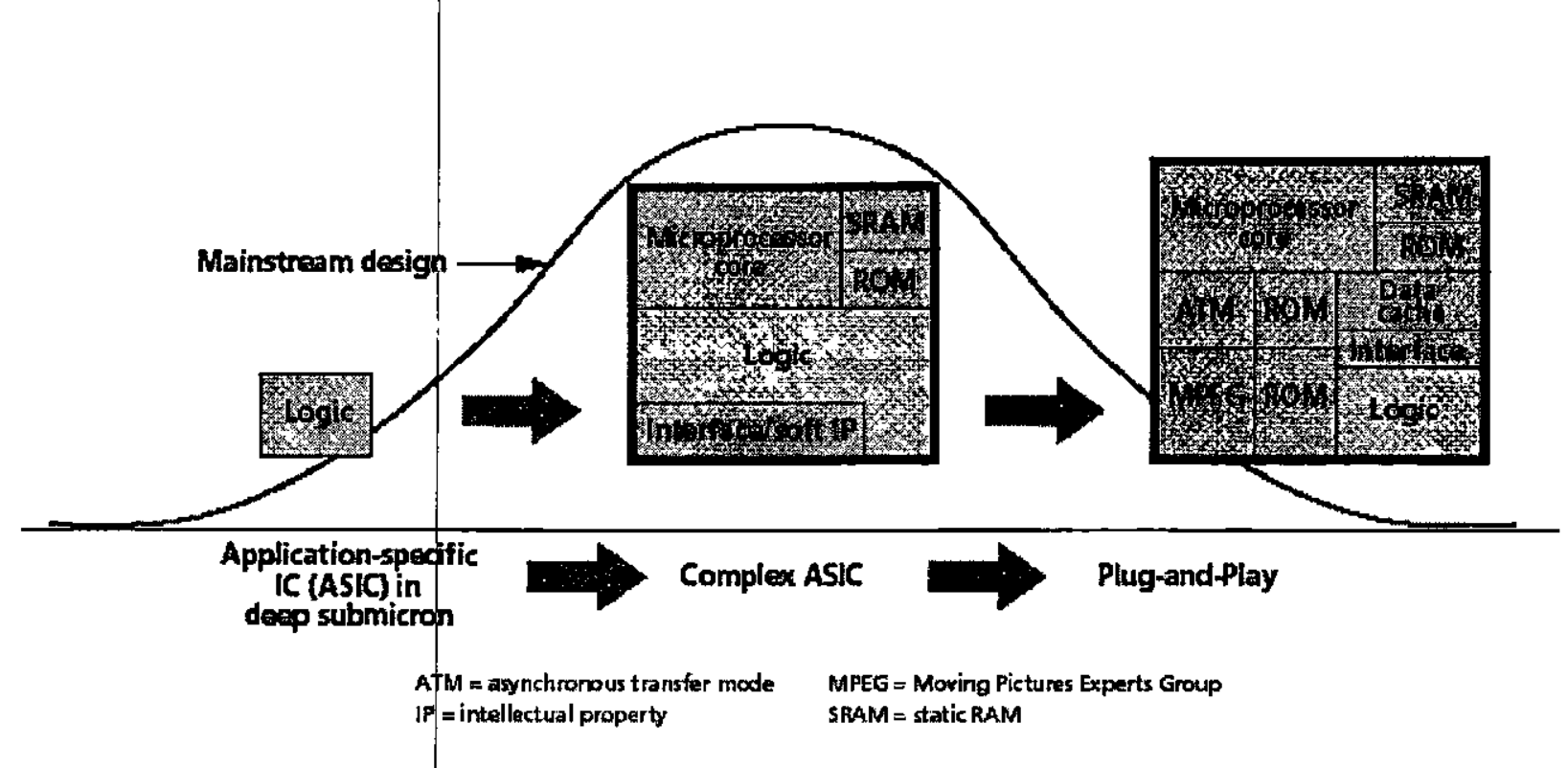

Flgura 21 - Evolução dos métodos de projeto

Este novo método de projeto, mostrado na Figura 22, é a única forma para desenvolver grandes sistemas em uma única pastilha com um ciclo de desenvolvimento curto. O projeto inicia ao nível de sistema através da reutilização de componentes funcional, incluindo processadores programáveis, funções de mistura de sinais, e software. O primeiro passo é identificar e adquirir componentes que executam as funções desejadas e que são comumente chamados de 'intelectual property' (IP). Um verdadeiro sistema numa pastilha terá pouca ou nenhuma lógica separada dos componentes funcionais.

Muitas companhias hoje em dia oferecem ferramentas no nível de sistemas para o projeto de hardware e software simultaneamente. Para a realização deste tipo de projeto, os projetistas passarão por diversos processos: descrição; correção da funcionalidade do sistema independente da arquitetura; divisão do código em hardware e software; síntese do código para obter a 'netlist' no nível de portas lógicas; verificação do hardware/software.

Como o termo indica, o projeto integrado de hardware/software (HW/SW) permite que os engenheiros de software iniciem a integração das funções de software com o hardware que irá suportá-lo sem esperar por um protótipo. No escopo de projeto, 
as interfaces HW/SW ràramente são testadas juntas para verificação de consistência e precisão antes da fase de prototipação. Mas, tem crescido a demanda por ferramentas que façam a ligação entre os dois ambientes de desenvolvimento, de modo que os erros de interface sejam detectados e a funcionalidade dos dois segmentos sejam verificadas ainda nos primeiros ciclos do projeto.

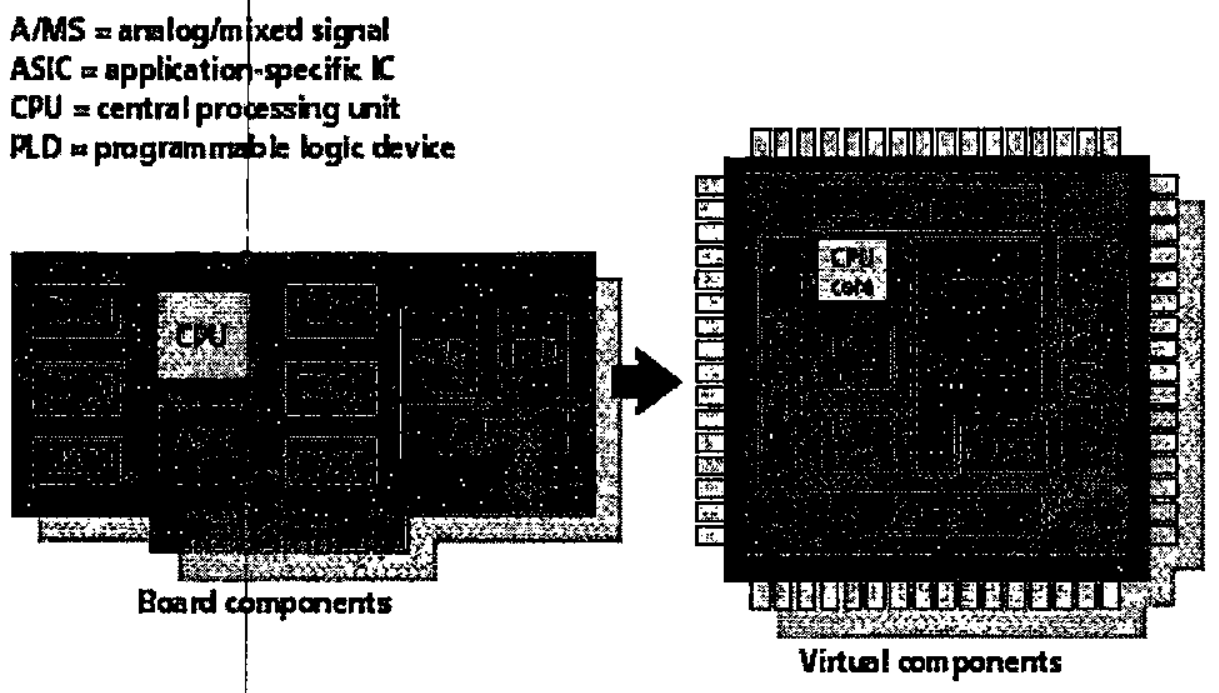

Figura 22 - System on-chip

O projeto de componentes para re-utilização é um pré-requisito para a conclusão com sucesso do desenvolvimento de sistemas numa pastilha (SOC). Estes sistemas dependem fortemente do reuso de blocos funcionais, o que coloca o projetista de frente com dois problemas: onde conseguir estes componentes, e como verificar que eles trabalham juntos da forma desejada.

Para resplver questões de disponibilidade e de verificação, as companhias EDA eståo investindo no mercado de IP. Na primeira metade de 1998, os produtos e ferramentas IP registraram o maior crescimento no faturamento, em porcentagem para as indústrias EDA. Hoje poucas companhias possuem tempo e recurso para projetar todos os componentes necessários para uma dada aplicação. Grupos de projeto freqüentemente reutilizam componentes que já foram posicionados, roteados, e verificados. Estes são chamados de 'hard blocks' ou 'hard $I P^{\prime}$, mas, devido ao fato deles nẩo poderem ser facilmente portados para tecnologia menores $\mathrm{e}$ poucos deles terem a documentação necessária, a maioria não pode ser reutilizada. Projetar blocos para reuso é um passo essencial na era do sistema numa pastilha (SOC).

Embora o 'hard IP' não seja muito flexível, ele é confiável e pode na maioria das vezes proporcionar um desempenho melhor do que os chamados 'soft IP'. 'Soft IP' é fornecido como uma descrição de hardware no nivel de transferência em registros. Inclui um modelo de simulação, plano de teste, scripts de síntese, e possivelmente algumas informações de layout. Geralmente, se o componente 'soft' possui informações de ayout, ele é chamado de 'firm block'. 
Quando o\$ projetistas resolvem usar componentes 'hard', 'firm' ou 'soft', eles já deparam com o problema de suprimento: não existem blocos projetados para reuso. Projetar um bloco para reuso pode ser mais demorado quando ele será usado em apenas um projeto, mas, pode economizar tempo e dinheiro caso contrário. Um componente projetado para reuso necessita ser facilmente incorporado em vários projetos e ser portável para as diversas tecnologias de processo.

Os problemas atuais de reuso de IP, incluindo direito legal de propriedade e formatos padrão, estão sendo resolvido pela Virtual Socket Interface Alliance [35]. Mais de 165 companhias EDA e IP fazem parte da VSI Alliance, que foi formada em 1996. O conselho ASIC da Silicon Integration Initiative (SI2), formado por fabricantes de semicondutores e fundado em 1988, assim como a CAD Framework Initiative Inc, também é uma contribuição para padronização de formatos e práticas. No decorrer destes processos de padronizaçăo, mais ferramentas irão surgir para ajudar os projetistas nos gerenciamento de IP.

Devido ad aumento da densidade de portas e dos 'shrinking feature sizes', grandes projetos sofrem com problemas de temporização e consumo. Para ajudar na solução destes problemas, as ferramentas EDA devem fornecer análise detalhada de temporização, consumo, e confiabilidade em grandes projetos, e não devem levar muito tempo para fazer isto.

Os circuitos desenvolvidos necessitam usar uma combinação de planejamento de projeto de alto-nível, e uma forte consistência entre o layout físico e a síntese lógica. A união da síntese lógica com os niveis de detalhes mais baixos do projeto, como o posicionamento e o roteamento, diminui as iterações do processo, e além do fato de que problemas descobertos nas iterações iniciais tornam-se mais gerenciáveis, e pode se conseguir a temporização desejada de maneira muito mais fácil.

Para sistemas que necessitam de confiabilidade e portabilidade, ou seja, praticamente todos os equipamentos eletrônicos, o consumo é um problema muito sério. Projetar a fonte de alimentação de um circuito integrado usualmente sempre foi razoavelmente fácil. Geralmente os projetistas procuram trabalhar com baixa potência, a menos que a relaçăo custo-benefício entre desempenho, tamanho e consumo se choque com esta meta.

Em adição aos esforços da VSI Alliance, as companhias EDA estão publicando padrões para as novas implementações em IP e blocos reutilizáveis. Mas, 0 efetivo reuso de grandes blocos IP requer metodologias de projeto que garantam a criação de blocos com procedimento previsivel, e que possam ser otimizados para área, velocidade e consumo, além de serem integrados com confiança.

Com as novas metodologias e ferramentas em mãos, grandes avanços estão sendo feitos no projeto de sistema numa pastilha. Em 1998, ferramentas foram desenvolvidas para atender as necessidades de alto nivel de projetos de grande escala, de circuitos mais complexos, assim como aos problemas do nível de submicron, como por exemplo, manipulação da convergência de temporização, 
gerência de consumo, redução de ruído, e integridade do sinal. Agora, estas ferramentas estão avançando na solução dos problemas de baixo nível, e num maior suporte das companhias EDA para ajudar na mudança de paradigma no projeto de circuitos integrados.

Com base nestes conceitos, foram desenvolvidas pesquisas na abordagem SOC. O estudo foi feito no sentido de se colocar dois controladores Ethernet em um único chip, juntamente com toda lógica necessária para suporte da redundância. Com esta solução, o hardware se resumiria a um chip que teria uma interface para uma CPU genérica. $\mathrm{O}$ desenvolvimento deste $\mathrm{Cl}$ seria feito usando a linguagem de descriçăo VHDL, associando conceitos relacionado ao reuso de módulos de hardware através da utilização de interfaces padronizadas [35]. Estes mecanismos permitiriam a re-utilizacão de módulos já implementados, por outras empresas, que executam a funçåo do controlador Ethernet.

Como o desenvolvimento de um controlador Ethernet seria algo bastante complexo, a pesquisa foi feita no sentido de encontrar um núcleo controlador Ethernet disponivel no mercado, para que de posse dele seria então feito o trabalho de duplicação do módulo e criação das interfaces necessárias. Através de pesquisas foram encontrados dois fornecedores do núcleo controlador Ethernet [36], [20].

O núcleo FEM (Controlador de Acesso para Mídias Fast Ethernet) implementa o protocolo MAC Ethernet de acordo com a especificaçăo IEEE 802.3 Fast Ethernet. O MAC tem uma interface independente de mídia (MII) padrão para conexão em qualquer interface PHY. O FEM é satisfatório tanto para operação a $10 \mathrm{Mbits} / \mathrm{s}$ quanto para operações a 100Mbits/s.

O projeto completamente modular do núcleo facilita a utilização em cada tipo de aplicação para agregar valor e adicionar características distintas.

O núcleo é fornecido em código fonte VHDL ou Verilog completamente sintetizada em RTL para Transmissor e Receptor 802.3. O diagrama de blocos de um deles é mostrado na Figura 23. Ele atende recomendação da VSI Alliance versão 1.0 [35] para um Componente Soft Virtual. Isto é alcançado através de uma especificação detalhada e compreensível, um documento com a teoria de operação, uma interface de usuário bem definida e bem modelada, um plano de teste programável, complacente com Ethernet, compilação e scripts de síntese.

\section{Principais características:}

- De acordo com a especificação ISO/IEC 8802.3 de 1996;

- Suporta equipamentos PHY de 10 e 100 Mbits baseados em MII;

- Projeto compacto e modular, ideal para aplicações multiportas, 'switch' e roteadores;

- Suporta operações 'half duplex' e 'full duplex';

- Várias informações estatísticas nos quadros transmitidos e recebidos;

- Retransmissão flexível de quadros ou característica de abortagem;

- Transmissão de quadros pequenos por 'padding'; 
- Opcional transmissãb de quadros grandes e característica de recepção de até 4096 octetos;

- Interface Independente de Mídia (MII) para conexão com a camada PHY;

- Interface para transferência de dados como 'host' simples;

- Barramento de dados da interface 'Host' configurável (8 ou 16 bits);

- VHDL completamente sintetizável em RTL;

- Sintetizado no Synopsys, Mentor Autologic II e Exemplar;

- Scripts de síntese disponibilizados como o núcleo;

- Lógica única de 'clock' completamente síncrona;

- Atende a especificação para Componente Soft Virtual da VSI;

- Disponível um compreensivo plano de testes programável pelo usuário;

- Projeto modular que facilita a adequação ao projeto do usuário.

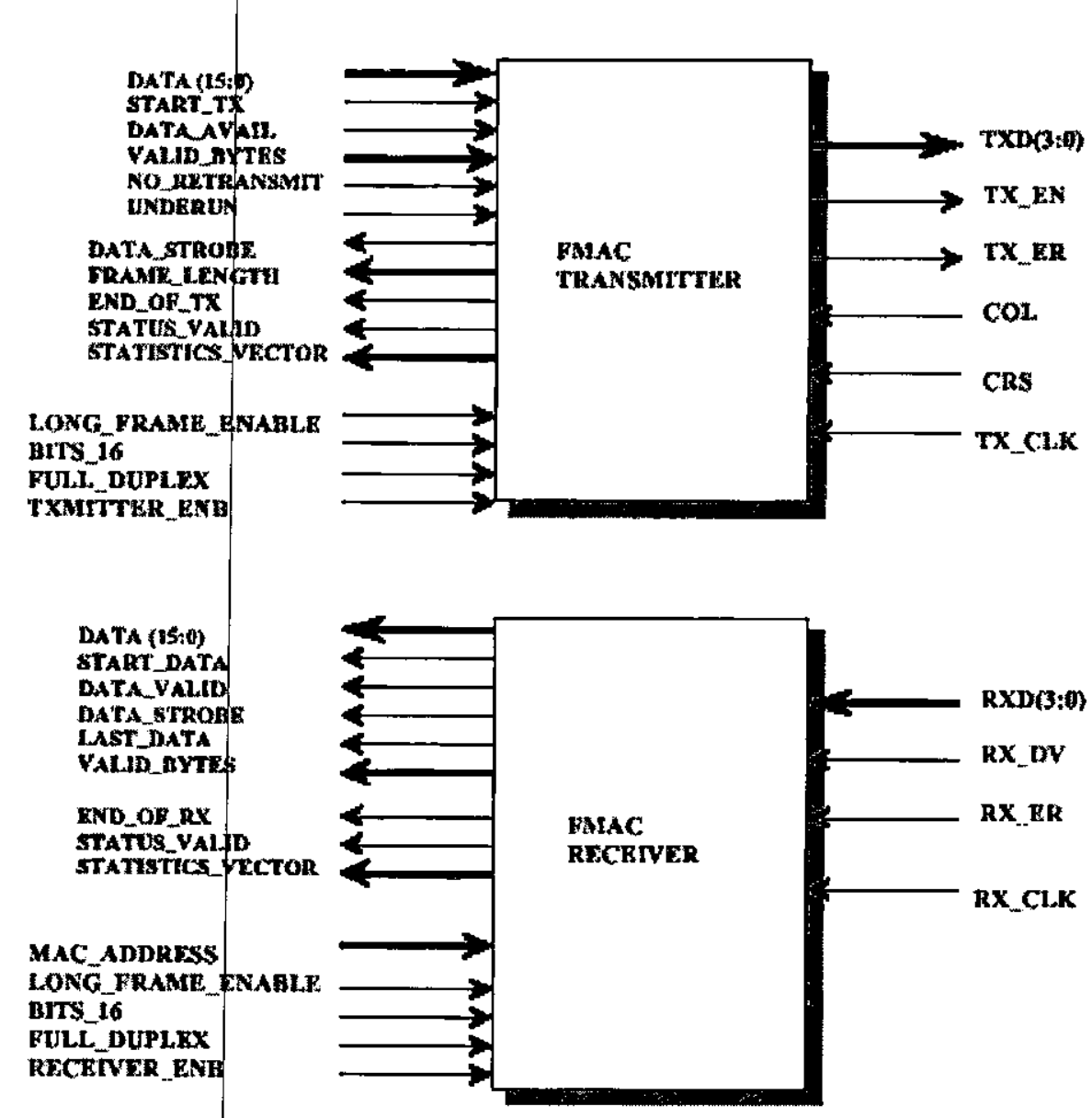

Flgura 23 - Diagrama de Blocos do CS-1100

Esta solução, apesar de se apresentar como uma ótima forma de abordagem para o trabalho, se tornou inviável pelo custo. A licença com acesso ao código fonte é da ordem de U\$100.000,00 (cem mil dólares), enquanto que a licença para uso do netlist é da ordem de $\cup \$ 20.000,00$ (vinte mil dólares). Como este projeto tem sido desenvolvido de forma independente (não financiado por uma empresa ou órgão de pesquisa), năo se dispunha de recursos para aquisição deste módulo, esta solução teve que ser abandonada. 


\subsection{Computação Tradicional}

Por outro lado, a necessidade de flexibilidade de projeto têm aumentado devido a pressões do mercado e constantes mudanças de especificações dos sistemas. Em particular, dois tipos de componentes programáveis têm suportado a carga de manter a flexibilidade e aumentar a integração dos sistemas: os microprocessadores e os dispositivos lógicos programáveis (PLDs).

A solução atual para incluir num produto conexão à rede significa que muitos produtos e fabricantes são necessários:

- Processador;

- Controlador Ethernet;

- Controlador de DMA;

- Controlador de memória;

- Servidor Web;

- RTOS;

- Além de um PLD para lógica adicional.

A abordagem tradicional no projeto de sistemas é a combinação de um microprocessador e outros dispositivos em uma placa, atribuindo-se as funções da placa aos componentes mais adequados para realizá-las. Apesar desta abordagem aparentemente ser a mais natural, ela ignora as vantagens da alta integração em nível de dispositivo. Com a alta integração em nível de dispositivo, a eliminação de atrasos na comunicação dos componentes melhora o desempenho. $O$ consumo de potência também é melhorado. Finalmente, há redução de custos de manufatura associados com os baixos requisitos de testes e inventário.

\subsection{Processadores Dedicados}

Já que os processadores estão presentes em praticamente todos os sistemas, faz sentido combiná-los com outras funções em um único dispositivo. Processadores dedicados (embedded processors), assim como ASICs e produtos padronizados para aplicações específicas (ASSPS) adotam esta abordagem. Entretanto, cada uma dessas alternativas apresenta deficiências como falta de flexibilidade e elevado tempo de projeto, principalmente no caso de ASICs. 
Usando a tecnologia system-on-silicon (system-on-chip), NET+Works se apresenta como uma solução completa (embedded), com todo hardware e software para disponibilizar uma conexão Ethernet/Internet para produtos de diversos tipos de indústria. Esta solução integra processador ARM, controlador Ethernet, controlador de DMA, sistema operacional (RTOS), drivers e servidor Web em um único produto. Através de OEM, permite que o desenvolvimento de produtos seja melhor, mais rápido e a um baixo custo.

NET+Works é uma solução alternativa (à tradicional) que já está disponivel no mercado. Esta solução já é um grande avanço em termos de complexidade, custo e escalabilidade. Todo o hardware e software necessário já vem integrado em um único produto de baixo custo.

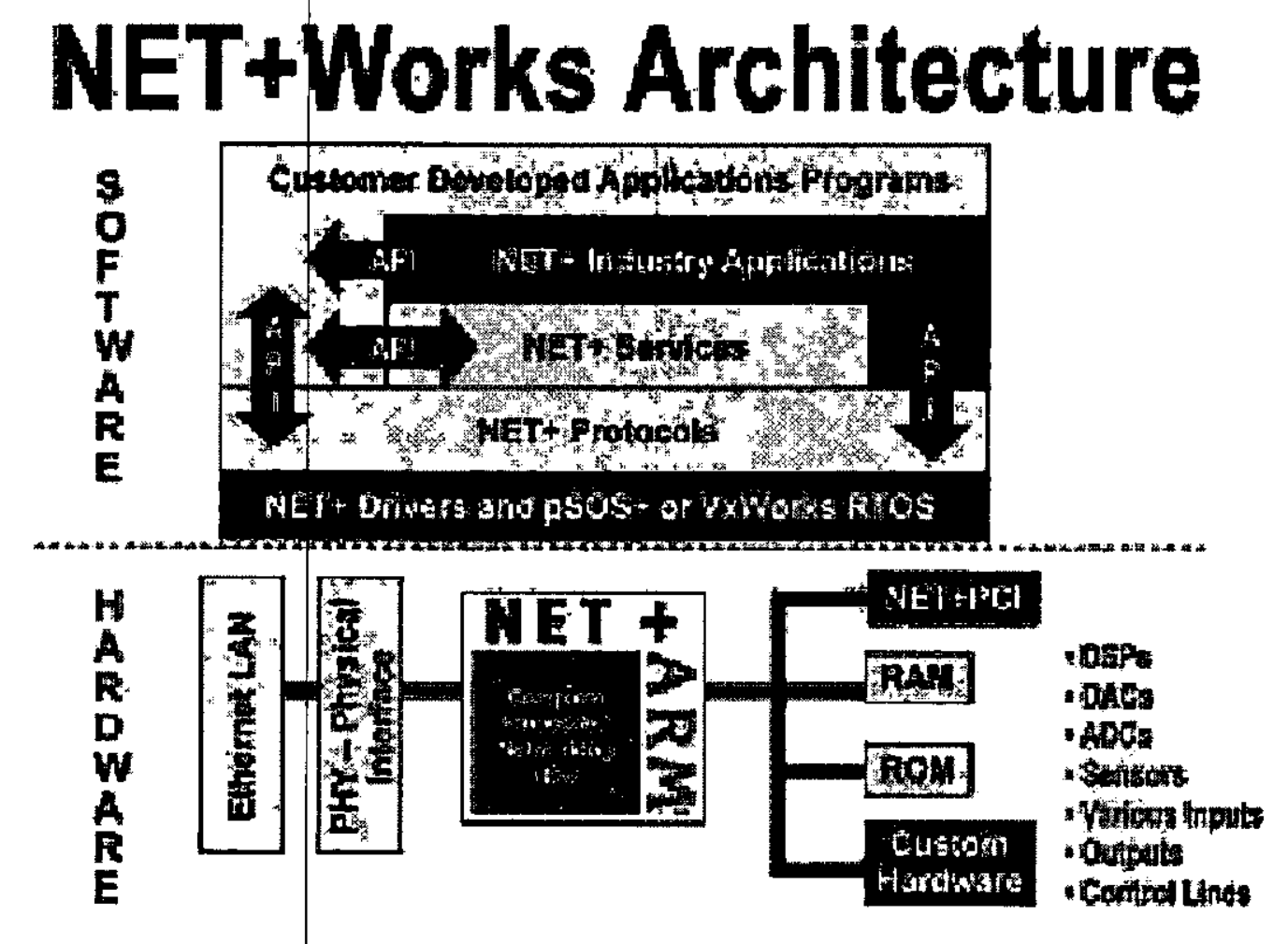

Figura 24 - NET+Works Architecture Overvlew

Este produto torna a Internet TCP e a conectividade Ethernet fácil de se implementar e num baixo custo. A arquitetura NET+Works, mostrada na Figura 24, disponibiliza não apenas o hardware necessário para a conexão, mas também todo 0 software, incluindo RTOS, drivers e aplicações de rede.

O coração deste produto (NET+Works) é o ASIC personalizado baseado no processador ARM, chamado de NET+ARM, o qual é a base para a plataforma de hardware.

Este pacote inclui:

O NET+Works se completa com o pacote de software chamado NET+OS. 
- API (Application Programming Interfaces) para todas as funções;

- NET+Services, incluindo: Web Server (HTTP), Internet mail (POP3 e SMTP), transferência de dados (FTP), gerenciamento (SNMP e HTTP) e instalação (Bootp, DHCP e Telnet).

- NET+Protocols: TCP, UDP, RARP, ICMP, PPP, IGMP.

- RTOS: pSOS+, VxWorks ou ThreadX

- NET+Drivers com codigo fonte.

Esta família é então uma solução completa para conectividade Ethernet, e quando acoplado com PHY e memórias, contém todo hardware e software necessário para adicionar Ethernet/Internet a maioria dos projetos de produtos eletrônicos. Esta solução permite uma grande economia no tempo de projeto.

Novas tecnologias de microprocessadores que oferecem arquiteturas e/ou conjunto de instruções reconfiguráveis estão sendo pesquisadas e desenvolvidas. Apesar de ambiciosas em seus objetivos de prover operação otimizada para uma variedade de aplicações, estas abordagens são problemáticas em vários pontos. Mudando-se a arquitetura do microprocessador significa que o código de boot deve mudar também. A maioria dos sistemas conta com um código de boot fixo para recuperação de falhas ou instabilidade. Introduzindo um código de boot mutável pode resultar em um sistema que não pode se recuperar de falhas durante a operação. No caso de um conjunto de instruçóes customizadas, o uso de tal processador irá depender de ferramentas de desenvolvimento proprietárias, eliminando a portabilidade do código, tornando sua arquitetura dependente do processador e limitando as opções de desenvolvimento. Finalmente, a introdução de arquiteturas e/ou conjunto de instruções reconfiguráveis adiciona muitas camadas de complexidade ao processo de verificação de tais sistemas.

\subsection{PLD com processadores embutidos}

Devido as limitações das outras alternativas, o próximo passo na evolução da integração de sistemas deve ser a combinação de processadores dedicados e lógica programável [61]. Além de oferecer todas as vantagens da alta integração, as soluções baseadas em PLDs com processadores embutidos também provêem vantagens únicas para o projetista de sistemas devido a extrema flexibilidade da lógica programável. Esta flexibilidade permite que o projetista não somente desenvolva um produto num tempo mais curto, mas também explore diferentes opções de particionamento para entregar a melhor combinação (software/hardware) no produto desenvolvido. 
PLDs com processadores embutidos oferecem ao projetista de sistemas uma liberdade sem precedentes para determinar quais funçōes devem ser executadas em software e quais devem se beneficiar de implementaçōes em hardware dedicado na forma de periféricos ou elementos de co-processamento. A Tabela 5 compara as capacidades de PLDs integrados com processadores embutidos com outras soluções em nivel de componentes para a integração de sistemas.

\begin{tabular}{|c|c|c|c|c|}
\hline & & ASICs & $\mathbf{A S S P}_{\mathbf{3}}$ & PLDs com Processadores Embutidos \\
\hline Ny'ilde Integracto & $\mathrm{P}^{\text {3. }}$ & Alto & Moderado & 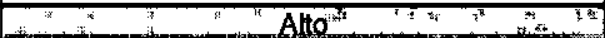 \\
\hline Custo de Desenvolvimento & & Alto & Baixo & Baixo \\
\hline Ciñoñ & 8 & Baró. & Baxa: & Moderado? \\
\hline 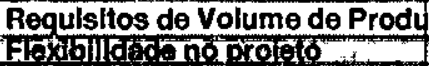 & căo & Alto & $\begin{array}{l}\text { Baixo } \\
\text { Baixa. }\end{array}$ & Baixo \\
\hline Tempo de Desenvolvimento (Tit & ne to market) & Longo & Moderado & Curto \\
\hline
\end{tabular}

Tabela 5 - Comparação de soluçóes para desenvolvimento de hardware

Um dos maiores desafios em oferecer PLDs com processadores embutidos é a extraordinária gama de aplicações potenciais. Por um lado, há sistemas que requerem menos que 10 MIPS; em outro extremo há sistemas que demandam centenas de MIPS, cada um necessitando diferentes graus de flexibilidade. A linha Excalibur da Altera é uma solução que cobre este intervalo de necessidades provendo tanto a capacidade de configuração dos dispositivos lógicos programáveis e o desempenho e facilidade de uso dos processadores embutidos [62]. A linha Excalibur da Altera oferece cores de processadores RISC otimizados especialmente para lógica programável [37]. Possuindo tanto soft cores como hard cores, esta linha é capaz de atender os requisitos de flexibilidade e desempenho de uma grande variedade de aplicações. Esta soluçăo é suportada por um completo conjunto de ferramentas de desenvolvimento que automatizam o processo, incorporando metodologias familiares para projeto de hardware e software (código em $\mathrm{C} / \mathrm{C}++$ ).

\subsubsection{Soft Core NIOS}

O processador embutido NIOS ${ }^{\mathrm{TM}}$ é um soft core de um processador RISC configurável com um conjunto de instruçōes de 16 bits e um datapath selecionável de 32 ou 16 bits. Tendo sido desenvolvido especificamente para lógica programável, 0 NIOS é otimizado para ocupar uma reduzida área do PLD e pode prover até 50 MIPS de desempenho. Inicialmente sendo destinado para a família de dispositivos APEX da Altera, este processador ocupa apenas $12 \%$ da área de um dispositivo de 200 mil portas (EP20K200E). A família APEX já possui dispositivos com 1,5 milhão de portas, significando que há uma infinidade de recursos disponíveis para o restante do sistema. Vários periféricos já estão disponiveis e em desenvolvimento para o NIOS, como timers, contadores, UART, PIO, controladores de disco, 10/100 Ethernet MAC e controladores de acesso a SDRAM. 
As possibilidades para o processador embutido NIOS são bem amplas; por exemplo, sistemas DSPs podem ser desenvolvidos com a adição de itens como filtros FIR, osciladores e FFT. A eficiência de uso do dispositivo possibilita também que múltiplas instâncias do processador possam ser usadas para aplicações de alto desempenho que requerem implementações com múltiplos processadores, como mostra a Figura 25.

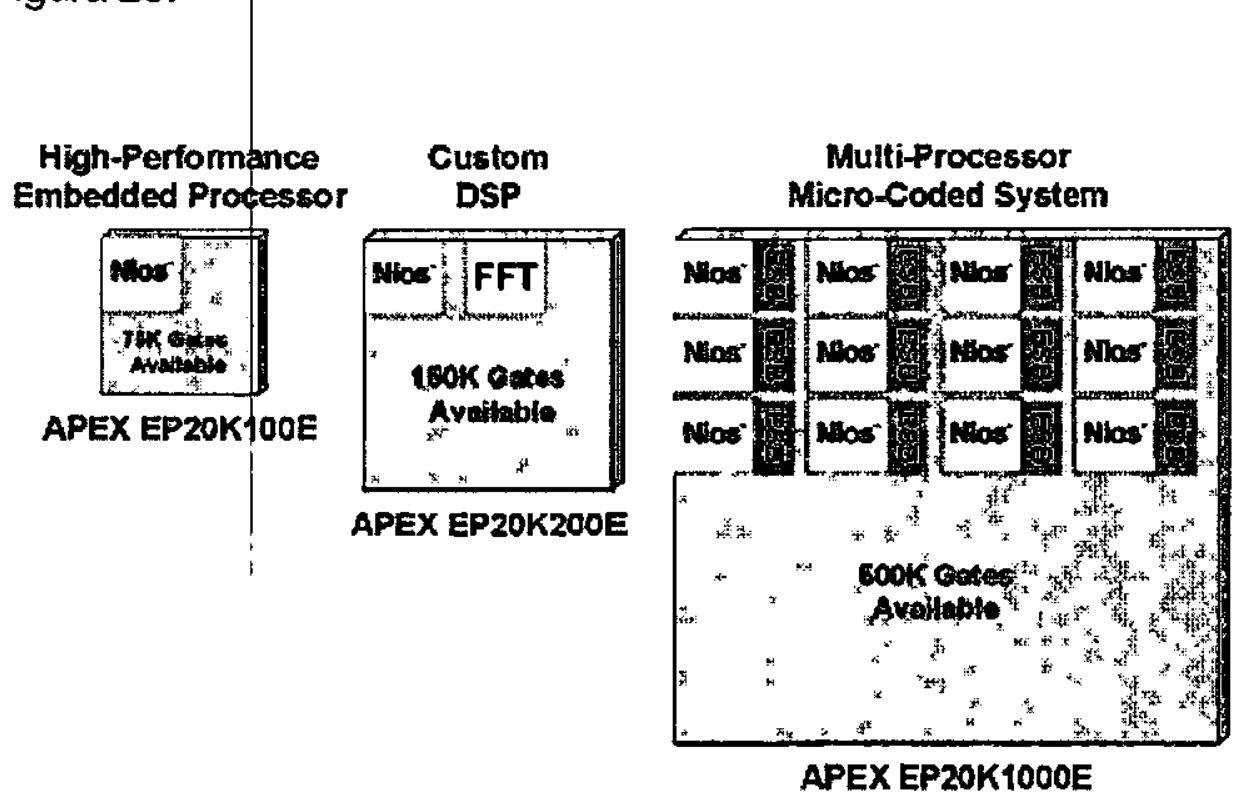

Figura 25 - Flexibilidade e escalabllidade dos processadores embutidos NIOS.

O proces\$ador NIOS pode ser parametrizado, permitindo que o usuário faça o balanço entre custo e desempenho, sem a necessidade de ser um especialista em projeto de processadores. Apesar da configuração, o conjunto de instruções permanece o mesmo, possibilitando o uso de ferramentas de desenvolvimento de software padrões de mercado como compiladores $\mathrm{C} / \mathrm{C}++$.

\subsubsection{Hard Cores ARM e MIPS}

As soluçôes Excalibur da Altera com hard core são baseadas nos processadores da ARM Limited e MIPS Technologies. A implementação desses processadores em hard cores foi otimizada para a integração com a arquitetura APEX da Altera, resultando em processadores que podem atingir centenas de MIPS de desempenho e mantendo a compatibilidade com as ferramentas de desenvolvimento já existentes para estes processadores. A figura 5 apresenta um diagrama de blocos de um dispositivo com um hard core de processador embutido. Além do hard core do processador, estes dispositivos também incluem implementações otimizadas de RAM on-chip, cache, UART e barramento para interface externa. Estes dispositivos oferecem desempenho, capacidade de memória e densidade de portas comparável aos ASICs. 


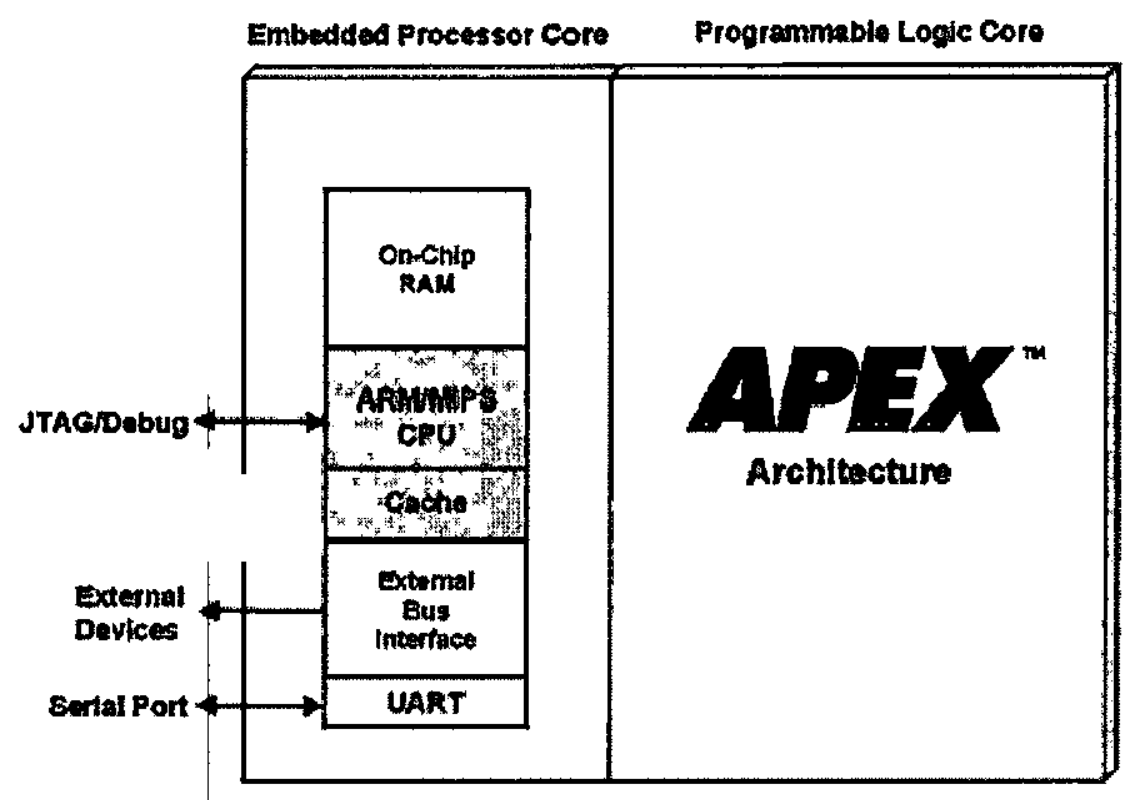

Figura 26 - Dlagrama em blocos do hard core Excalibur ARM/MIPS

No futuro, a Altera pretende adicionar outros módulos funcionais opcionalmente de acordo com o interesse do usuário, como por exemplo 10/100 Ethernet MAC, ATM Processor, SDRAM controller, IIC Master/Slave, USB Controller, etc. Isto tornará mais acessivel o custo da Propriedade Intelectual (IP), uma vez que a Altera amortizará o custo na venda dos componentes.

Apesar desta solução ter muitos aspectos positivos ela foi abandonada, uma vez que a linha Excalibur com o processador ARM ainda não estava disponivel para comercialização no momento das definições do rumo do trabalho e o interesse era trabalhar com um processador mais genérico para dar mais liberdade na escolha do sistema operacional e do ambiente de desenvolvimento.

\subsection{Considerações Finais}

Considerando todos estes fatores optou-se por desenvolver o trabalho baseado na arquitetura NET+Works, usando o módulo processador NET+40 (Figura 27), uma vez que seu hardware é baseado num processador ARM, cuja arquitetura está sendo muito utilizada nos dias atuais para projeto de equipamentos embutidos. Os detalhes dos componentes desta arquitetura serão comentados no Capítulo 6. 


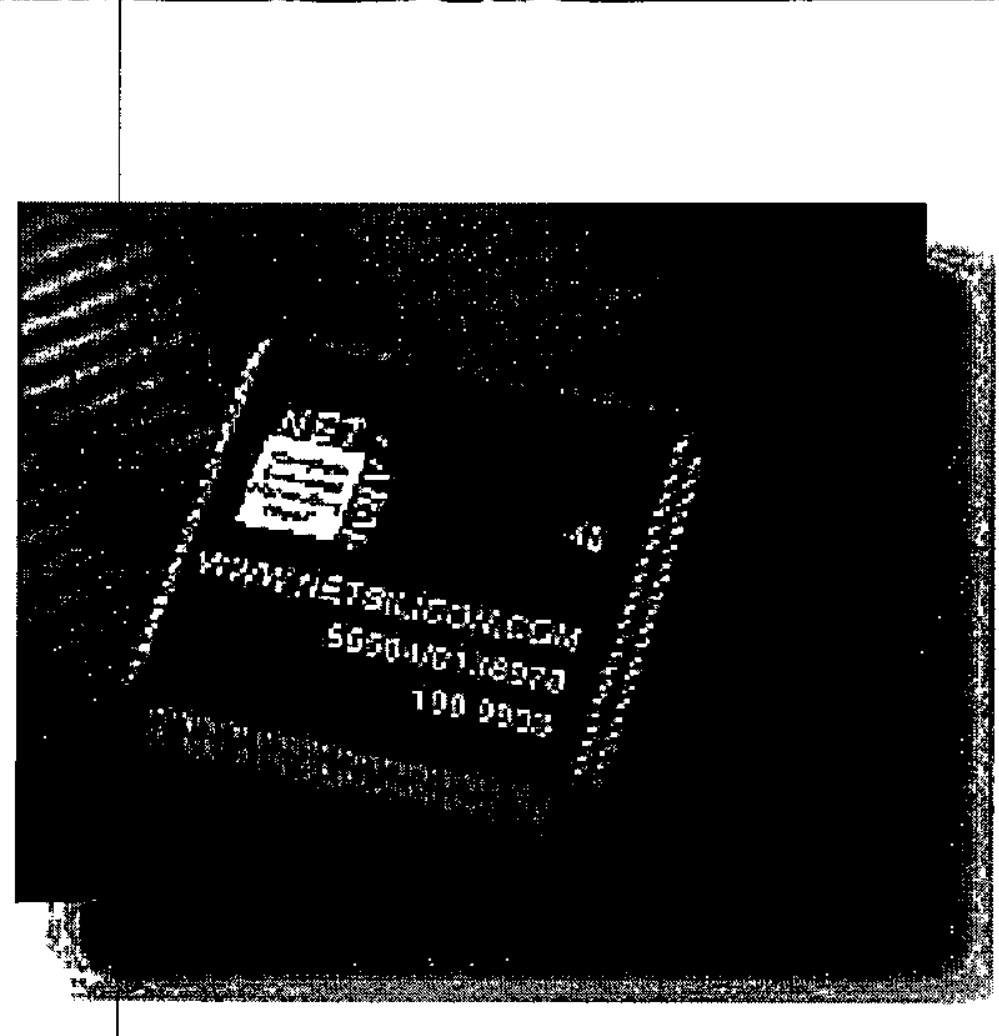

Figura 27 - Módulo processador NET+40

Apesar das limitações em trabalhar com uma arquitetura que é dependente do processador, necessidade de ferramentas proprietárias e a dependência do fabricante do chip, esta família trabalha com ferramentas de desenvolvimento e sistemas operacionais consagrados no mercado de desenvolvimento de equipamentos embutidos. O sistema operacional usado será o Thread X (Express Logic, Inc.) e o ambiente será o Multi2000 (Green Hills Software, Inc.). 


\section{COMPONENTES do SISTEMA}

Após todos estas pesquisas e estudos, criou-se a base necessária para a escolha dos principais componentes do sistema. Aqui será feita uma descrição detalhada destes componentes para que a filosofia do trabalho fique bem clara. Os outros componentes serão definidos após a escolha da arquitetura. A escolha da arquitetura será feita no Capítulo 7.

\subsection{NET+ARM}

O produto NET+ARM provê todo o hardware necessário para a conexão em rede, exceto a interface física para a Ethernet e as memórias (RAM e ROM). Por outro lado já vem com portas seriais e paralelas, uma memória compartilhada ENI (embedded networking interface) e um barramento $/ / O$ de propósito geral para conexão em hardware de controle. A Figura 28 mostra a arquitetura deste componente numa aplicação genérica.

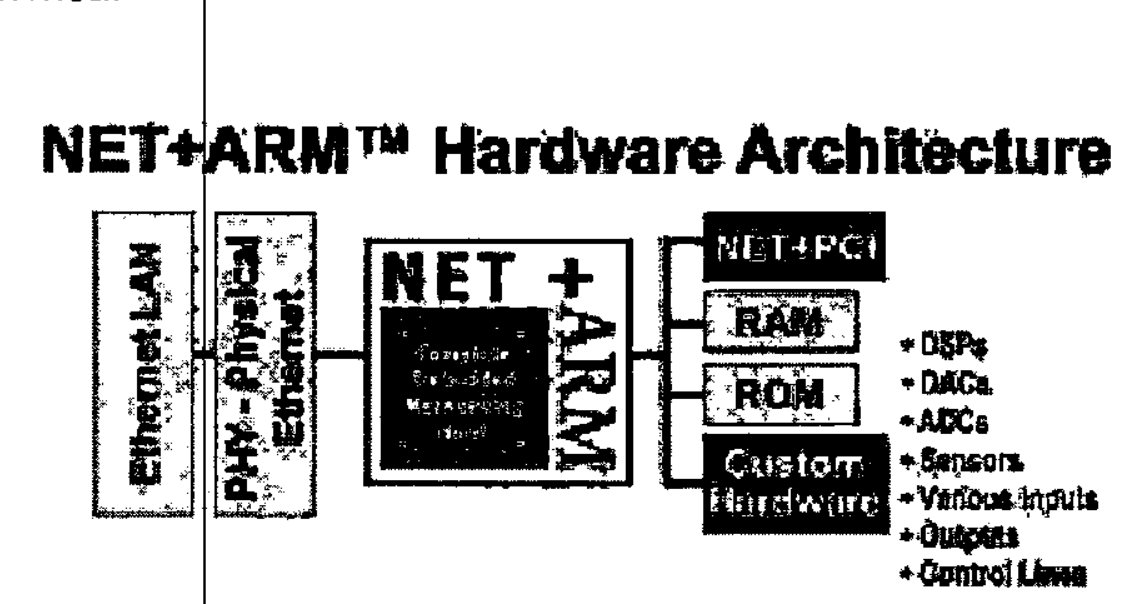

Figura 28 - NET+ARM Hardware Architecture

Os benefícios do NET+ARM incluem seu alto desempenho, escalabilidade, compatibilidade de pino e função (dentro da família), compatibilidade de software, e baixa complexidade para o projeto e desenvolvimento de produtos. Isto simplifica a migração uma vez que diminui o tempo de desenvolvimento. 
É importahte notar que a maior parte da capacidade do processador fica disponivel para a aplicação do usuário. A maiorias dos OEMs não irão precisar de uma CPU separada, uma vez que o NET+ARM tem uma capacidade substancial disponível. Para uma aplicação que exige muito recurso computacional, outra CPU poderá ser necessária. O NET+ARM trabalha bem como um processador 'front-end $1 / O^{\prime}$ conectado a uma CPU de aplicação pelo barramento da ENI. Para interface com hardware específico, o chip disponibiliza uma estrutura de barramento de propósito geral para a conexão com quaisquer periféricos necessários para a aplicação. Ele funciona tanto como mestre como escravo do barramento, enquanto que os canais de DMA podem ser usados para transferência de dados em alta velocidade, sem sobrecarga do processador.

Esta arquitetura foi desenvolvida para otimizar o desempenho na rede, reduzir o consumo, reduzir 'footprint' de RAM/ROM para que o custo torne viável para aplicações embutidas. Estes são os principais componentes do chip NET+ARM:

- Processador RISC 32-Bit ARM7TDM!

- Completo MAC Ethernet 10/100 (suporta 10BaseT e 100BaseT)

- Cache integrado de 8K

- Controlador de Memória

- Suporte para a tecnologia DRAM síncrona

- Controlador de DMA com 10 canais

- 2 portas Serial/SCC

- Porta paralela 1284

- Suporte HDLC comunicação síncrona

- Suporte SPI para IEEE 1451.2

- Controlador de barramento

- Gerador de clock e timers

- 24 pinos programáveis de $1 / O$

- 4 pinos com interrupção programada

O núcleo deste chip é o processador ARM 7, o qual foi escolhido por seu auto desempenho e baixo consumo. Além disto, o ARM 7 oferece ganhos significantes no armazenamento de programa sobre a maioria dos processadores, tanto RISC (reduced instruction set computer) quanto CISC (complex instruction set computer). Através da integração do MAC Ethernet 10/100 no processador NET+ARM, junto com - DMA, controlador de memória e temporizadores, possibilitaram a criação do componente de baixo custo.

A tecnologia do RISC ARM 32-bit possui um equilíbrio ótimo entre alto desempenho, baixo custo, pequeno tamanho, e consumo eficiente. A mais significante vantagem arquitetural dos produtos ARM é sua MIPS por Watt, que é a menor do mercado. Através de um baixo custo por MIPS de processamento, os processadores ARM podem oferecer produtos com os preços mais competitivos de sua classe, possibilitando uma explosão virtual dos novos produtos de consumo. 
Dada a grande vantagem em termos de integração, foi feita uma análise de custo e desempenho com um processador conhecido e usado em aplicações semeihantes. O resultado é mostrado na Tabela 6:

\begin{tabular}{|l|c|c|}
\hline & NET+40 & 1960 \\
\hline Desempenho & $31 \mathrm{MIPS}$ & $18 \mathrm{MIPS}$ \\
\hline Custo & $\mathrm{U} \$ 25,00$ & $\mathrm{U} \$ 40,00$ \\
\hline
\end{tabular}

Um dos maiores resultados desta arquitetura tem sido a extensão para a arquitetura Thumb. Esta extensão emprega uma técnica simples que disponibiliza um reduzido conjunto de instruções tanto com o núcleo Thumb quanto com o ARM7TDI. Isto permite que o projetista de sistemas de 16-bit e 32-bit tenha acesso a toda performance do chip ARM 32-bit ao custo de um sistema de 16-bit. Operações a 100 megabit requerem RAM de 32-bit, porque a configuração de RAM de 16-bi não possui largura de banda suficiente. A Figura 29 mostra um diagrama de blocos dos módulos componentes do chip NET+ARM, mais especificamente o NET+40 que estará sendo usado.

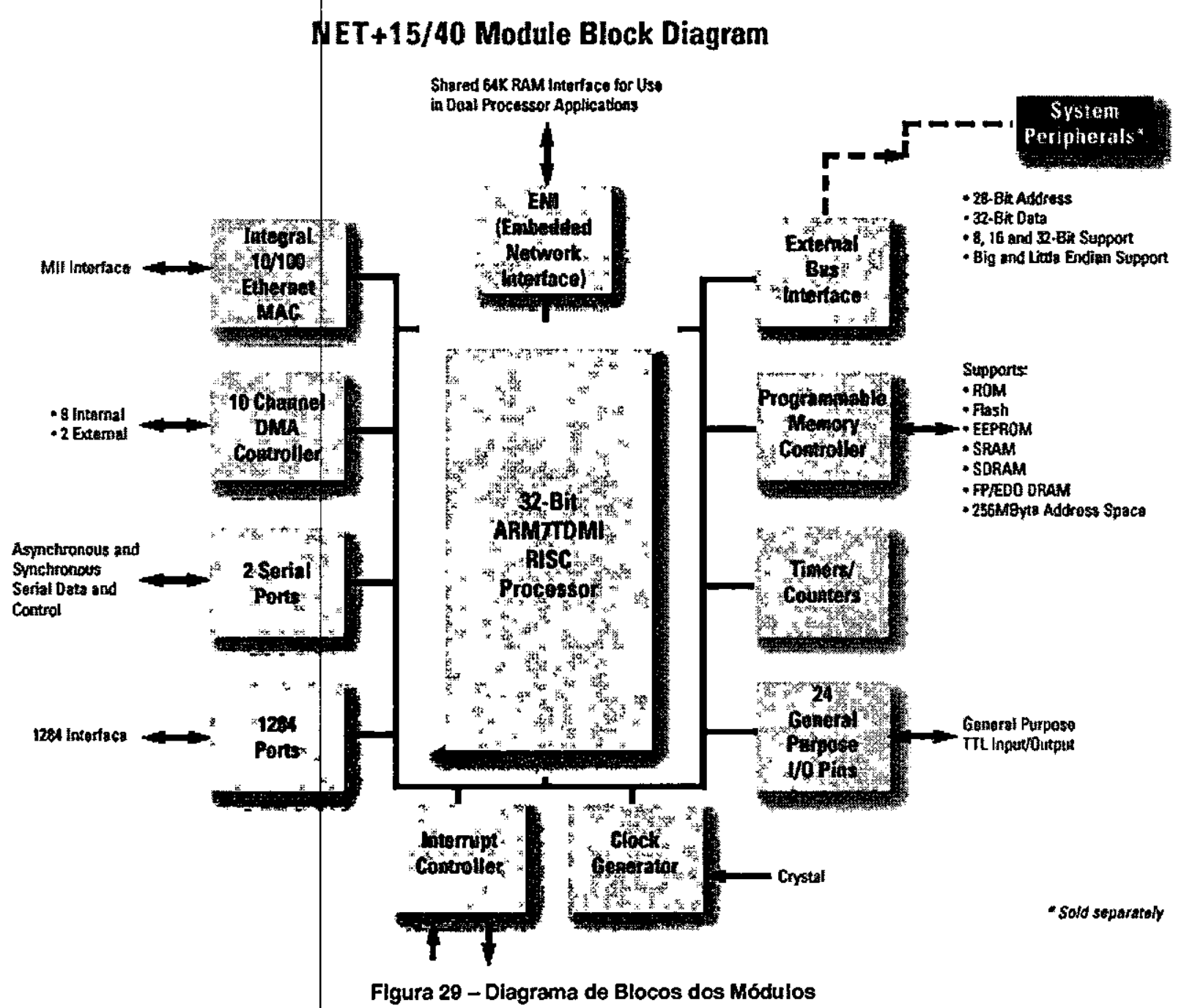


$O$ chip NET+ARM pode ser usado em qualquer produto que requisite serviços de uma LAN Ethernet. Este chip pode interfacear com outro processador usando o padrão IEEE 1284, usando registradores ou usando a interface para RAM compartilhada. Ele ainda disponibiliza todas as ferramentas indispensáveis para qualquer aplicação de rede.

A Figura 30 mostra um hardware típico usado numa aplicação de rede, onde a aplicação especifica do produto usa o processador RISC interno ao chip NET+ARM.

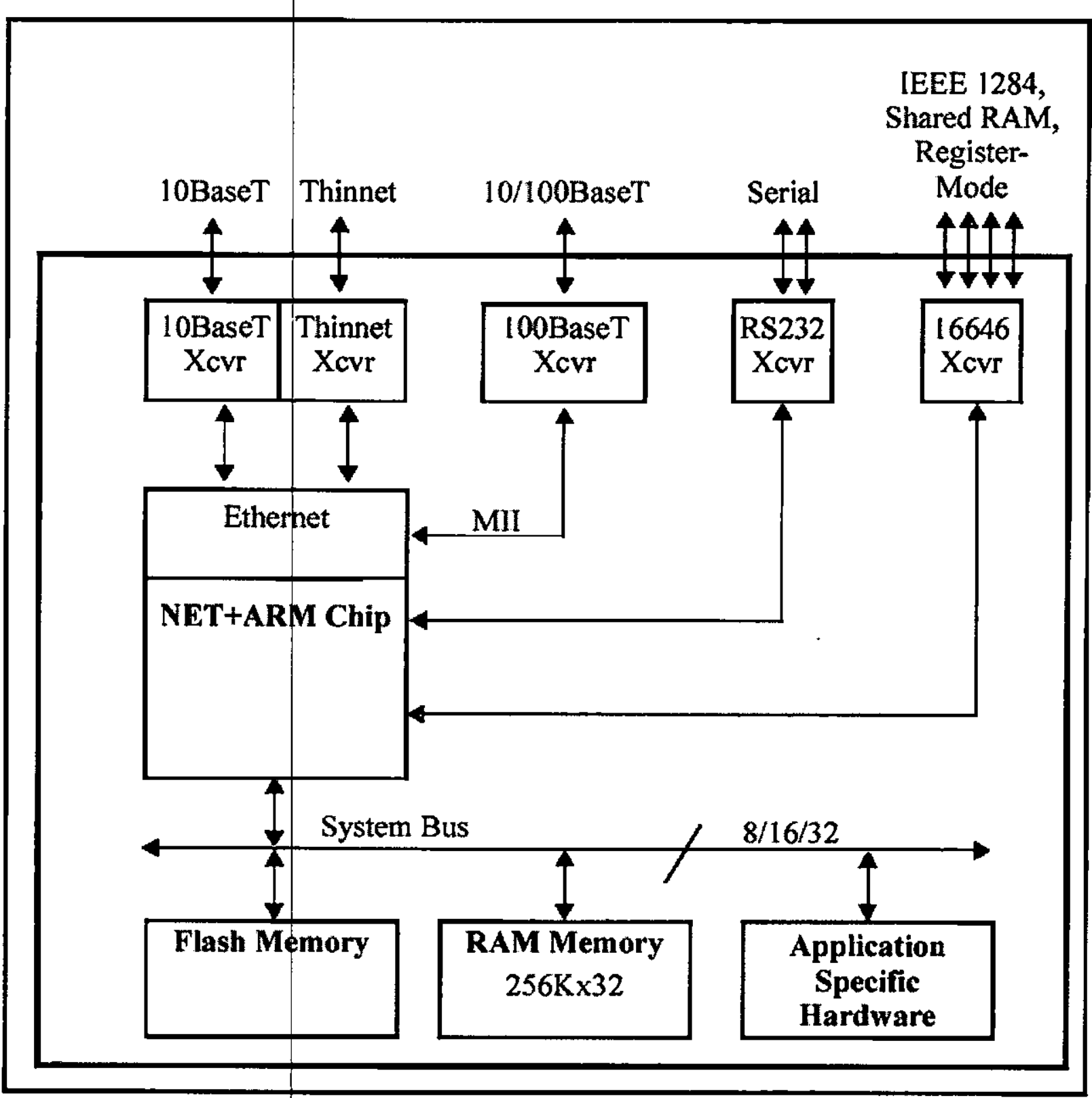

Figura 30 - NET+ARM Chlp Hardware Block Diagram 
A Figura 31 mostra a especificação dos pinos para o chip NET+ARM. Este é um dos pontos importantes deste produto, uma vez que a linha abrange uma grande faixa de topologias com diferentes valores de tensão, mas mantém a interface de software e a pinagem do chip. Isto permite mudar entre os diversos chips da família dentro de um mesmo projeto, sem alteração de hardware e software.

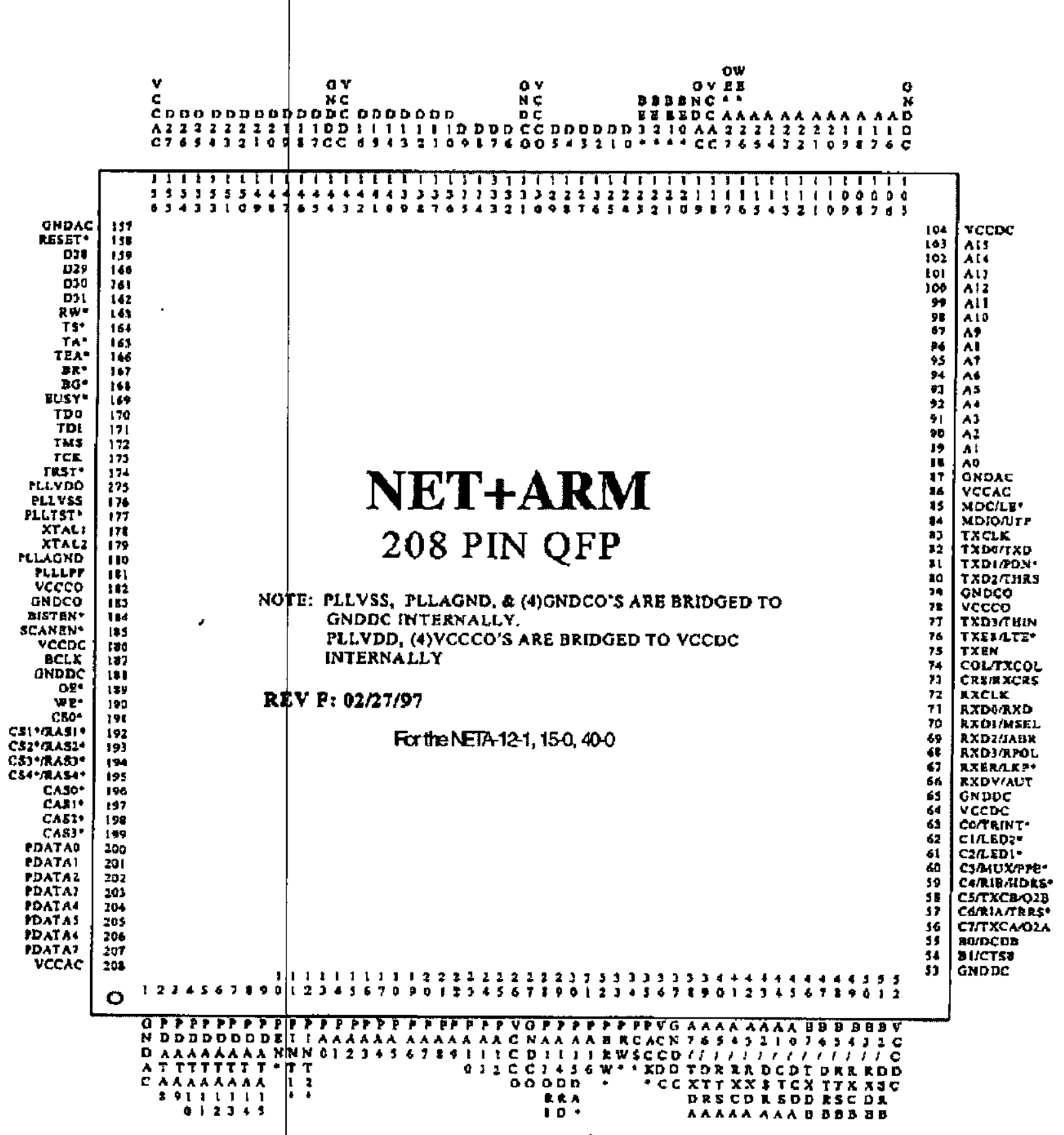

Figura 31 - NET+ARM Chip Pinout 


\section{2. $\mathrm{NET}+\mathrm{OS}$}

Enquanto o projeto de hardware produz uma solução de baixo custo, é o $\mathrm{NET}+$ Works software que representa o mais importante papel no projeto de sistemas embutidos OEM. O NET+Works se completa com o software representado na Figura 32:

\section{NET+Works Software Architecture}

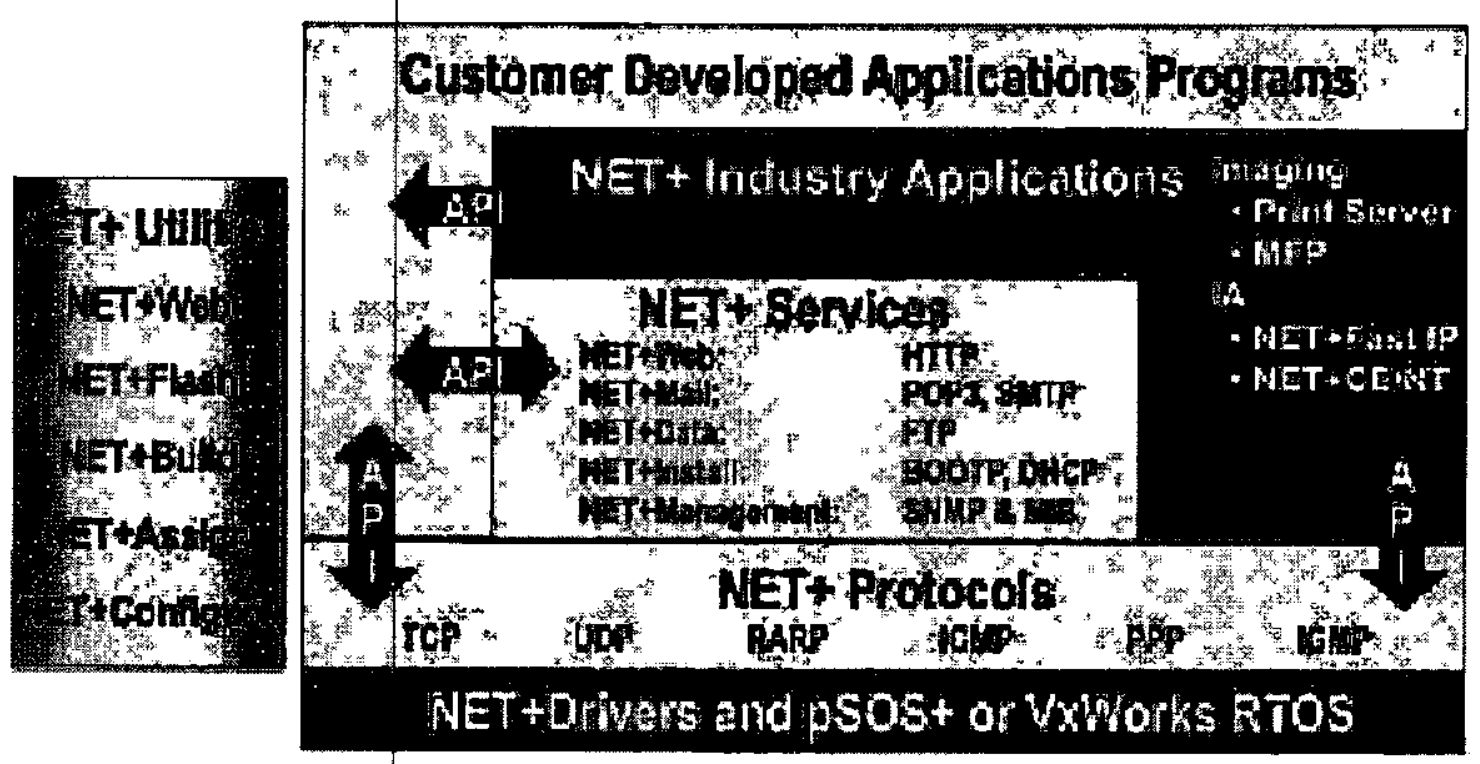

Figura 32 - NET+Works Sottware

Este pacote inclui:

- API (Application Programming Interfaces) para todas as funções;

- NET+Services, incluindo: Web Server (HTTP), Internet mail (POP3 e SMTP), transferência de dados (FTP), gerenciamento (SNMP e HTTP) e instalação (Bootp, DHCP e Telnet).

- NET+Protocols: TCP, UDP, RARP, ICMP, PPP, IGMP

- RTOS: pSOS+, VxWorks ou ThreadX e NET+Drivers com código fonte.

A Figura 33 mostra uma visão mais detalhada do NET+Works Software. Cada nivel do software, começando dos drivers e passando pelas aplicações de rede, tem sido aprovado no campo e otimizado para ambientes embutidos. Para tornar o uso do software mais direto, um conjunto de APIs foram desenvolvidas, as quais, permite 0 acesso necessário às várias funcionalidades do software. 


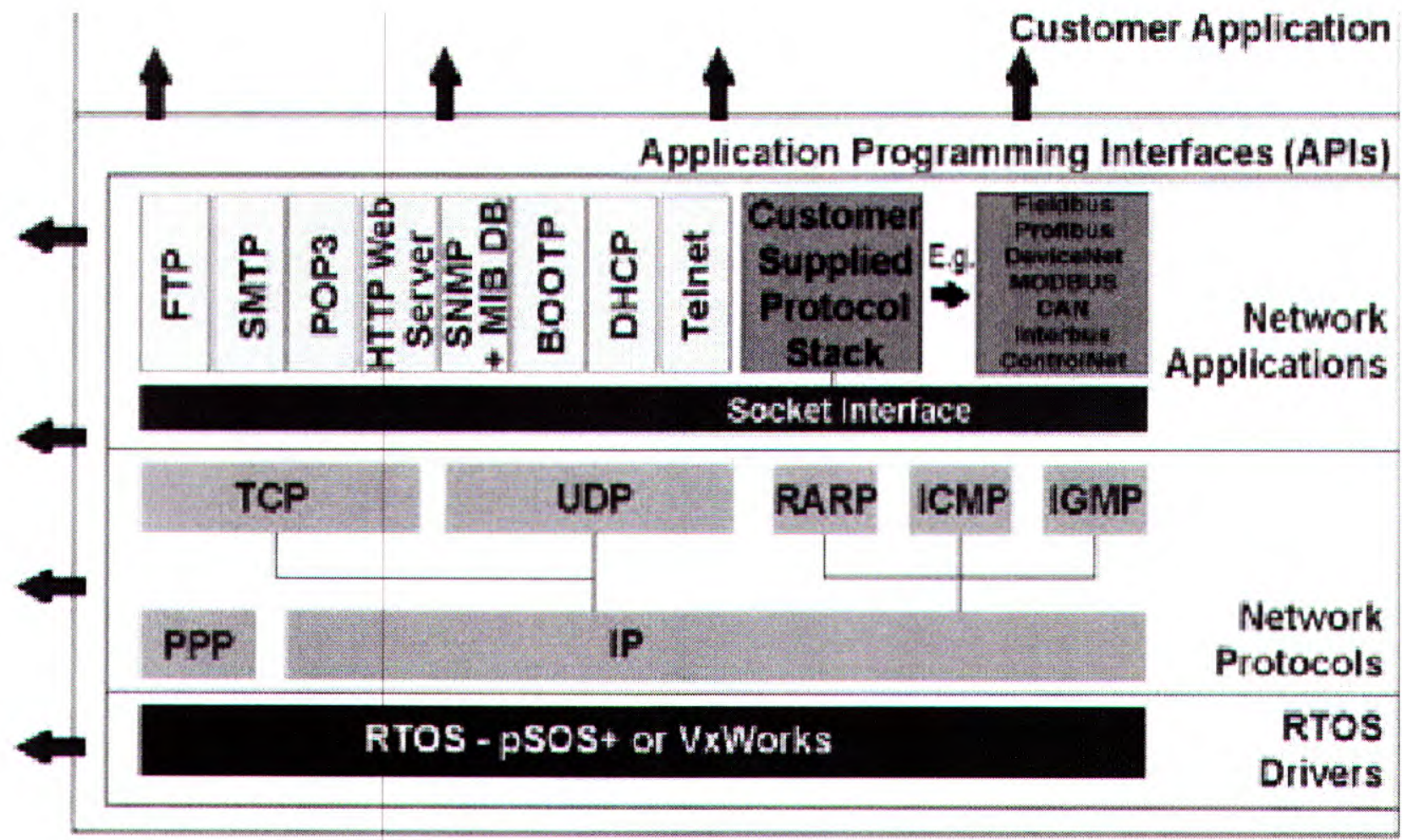

Figura 33 - NET+Works Software em Camadas

O conjunto de APIs atende a todas as funções requeridas pelos programas de aplicação. O uso destas APIs acelera o desenvolvimento da aplicação e permite que os esforços sejam direcionados para as funcionalidades da aplicação.

A seguir temos alguns exemplos do poder e do escopo das APIs que estarão sendo usadas:

- HTTP: permite ao equipamento apresentar sua própria página HTML. Estas páginas podem ser usadas para controlar, monitorar, corrigir, ou mesmo para fazer propaganda do produto. Permite que sejam usadas as interfaces gráficas dos navegadores.

- FTP: permite a criação de arquivos ou a concatenação de dados num arquivo. Pode-se enviar ou receber dados com a transferência sendo iniciada no equipamento ou em outro computador.

- Mail: através de um endereço e uma mensagem, esta API encaminha a mensagem para a caixa postal apropriada. 


\subsection{MAX 3000A}

Os dispositivos da família MAX $3000 \mathrm{~A}$ são baseados na arquitetura MAX da Altera e combinam o baixo custo com o alto desempenho [34]. Esta arquitetura é baseada numa conexão de alto desempenho entre os blocos de arranjos lógicos (logic array blocks - LABs). Estes LABs consistem de 16 arranjos de macrocélulas, unidas por uma estrutrua contínua de roteamento, chamada de arranjo de interconexão programável (programmable interconnect array - PIA).

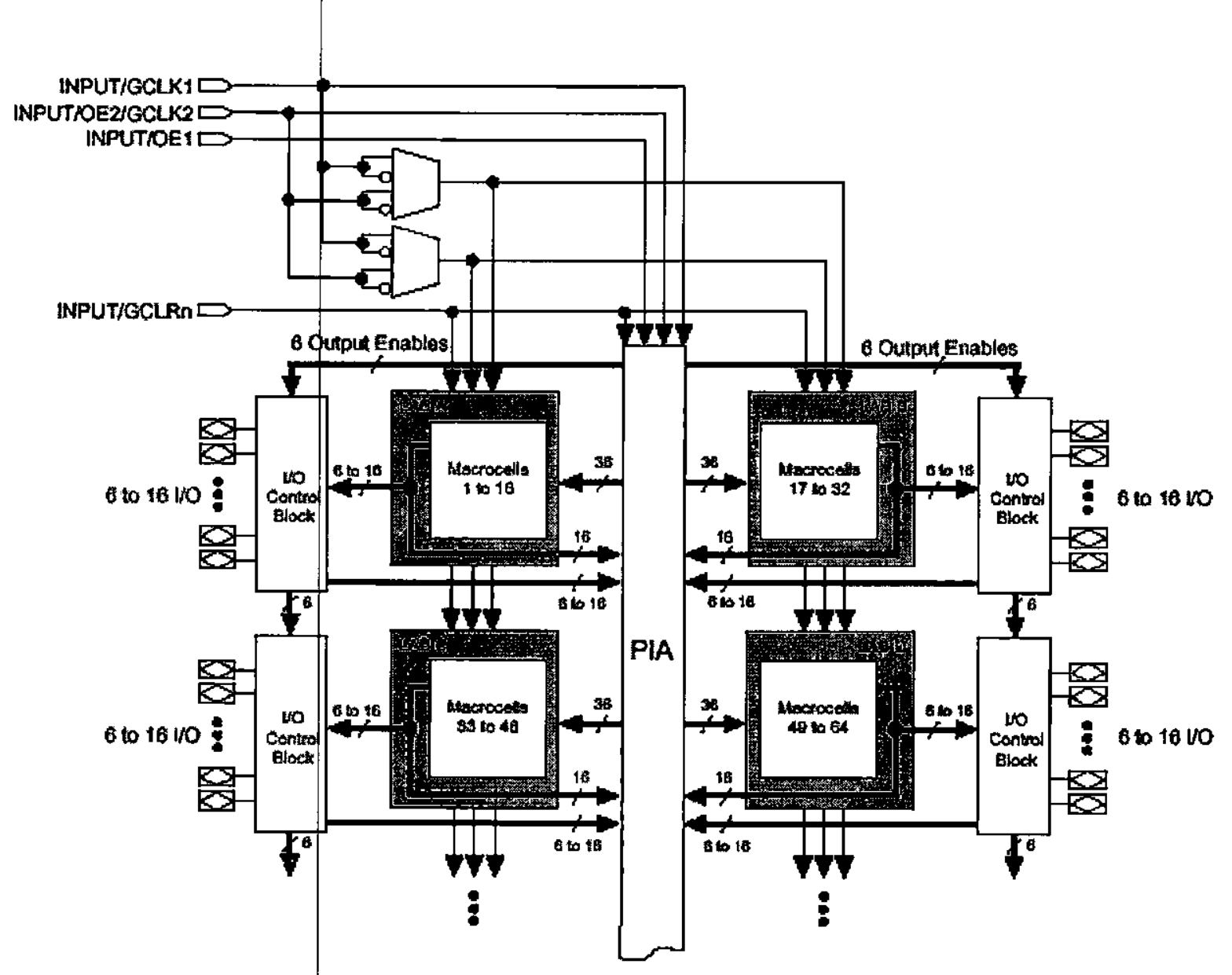

Flgura 34 - Diagrama de Blocos do MAX3000A

Cada macrocélula pode ser configurada individualmente, tanto para operações de lógica seqüencial quanto para lógica combinacional. A maioria das funções lógica podem ser implementadas diretamente numa macrocélula, e através dos expansores pode se implementar funções muito mais complexas usando macrocélulas do mesmo LAB. Estes expansores asseguram que a lógica foi sintetizada com a menor quantidade de lógica possivel para obter a melhor velocidade. 


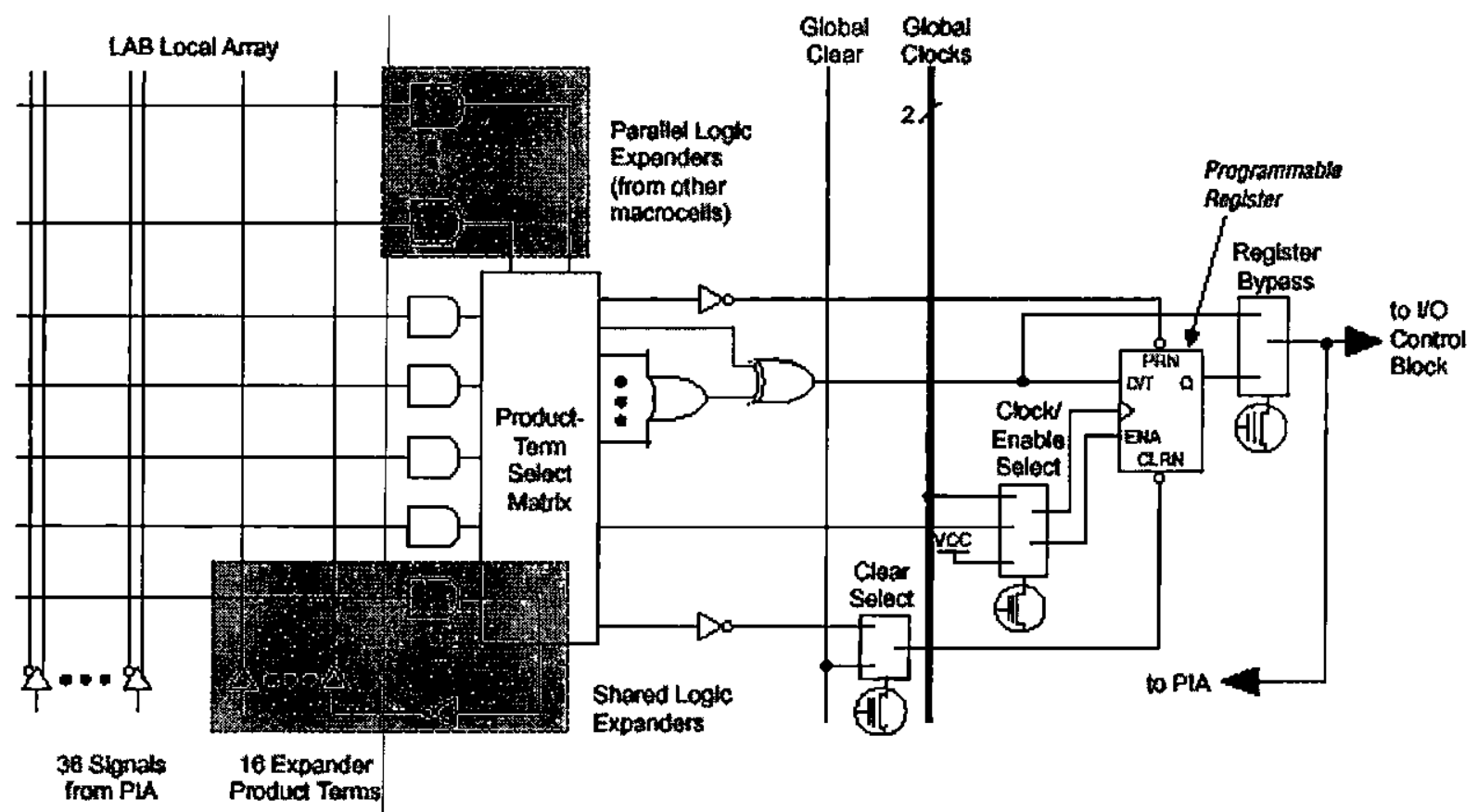

Figura 35 - Macrocéiula do MAX3000A

Esta arquitetura facilmente integra múltiplos dispositivos, incluindo PAL, GAL, MACH e pLSI. Ainda fornece corrente para dispositivos 3.3V programáveis no próprio sistema (in-system programmability - ISP) através de uma interface JTAG (Joint Test Action Group).

Esta característica permite que a programação do PLD possa ser feita após a montagem da placa, permitindo que atualizações do hardware sejam feita no campo. Veja os modos possíveis de programação destes dispositivos na Figura 36.

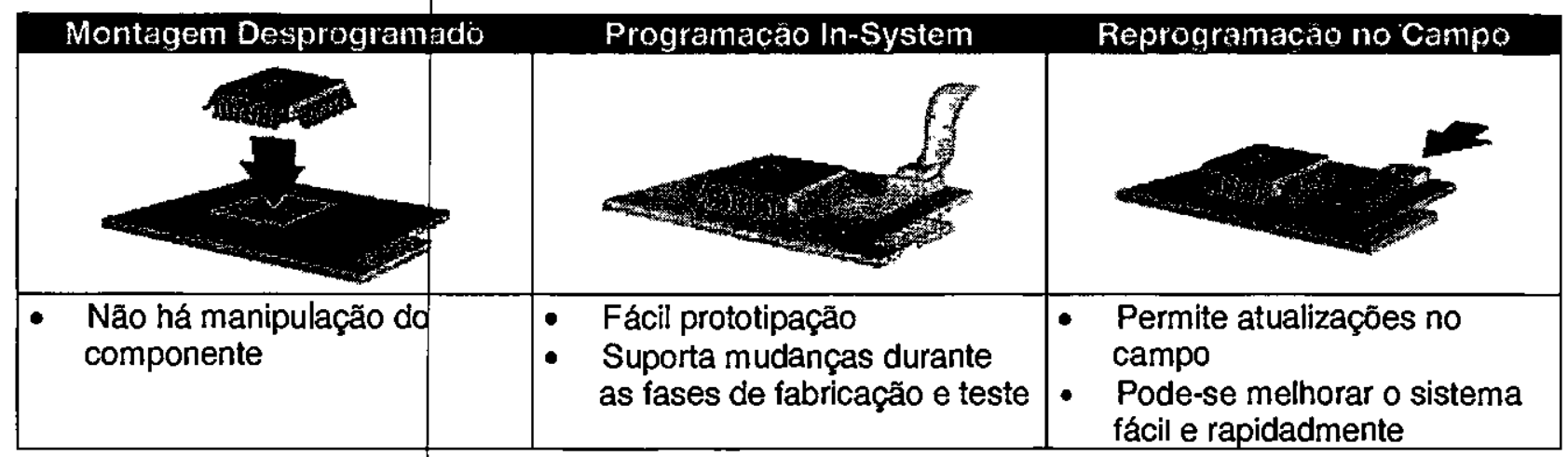

Figura 36 - Fácil atualização 


\subsection{MAX+Plus II}

O software de desenvolvimento MAX+PLUS II em conjunto com outras ferramentas suporta todas fases de um projeto SOPC (system-on-a-programmablechip) [64]. O ambiente de desenvolvimento MAX+PLUS II integra projeto, síntese, roteamento e verificação em um ambiente.

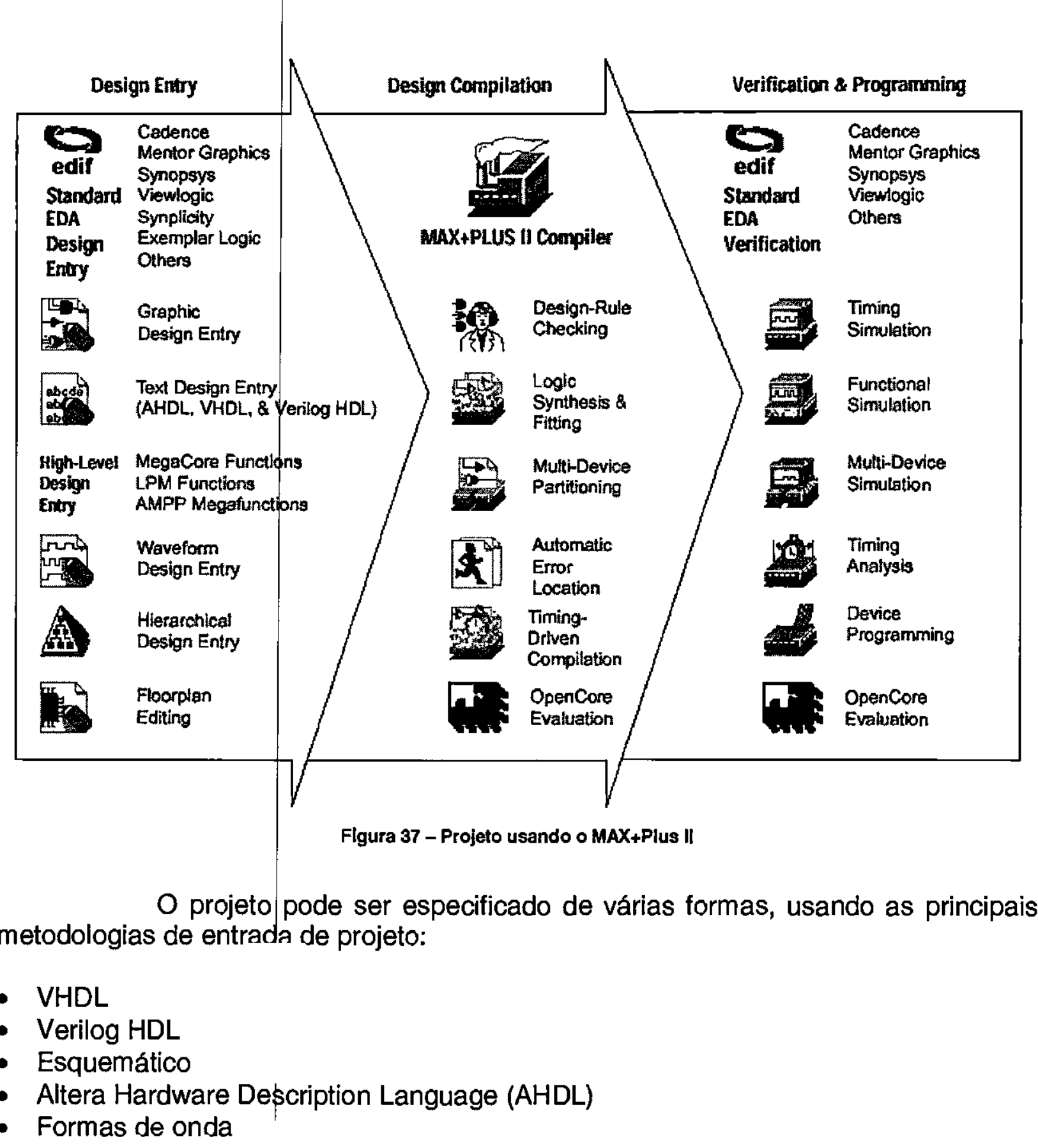


O software MAX+PLUS II permite que mudanças sejam implementadas rapidamente. Novos roteamentos podem ser programados no dispositivo através da interface JTAG (ISP), permitindo que os testes sejam feitos direto na placa, dando mais flexibilidade ao projeto.

\subsection{Consideraçoes Finais}

O PLD sérá o coração deste projeto, e devido a sua característica de reprogramação na placa, dará muita flexibilidade ao circuito. $\mathrm{Na}$ escolha do componente ideal, pretende se trabalhar com o dispositivo que tenha maior capacidade de pinos de $1 / 0$ e macrocélulas.

A solução NET+Works permitirá uma rápida prototipação do projeto e dará um suporte de software muito grande, permitindo uma rápida implementação de aplicações de teste, após concluídos os testes de hardware. 


\section{DEFINIÇÃO DA ARQUITETURA}

Depois que foi definido que iria se trabalhar com dois módulos NET $+40,0$ que em outras palavras significa duas CPUs, surgiu o problema de como realizar a comunicação entre as duas CPUs. Algumas alternativas foram então estudas:

\subsection{Memória Dual-Port}

teria:

Neste modo, cada CPU rodaria um programa independente. Cada CPU

- Barramento de dados;

- Barramento de endereços;

- ROM

- RAM

A comunicação entre as duas CPUs seria feita por uma memória tipo RAM, [30] cujo acesso seria feito por um barramento compartilhado, o qual seria controlado pelo PLD, para garantir que apenas uma CPU acesse a dual-port por vez. Um diagrama de blocos simplificado deste modelo pode ser visto na Figura 38:

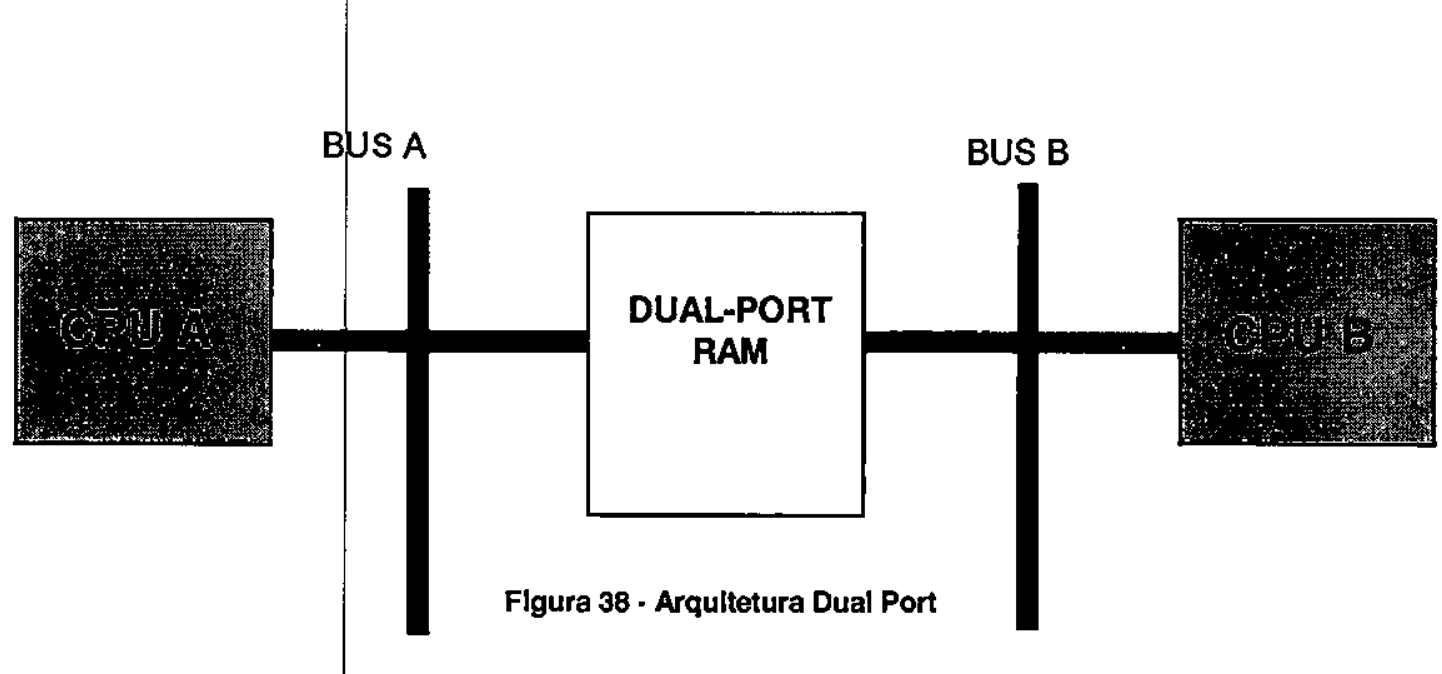

Esta é uma solução que traz complicações para o hardware, principalmente relacionadas com o controle de acesso à memória dual-port. Por outro lado, dá liberdade ao desenvolvimento do software, de modo que o tratamento dos dados e a comunicaçáo sejam implementados sem maiores dependências entre 0 hardware e o software. 
Em termo\$ de software esta é a solução mais fácil para ser desenvolvida. A partir do momento que o controle de acesso à memória compartilhada for implementado, as CPUs trocarão dados simplesmente através de escritas e leituras nesta memória.

\subsection{Mestre/Escravo}

O NET+ARM pode ser usado na configuração Mestre/Escravo [28]. Nesta configuração, os periféricos do NET+ARM Escravo podem compartilhar o mesmo espaço de endereçamento. Desta forma, pode-se facilmente integrar os MACs Ethernet, as portas seriais, etc. Esta forma de operação é mostrado de um modo simples na Figura 39.

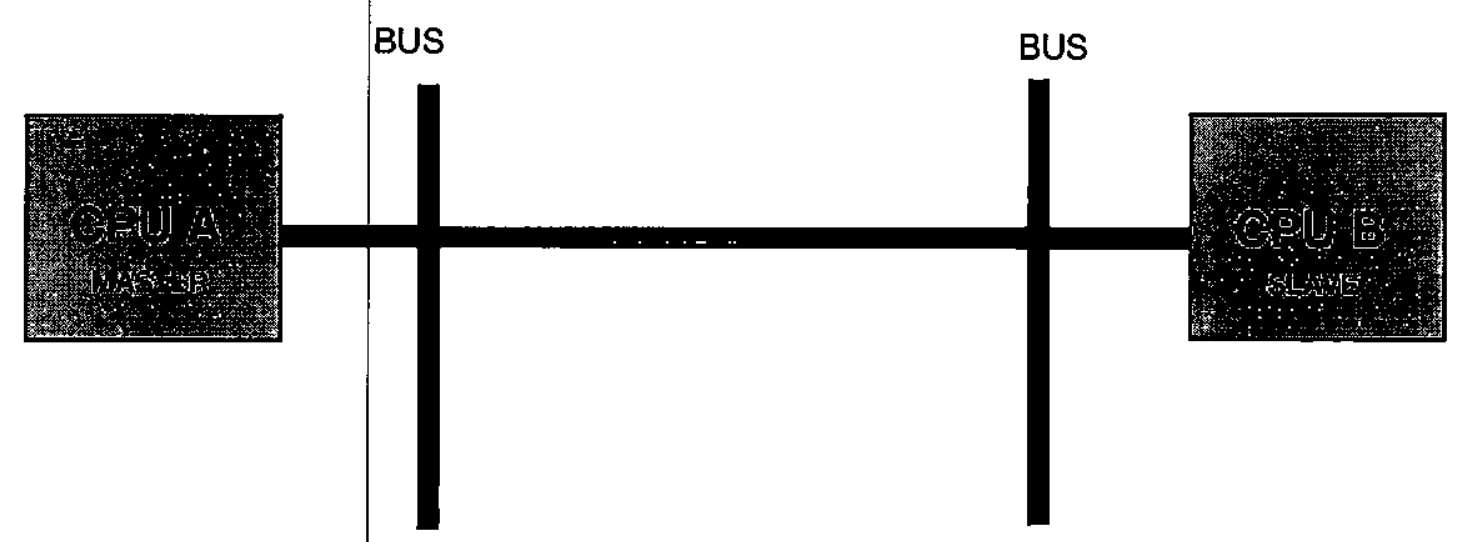

Figura 39 - Arquitetura Mestre/Escravo

Este foi o modelo adotado com base, num primeiro momento, para o desenvolvimento deste trabalho, por ser o modelo apresentado pelo fabricante do chip num Application Note. A grande vantagem deste modelo é a presença de apenas uma CPU (uma vez que a outra está desabilitada), o que significa que haverá apenas um software rodando. A CPU mestre terá acesso a todos os periféricos da CPU escrava.

Ao se estudar esta arquitetura, verificou-se que ela exigiria que o sistema operacional que fosse rodar na CPU mestre (única em funcionamento) possuísse driver para dois controladores Ethernet operando simultaneamente. Como este driver para dois controladores ainda não está disponível comercialmente no NET+OS, isto tornouse uma das grandes desvantagens deste modelo. 


\subsection{Memória compartilhada via ENI}

Dois sistemas NET+ARM podem ser conectados usando a interface ENI [26]. O NET +ARM Mestre usa seu barramento de dados para inicializar a transferência de dados para o NET+ARM Escravo, o qual usa sua ENI para trocar dados com o mestre. Depois de tudo configurado, o mestre pode comunicar com o escravo como se ele fosse uma memória estática de 64Kbytes. O circuito adicional necessário para esta conexão é mostrado na Figura 40.

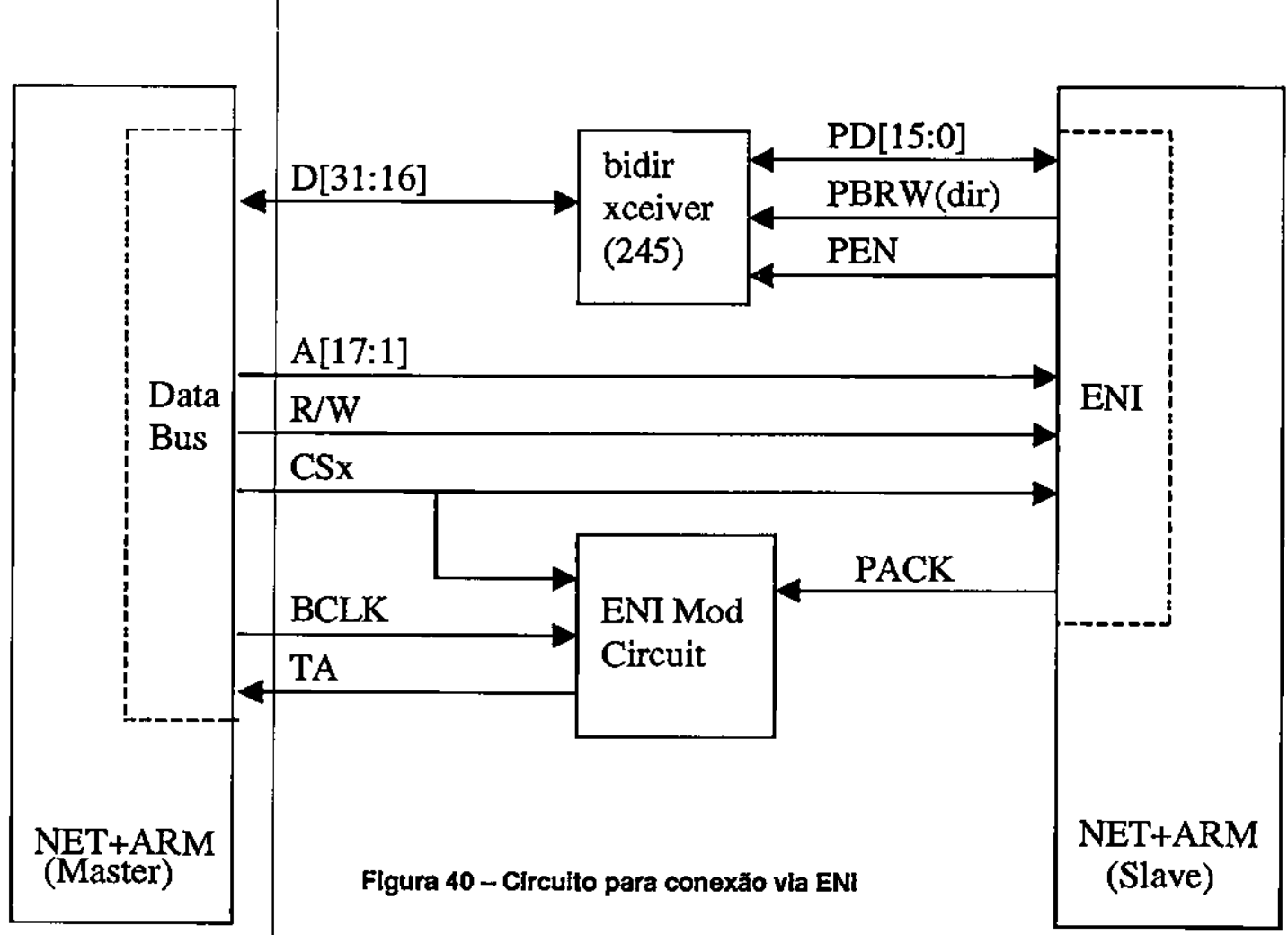

Este modelo usa uma porta específica da CPU para troca de informaçōes. É o melhor modelo, pois, permite a utilização da capacidade das duas CPUs sem adição de muitos componentes físicos ao sistema, nem mesmo componentes lógicos, uma vez que este tipo de acesso já está disponivel no NET+ARM. A Figura 41 mostra o diagrama de blocos para esta arquitetura. 


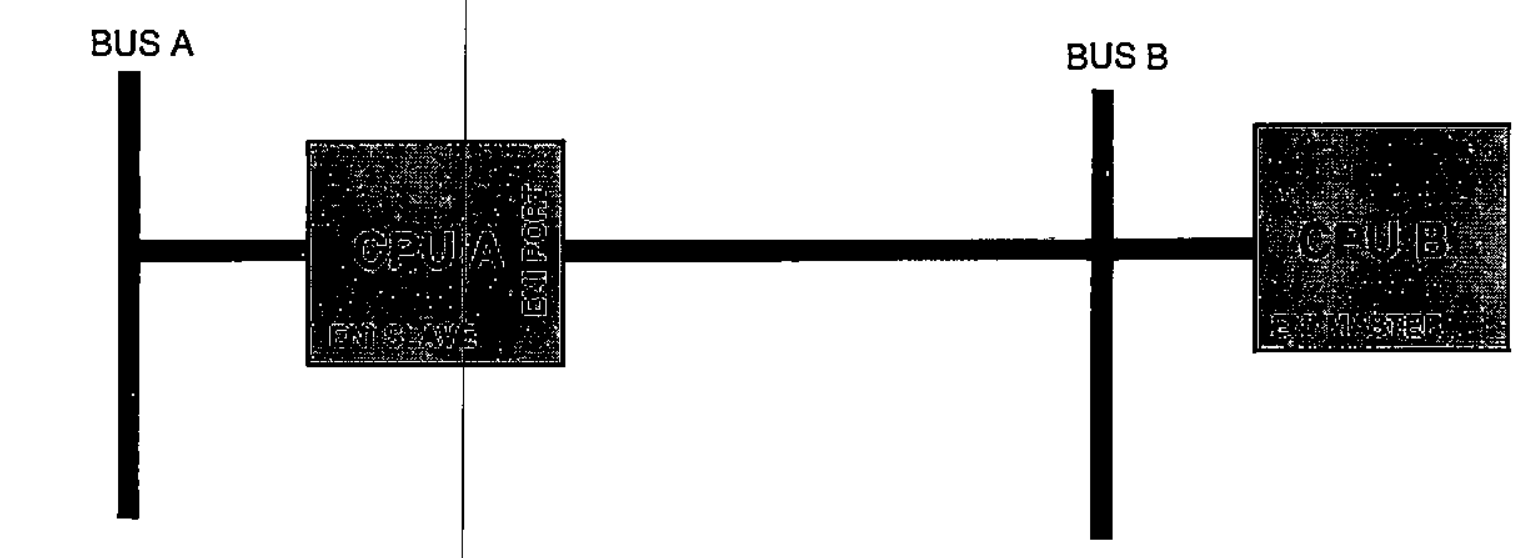

Figura 41 - Arquitetura ENI Shared RAM

\subsection{Hardware Reconfigurável}

O projeto então seguiu no caminho de criar um hardware que suportasse todos os modelos de arquitetura estudados, de forma que esta decisão pudesse ser tomada depois que cada uma destas soluçōes estiverem mais familiarizadas. Através da programação do PLD (aqui chamado de MPC - Memory and Peripheral Controller) poderá se passar de um modo para o outro, usando a mesma plataforma de hardware. Um sumário de cada um destes modos pode ser visto na Tabela 7.

\begin{tabular}{|c|c|c|l|}
\hline MODOS & CONFIGURAÇÃO & COMUNICAÇÃO & \multicolumn{1}{c|}{ DESCRIÇÃO } \\
\hline A & $\begin{array}{c}2 \mathrm{CPU} \\
2 \times 100 \mathrm{MB}\end{array}$ & Independente & $\begin{array}{l}\text { Não haverá comunicação entre as CPUs, e ter- } \\
\text { se-á duas portas Ethernet independentes }\end{array}$ \\
\hline B & $\begin{array}{c}1 \mathrm{CPU} \\
2 \times 100 \mathrm{MB}\end{array}$ & Mestre/Escravo & $\begin{array}{l}\text { A CPU B (Slave) estaráa desabilitada, funcionando } \\
\text { apenas como um segundo controlador Ethernet. } \\
\text { O sistema terá um software único rodando na } \\
\text { CPU A (Master), sendo que o driver Ethernet } \\
\text { deverá suportar dois controladores. }\end{array}$ \\
\hline C & $\begin{array}{c}2 \mathrm{CPU} \\
2 \times 100 \mathrm{MB}\end{array}$ & ENI Shared RAM & $\begin{array}{l}\text { Cada CPU terá o seu software. Neste modo a } \\
\text { CPU B (ENI Master) tem acesso à SDRAM da } \\
\text { CPU A (ENI Slave) pela ENI, o que possibilitará a } \\
\text { troca de dados. }\end{array}$ \\
\hline D & $\begin{array}{c}2 \mathrm{CPU} \\
2 \times 100 \mathrm{MB}\end{array}$ & Dual Port Memory & $\begin{array}{l}\text { Software independente com a comunicação } \\
\text { sendo feita pela memória dual-port, cujo acesso } \\
\text { será controlado pelo FPGA. }\end{array}$ \\
\hline
\end{tabular}

Tabela 7 - Modos de operação

Com isto foi elaborado o diagrama de blocos mostrado na Figura 42. Este digrama serviu tanto de base para o esquema elétrico quanto para a pesquisa de componentes. 


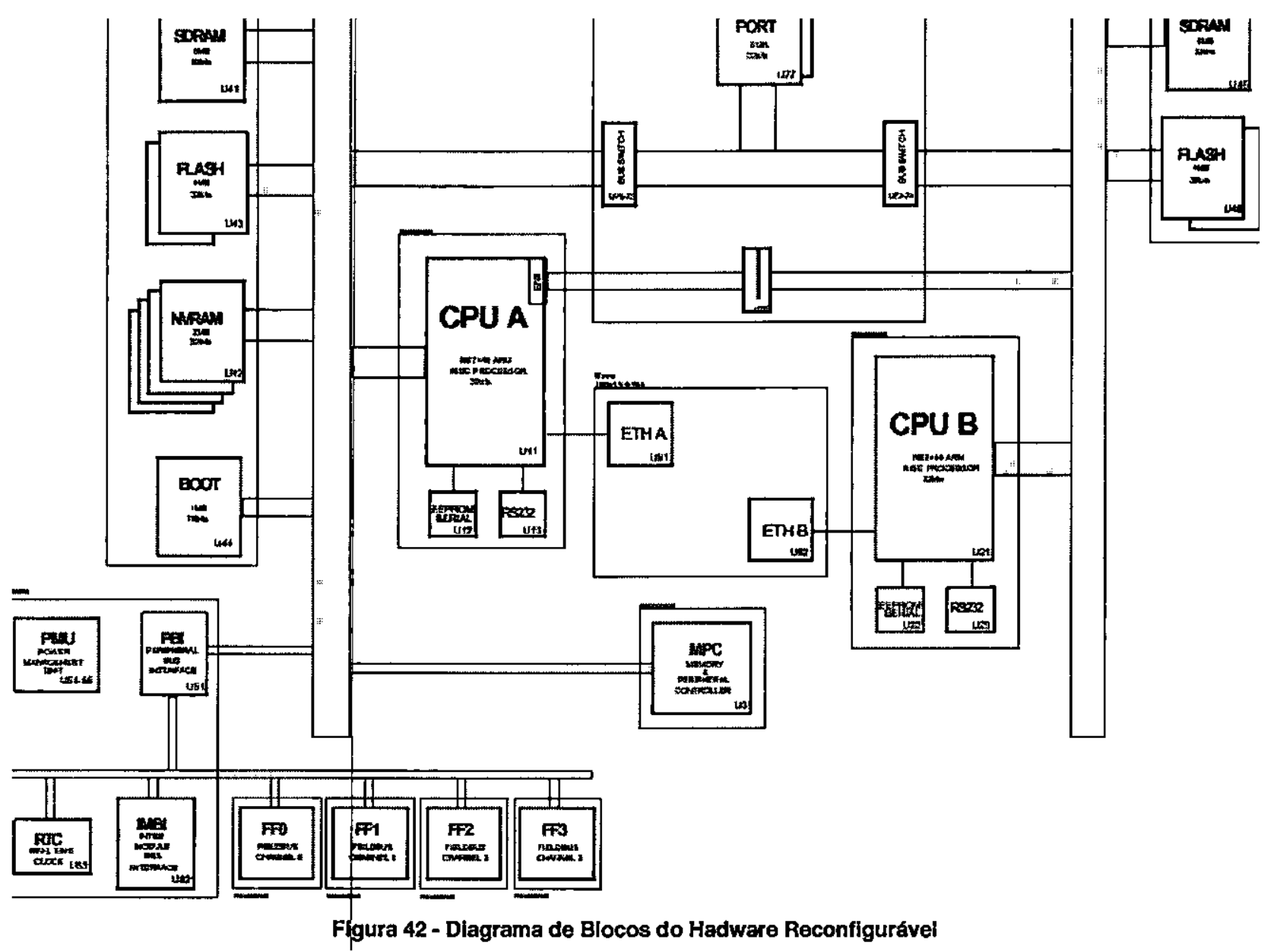

\subsection{Considerações Finais}

Esta abordagem de várias arquiteturas permitirá estudar o comportamento detalhado de cada uma. Aspecto como análise de custo, desempenho, complexidade de projeto, serão levantados de forma bem precisa. Outro fator importante que também será levado em questão é a simplicidade no desenvolvimento do software, além da flexibilidade do sistema para futuras melhorias. 
Após o estudo das tecnologias envolvidas, iniciou-se o projeto do hardware que envolve várias fases:

1. Escolha do paradigma a ser utilizado (Capítulo 5)

2. Definição da arquitetura (Capítulo 7 )

3. Requisitos do projeto

4. Projeto do circuito elétrico

5. Fabricação e montagem da placa

6. Programação do PLD

7. Testes

8. Validação do sistema

Todas estas fases, que ainda não foram abordadas, serão descritas detalhadamente nas próximas seções.

\subsection{Requisitos|do projeto}

Os principais requisitos deste projeto são [27], [29]:

- $\mathrm{CPU}$

Dois módulos processadores NET+40.

- FPGA

Usar um FPGA que possa ser reprogramado na própria placa através de um conector JTAG. Será usado um PLD da família MAX3000A [34].

- ROM

Usar umá memória tipo Flash para armazenamento do programa do usuário, e usar outra memória tipo SRAM, mas alimentada por bateria que possa manter os dados de configuração.

- RAM

Especificar uma RAM onde se possa rodar toda a aplicação (código e dados), para que o processo de 'debug' seja simplificado.

- E2PROM Serial

Uma memória pequena para armazenar alguns parâmetros de configuração, como endereço IP, máscara de subrede, etc... 
- BOOT

Uma memória tipo Flash (ou E2PROM) para armazenar um programa monitor com algumas características básicas:

1. Rodar setup

2. Configurar porta Ethernet

3. Inicializar conexāo TCP/IP

4. Chegar e/ou gravar programa aplicativo na ROM

5. Executar o programa que na ROM

- Porta JTAG da CPU

Criar um conector para esta porta, para permitir o uso de um ICE (In Circuit Emulator) para 'debug' do hardware e do software. Isto é essencial para fazer a placa funcionar pela primeira vez.

- Porta JTAG do FPGA

Criar um conector para esta porta, pois, assim a programação do FPGA poderá ser alterada na própria placa.

- Porta serial

Usar a porta serial para o envio de mensagens de diagnóstico. Isto ajudará muito o 'debug', dada a facilidade oferecida pelo NET+Works para este tipo de comunicação.

- Porta Ethernet

Como o objetivo é de se implementar a redundância, deve-se ter neste hardware duas portas Ethernet. Para se conseguir isto deverá ser usado dois NET+40 (CPU com um controlador Ethernet embutido).

- Canais Fieldbus

Os canais fieldbus permitiram que o equipamento desenvolvido seja classificado com um Linking Device HSE.

\subsubsection{Pesquisa de componentes}

Foi feita uma pesquisa de componentes que atenderiam aos requisitos do projeto. Dentre os componentes necessários foram pesquisados equivalentes de vários fabricantes para facilitar a aquisição. Esta pesquisa foi feita através de fornecedores de componentes eletrônicos na Internet [72], [73], [74]. A Tabela 8 descreve os principais componentes utilizados neste projeto. 


\begin{tabular}{|c|c|c|}
\hline DESCRIÇĀo & FABRICANTE & CODIGO \\
\hline IC 3256 EPLD-208 LOGIC CEIL $10 \mathrm{~ns}$ (PQFP 158) & $\overline{\text { ALTERA }}$ & EPM3256AQC208-10 \\
\hline SDRAM $4 \times 512 \mathrm{k} \times 32$ 3.3V $10 \mathrm{~ns} 143 \mathrm{MHz}$ (TSOPII86) & $\begin{array}{l}\text { MICRON } \\
\text { HYUNDAI } \\
\text { NEC } \\
\text { TOSHIBA }\end{array}$ & $\begin{array}{c}\text { MT48LC2M32B2TG-7 } \\
\text { HY57V653220BTC-7 } \\
\mu \text { PD4564323G5-A70-9JH } \\
\text { TC59S6432CFTL-70 }\end{array}$ \\
\hline SRAM 512kx8 3.3V 70ns (TSOPII32) & $\begin{array}{l}\text { TOSHIBA } \\
\text { HITACHI } \\
\text { HYUNDAI } \\
\text { MITSUBISHI } \\
\text { SAMSUNG } \\
\text { CYPRESS }\end{array}$ & $\begin{array}{l}\text { TC55V4000ST-70EL } \\
\text { HM62W8512BLTT-5 } \\
\text { HY62V8400ALT2-70 } \\
\text { M5M5V408BTP-70L } \\
\text { KM68V4000BLT-7L } \\
\text { CY62148VLL-70ZIT }\end{array}$ \\
\hline Dual Port - SRAM 256kx16 3.3V 12ns (TSOPII44) & \begin{tabular}{|c|} 
ALLIANCE SEMICONDUCTOR \\
HITACHI \\
CYPRESS \\
SAMSUNG \\
MITSUBISHI
\end{tabular} & $\begin{array}{l}\text { AS6UA25616-70TC } \\
\text { HM62V16258BLTT-7SL } \\
\text { CY62146VLL-70ZI } \\
\text { KM616V4000CL-7L } \\
\text { M5MV416BTP-70L }\end{array}$ \\
\hline FLASH $1 \mathrm{M}$ x $163.3 \mathrm{~V} 70 \mathrm{~ns}$ (TSOP 48) & $\begin{array}{c}\text { INTEL } \\
\text { ATMEL } \\
\text { AMD } \\
\text { MITSUBISHI } \\
\text { ST MICROELECTRONICS } \\
\text { FUJITSU } \\
\end{array}$ & $\begin{array}{c}\text { TE28F160C3TA70 } \\
\text { AT49BV1614T-70 TI } \\
\text { Am29LV160BT-70EC } \\
\text { M5M29GT160BVP-80 } \\
\text { M29W160BT-90N6T } \\
\text { MBM29LV160-TE70-TN }\end{array}$ \\
\hline FLASH 512k x $163.3 \mathrm{~V} 70 \mathrm{~ns}$ (TSOP 48) & INTEL & TE28F160C3TA70 \\
\hline Serial EEPROM SPI $1 \mathrm{~K} \times 83.3 \mathrm{~V}$ (SO8) & $\begin{array}{c}\text { ATMEL } \\
\text { MICROCHIP } \\
\text { CATALYST } \\
\text { XIRCOR } \\
\text { ST MICROELECTRONICS }\end{array}$ & $\begin{array}{c}\text { AT25080N-10SC-2.7 } \\
\text { 25LC080SN } \\
\text { CAT25C08-2.5 TE13 } \\
\text { X25097-S 2.7 } \\
\text { M95080-WMN6T }\end{array}$ \\
\hline IC HC245 8 bit BUS TRANSCEIVER (SSO20) & TEXAS INSTRUMENTS & $\mathrm{CD} 74 \mathrm{HC} 245 \mathrm{DB}$ \\
\hline IC 232 Line Driver/Receiver RS232 3.3 V (SO16) & $\begin{array}{l}\text { ANALOG DEVICE } \\
\text { MAXIM } \\
\text { INTERSIL }\end{array}$ & $\begin{array}{l}\text { ADM3202ARW } \\
\text { MAX3232ESE } \\
\text { ICL3232IB }\end{array}$ \\
\hline IC 793 Adjustable $\mu$ P Supervisory Circuit $3.3 \mathrm{~V}$ (SO16) & MAXIM & MAX793TCSE \\
\hline IC DS1501 Watchdog Timekeeper 3.3 V (TSOP28) & DALLAS & $\overline{\mathrm{DS} 1501 \mathrm{EW}}$ \\
\hline IC $10 / 100$ PHY MII $3.3 \sqrt{V}$ (MQFP80) & LUCENT & LU3X31FT-J80-DB \\
\hline IC TRANSFORMER IOO BASE TX & $\begin{array}{l}\text { OASIS } \\
\text { PULSE }\end{array}$ & $\begin{array}{l}\text { XMS0105 } \\
\text { H1012 }\end{array}$ \\
\hline Regulator LDO $1.25 \mathrm{~A} 3.3 \mathrm{~V}$ & $\begin{array}{c}\text { MICREL } \\
\text { NATIONAL }\end{array}$ & $\begin{array}{l}\text { MIC2904A33BY } \\
\text { LM3940IS -3.3 V }\end{array}$ \\
\hline Lithium Ion Battery $2 / 3 \mathrm{~A} 3,0 \mathrm{~V}(1200 \mathrm{~mA} / \mathrm{h})$ & $\begin{array}{l}\text { PANASONIC } \\
\text { DURACEL }\end{array}$ & $\begin{array}{l}\text { BR-2/3A } \\
\text { DL-2/3A }\end{array}$ \\
\hline Oscillator Ceramic SMD (32MHz) & $\begin{array}{l}\text { ECLIPTECK } \\
\text { FOX }\end{array}$ & $\begin{array}{l}\text { EC2600-TTS-32.000M } \\
\text { F4100-32.000M }\end{array}$ \\
\hline Crystal 25MHz 100PPM & FOX & FPX250F-20 \\
\hline IC NET+ARM 4032 bit RISC CPU 50MHz (QPF-208) & NET Silicon & NETA-40-5 \\
\hline
\end{tabular}

Tabeia 8 - Lista dos PrInclpais Componentes 


\subsubsection{Projeto do mecanismo de inicialização}

Para inicialização desta placa serão usado basicamente dois métodos. Independente do modo usado para inicialização, o FPGA deve ser previamente programado num dos modos de operação desejado de acordo com a Tabela 7.

\subsubsection{Conector JTAG da CPU}

Este conector será usado para escrever um programa na RAM através de um emulador disponivel comercialmente. Este procedimento será muito útil durante a fase de testes e/ou debug, quando serão freqüentes as alterações no software.

\subsubsection{Mémoria de Boot}

Após o desenvolvimento (e estabilidade) do programa básico que servirá para dar vida à placa será gravada uma memória tipo flash (com este programa) que dará a partida na placa e fará a configuração inicial. Este programa também será responsável pela escrita do programa aplicativo na ROM.

\subsection{Programação do PLD}

O aspecto principal na escolha da capacidade do FPGA foi o número de pinos de $1 / O$ e a capacidade lógica disponível para programação. Outro aspecto muito importante foi a capacidade de programação na própria placa através da porta J-TAG. Foram relacionados todos os pinos necessários e então escolhido um modelo, dentro da família MAX 3000A (da Altera) [32], que atendesse às necessidades do projeto. Para definir qual sinal iria ficar em qual pino, foi usado o roteamento automático do software da Altera, o Max Plus II, após o término da programação inicial do FPGA.

A partir da definição do mapa de memória (Tabela 9) pôde-se iniciar o desenvolvimento das máquinas de estado para posterior programação. 


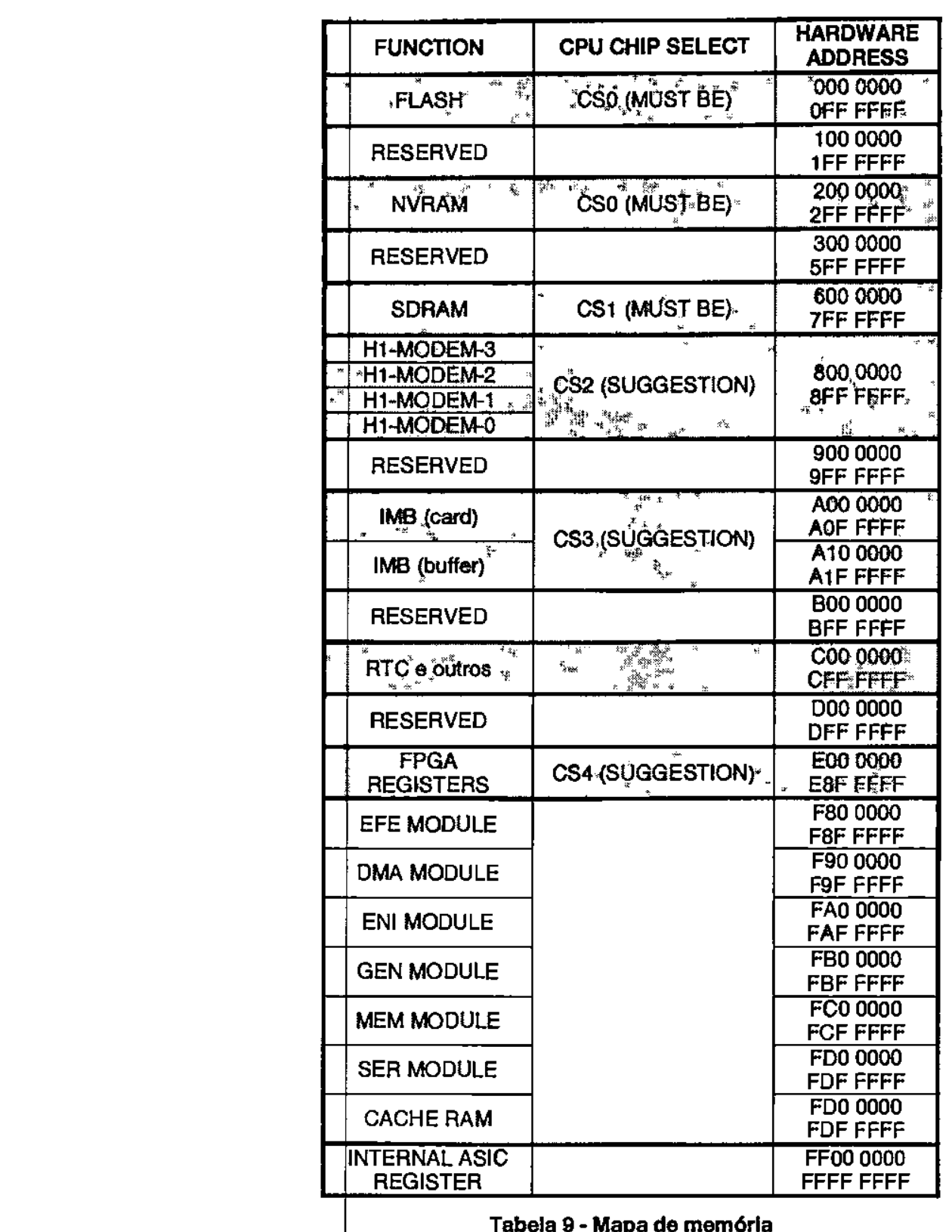

\subsubsection{Máquinas de estado}

Aqui serão descritas as máquinas de estado mais importante do projeto: 


\subsubsection{Escrita em Memória}

Os sinais $1 B W E[3 . .0]$ são necessários para os acessos de escrita na flash ou na RAM. Esses sinais são gerados a partir dos sinais /BE[3..0] da CPU [33]. A máquina $Y$, que auxilia a máquina $Z$, trabalha na borda invertida do clock para economizar wait-states.

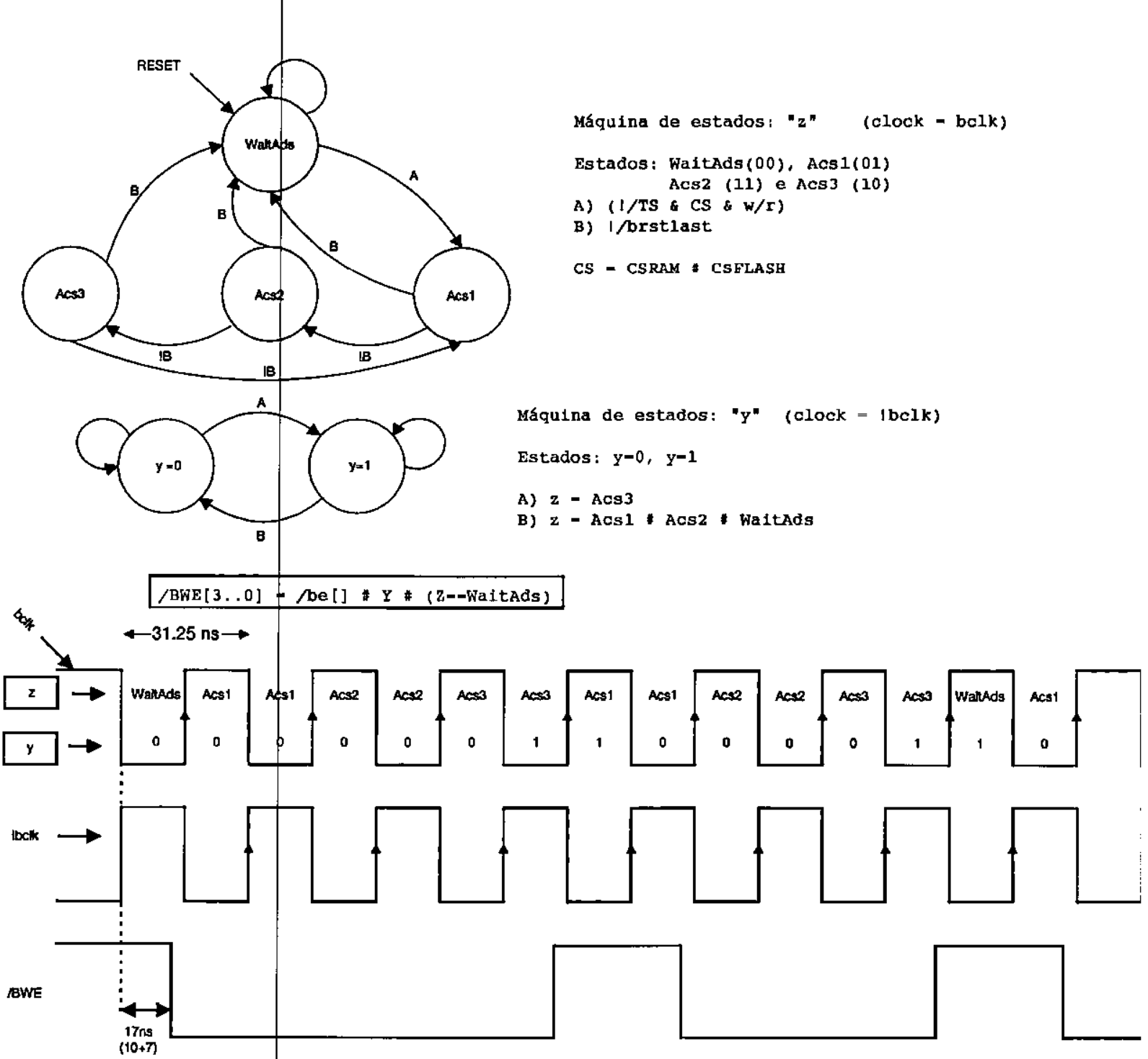




\subsubsection{Reset Watchdog}

Cada escrita RESETWDG=0 (ou seja, escrita em 0xE300000 com o bit $\mathrm{D} 0=0$ ) provoca toggle na linha WDG do DF51. Esse procedimento, que deve ser feito periodicamente pela CPU, faz com que ocorra refresh no contador de watchdog contido no chip MAX793. Escritas RESETWDG=1 não têm nenhum efeito.

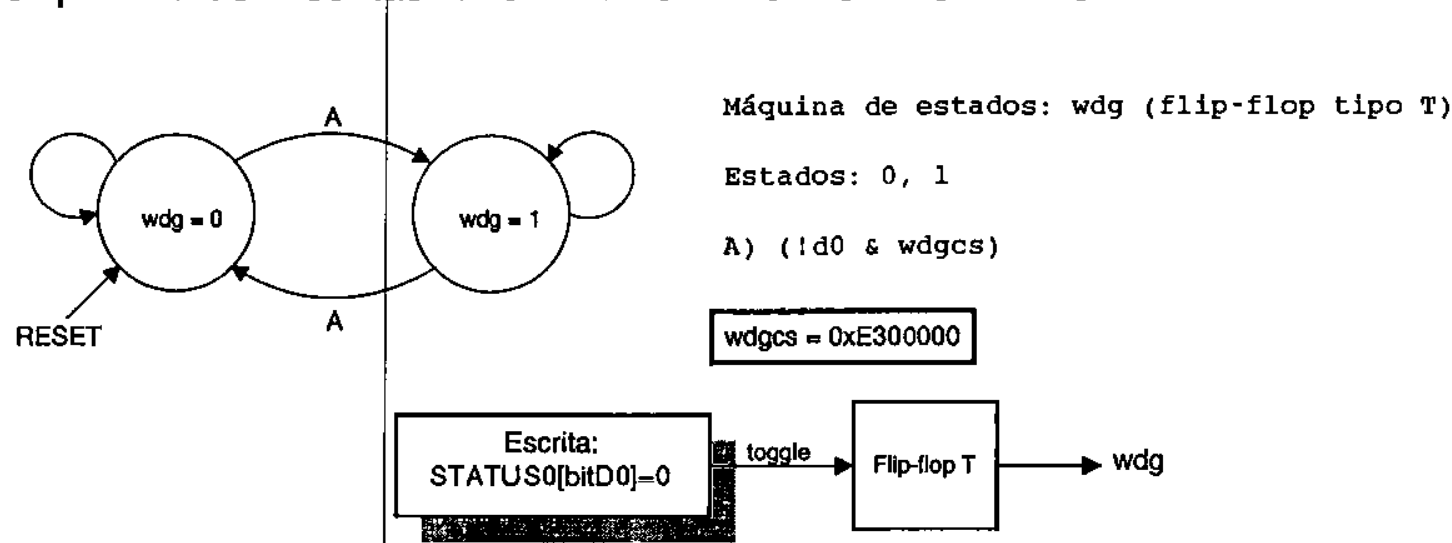

\subsubsection{Registro de Estados}

Existem quatro registros de estados, denominados STATUSO, STATUS1, STATUS2 e STATUS3. Todos eles estão dentro da região 0xExxxxxx composta pelo PLD REGISTERS. Cada registro de status terá o seu chip select num determinado endereço e terá uma fuhção determinada.

- status0 chip select

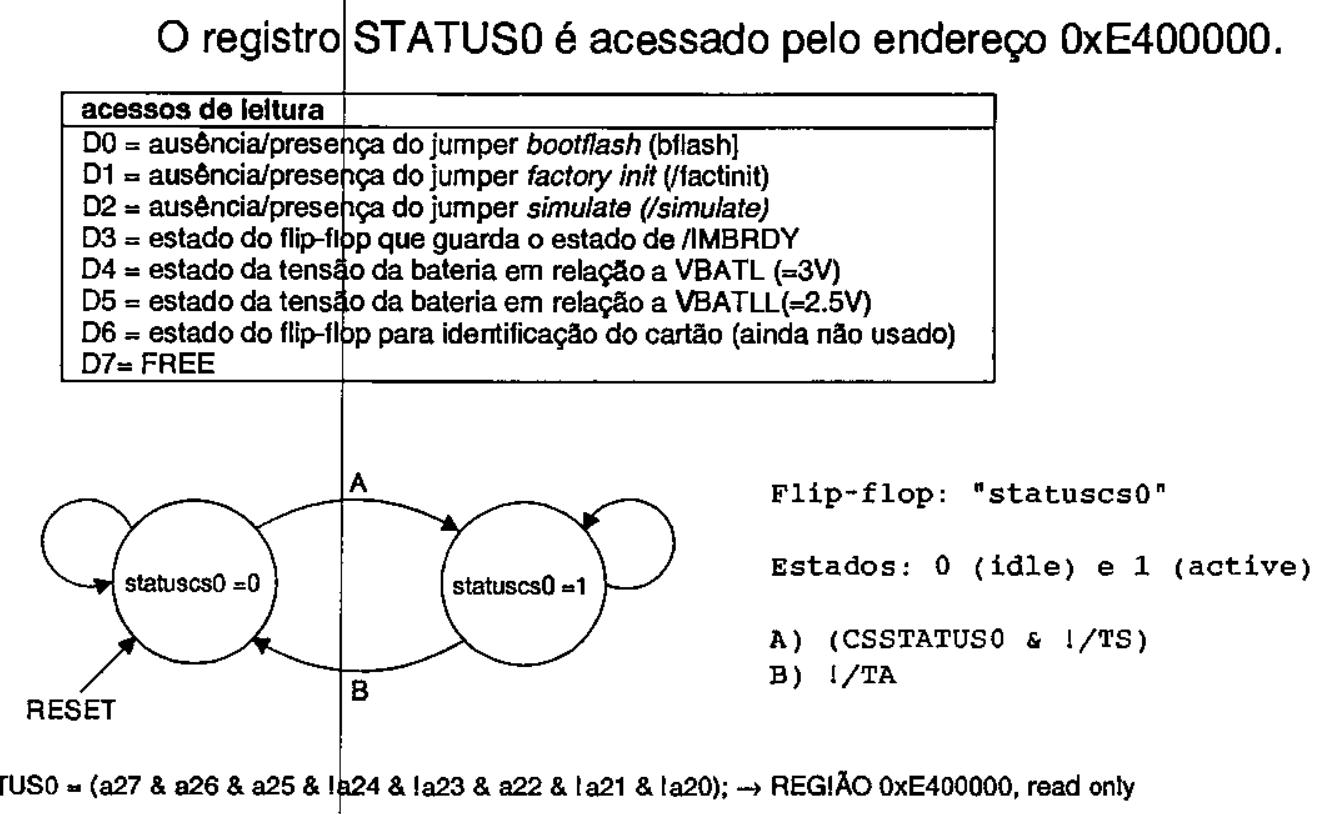


- status1 chip select

O registro STATUS1 é acessado pelo endereço 0xE500000. Este registro tem a função de ler os valores dos switches.

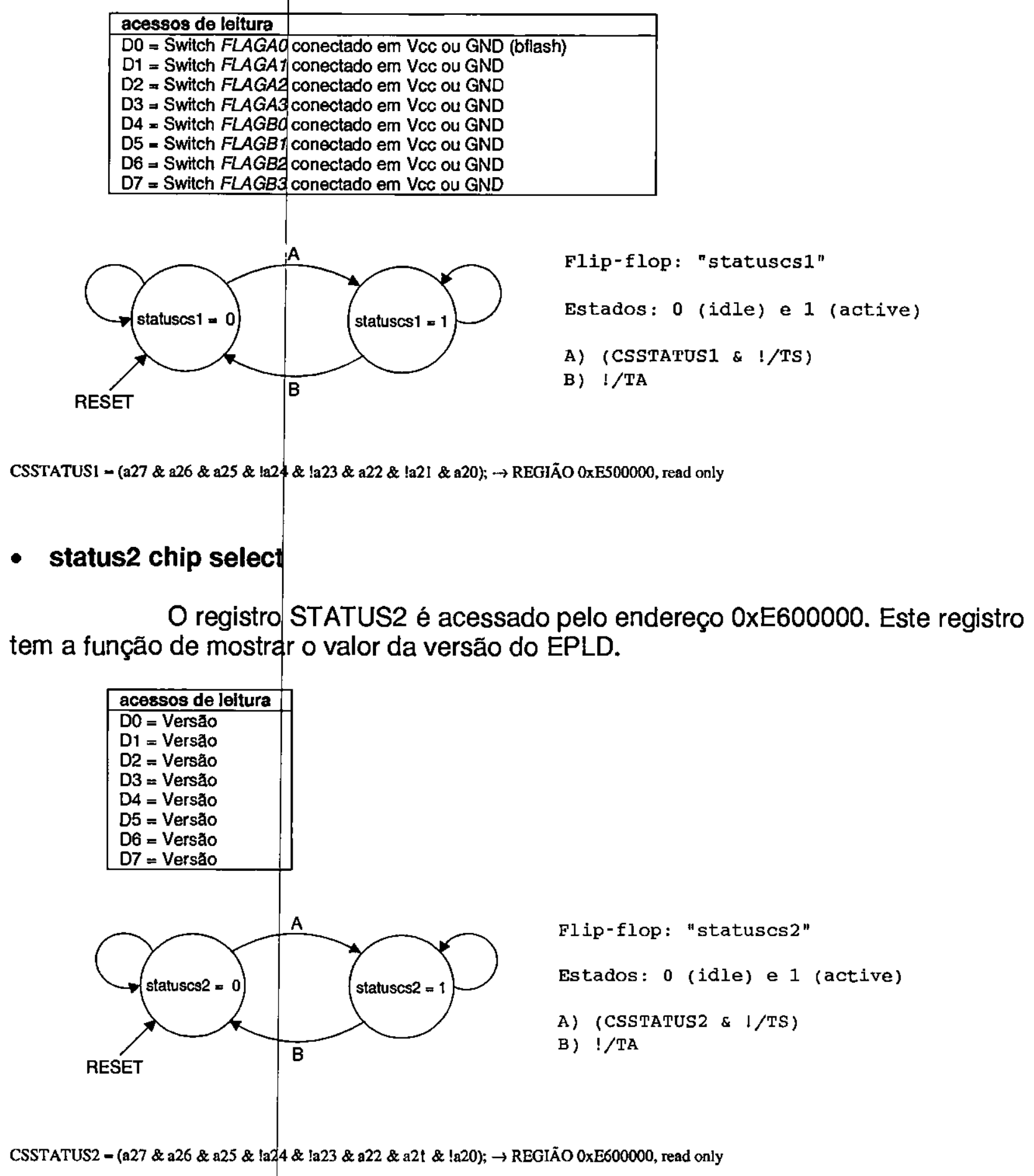




\subsubsection{Comandos Reset}

\section{- Reset Chip Select}

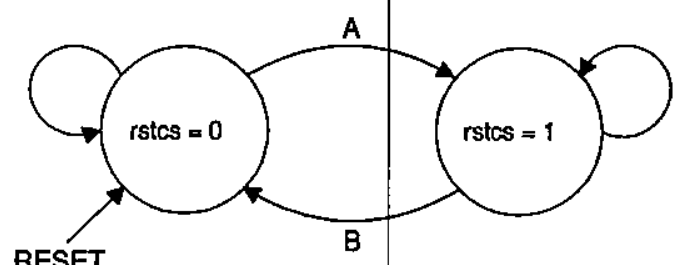

Flip-flop: "rstcs"

Estados: 0 (idle) e 1 (active)

A) (CSRST \& ! /TS)

RESET

B) ! T TA

CSRST

- (a27 \& a26 \& a25 \& !a24 \& a23 \& !a22 \& la21 \& la20); $\rightarrow$ REGIÃO 0xE800000, write only

- Máquina de estados 'stq'

RESET.

A máquina de estados 'stq' diz como a CPU será levada ao estado de

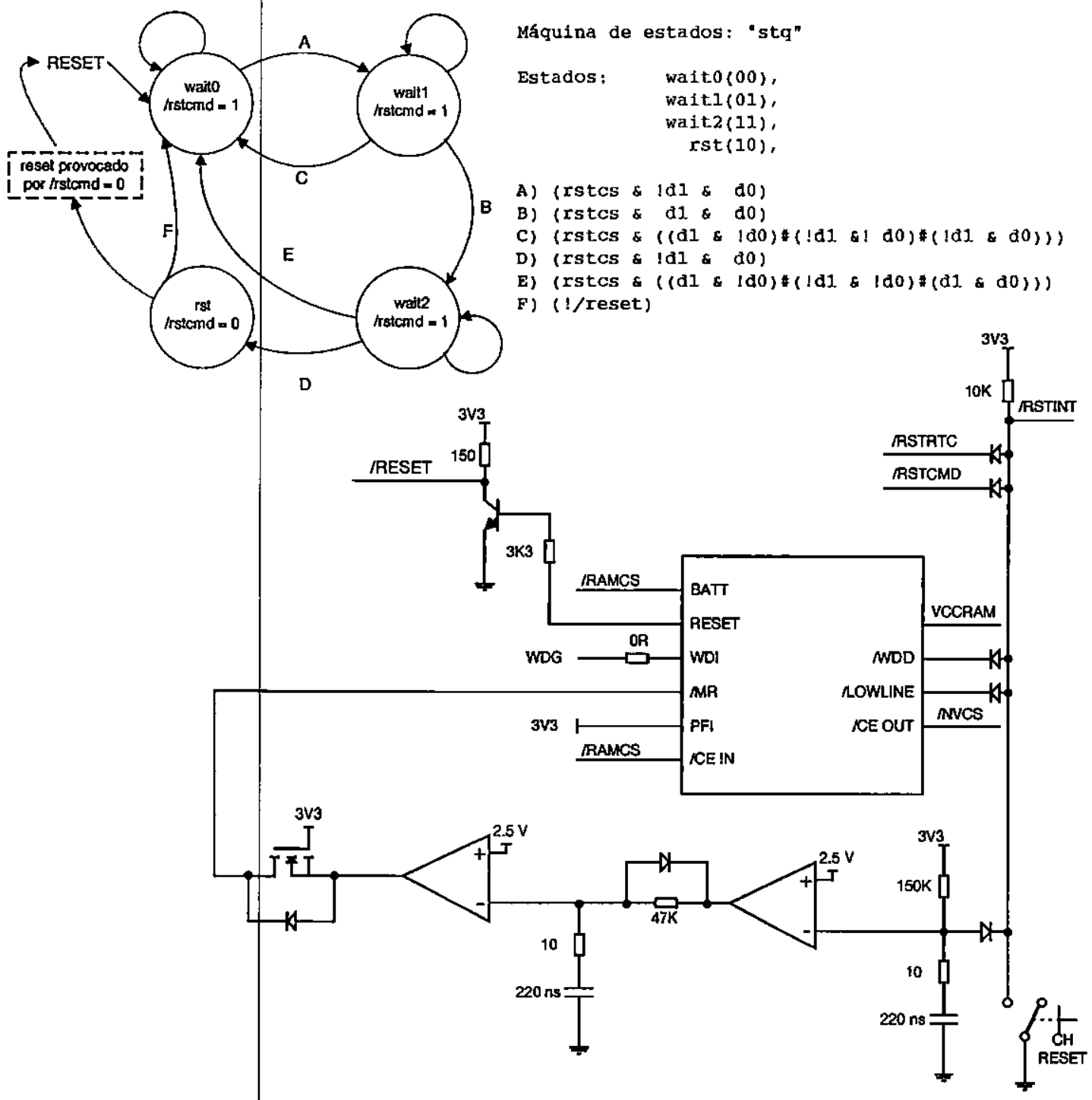




\section{- Descrição do comando RESET}

Para que a CPU entre no modo RESET é preciso percorrer a máquina de estados 'stq' na seqüência $A \rightarrow B \rightarrow D$. Isso é conseguido a partir de sucessivas escritas em 0xE8xxxxx, respeitando-se os seguintes valores para D0 e D1:

1. escrita em $0 \times E 8 \times x \times x \times c \phi m$ D0 $=0$ e $D 1=0 \rightarrow$ garante que a máquina stq partirá do estado 'waito'

2. escrita em $0 \times E 8 \times x \times x \times c o m ~ D 0=1$ e $D 1=0 \rightarrow$ conduz 'stq' ao estado 'wait1' através do caminho ' $A$ '

3. escrita em $0 \times E 8 \times x \times x \times c o m$ D0 $=1$ e $D 1=1 \rightarrow$ conduz 'stq' ao estado 'wait2' através do caminho ' $B$ '

4. escrita em $0 \times E 8 \times x \times x \times c o m ~ D 0=1$ e $D 1=0 \rightarrow$ conduz 'stq' ao estado 'rst' através do caminho ' $D$ "

\subsubsection{Programação}

Para a programação foi utilizada a linguagem AHDL. Os sinais foram divididos em grandes blocos funcionais. O diagrama hierárquico (Figura 43) mostra de forma esquemática as dependências e o local de utilização dos diversos blocos funcionais do projeto.

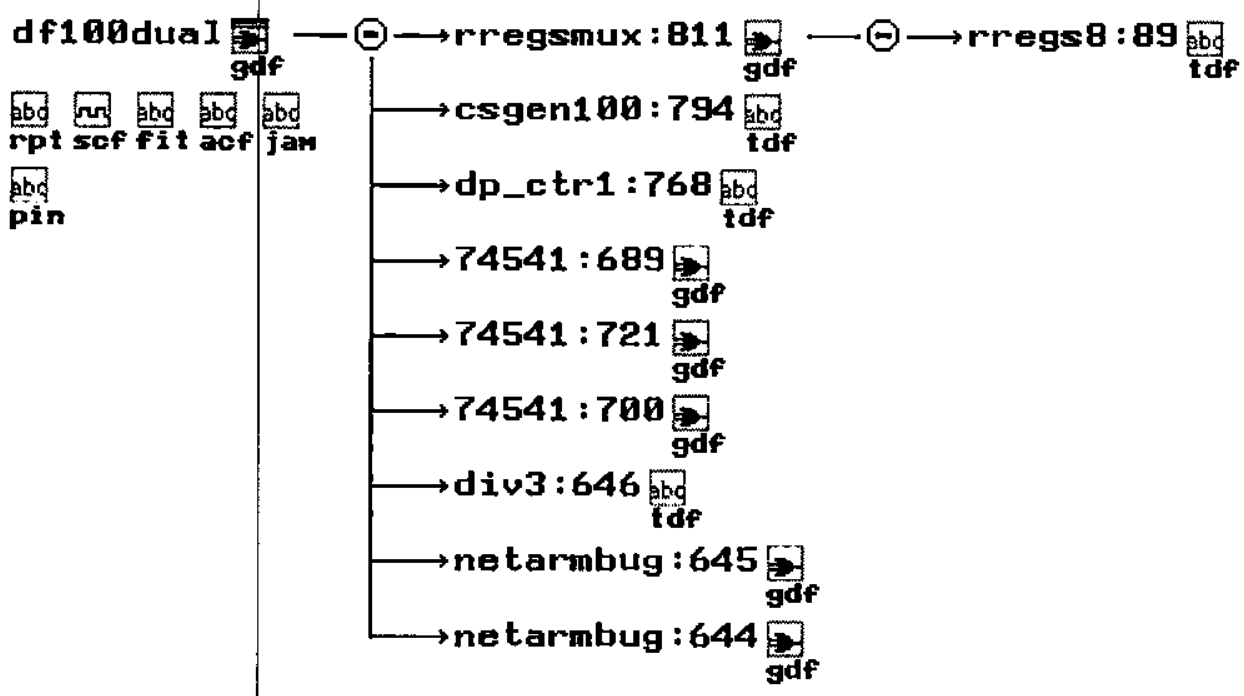

Figura 43 - Diagrama hierárquico 
O bloco dsgen100 (Figura 44) é responsável pela interface de alguns sinais do barramento da CPU com outros dispositivos do sistema. A partir dos sinais de entrada (com auxilio de decodificadores, maquinas de estado, registros internos, etc) são gerados sinais de "chip select", "output enable", "write enable", sinalização para transferências em modo "BURST" (rajada), linhas de controle, sinais para interface com outro barramento etc.

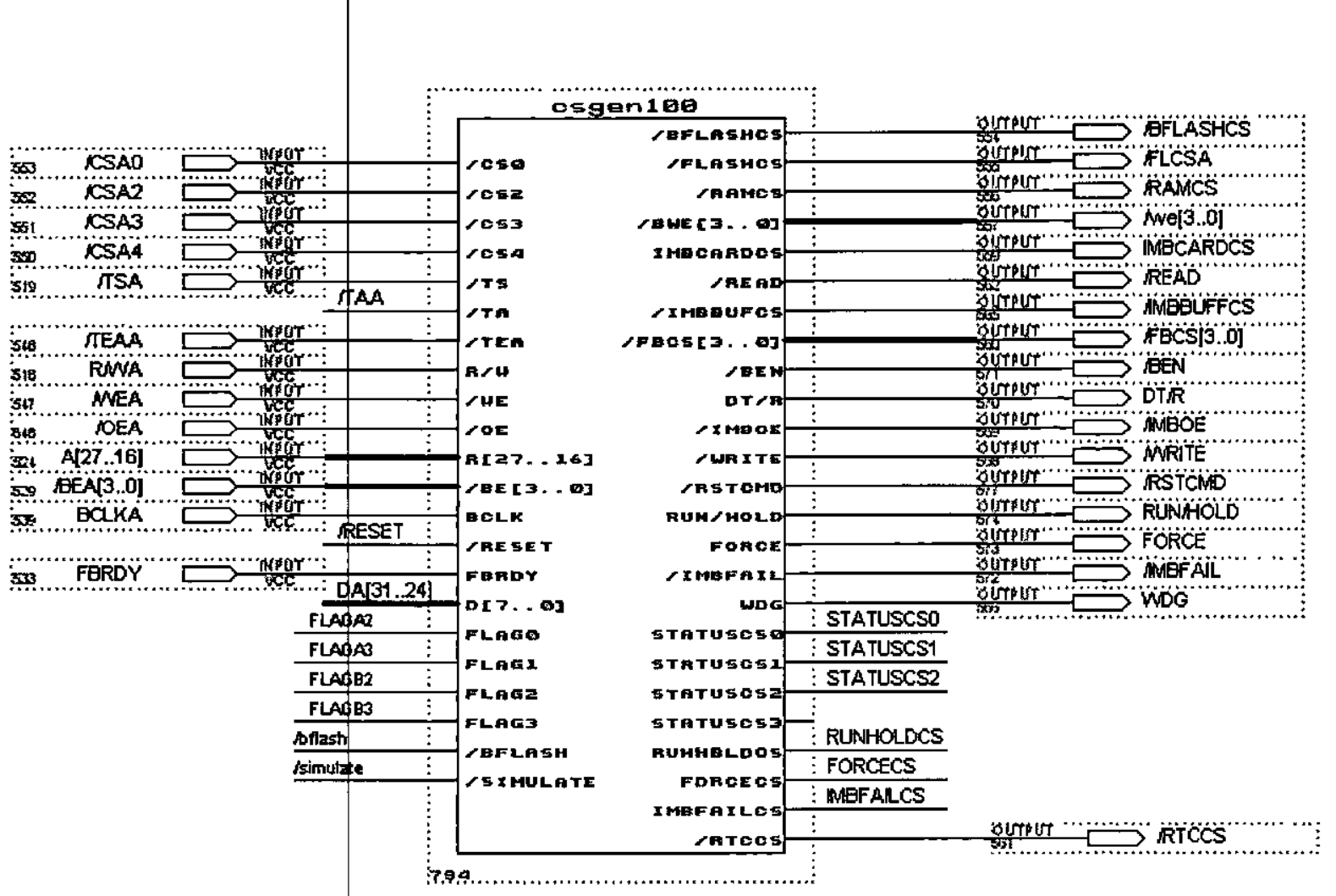

Figura 44 - Bloco csgen 100

No bloco rregmux (Figura 45) são implementadas as portas de leitura. Através dele, a CPU pode ler bytes mapeados no seu espaço de endereçamento. As linhas CS[7..0], acionadas pelo bloco csgen 100 , selecionam o byte e geram o sinal de "output enable", colocando o byte desejado no barramento de dados da CPU. Os bits lidos trazem informações de várias partes do sistema. 


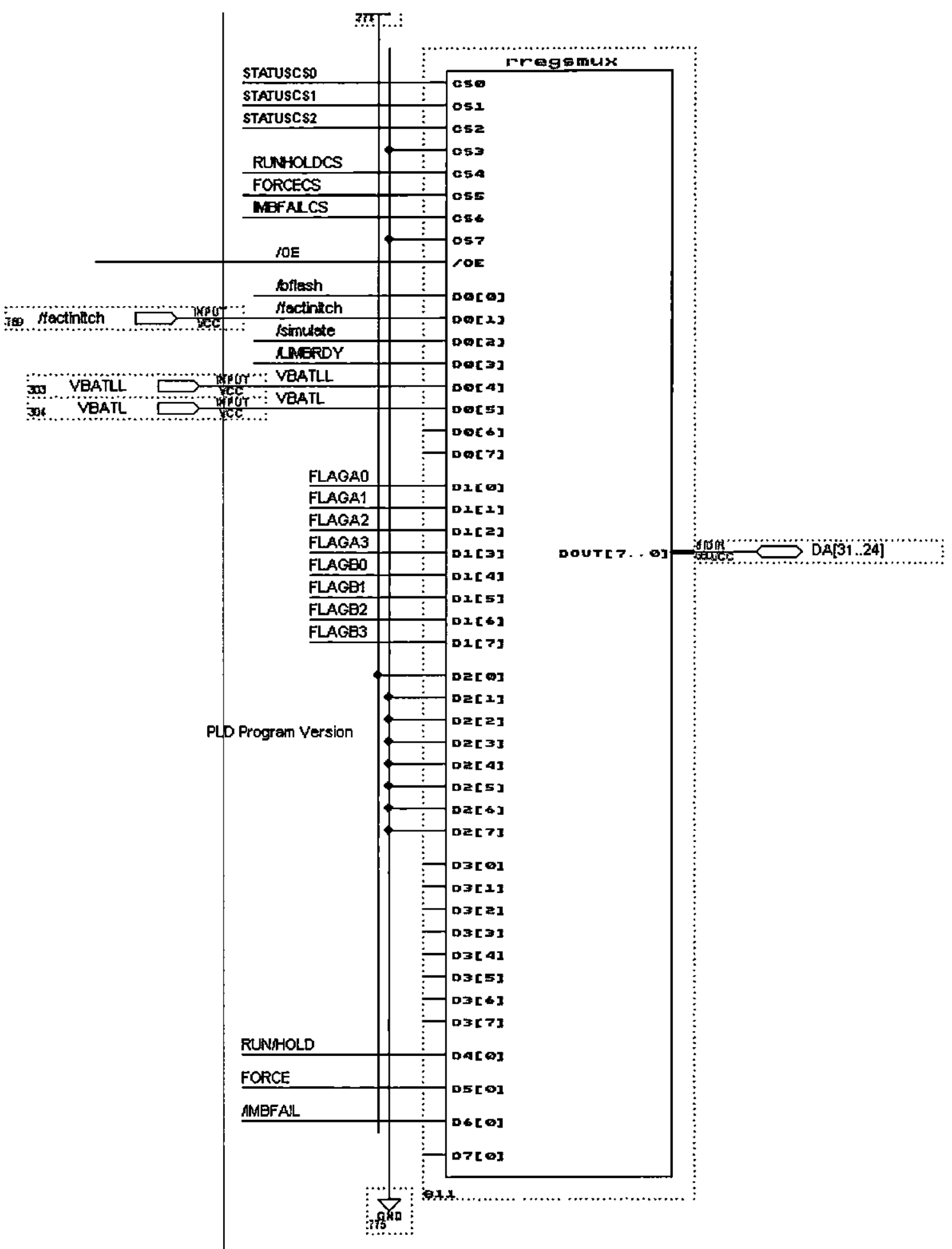

Flgura 45 - Bloco rregsmux

Já o bloco dp_ctrl (Figura 46) fará o controle de acesso à memória dual port, cuidando então deste tipo comunicação. 


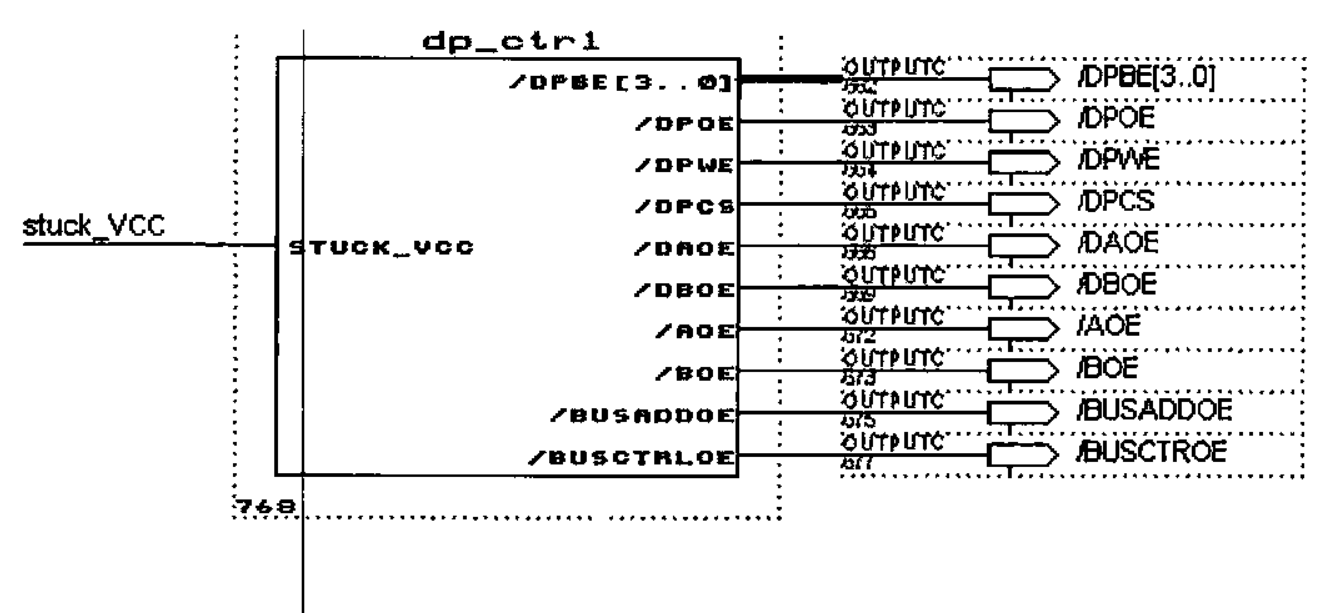

Flgura 46 - Bloco dp_ctrI

E finalmente alguns sinais de interrupção externa (Figura 47) deverão ser compatibilizados com a CPU.

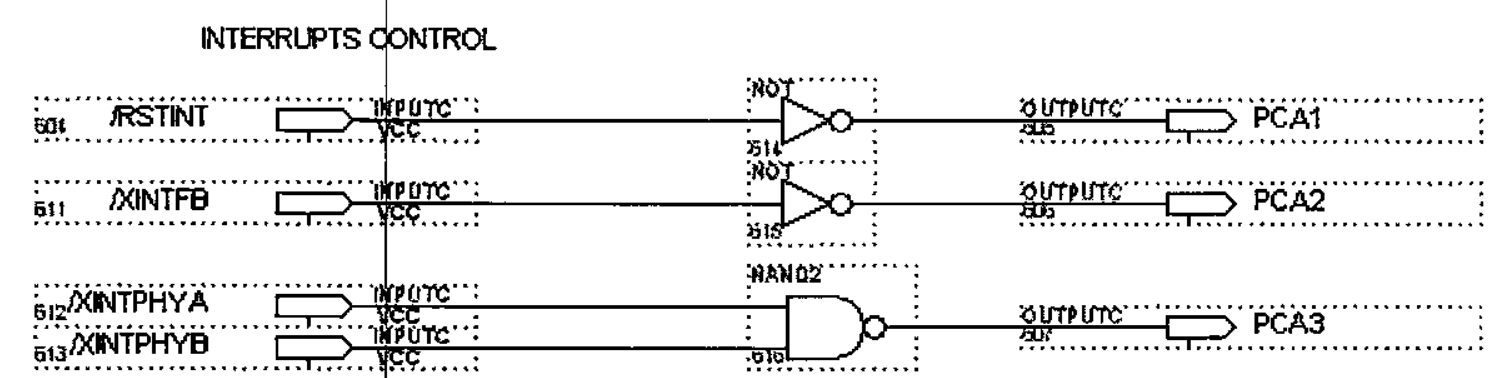

Figura 47 - Interrupçð̄es externas

A Figura 48 mostra os sinais de entrada e saída do FPGA.

Depois de definida e programada as funcionalidades básicas, foi feito um roteamento automático para definir as posiçōes dos pinos para a conclusão do circuito elétrico. Com este roteamento automático poderá se obter uma utilização otimizada do PLD. 


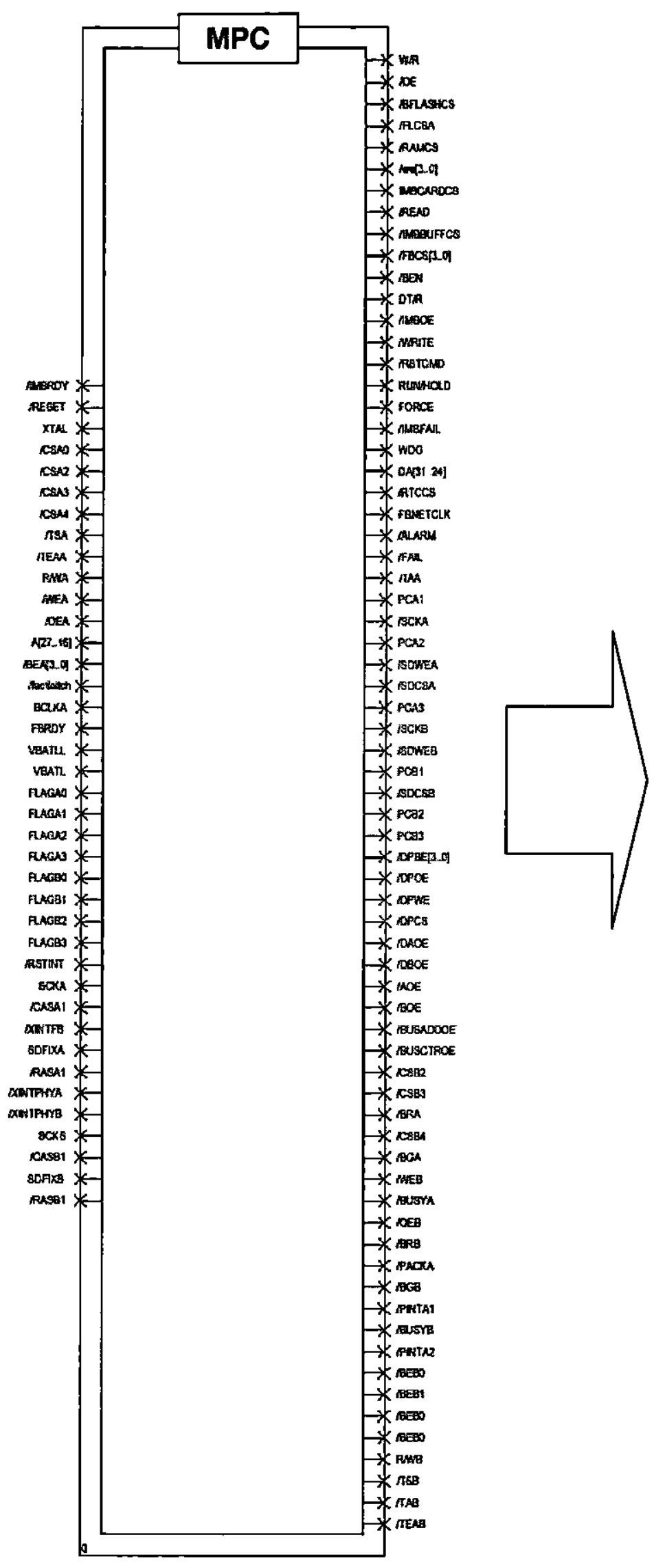

Figura 48 - SInals de entrada e saida 


\subsection{Circuito elétrico}

O circuito elétrico foi desenvolvido usando o software da Protel International Limited, o Design Explorer 99 SE (Versão 6.5.2, Service Pack 5), cuja tela pode ser vista na Figura 49. Todo esquemático do circuito elétrico pode ser visto na Seção 0.

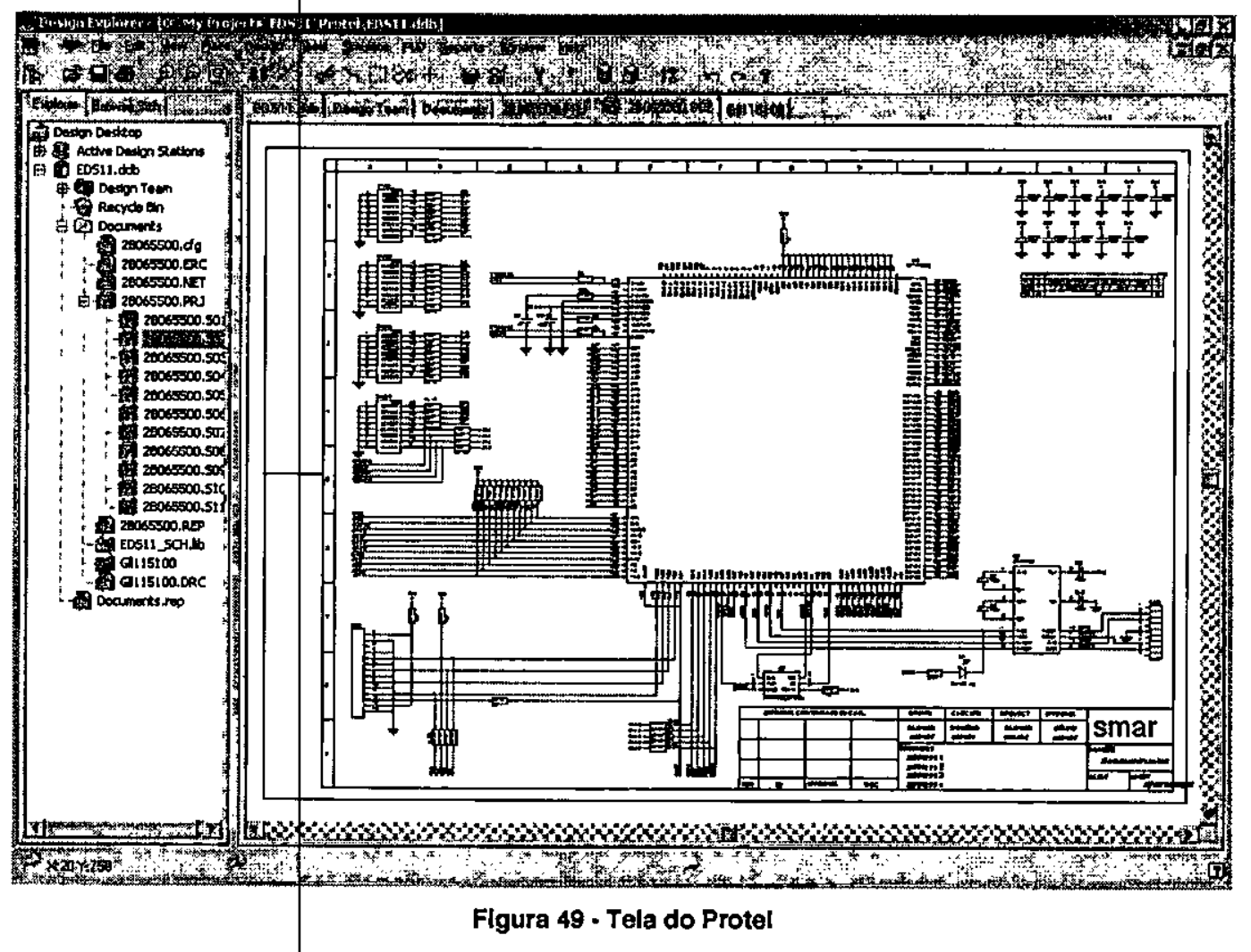

Usando este mesmo ambiente de desenvolvimento foi feita então o layout da placa que passou pelas seguintes fases:

\subsubsection{Definição das camadas da placa}

Decidiu-se criar uma placa de 6 camadas para facilitar a circulação dos sinais. Esta decisão foi baseada numa sugestão do fabricante do módulo processador $\mathrm{NET}+40$. Um visão geral da distribuição das camadas da placa pode ser vista na Figura 50 . 


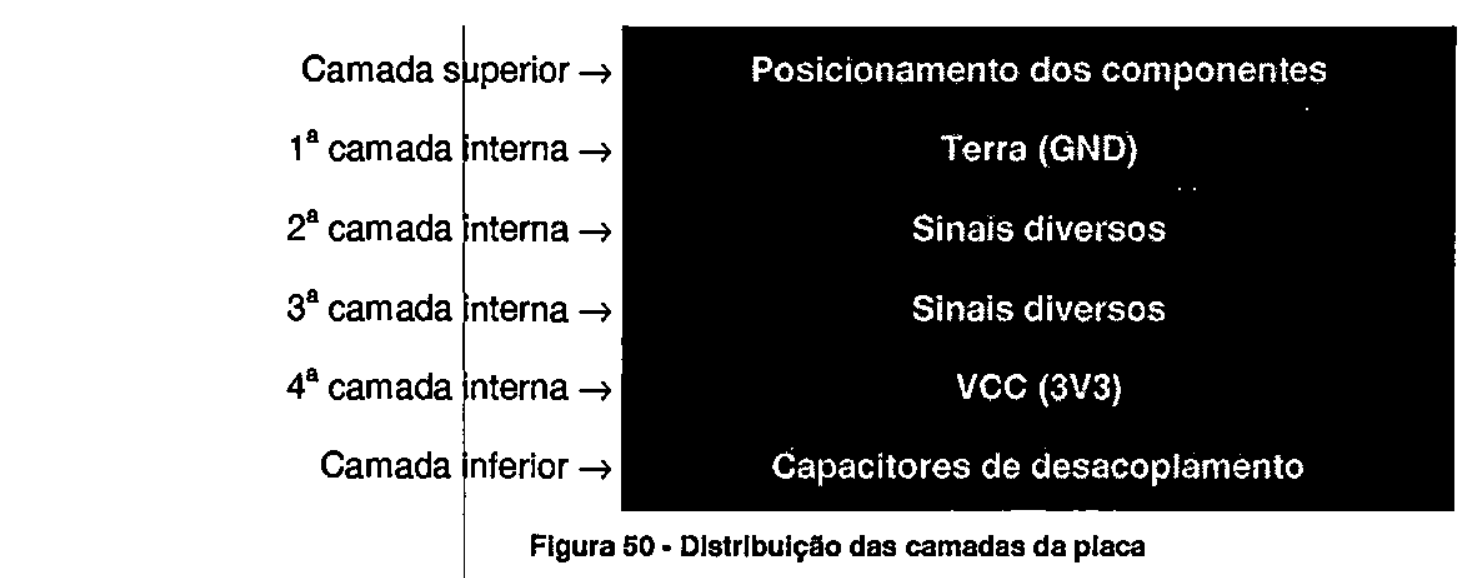

\subsubsection{Posicionamento dos componentes}

Para o posicionamento os componentes foram separados, na medida do possível, pela sua funcionalidade, obedecendo o diagrama de blocos apresentado na Figura 42. O objetivo disto foi tornar o roteamento mais fácil, uma vez que os componentes inter-relacionados foram colocados o mais próximo o possível. Conforme já comentado, os componentes foram posicionados na camada superior para facilidade de 'debug' e análise dos sinais elétricos durante os testes, e principalmente devido à liberdade com relação ao tamanho da placa.

\subsubsection{Roteamento}

O roteamento foi feito usando o roteamento automático da ferramenta de desenvolvimento, mas, o software conseguiu concluir somente $99,4 \%$ das ligações. A conclusão das ligações teve que ser feita manualmente. Aproveitou-se então para melhorar algumas ligações feitas automaticamente para deixar a placa com uma aparência mais limpa.

O lay-out da camada superior da placa pode ser visto na Figura 51.

\subsection{Produção}

seguintes:

A produção da placa envolveu três fases que serão descritas nas seções 


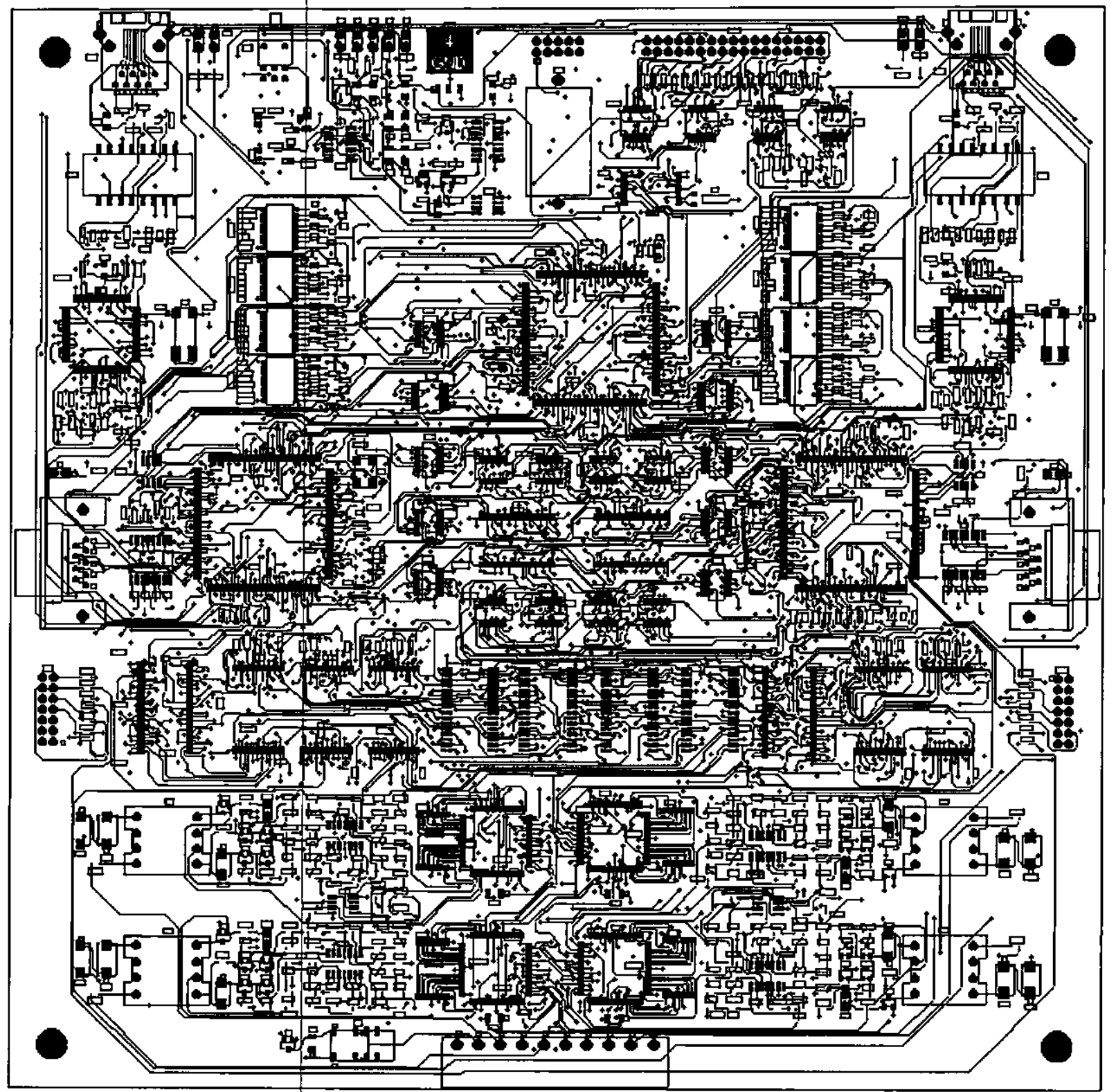

Flgura 51 - Camada superior da placa

\subsubsection{Fabricação da placa}

Terminada a disposição dos componentes e roteamento da placa foi feito uma conferência, o arquivo foi enviado para um fabricante de placa de circuito impresso. A empresa que fabricou a placa é a CadService, em Campinas - SP. O custo de confecção da placa foi doado pela Smar Equipamentos Industriais Ltda, em apoio a este projeto. 


\subsubsection{Aquisição dos componentes}

Os principais componentes foram requisitados aos fabricantes como amostras, e a outra parte foi doada pela Smar. $O$ fato dos componentes terem sido enviados como amostras causou maior demora na aquisição. Além disso, o fornecimento envolve importação o que torna o processo ainda mais demorado.

placa.

Após a chegada da maioria dos componentes iniciou-se a montagem da

\subsubsection{Montagem}

A montagem da placa foi feita no laboratório do Departamento de Desenvolvimento Eletrônico da Smar. Foram detectados algumas pequenas falhas de projeto e alguns erros no layout da placa. Mas todos problemas puderam ser contornados de alguma forma, o que permitiu que se avançasse no projeto.

Mesmo faltando alguns componentes para a montagem completa da placa, iniciou-se a fase de testes para que pudesse se concluir o trabalho dentro do tempo previsto.

\subsection{Testes Modulares}

Após a montagem de grande parte dos componentes, pode-se iniciar a fase de testes. Esta é uma fase muito importante, pois, os testes modulares já estarão validando partes do sistema.

Devido a esta validação, alguns dos resultados aqui apresentados serão comentados novamente no próximo capítulo, onde será feita a conclusão do trabalho.

de:

Para os testes, foi montada a bancada mostrada na Figura 52, que consta 
- Fonte alimentação.

- Osciloscópio digital.

- ICE (In Circuit Emulator) Debugger para acesso ao modulo processador via JTAG.

- Cabo serial 232.

- Cabo Ethernet.

- Cabo byte-blaster para programação do PLD.

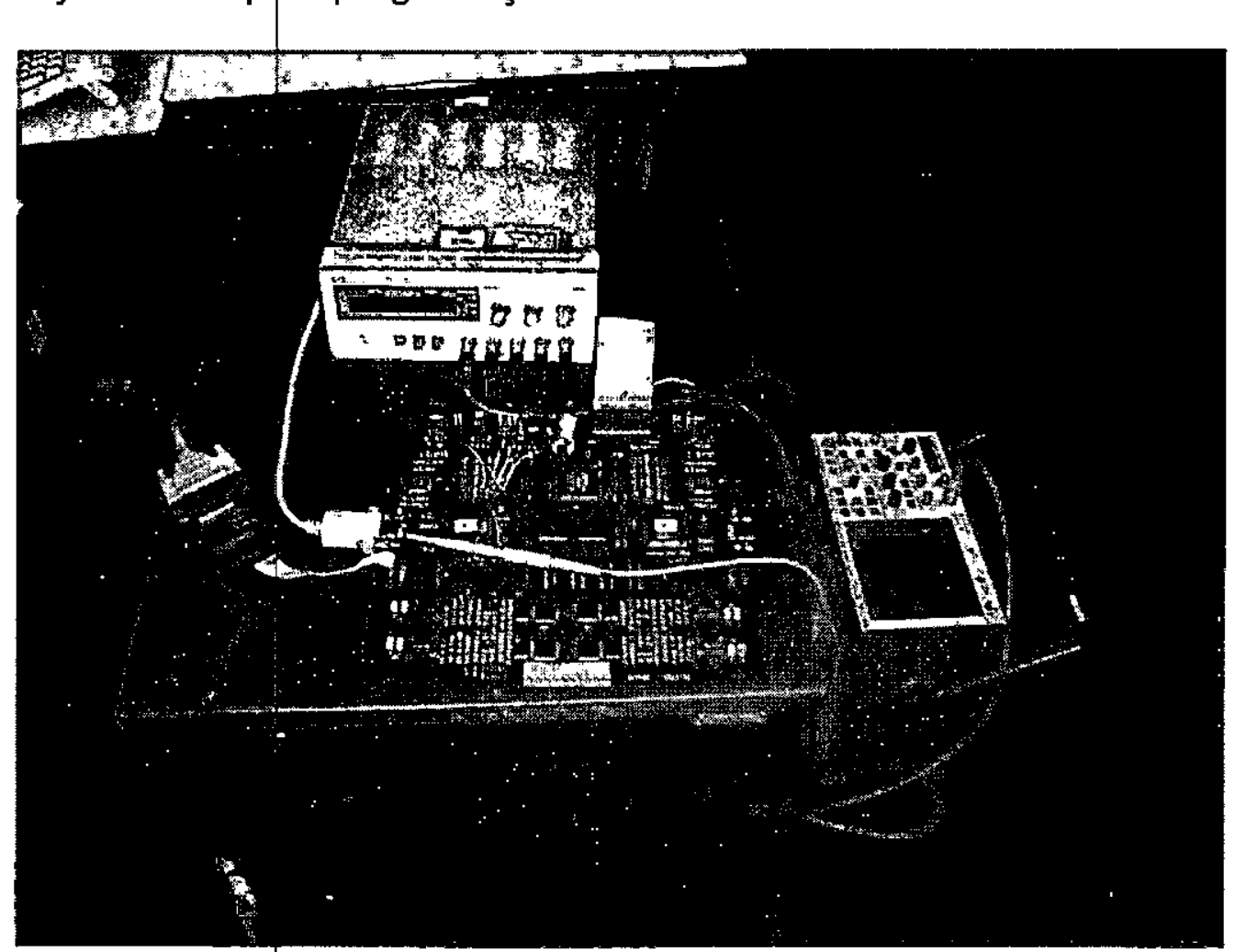

Figura 52 - Bancada de testes

Também hesta fase de preparação foram configurados os arquivos de configuração do NET+OS, para adaptar as características que são dependentes do hardware desenvolvido. As principais alterações observadas foram relacionadas ao clock do sistema, pois, o NET+OS estava baseado num clock de $18.432 \mathrm{MHZ}$ e este projeto está usando um oscilador de $32 \mathrm{MHz}$. Houveram também alterações quanto ao uso das portas seriais e paralelas.

\subsubsection{Geração do Chip-select}

O primeiro passo nos testes foi a simulação funcional no MAX+Plus II para determinar se estavam sendo gerados os chip-selects necessários para acesso às memórias. A Figura 53 mostra uma cópia da tela de simulação. 


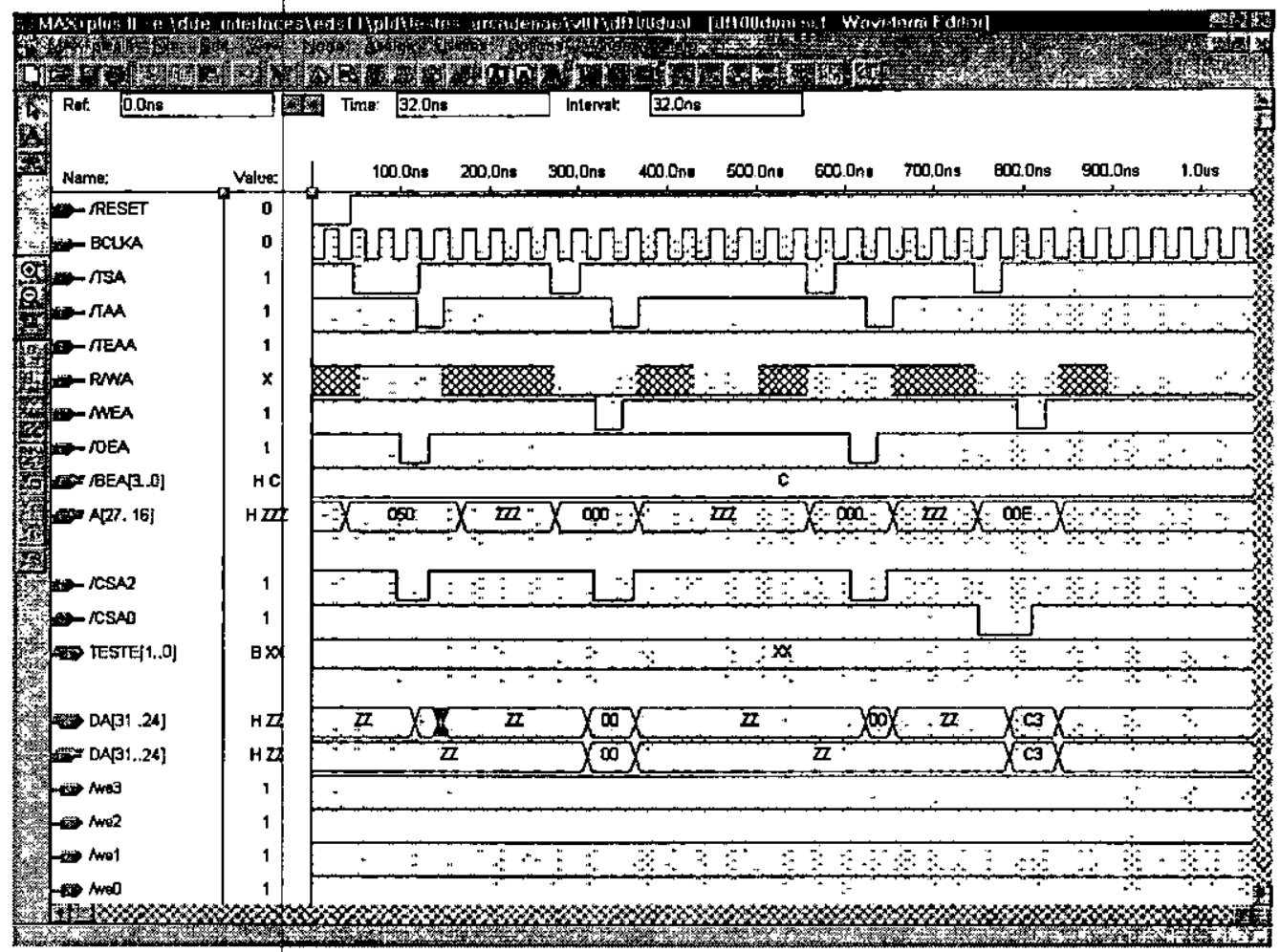

Flgura 53 - Tela de simulaçāo dos chip-selects

Pode-se observar que tantos os chip-selects (/CSA0 e /CSA2) estão sendo ativados, como também o sinal de reconhecimento da transmissão (/TAA).

\subsubsection{Gravação do PLD}

Através do programa MAX+Plus II foi realizada a compilação do programa do PLD (Figura 54) e também a gravação via conector JTAG (usando o cabo byteblaster).

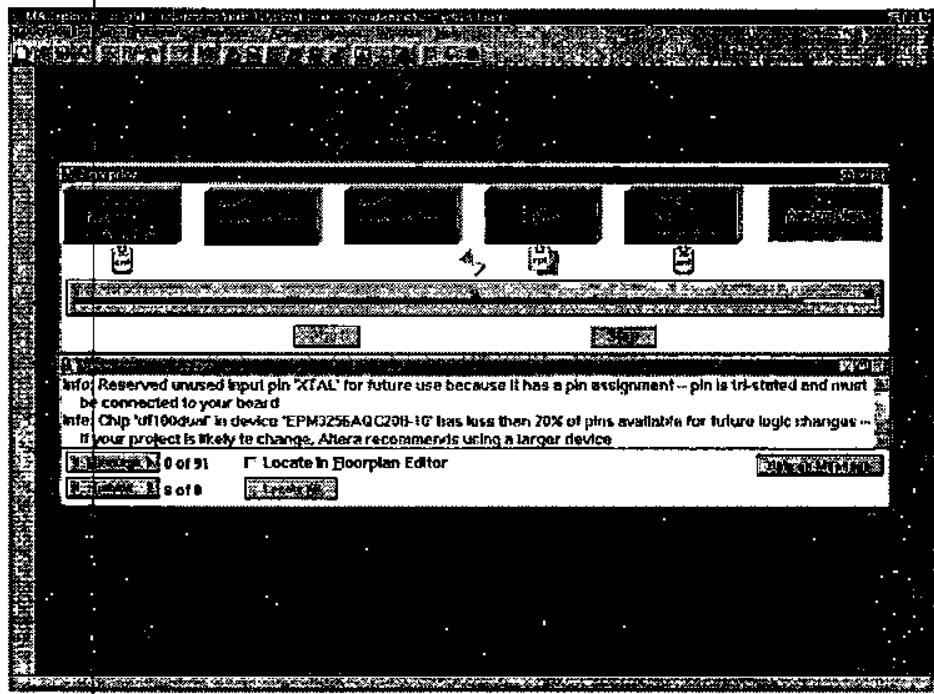

Flgura 54 - Tela de compllação do PLD 
A tela da programação pode ser vista na Figura 55. Como o resultado foi positivo, pode-se verificar que parte do circuito já estava funcionando, principalmente relacionada ao circuito de alimentação e reset.

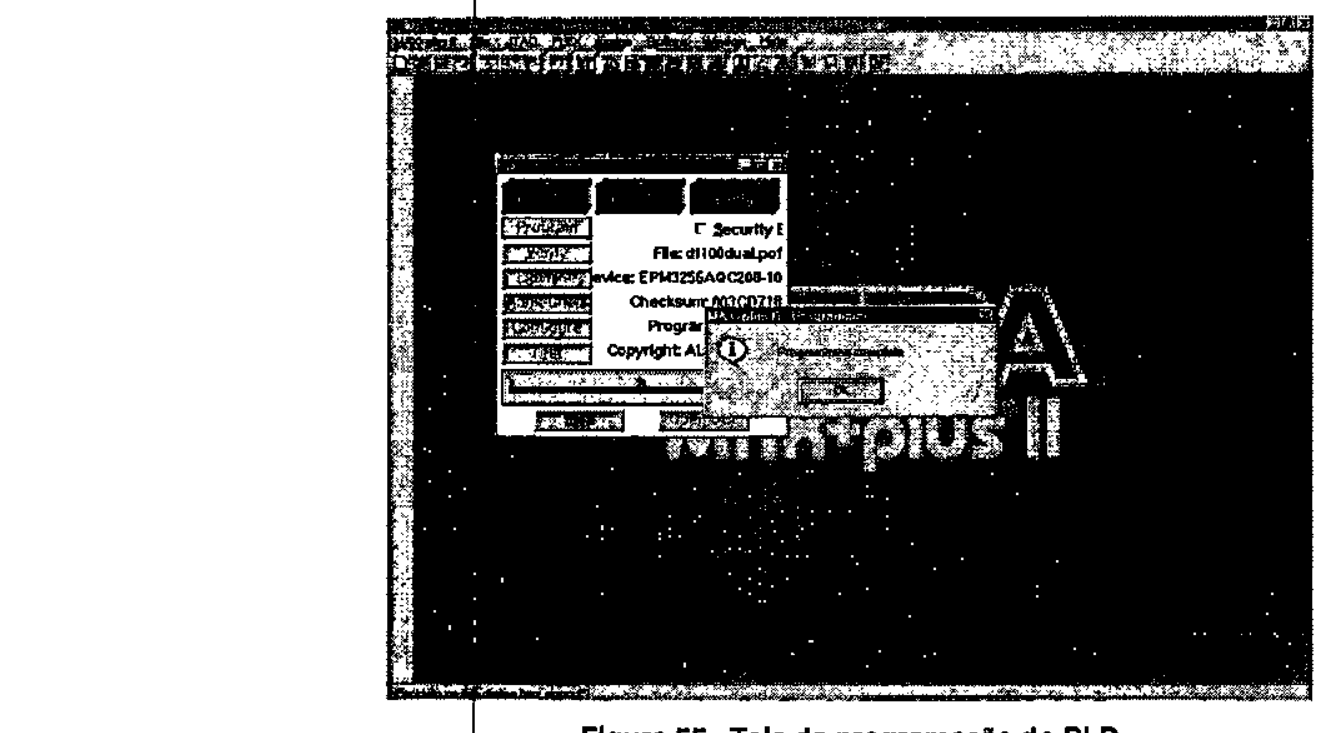

\subsubsection{Comunicação com a CPU via ICE}

Antes de se prosseguir foram verificados alguns sinais importantes como alimentação e clock.

Então, através de um programa exemplo que acompanha o ambiente de desenvolvimento do software (Figura 56), pode se criar uma aplicação para os testes de comunicação.

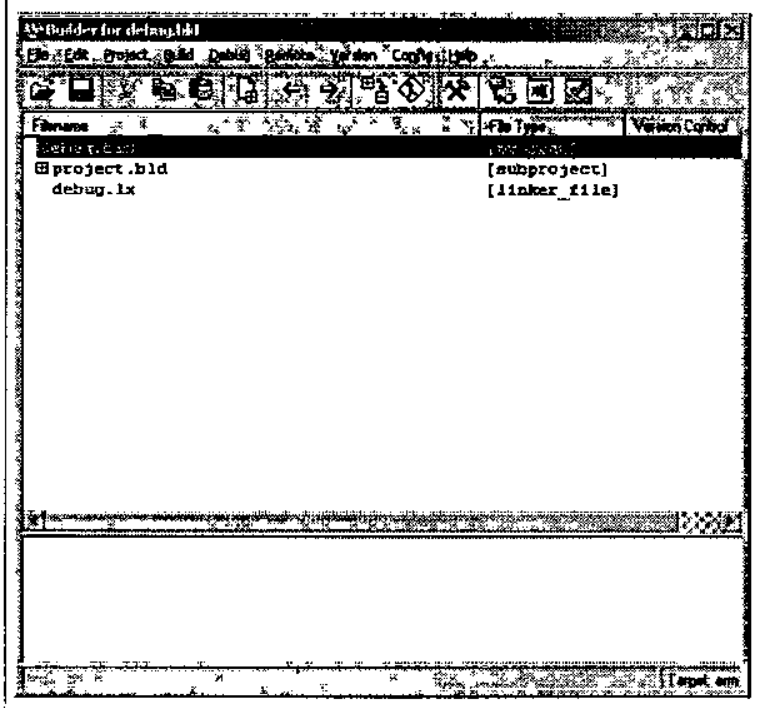

Figura 56 - Amblente de desenvolvimento do MULTI 2000 
A aplicaçã̃o foi então compilada, e usando o ICE Debugger conectou-se a um dos módulos processadores da placa e iniciou o download do programa para a RAM. Mas esta escrita do programa na memória (download) foi interrompida após a escrita dos registros do módulo processador. Foi detectada falhas de montagem, principalmente curto na soldagem dos componentes. Corrigidos estes problemas foram feitos alguns testes de escrita na memória usando a ferramenta de debug (Figura 57).

Aqui são mostrados como exemplo apenas duas escritas, mas, na realidade foram realizados vários testes para garantir que não havia mais curto nas linhas de endereço, nem nas de dados. Como as escritas e leituras foram corretas, pôde-se então realizar uma escrita completa do programa na memória da placa. A Figura 58 mostra uma tela com a progressão desta escrita.

Estes testes foram repetidos para o outro módulo processador, conseguindo desta forma validar grande parte do sistema. 


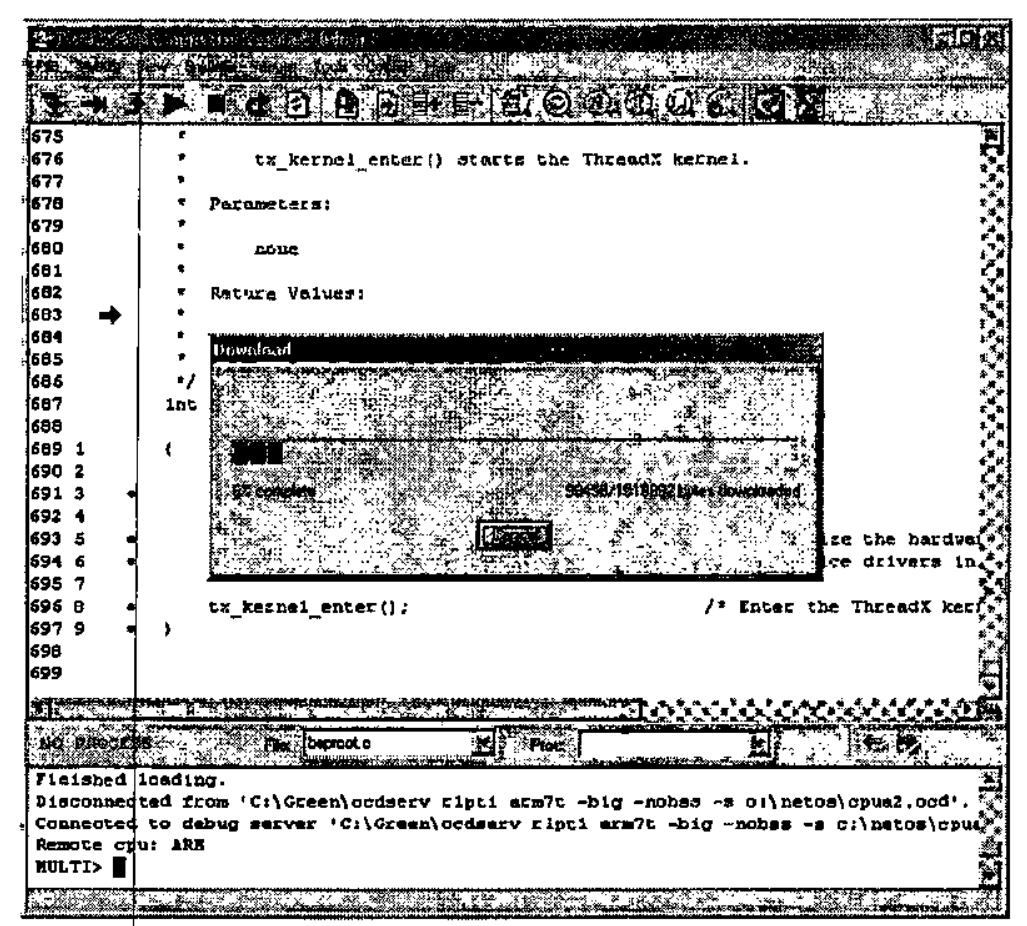

Figura 58 - Escrita do programa na memórla da placa

\subsubsection{Comunicação Serial}

Os testes então avançaram para as portas de comunicação. Iniciou-se pela porta serial, pois, ela é muito importante para o ambiente de desenvolvimento, uma vez que ela pode ser usada para mandar informaçōes do programa em execução, mas, principalmente porque ela é usada para configurar os parâmetros IP, como endereço IP, máscara de subrede e gateway padrão.

O grande problema para a serial foi casar a freqüência utilizada para o sistema $(32 \mathrm{MHz})$ com as taxas de transmissão padrão. Foram então desenvolvidos os cálculos para obtenção da maior taxa de transmissão padrão possível para este projeto. Os cálculos foram baseados na seguinte fórmula [33]:

$$
\text { bit_rate }=\frac{F_{X T A L}}{2 * 5 * 16 *(\text { divisor }+1)}
$$

Onde:

- Bit_rate é a taxa de transmissão desejada.

- FXtal é a freqüência do sistema.

- Divisor é o valor a ser armazenado no registro de configuração da serial.

- O número 16 representa do modo que está sendo usado (assíncrono) 
Isolando $b$ divisor desta fórmula pode-se chegar a seguinte equação:

$$
\text { divisor }=\frac{F_{X T A L}}{2 * 5 * 16 * \text { bit_rate }}-1
$$

O erro na transmissão pode ser calculado a partir da seguinte fórmula:

$$
e r r o=\left|\frac{b i t_{-} r a t e_{\text {obtido }}-b i t_{-} r a t e_{\text {desejado }}}{b i t_{-} r a t e_{\text {desseado }}}\right|
$$

Os cálculos foram então desenvolvidos a partir da taxa de transmissão de

\begin{tabular}{|c|c|c|c|}
\hline & & (nod & (6od \\
\hline 115200 & 0.73611 & $73.6 \%$ & $13.2 \%$ \\
\hline 57600 & 2.47222 & $15.7 \%$ & $13.2 \%$ \\
\hline 38400 & 4.20833 & $4.17 \%$ & $13.2 \%$ \\
\hline 28800 & 5.94444 & $15.7 \%$ & $0.80 \%$ \\
\hline 14400 & 12.88888 & $6.84 \%$ & $0.80 \%$ \\
\hline 9600 & 19.83333 & $4.17 \%$ & $0.80 \%$ \\
\hline
\end{tabular}
115200 bps e os resultados, para um $F_{X T A L}=32 \mathrm{MHz}$, foram resumidos na Tabela 10 .

Tabela 10 - Cálculo das taxas padróes possíveis

Notou-se que abaixo de 28800 bps conseguia-se uma baixa taxa de erro nas transmissões. Notou-se que para taxas mais baixas os erros eram menores, então, nesta fase de teste, configurou-se o software do PC e software da placa para transmissões a 1200 bps. Colocando o canal A1 do osciloscópio no pino de transmissão do conector DB-9 da placa pode-se obter a forma de onda mostrada na Figura 59. 


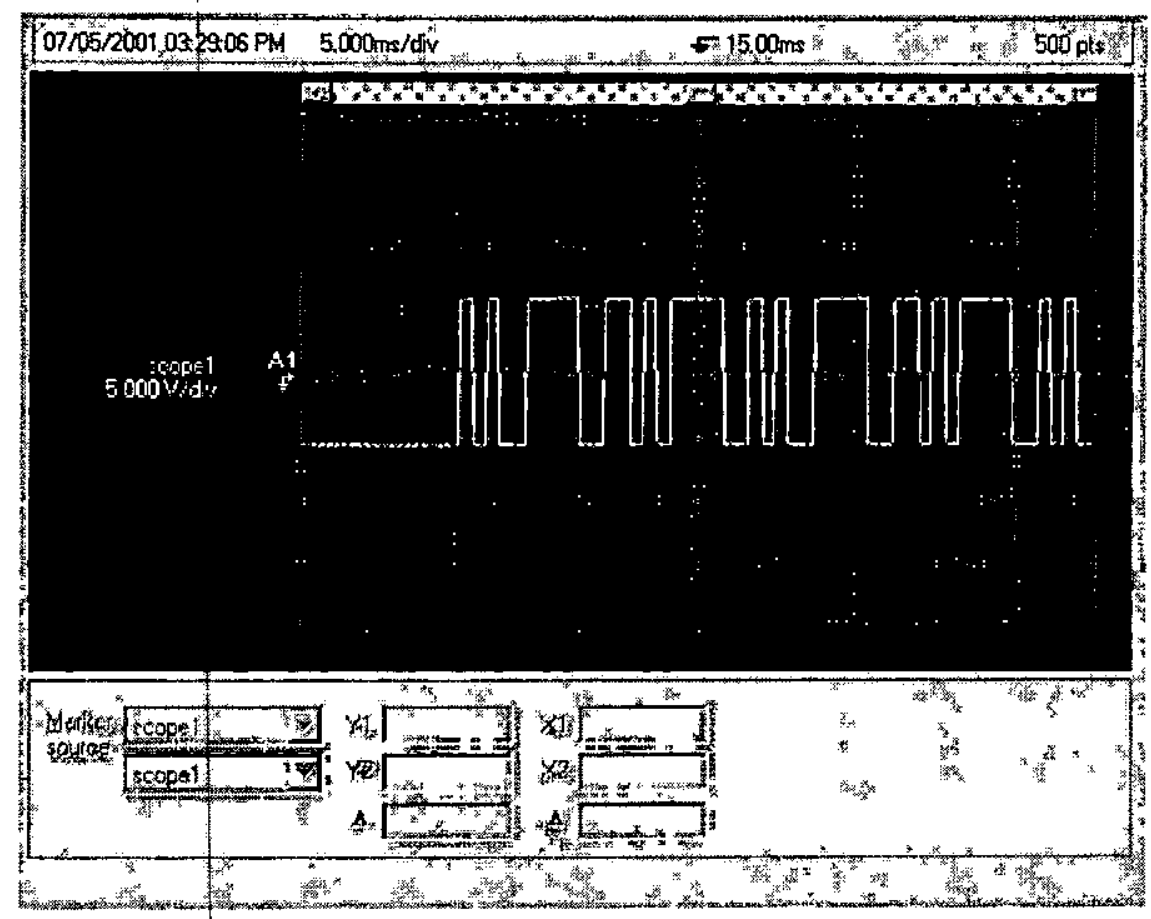

Figura 59 - Visualizaçăo de uma transmissão no osciloscópio

A seguir foi alterada a configuração para 9600 bps e recompilada a aplicação de teste. Esta aplicação foi descarregada na placa via ICE e então, através do Hyper Terminal do Windows pôde-se configurar o endereço IP, a máscara de subrede e o gateway padrão (Figura 60 ) permitindo então que os testes da comunicação Ethernet fossem realizados.

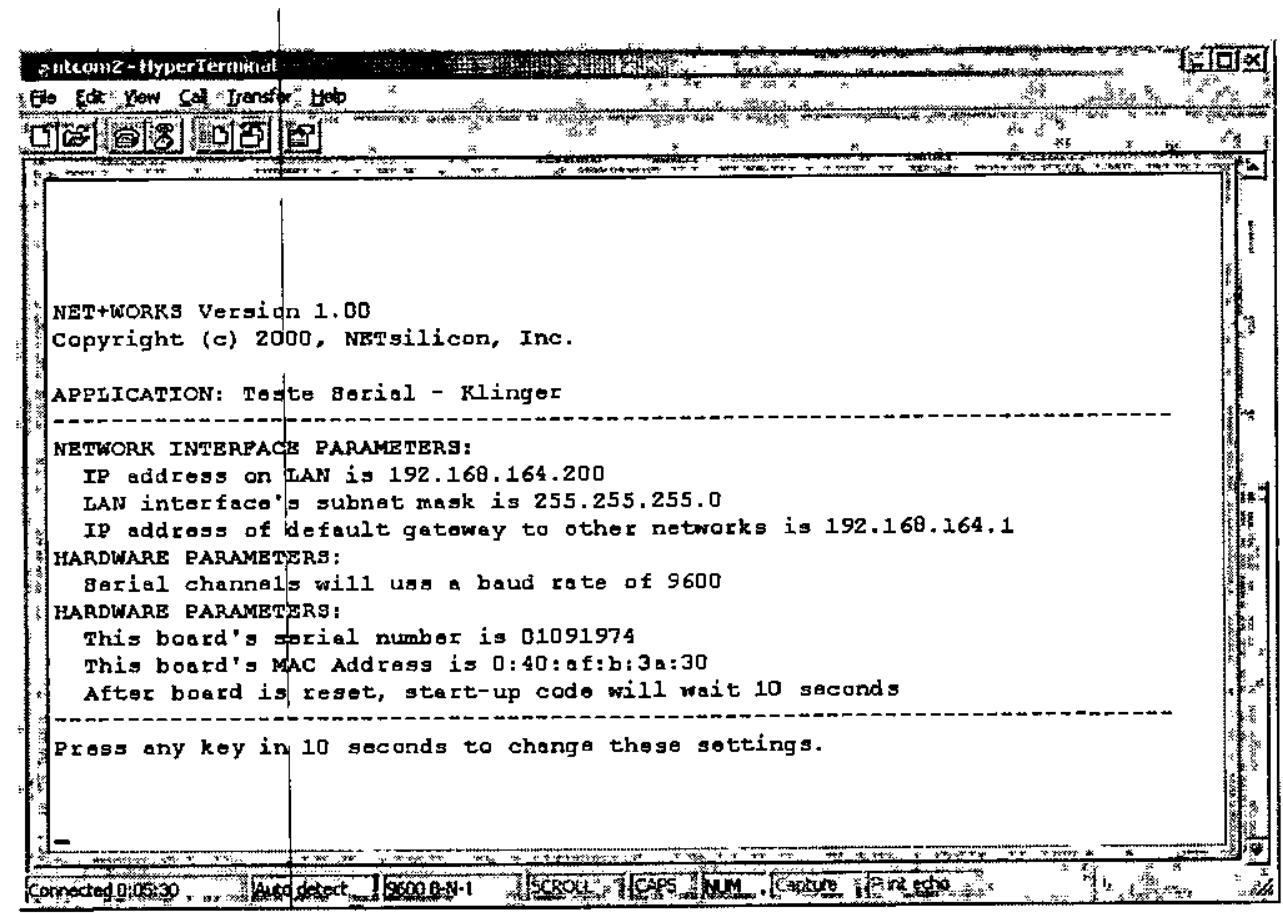

Flgura 60 - Conflguração dos parametros IP 


\subsubsection{Comunicação Ethernet}

Para este teste foi compilado um dos programas de exemplo da plataforma de desenvolvimento (NAHTTP), o qual implementa um servidor Web e permite então que seja visualizados os 'frames' recebidos e transmitidos pela placa.

Para esta, visualização utilizou-se o software Microsoft Network Monitor, cuja tela principal podel ser vista na Figura 61. Note que o total de 'frames' Ethernet capturados nesta aplicação foram 105 incluindo recepção e transmissão.

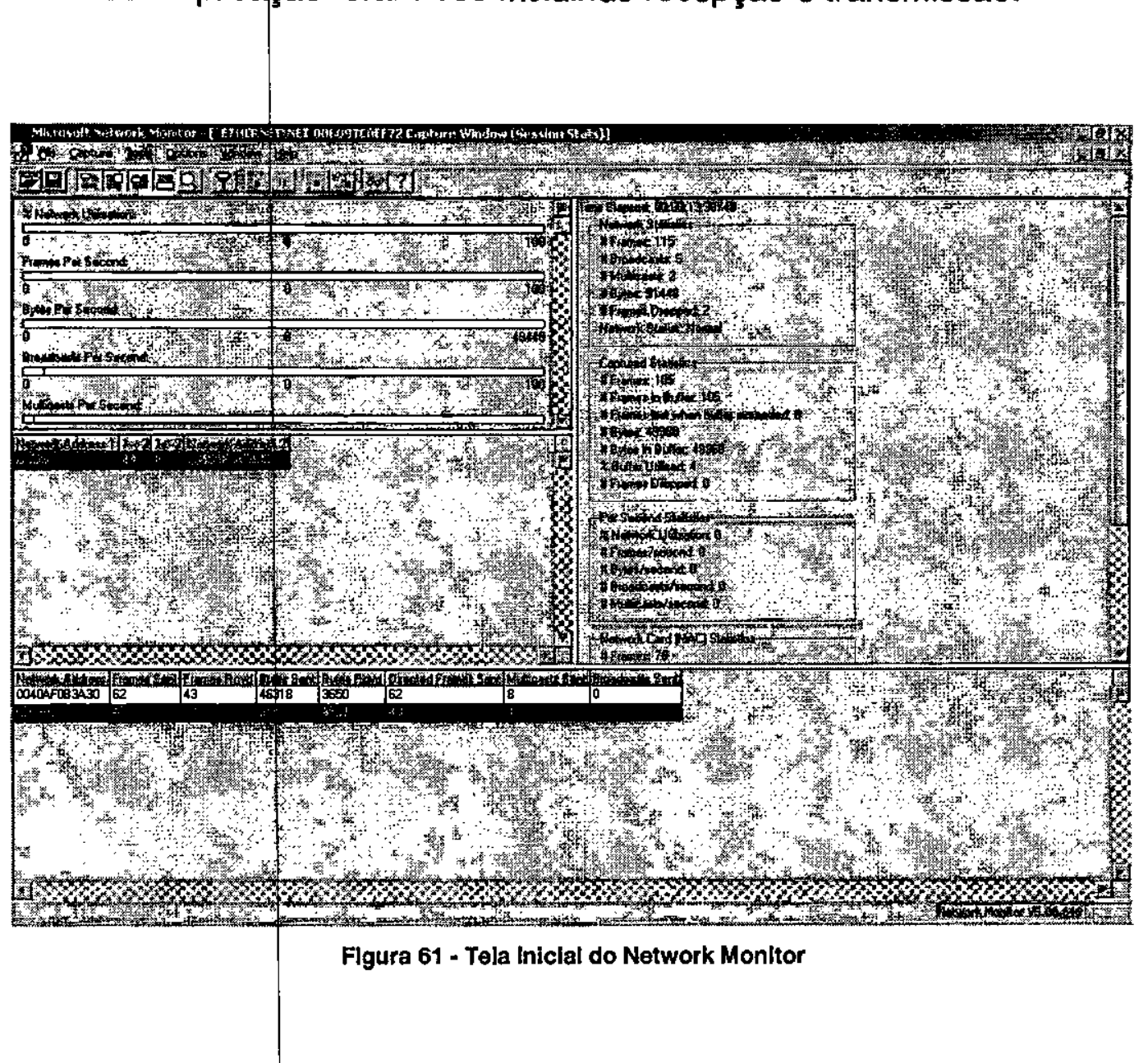

Ao se visualizar estes frames (Figura 62) pode-se ver o tipo de protocolo de cada um, de onde e para onde foi enviado, e ao se selecionar um frame individual, pode-se ver suas partes componentes, como cabeçalho Ethernet, cabeçalho IP, cabeçalho TCP e finalmente os dados transmitidos (Figura 63). 


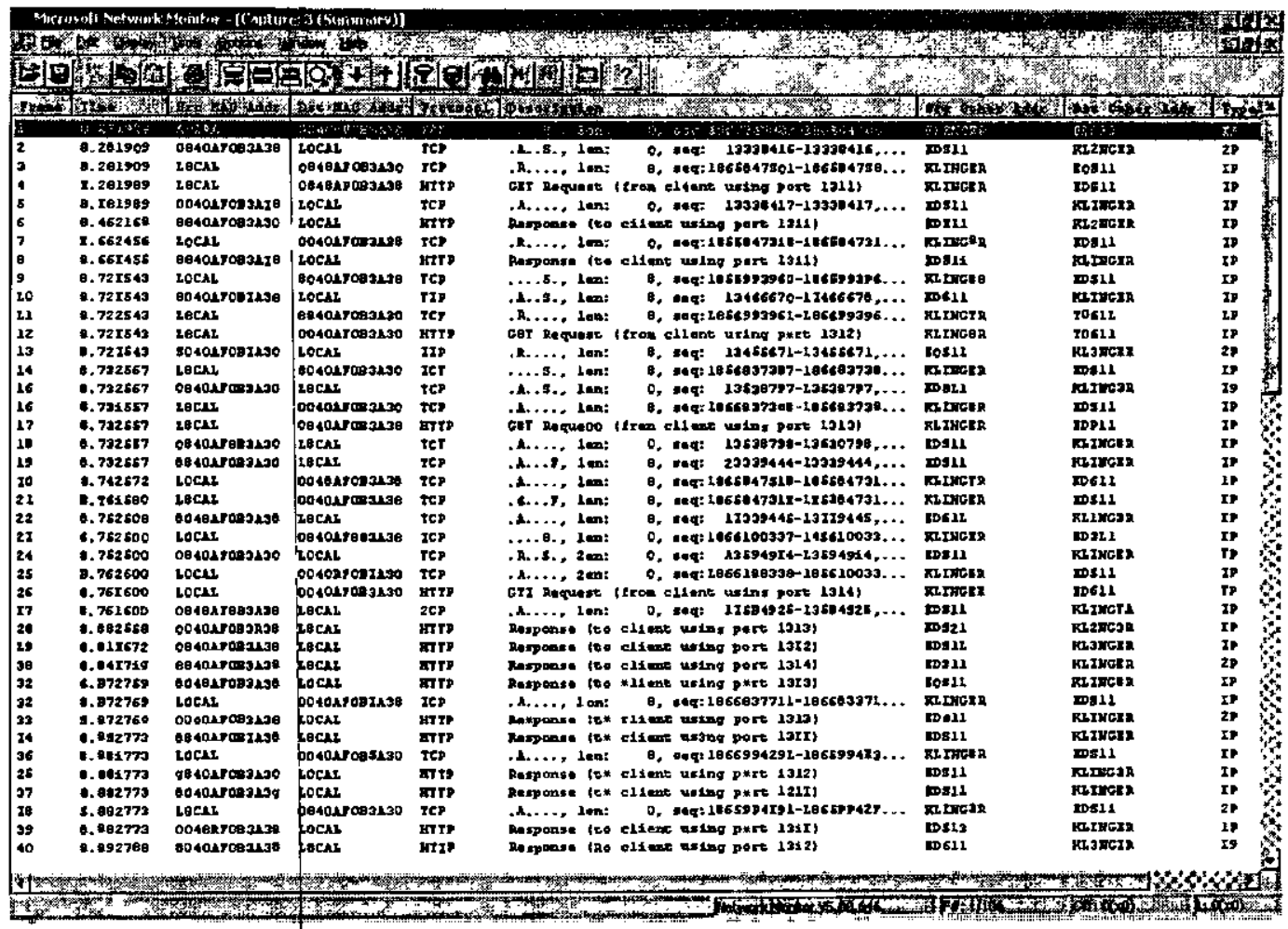

Figura 62 - Visualização dos frames

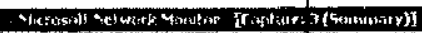

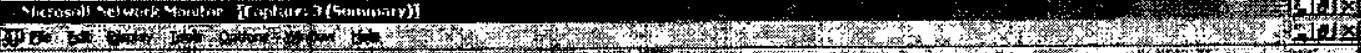

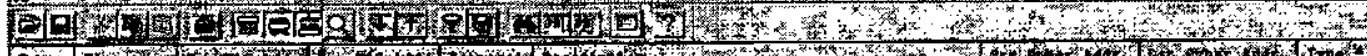

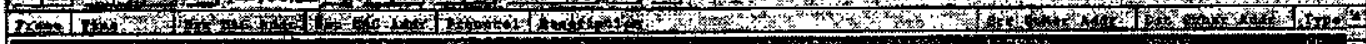

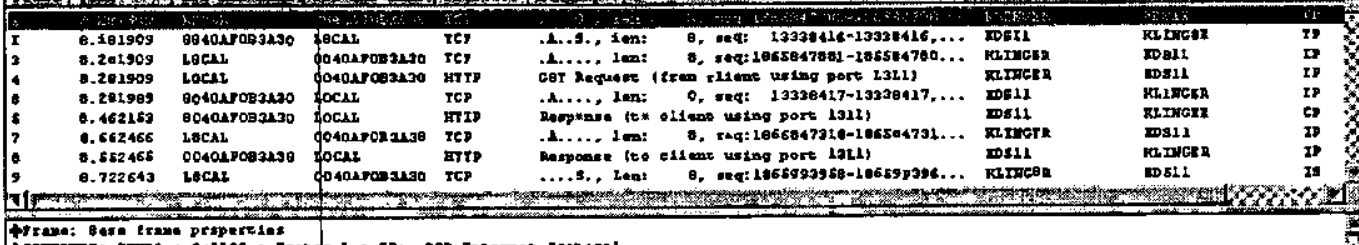

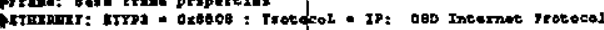

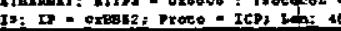

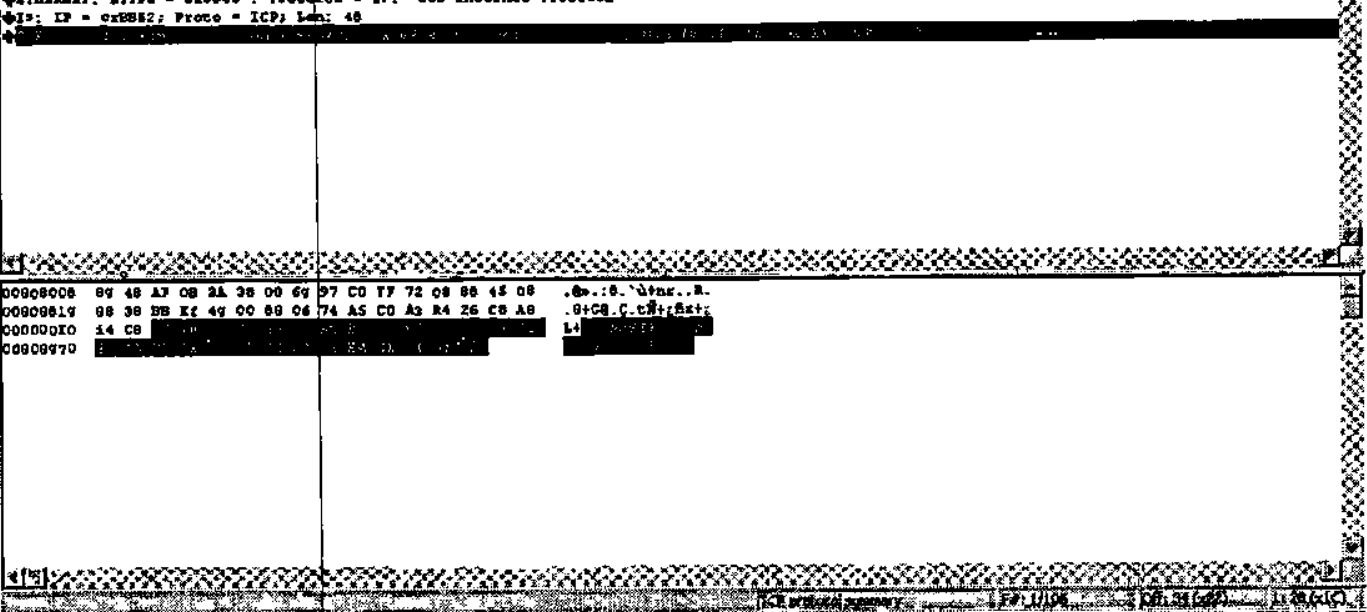

Figura 63 - Estrutura $\theta$ composlção de um frame 
Através da análise de vários frames, pode-se verificar que a comunicação Ethernet deste módulo processador estava funcionando o que permitiu então rodar as aplicações que estarão sendo mostradas no Capítulo 9.

\subsection{Considerações Finais}

Através dos testes modulares pode-se validar grande parte do projeto:

- Programação do PLD

- Escrita nas memórias RAM das duas CPUs

- Escrita na memória NVRAM (que está fazendo o papel de ROM para a CPU A)

- Comunicação serial das duas CPUs.

- Comunicação Ethernet na CPU A

Como foi mostrado, até o momento somente foi possível deixar um das portas Ethernet funcionando. $O$ funcionamento da outra porta ainda requer um pouco mais de tempo para localização e correção da falha.

É importante salientar que o funcionamento da segunda porta é fundamental para a validação completa do sistema, mas a falta e os atrasos de alguns componentes impossibilitaram o avanço dos testes. 


\section{Conclusão}

Este trabalho se mostrou mais complexo do que o previsto inicialmente, pois, as fases do projeto eram relativamente longas: projeto do circuito elétrico, programação do PLD, fabricação da placa, aquisição de componentes e os testes. Todas estas fases seryiram de aprendizado do processo de desenvolvimento de um hardware, uma vez que esta não era uma área muito familiar para o aluno de mestrado, pois o mesmo era da área de desenvolvimento de software.

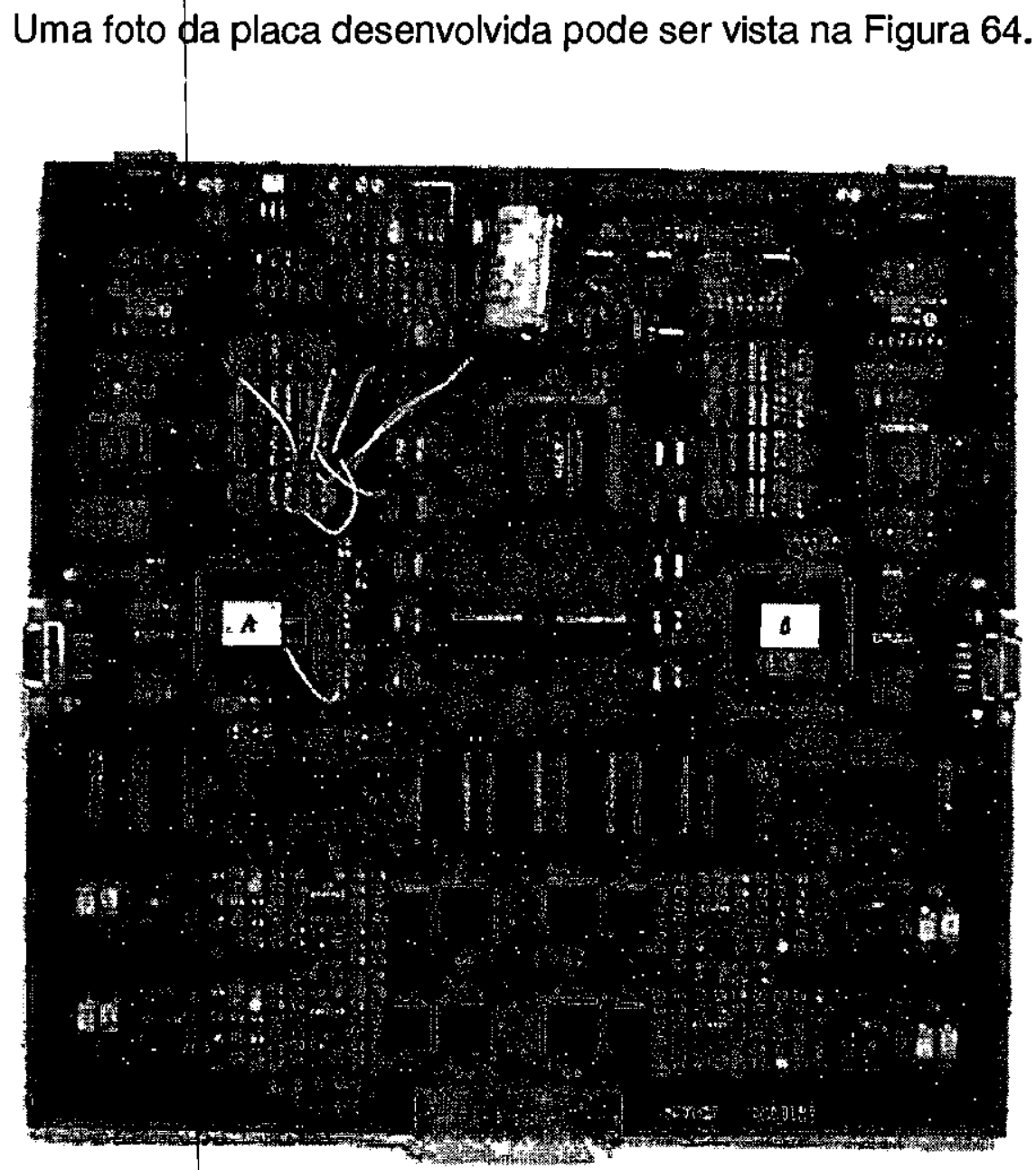

Figura 64 - Foto da placa desenvolvida 


\subsection{Contribuições}

Várias atividades foram realizadas para alcançar o objetivo proposto, mas a principal contribuição lfoi o aprendizado de metodologias avançadas para o projeto de hardware. Pôde-se também analisar tecnologias emergentes e sua aplicabilidade para a indústria nacional. Deve-se ressaltar aqui, a flexibilidade que pode ser obtida em sistemas reconfiguráveis, representando isto uma grande vantagem arquitetural, pois, as alteraçöes podem ser feitas mais rapidamente.

Uma aplicação que passou a ser explorada por este trabalho foi a utilização da tecnologia Web para equipamentos embutidos, que pode ser feito através da incorporaçăo de um servidor Web no equipamento. Este tipo de solução criará um leque muito grande de pesquisas, uma vez que conceitos consolidados na Ethernet comercial (ou doméstica) serão validados para a Ethernet industrial. O equipamento que está sendo aqui desenvolvido será uma ótima plataforma de teste para esta tecnologia e poderá ser aproveitado em trabalhos futuros.

Apesar do atraso de alguns componentes ter atrasado a montagem completa da placa o sistema já em funcionamento permitiu explorar diversas características inovadoras em sistemas embutidos que estarão sendo mostradas na seção seguinte.

\subsection{Resultados}

O sistema de desenvolvimento vem com um utilitário que possui três componentes básicos (Figura 65), a saber:

- FTP Download - transfere o programa imagem do PC para a placa.

- Conversor HTML - converte páginas HTML em arquivos $C$ que podem ser compilados com a aplicação.

- Gerador de aplicações - cria uma aplicação padrão, com alguns recursos básicos já incluídos.

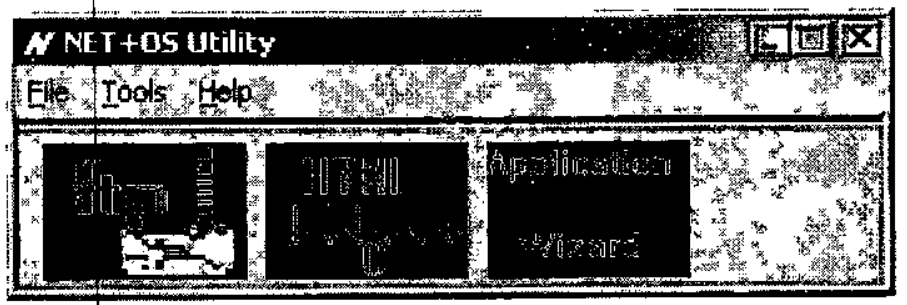

Figura 65 - NET+OS Utlliy 
Estes utilitários permitiram que fossem realizados testes de alto nível na porta Ethernet que estava funcionando.

Foi compilada uma aplicação chamada NAFTPROM, que nada mais é do que um exemplo de implementação de um servidor de FTP. Esta aplicação foi carregada na memória do equipamento através ICE Debbuger. Uma vez que ela estava rodando na ROM, esta aplicação faz com que o equipamento seja capaz de se comunicar com o software FTP Download (que é um cliente FTP) permitindo que uma nova aplicação seja escrita na memória ROM da placa, conforme mostrado na Figura 66.

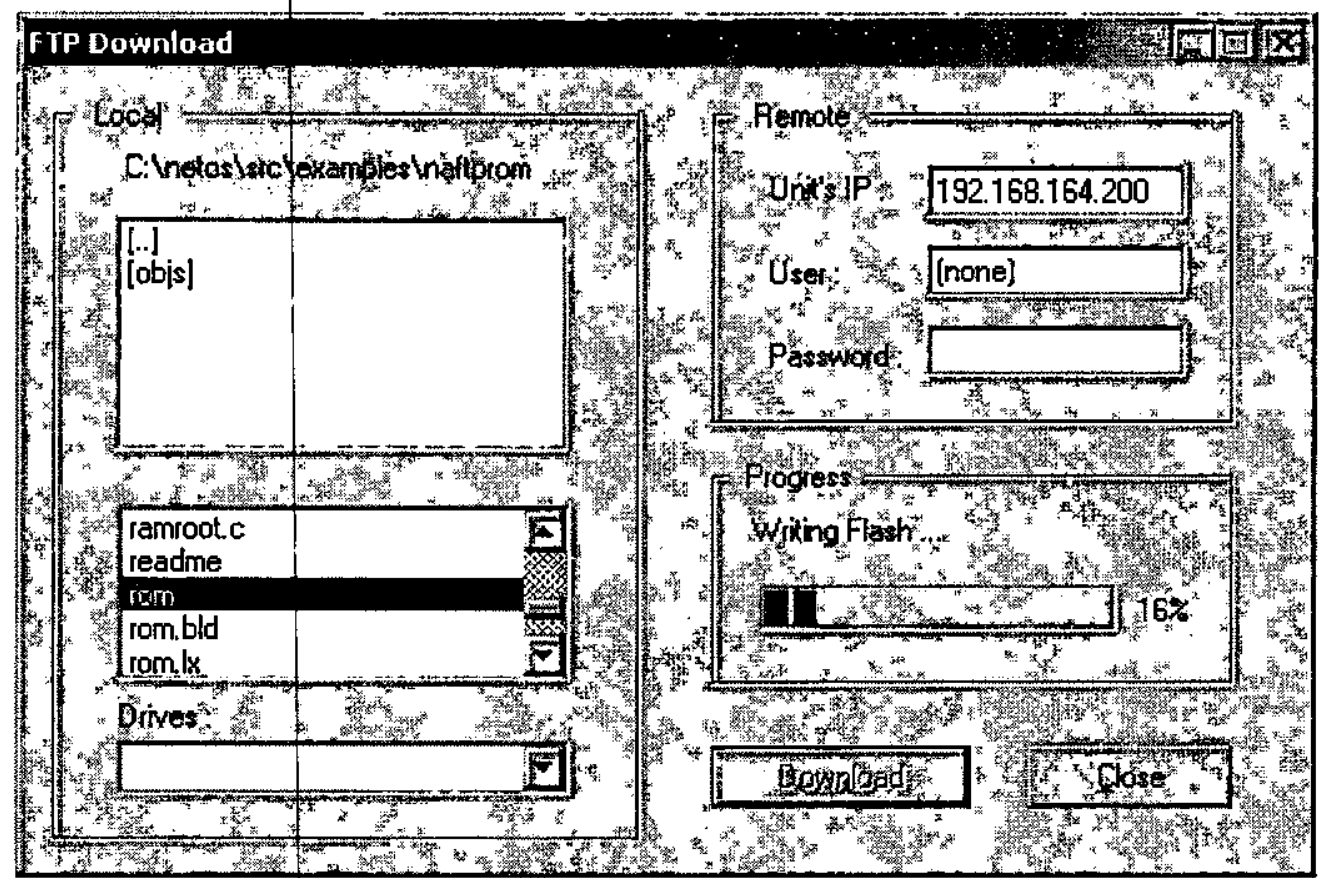

Figura 66 - FTP Downioad

Desta forma, o equipamento passa a ser capaz de fazer a atualização do software (ou firmware, mais especificamente) via Internet, usando ferramentas já consagradas pelo mercado através do uso de um protocolo padrão como o FTP.

Já o conversor HTML (Figura 67) é uma aplicação que converte páginas HTML em código C. Estas páginas convertidas podem ser compiladas junto com o firmware. Isto permite que as páginas que estarão no Servidor Web sejam criadas normalmente, usando ferramentas próprias para isto, e depois estas páginas sejam convertidas e incorporadas ao projeto. Uma vez incorporada ao equipamento, estas páginas podem ser acessadas através do endereço IP do equipamento, em qualquer lugar, seja na Internet seja na Intranet.

Para exemplificar esta idéia, foi compilado o programa NAHTTP que é um programa para teste do servidor Web (ou servidor HTTP). 


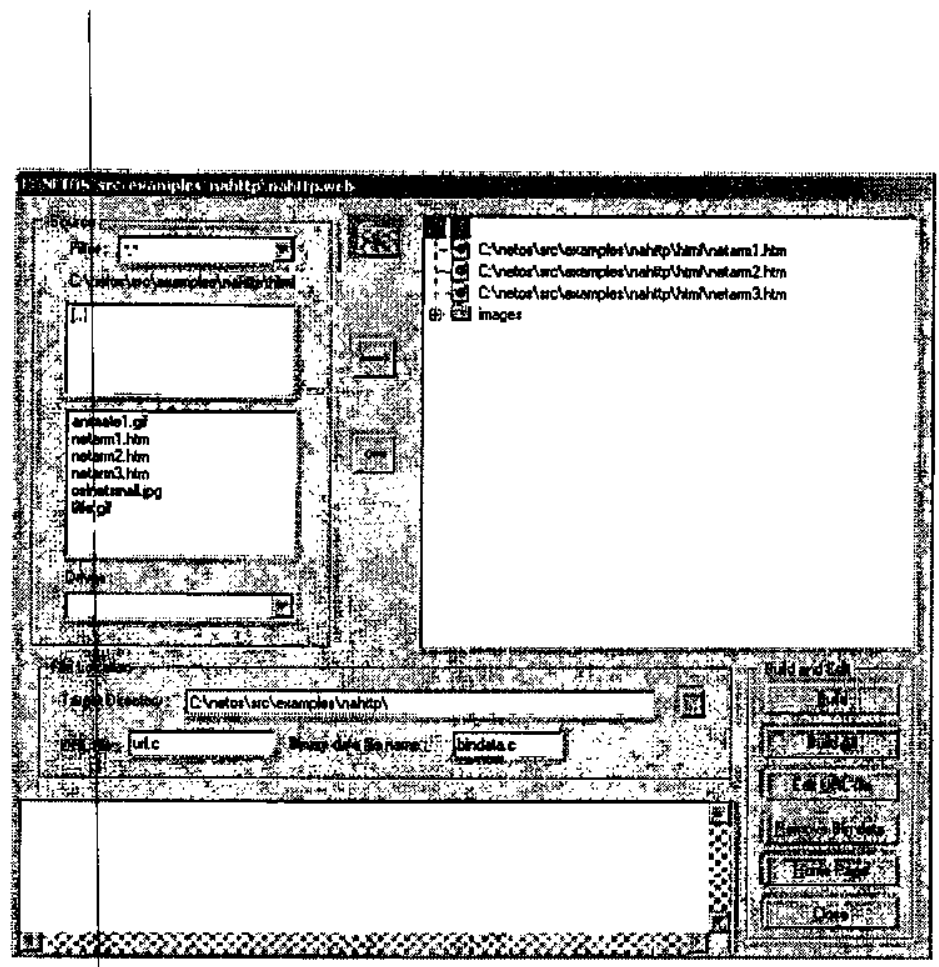

Figura 67 - Conversor HTML

Após compilado este programa foi descarregado na placa desenvolvida, e usando o navegador Internet Explorer (da Microsoft) pôde-se visualizar e interagir com a aplicação em execução (Figura 68) acessando o endereço IP que foi configurado na placa: 192.168.164.200.

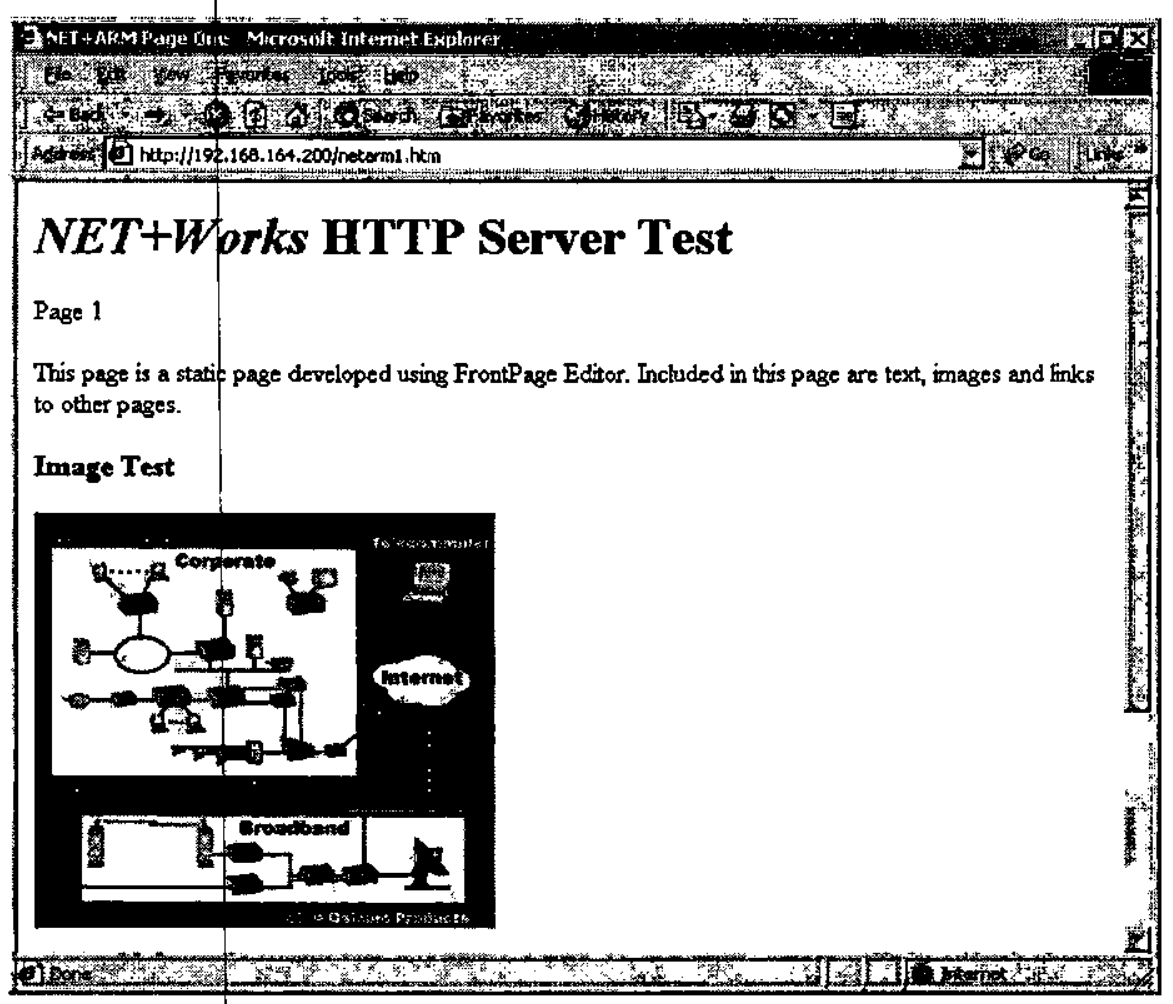

Figura 68 - Servidor Web sendo executado

Com a execução destes aplicativos na placa desenvolvida, pode se validar grande parte do projeto. Como a uma das portas Ethernet não estar 
funcionando até o mpmento da redação desta dissertação, isto impossibilitou 0 desenvolvimento do mecanismo para manter esta aplicação acessível mesmo quando uma das portas estiver com problemas. Devido a este fato, a redundância High Speed Ethernet Fieldbus proposta no Capitulo 4 não pôde ser testada.

Entretanto, os testes modulares realizados validaram em parte este projeto. Acredita-se que após o funcionamento do segundo controlador Ethernet 100 Mbps, a validação do HSE ocorrerá sem problemas.

Todas as tecnologias abordadas neste trabalho e assimiladas pelo aluno possibilitaram a publicação de dois trabalhos permitiram que fossem escritos dois artigos [75], [76] que serão apresentados em outubro de 2001 num congresso internacional de renomẹ na área de automação industrial no Brasil.

\subsection{Futuro}

Durante o desenvolvimento deste trabalho notou-se que os avanços tecnológicos nesta área que estão surgindo a cada momento. Algumas promessas são listadas para que sejam motivadoras de novas pesquisas:

- NET+150 (NETSilicon) - Módulo processador com dois controladores Ethernet embutido, além de um desempenho muito maior do que o NET+40 usado neste trabalho. A disponibílização comercial deste chip será um excelente avanço para a arquitetura aqui abordada.

- Linha Excalibur (Altera) - Através do uso de um núcleo processador ARM, um processador que tem sido muito bem aceito devido a sua relação custo / desempenho, esta linha de componentes será um excelente campo para continuação desta pesquisa, principalmente na abordagem de sistemas em uma única pastilha.

- A incorporação de tecnologias como HSE e Web aos equipamentos para automação e controle industrial fará com que as soluções para o chão de fábrica acompanhem e desfrutem das tendências tecnólogicas da Internet e ainda será uma porta aberta para a tão desejada interoperabilidade.

Além disto, pesquisadores da Hewlett-Packard estão desenvolvendo computadores para o ano de 2010 baseados em FPGA, de modo que o usuário possa configurar a arquitetura de seu computador de acordo com a sua aplicação. Eles estão construindo um conjunto de ferramentas que simplificarão o processo de programação de um FPGA, para que qualquer usuário médio possa reprogramá-lo de acordo com as mudanças necessárias para ele. Eles querem "fazer para os FPGAs o que os navegadores fizeram para a Internet. Torna-los vastamente acessíveis" [67].

"A melhor maneira de prever o futuro é criá-lo." (Peter Drucker) 
[1] Villasenor, J.; Smith, W. - "Configurable Computing", Scientific American, USA, June 1997.

[2] Dolin, M. - "CPLD/FPGA devices, tools lure PLD designers into faster, denser logic", Computer Design, p. 81-98, November 1995.

[3] Turk, B. - "FPGAs race for the gold in product development", Computer Design, p. 88-104, April 1992.

[4] Chan, P.; Mourad, S. - "Digital Design using Field Programmable Gate Arrays", Prentice Hall, 1994.

[5] Rose, J.; Gamal A. E.; Vicentelli, A. S. - "Architecture of Field-Programmable Gate Arrays", Proceedings of the IEEE, vol. 81, no. 7, p. 1012-28, July 1993.

[6] Brown, S.; Rose J. - "Architecture of FPGAs and CPLDs: A Tutorial", IEEE Design and Test of Computers, vol. 13, no. 2, pp. 42-57, June 1996.

[7] Harding, B. - "HDLs: a high-powered way to look at complex design", Computer Design, p. 74-84, March 1990.

[8] Dolin, M. - "Designers cross over to language-based tools", Computer Design, p. 69-88, January 1996.

[9] Dolin, M. "Designers moving to HDLs face challenges, reap benfits", Computer Design, p. 69-75, October 1996.

[10] Dehon, A.- "Reconfigurable Architecture for General-Pupose Computing", Ph.D. Thesis, Massachusetts Institute of Technology, 1996.

[11] Lysaght, P.; Dunlop, J. - "Dynamic Reconfiguration of Field Programmable Gate Arrays", More FPGAs, Edited by Will Moore and Wayne Luk, Abingdon EE\&CS Books, Oxford, England 1994.

[12] Lysaght, P. et al. - "Prototyping Environment for Dynamically Reconfigurable Logic", Lectures Notes in Computer Science, no. 975, p. 409-418, July 1995. 
[13] Byres, E. - “Ethernet to link automaion hierarchy”, InTech, pp. 44-47, June 1999.

[14] Aragão, A.; Marques, E. - "A tecnologia FPGA", Relatórios técnicos do ICMC, no. 60, São Carlos, Julho 1997.

[15] Brown, S. - "Routing Algorithms and Architectures for Field Programmable Gate Arrays", Ph.D. Thesis, Dept. Of Electrical Engineering, University of Toronto, February, 1992.

[16] Pellerin, D. - "An Introduction to VHDL for Synthesis and Simulation", Accolade Design Automatin, Inc., 1995. (http://www.acc-eda.com/h intro.htm).

[17] Geppert, L., Martin, B. - “Electronic Automation Design”, IEEE Spectrum, Vol. 36, No. 1, January 1999 - pp. 57-61.

[18] Advanced Micro Devices - "Am79C973/Am79C975 Preliminary Data Book", February 1999, p. 1-2.

[20] CoreEl MicroSystems - "CS-1100 DataSheet" , p. 1-2.

[21] Marques. E. - "Projeto de uma rede local de computadores de alta velocidade", Universidade de \$ão Paulo, São Carlos, Junho de 1988, p. 9-13.

[22] Anderson, T.; Randell, B. - "Computing Systems Reliability", Cambridge University Press, Cambridge, 1979, p. 153-164.

[23] Citect Technical Information - "Redundancy" (http://www.cit.com.au/html/products.htm)

[24] Fieldbus Foundation - "FOUNDATION Specification System Architecture: High Speed Ethernet Addendum", Document FF-581, Revision DPS 0.9, September 30,1998, p.1-3.

[25] Fieldbus Foundation - "FOUNDATION Specification High Speed Ethernet Redundancy", Document FF-593, Revision DPS 2.00, June 22, 1999, p. 6-19.

[26] NETSilicon - "NET+ARM ENI Shared RAM Application Note", Version 0.1, September 24, 1999 , p. 1-4 
[27] NETSilicon - "NET+OS Board Support Package (BSP) Porting Guide", Version 1.0, February, 2000.

[28] NETSilicon - "Dual NET+ARM Development Boar Specification", Version 0.1, January 2000, p. 4-10.

[29] Smar Equipamentos Industriais Ltda - "GLL1047 Projeto do Módulo DF51 Família DFI302", Julho de 1998.

[30] Smar Equipamentos Industriais Ltda - "GLL1078 Projeto da PCl - Process Control Interface", Julho de 1996.

[31] Fieldbus Foundation - "FOUNDATION Specification System Architecture", Document FF-581, Revision FS 1.9, November 1, 2000.

[32] Fieldbus Foundation - "FOUNDATION Specification High Speed Ethernet Redundancy", Document FF-593, Revision PS 3.9, September 22, 2000.

[33] NETSilicon, Inc. - "NET+Works for NET+ARM Hardware Reference Guide", Part Number 8833198, Rev. C, February, 2000.

[34] Altera Corporation - "MAX3000A Programmable Logic Device Family Data Sheet", Version 1,1, September 2000.

[35] VSI Alliance - "VSI Alliance Architecture Document", Version 1.0, March 1997.

[36] Alcatel Internetworking (PE), Inc. - "PE-MACMII - 10/100 Ethernet Media Access Controller with MII Management Interface Data Sheet", Document IPD DS10M912.1, Release 3.2, 1999-2000.

[37] Altera Corporation - "Excalibur Embedded Processor Solutions" http://www.altera.com/products/devices/excalibur/exc-index.html

[38] Dehon, A.; Wawrzynek, J., "Reconfigurable Computing: What, Why, and Design Automation Requirements?" , in Proceedings of the 1999 Design Automation Conference, pp. 610-615, June 1999.

[39] Brown, S.; Rose, J.; Francis, R.; Vranesic, Z., "Field Programmable Gate Arrays", Kluwer Academic Publisher, 1997. 
[40] Chan, P. K.; Mourlad, S., "Digital Design using Field Programmable Gate Arrays", Prentice Hall, 1994.

[41] Star Bridge Systems, "Overview of SBS's Reconfigurable Computing Technology" http://www.starbridgessystems.com/tech-over.html

[42] Cardoso, J. M. P.; Vestias, M. P., "Architectures and Compilers to Support Reconfigurable Computing", January 2000.

http://www.acm.org/crossroads/xrds5-3/rcconcept.html

[43] Burns, J. et. al., "A Dynamic Reconfiguration Run-Time System", Proc. 5th Annual IEEE Symposium on Custom Computing Machines, IEEE Computer Society Press, 1997.

[44] Lysaght, P.; Dunlop, J., "Dynamic Reconfiguration of FPGAs", in More FPGAs. Abingdon EE\&CS Books, pp. 82-94, 1993.

[45] Brebner, G., "The Swappable Logic Unit: a Paradigm for Virtual Hardware", Proc. 5th Annual IEEE Symposium on Custom Computing Machines, IEEE Computer Society Press, 1997.

[46] Haug, G.; Rosenstiel W., "Reconfigurable Hardware as Shared Resource for Parallel Threads", Proc. 5th Annual IEEE Symposium on Custom Computing Machines, IEEE Computer Society Press, 1997.

[47] Merino, P.; López, J. C.; Jacome, M., "A Hardware Operating System for Dynamic Reconfiguration of FPGAs", Lecture Notes in Computer Science, Vol. 1482, pp 431-435, Springer, 1998.

[48] Brebner, G. A., "Virtual Hardware Operating System for the XC6200", $6^{\text {th }}$ International Workshop on Field Programmable Logic and Applications, Springer LNCS 1142, pp 327-336, 1996.

[49] Wirthlin, M. J.; Hutchings, B. L., "A Dynamic Instruction Set Computer", In Proceedings of the 4th IEEE Symposium on FPGAs for Custom Computing Machines (FCCM'95), pp. 99-107, Napa Valley, California, USA, April 1995.

[50] Atwell, J., "A Multiplexed Memory Port for Run Time Reconfigurable Applications", Virginia Polytechnic Institute and State University, Master Thesis, December 1999.

[51] Merino, P.; Jacome, M.; López, J.C., "A Methodology for Task Based Partitioning and Scheduling of Dynamically Reconfigurable Systems", IEEE Symposium on FPGAs for Custom Computing Machines, April 1998.

[52] Moye, C. D., "The Design and Implementation of a Spatial Partitioner for use in a Runtime Reconfigurable System", Virginia Polytechnic Institute and State University, Master Thesis, March 1999. 
[53] Ferreira, J.C.; Matos, J. S., "A prototype system for rapid application development using dynamically reconfigurable hardware", IEEE Symposium on FPGAs for Custom Computing Machines, April 1998.

[54] Goldstein, S. et. al., "PipeRench: A Reconfigurable Architecture and Compiler", IEEE Computer, pp. 70-77, April 2000.

[55] Hauser, J. R.; Wawrzynek, J., Garp: "A MIPS Processor with a Reconfigurable Coprocessor", University of California, Berkeley.

[56] Gonçalves, R. A.; Wolf, D. F.; Coelho, F. A. S.; Teixeira, M. A.; Ribeiro, A. A. L.; Marques, E., "ARCHITECT: Um Sistema de Computação Reconfigurável", Workshop de Computação Reconfigurável, CORE-2000, Marilia-SP, Agosto 2000.

[57] Dehon, A., "DPGA-coupled Microprocessor: Commodity Ics for the early $21^{\text {st }}$ Century", IEEE Computer, vol. 26, nr. 3, pp. 11-18, Macrh 1994.

[58] Fawcet, B. K., "Applications of Reconfigurable Logic", More FPGAs, Edited by Will Moore and Wayne Luk, Abingdon EE\&CS Books, Oxford, England, 1994.

[59] Hauser, J. R., "The Garp Architeture", University of California at Berkeley Department of Electrical Engineering and Computer Sciencies, October 1997.

[60] Guccione, S., "List of FPGA-based Computing Machines" http://www.io.com/ guccione/index.html

[61] Drayer, T. H., "A Design Methodology for Creating Programmable Logic-based Real-time Image Processing Hardware", Virginia Polytechnic Institute and State University, PhD Thesis, January 1997.

[62] Altera, "Excalibur Backgrounder White Paper", in www.altera.com , June 2000.

[63] Star Bridge Systems - Technology

http://www.starbridgesvstems.com/cont-tech.htm|

[64] Altera Corporation - "MAX+PLUS II Programmable Logic Development - System \& Software Data \$heet", Version 8, January 1998.

[65] Netsilicon - "NET+Works for NET+40 Errata", September, 2000. 
[66] NETsilicon, "NET+|Works for NET+OS BSP Porting Guide", February, 2000.

[67] Jamie Beckett, "New technology lets no-techies customize computers", 28 April 2000, Hewlett-Packard Laboratiories

http://www.hpl.hp.com/news/shackleford.html

[69] Altera Corporation - "Altera Data Book", January, 1998. pp. 3-4.

[70] Pradhan, Dhiraj K. - "Fault-tolerant computing", Englewood Cliffs: Prentice Hall, 1986.

[71] ZF Micro Device, Inc. - "Fail-safe Embedded PC-on-a-Chip" http://www.zflinux.com/zfx86.html

[72] Avnet Electronics Marketing http://www.avnetmarshall.com/dynamic/search

[73] FindChips.com http://www.findchips.com/cgi-bin/nph-findchips.cgi

[74] Arrow Electronics http://www.arrow.com/

[75] Klinger G. da Silva, et. Al. - "Redundância High Speed Ethernet Baseada em Computação Reconfigurável"; Congresso Internacional de Automação, Sistemas e Instrumentação "OS DESAFIOS DO SÉCULO XXI", Outubro, 2001.

[76] Klinger G. da Silva - "Servidor Web em Plataforma Fieldbus HSE"; Congresso Internacional de Automação, Sistemas e Instrumentação "OS DESAFIOS DO SÉCULO XXI", Outubro, 2001. 


\section{A - Esquema Elétrico do Projeto}

As páginas que compõe o esquemático deste projeto serão mostrada aqui apenas de modo ilustrativo, uma vez que pelo tamanho da página o nome dos sinais não são visíveis. As portas fieldbus são omitidas propositalmente em respeito à propriedade industrial. As figuras estão organizadas da seguinte forma:

Figura 69 - Diagrama de Blocos do Hardware

Figura 70 - Módulo processador NET+40 (CPU A)

Figura 71 - Módulo processador NET+40 (CPU B)

Figura 72 - Controle de Acesso a Memórias e Periféricos (PLD)

Figura 73 - Memórias

Figura $74-\mathrm{PMU}+\mathrm{PBI}+\mathrm{RTC}+\mathrm{IMBI}$

Figura 75 - Portas Ethernet

Figura 76 - Dual port + Bus switch

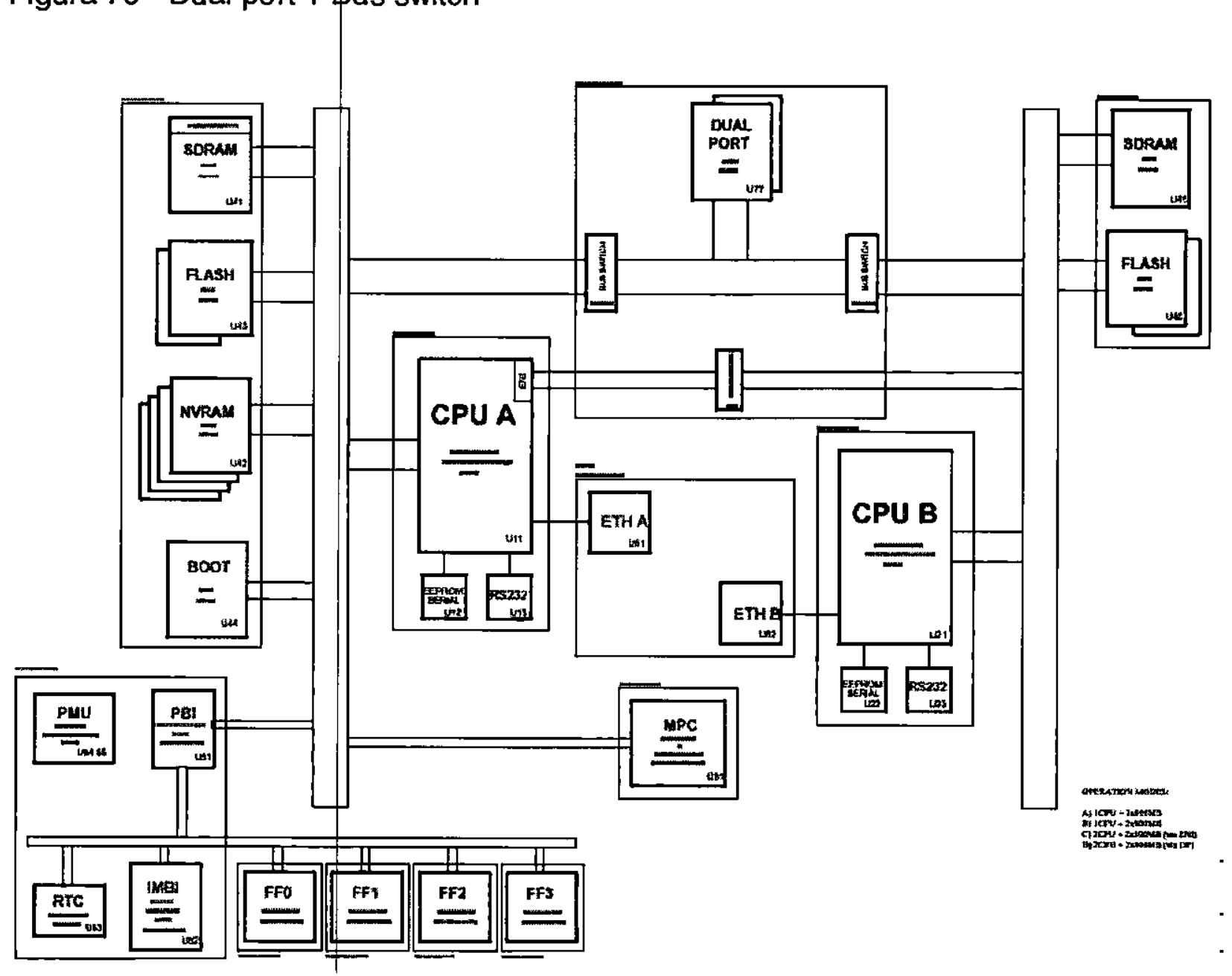

Figura 69 - Dlagrama de Blocos do Hardware 


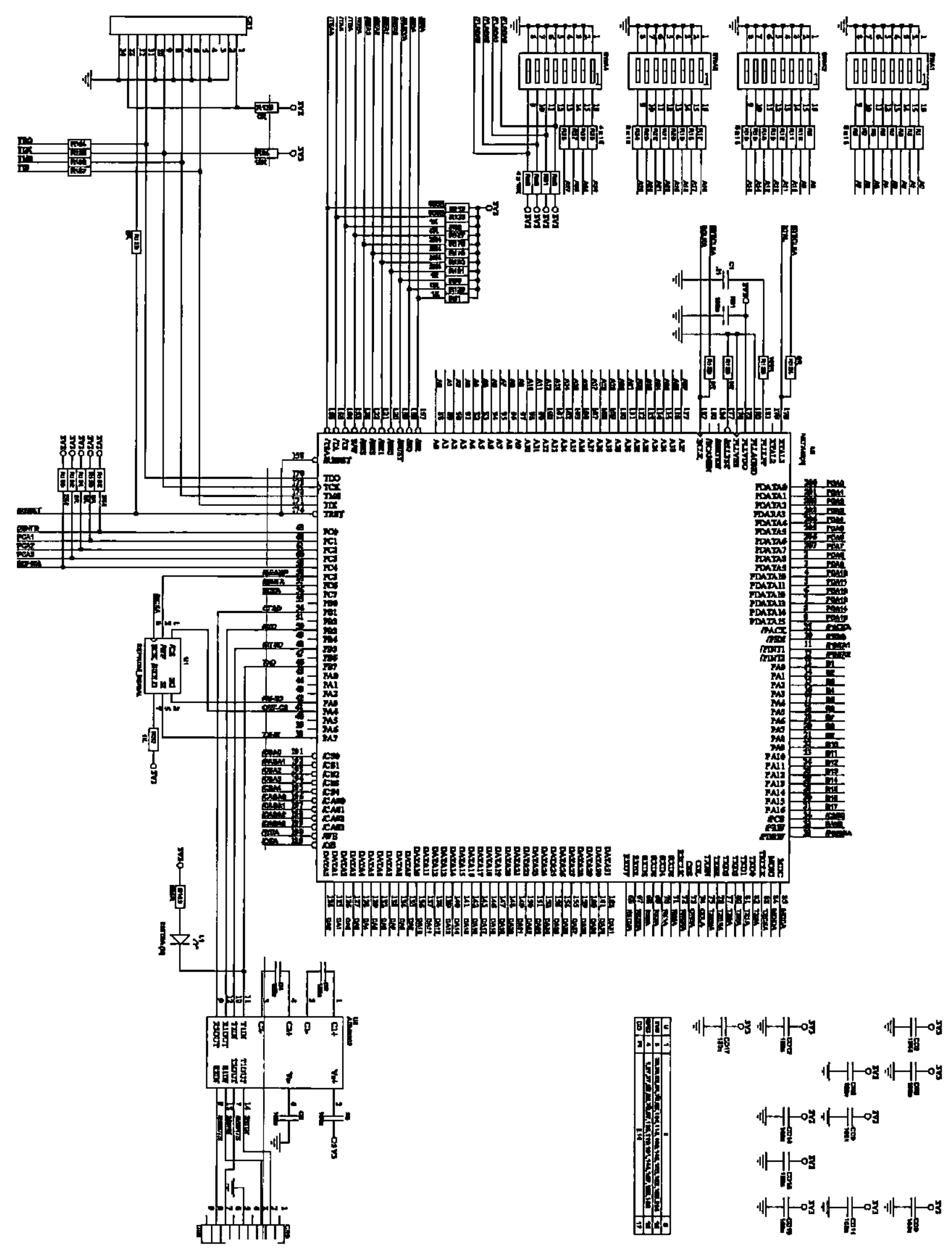

Figura 70 - Módulo processador NET+40 (CPU A) 


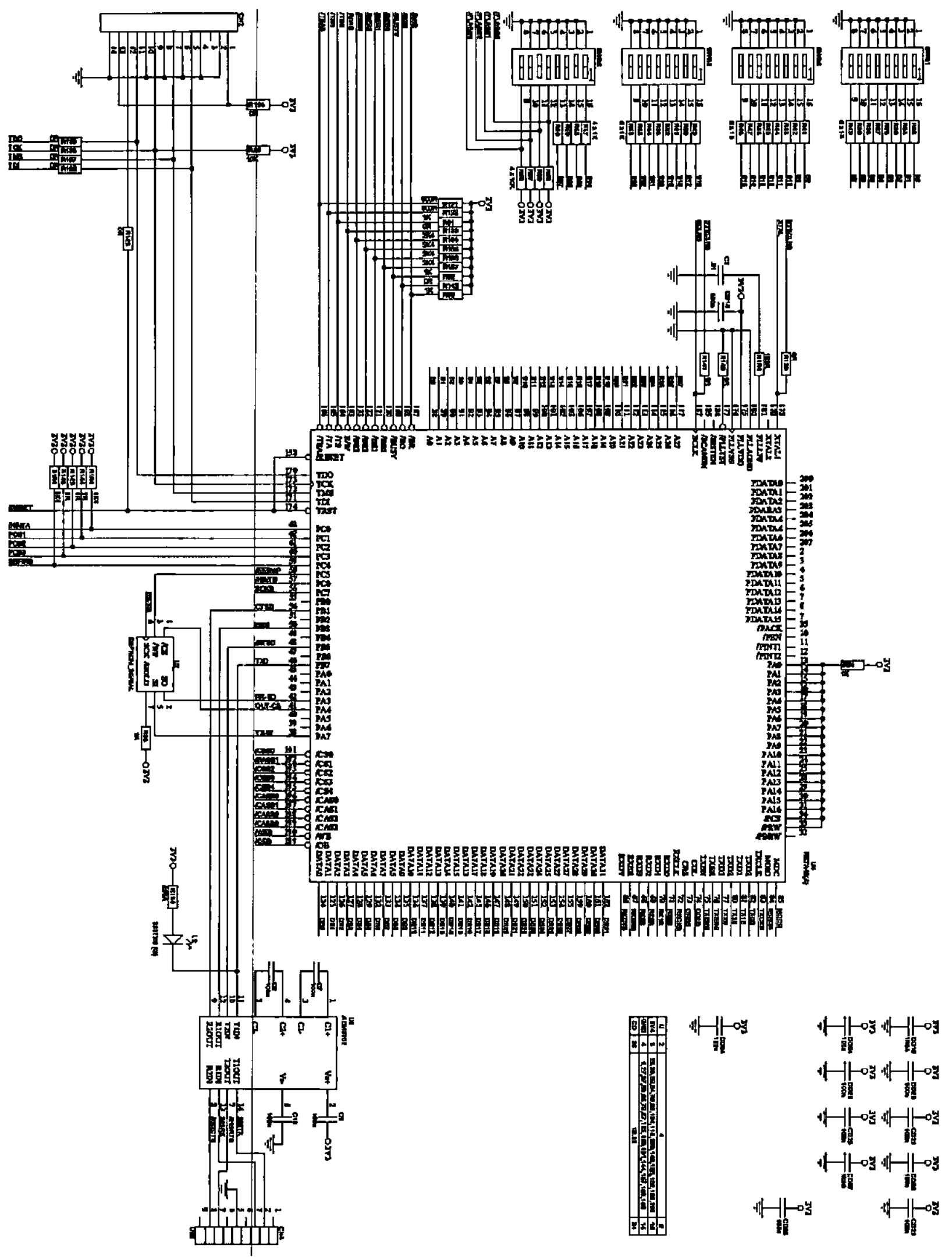

Figura 71 - Módulo processador NET+40 (CPU B) 


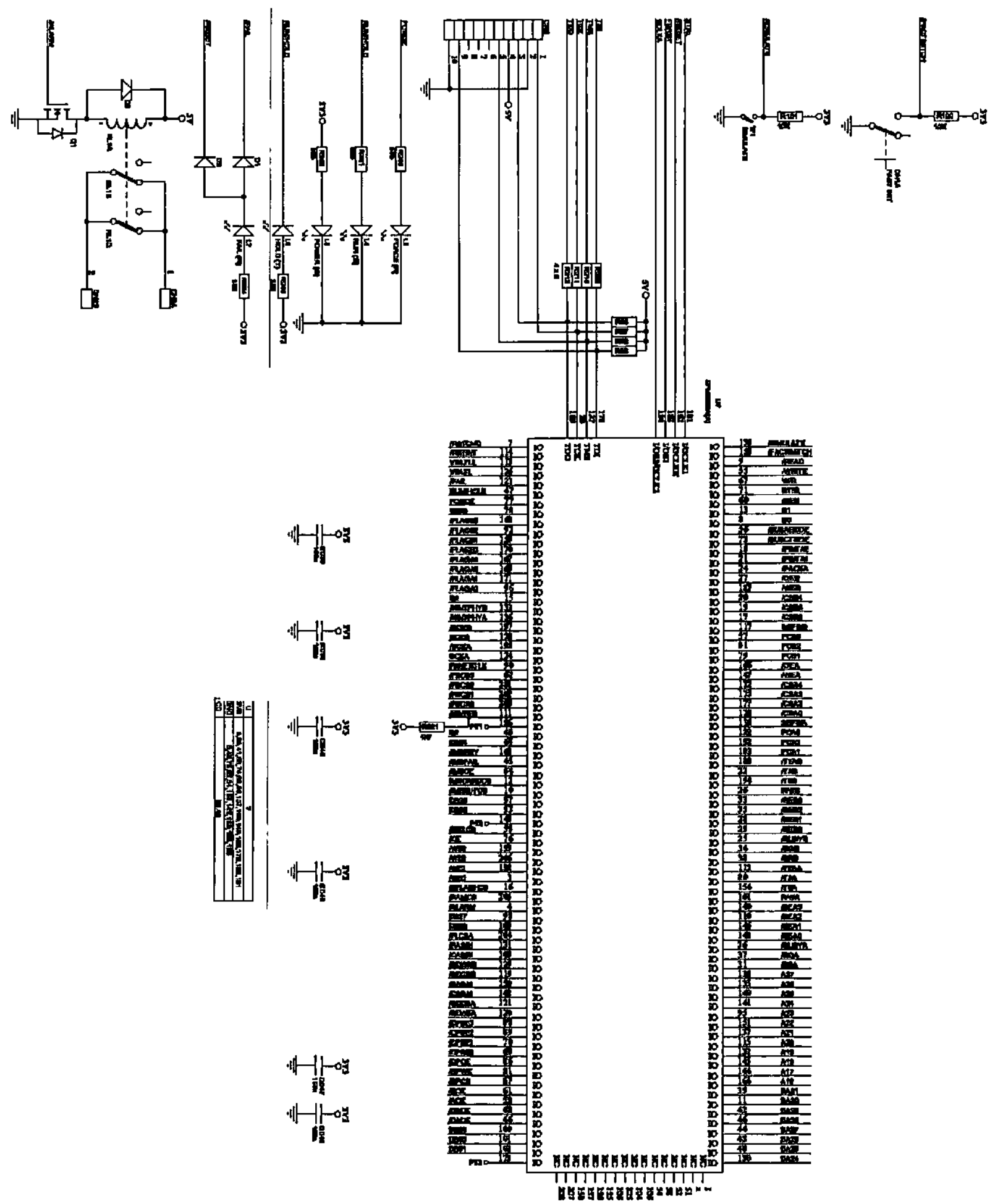

Figura 72 - Controle de Acesso a Memórias e Periféricos (PLD) 

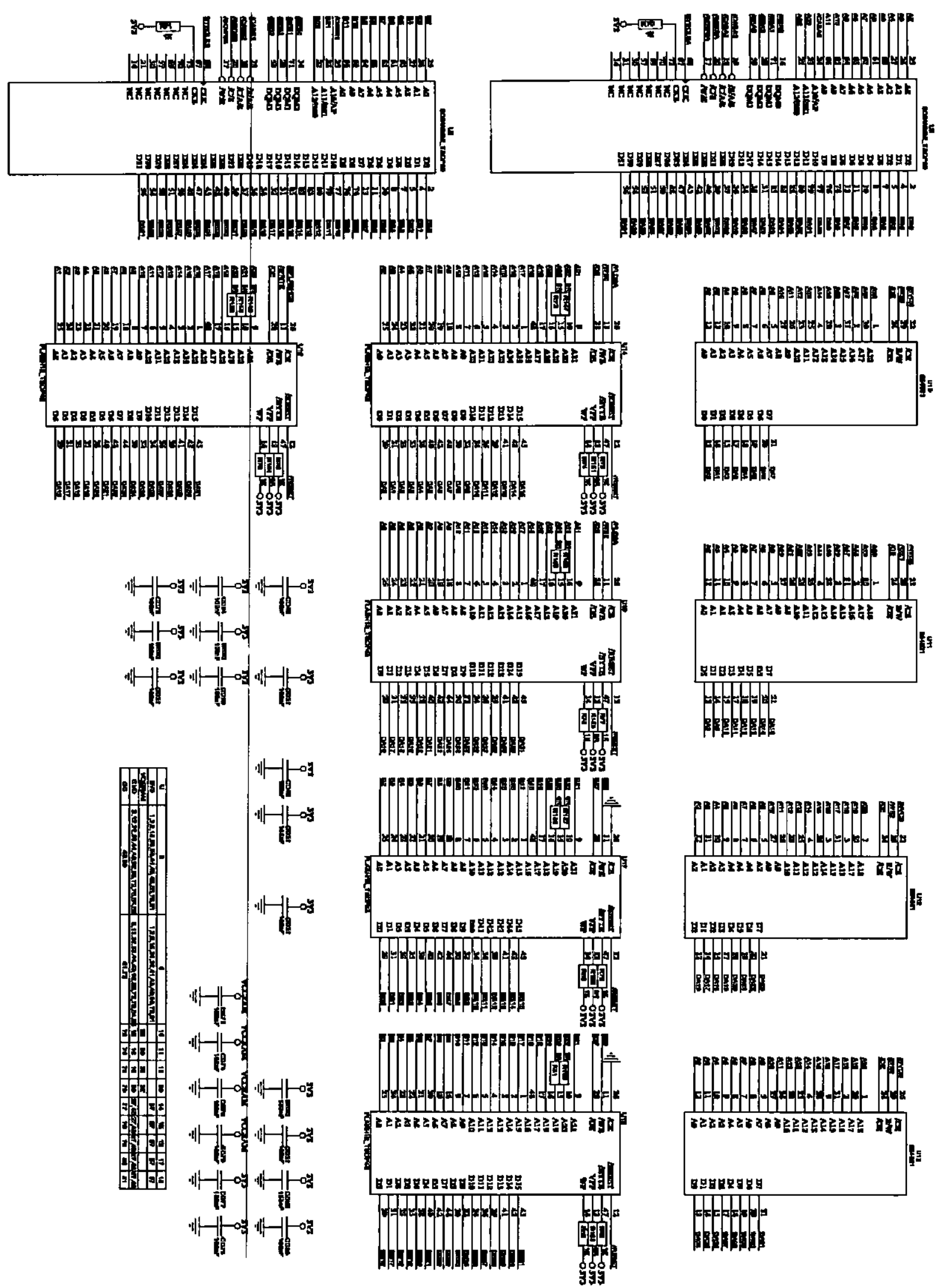

Figura 73 - Memorlas 

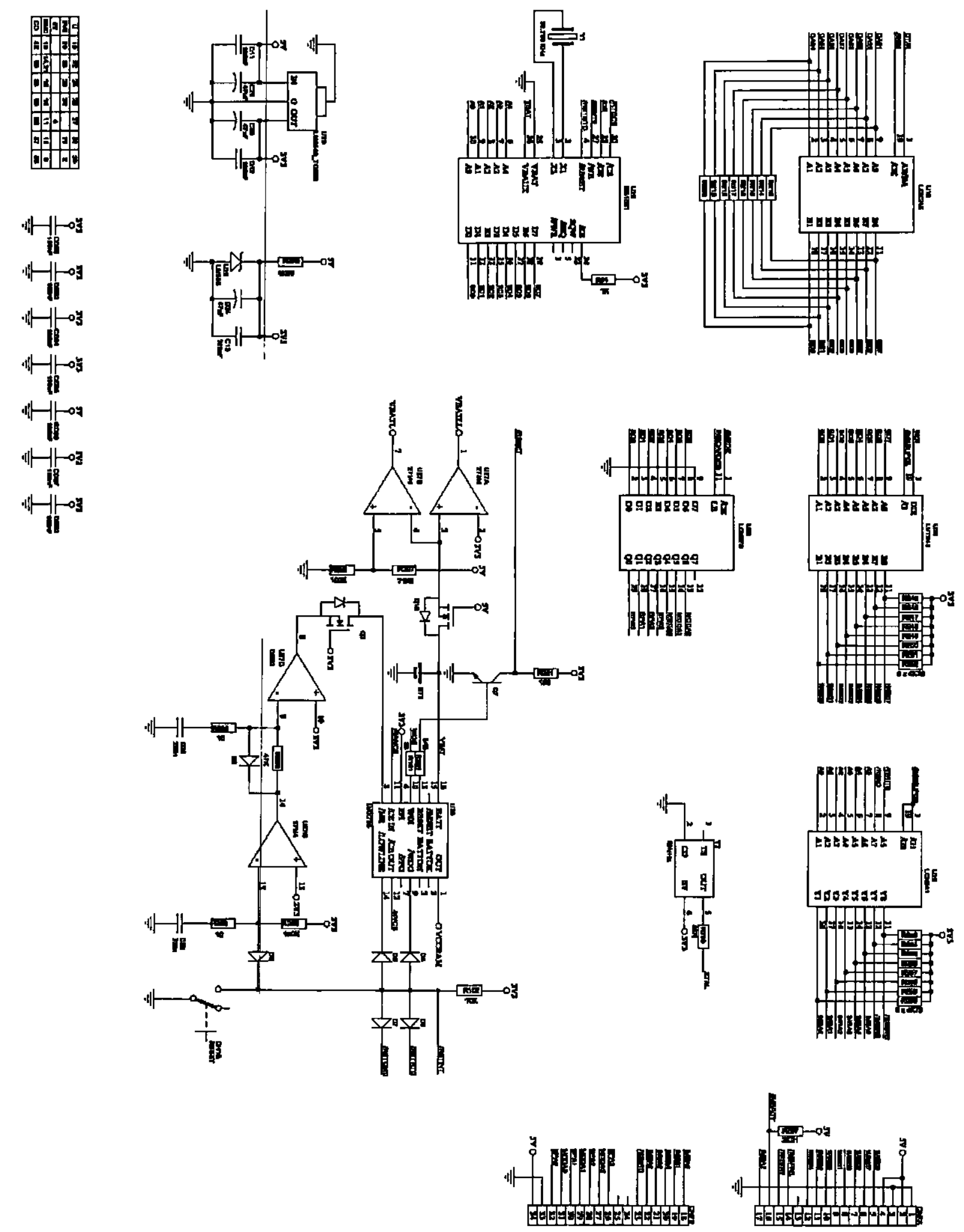

Figura $74-P M U$ + PBI + RTC + IMBI 


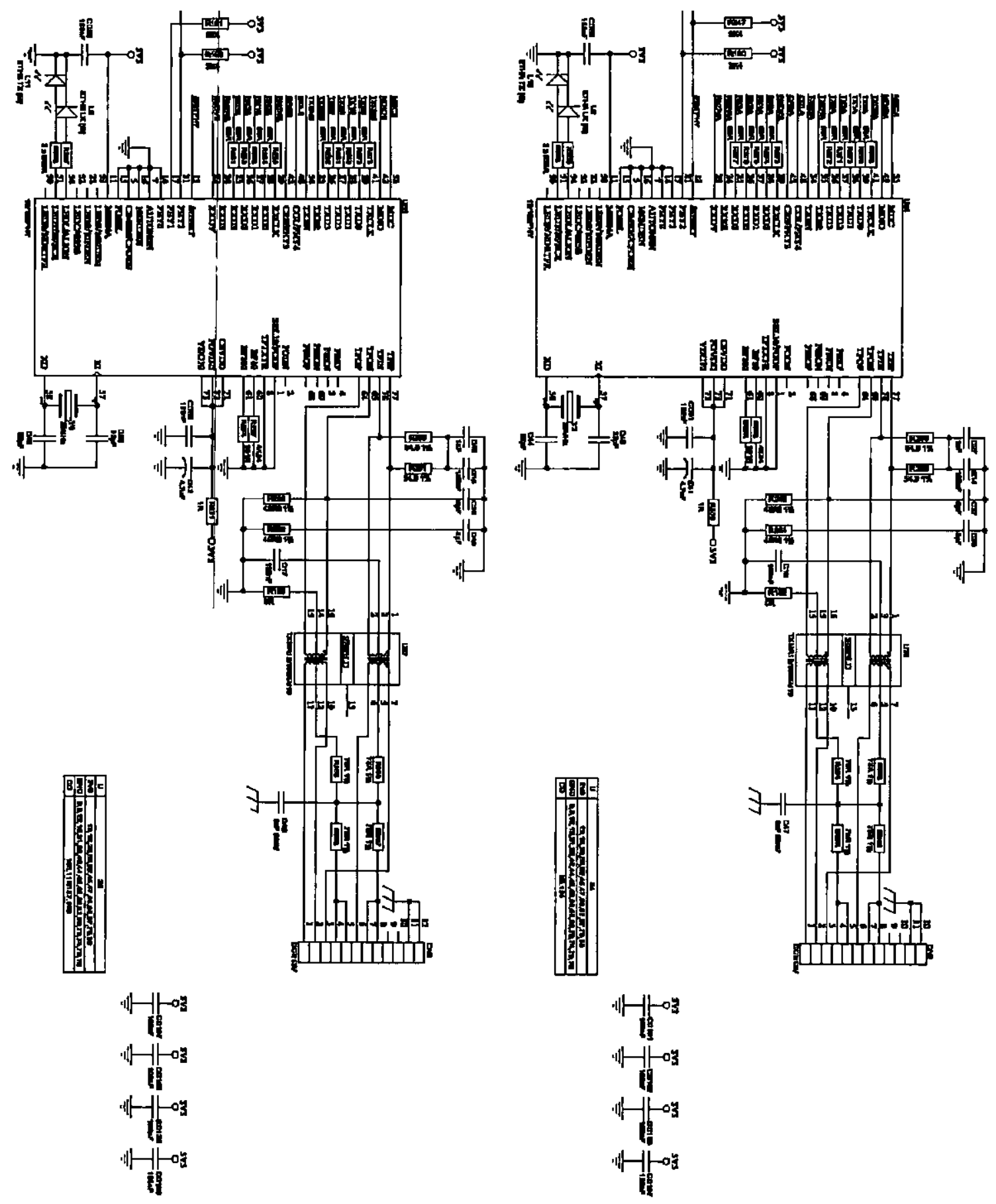

Figura 75 - Portas Ethernet 

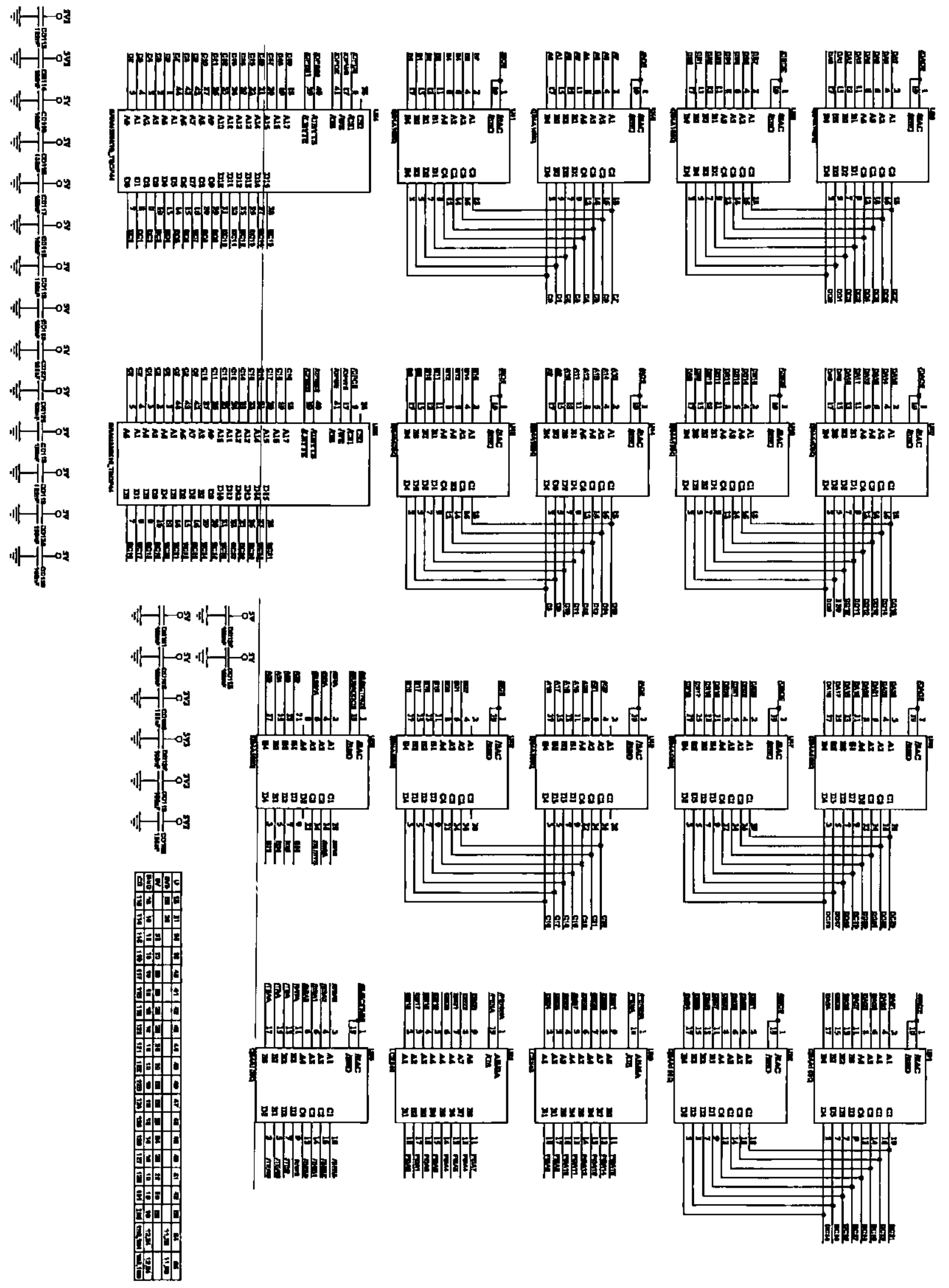

Flgura 76 - Dual port + Bus swltch 
Ao meu amigo Morghan. 